\title{
The Situation: An Introduction to the Situational Character, Critical Realism, Power Economics, and Deep Capture
}

\section{Citation}

Jon Hanson \& David Yosifon, The Situation: An Introduction to the Situational Character, Critical Realism, Power Economics, and Deep Capture, 152 U. Pa. L. Rev. 129 (2003).

\section{Published Version}

http://scholarship.law.upenn.edu/penn_law_review/vol152/iss1/9/

\section{Permanent link}

http://nrs.harvard.edu/urn-3:HUL.InstRepos:12964431

\section{Terms of Use}

This article was downloaded from Harvard University's DASH repository, and is made available under the terms and conditions applicable to Other Posted Material, as set forth at http:// nrs.harvard.edu/urn-3:HUL.InstRepos:dash.current.terms-of-use\#LAA

\section{Share Your Story}

The Harvard community has made this article openly available. Please share how this access benefits you. Submit a story.

Accessibility 


\title{
THE SITUATION: \\ AN INTRODUCTION TO THE SITUATIONAL CHARACTER, CRITICAL REALISM, POWER ECONOMICS, AND DEEP CAPTURE
}

\author{
JON HANSON ${ }^{\dagger} \&$ DAVID YOSIFON ${ }^{\dagger}$
}

What social psychology has given to an understanding of human nature is the discovery that forces larger than ourselves deternine our mental life and our actions-that chief among these forces . . . [is] the power of the social situation.

\section{- Mahzarin R. Banaji}

Perceptions are real. . . . They color what we see . . . what we believe . . how we behave. They can be managed. . to motivate behavior. . to create positive business results.

-Burson-Marsteller

Public Relations Firm Home Page ${ }^{2}$

${ }^{\dagger}$ Professor of Law, Harvard University.

"Law Clerk, Judge Patti B. Saris, United States District Court for the District of Massachusetts. B.A., Rutgers University; M.A., Carnegie Mellon University; J.D., Harvard Law School.

We are grateful to Kwaku Akowuah, Tom Allen, Tim Cullen, Chris Egleson, Garrett Moritz, Lena Salaymeh, Yoni Rosenzweig, Wes Shih, Mila Sohoni, Dan Weiner, Allen Wong, and Michelle Yau for excellent research assistance, to Adam Benforado, Jon Goldin, Sam Halabi, Brandon Hofmeister, Jith Meganathan, Matt Thompson, and Adam Wright for extraordinary research assistance, and to Carol Igoe for outstanding secretarial assistance. Financing from the Harvard Law School Summer Research Fund provided valuable research support. We are also grateful to participants in the Harvard Law School Faculty Workshop, the University of Michigan Law and Economics Workshop, and the Harvard Law School Graduate Student Workshop for helpful comments. We would particularly like to thank Ian Ayres, Guido Calabresi, Christine Desan, Phoebe Ellsworth, John Gillis, Lani Guinier, Mort Horwitz, James Livingston, Duncan Kennedy, Todd Rakoff, the late Gaston Rimlinger, Scott Sandage, Joseph Singer, Paul Slovic, Peter Stearns, Diana Strassmann, and Roberto Unger, among many others, for their enriching situational influences on us and this work. Finally, we would like to express our love and deepest gratitude to Kathleen, Emily, Erin, and Ian Hanson; Paula Noyes; and Michael, Viola, Michael, Jr., Tracy, Stephen, and Evan Yosifon.

${ }^{1}$ Mahzarin R. Banaji, Ordinary Prejudice, 14 PsYCHOL. SCI. AgENda 8,8 (2001).

${ }^{2}$ Sheldon Rampton \& JOHn Stauber, Trust US, We're EXPerts! 2 (2001) (all but first ellipsis in original) (quoting Burson-Marsteller, Inc., at http://www.bm.com (Sept. 27, 1997)). 
INTRODUCTION TO AN INTRODUCTION 132

I. SeTting THE Stage: TWo PuZzLeS 133

A. The First Puzzle ............................................................ 133

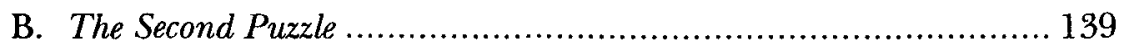

II. BRIEF INTRODUCTION TO THE SITUATIONAL. CHARACTER .............. 149

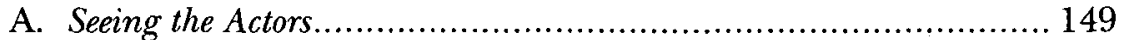

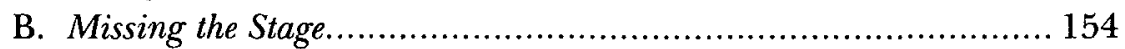

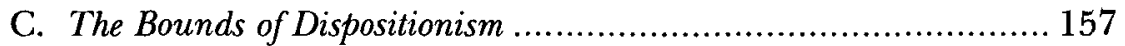

1. How Fundamental Is Our Dispositionism? ......................... 157

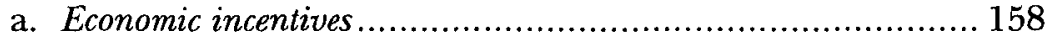

b. The limits of economists' situationism ............................. 159

c. Some situation behind our dispositionism ......................... 165

2. How Fundamental an Error Is Our Dispositionism?........... 167

D. Some Sources of Dispositionism ............................................... 174

E. The Fundamental Interior Attribution Error

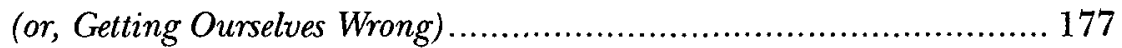

III. A BRIEF INTRODUCTION TO CRITICAL RE.ALISM ............................. 179

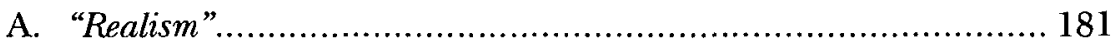

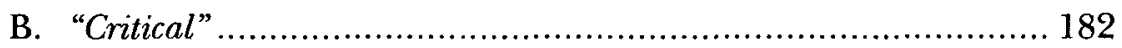

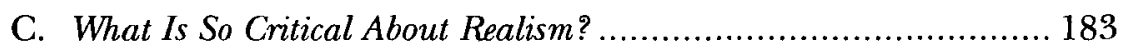

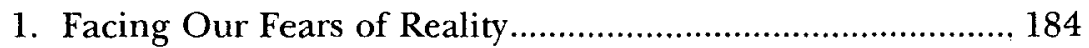

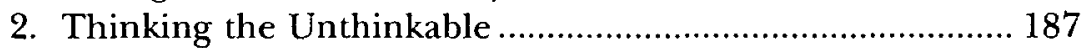



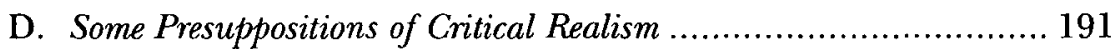

IV. BRIEF INTRODUCTION TO POWER ECONOMICS .............................. 193

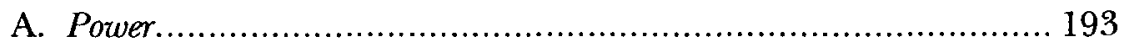

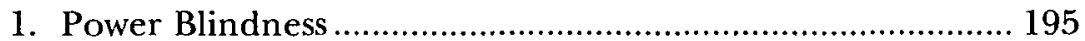

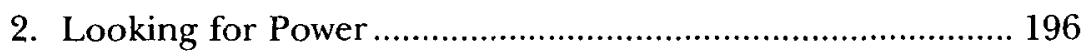

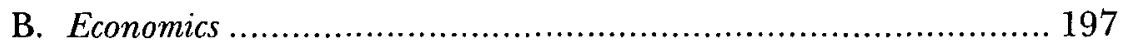

C. Some Implications of Power Economics...................................... 198

V. BRIEF INTRODUCTION TO DEEP CAPTURE ...................................... 202

A. Shallow Capture...................................................... 202

B. Deep Capture: An Historical Example.................................... 206

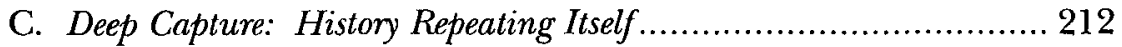

1. Some Deep Implications of Shallow Capture ...................... 212

2. The Depth of Capture ........................................................ 213

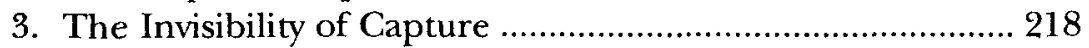

4. Learning from History...................................................... 219 
a. Institutions to deeply capture........................................ 219

b. Fundamental attribution errors ....................................... 223

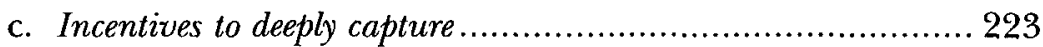

i. The stakes of geocentricism ........................................... 223

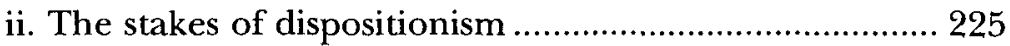

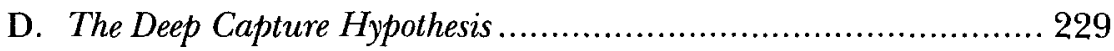

VI. SOME EVIDENCE OF THE DEEP CAPTURE HYPOTHESIS.................... 230

A. Some Shallow Evidence of Deep Capture ................................... 231

B. Some Less Shallow Evidence of Deep Capture .............................. 242

C. Some Cross-Cultural Evidence of Deep Capture........................... 250

D. Some Direct Evidence of Deep Capture .................................... 260

E. Some Deeper Evidence of Deep Capture: The Puzzles Revisited ....... 269

1. The Demand for Credible Messengers ............................... 269

2. The Creation of Credible Messengers................................ 272

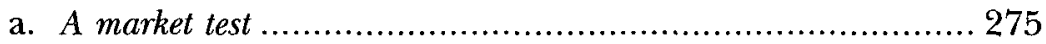

b. Re-imagining the marketplace of ideas............................... 278

VII. A ThEory OF ATtRibutional PRESUMPTIONS .......................... 285

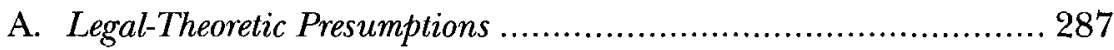

1. The Classical Theory of Contract ....................................... 288

2. The Dispositionism of Post-Classical Contract Theory ........ 292

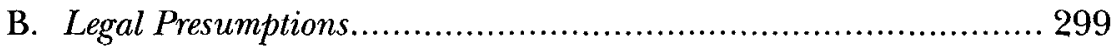

C. Social Policy Presumptions: Learning from History Again ............ 303

1. The Teacher's View of the Learner ........................................ 304

2. The Master's View of the Slave ............................................. 308

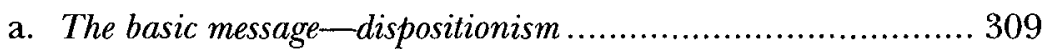

i. Revealed inferiority...................................................... 310

ii. Consent-implied and revealed..................................... 319

b. Amplifying dispositionism: The anti-slavery bogeypeople ......... 321

c. Dispositionalizing the opposition................................. 324

d. Our dispositionalization of slavery .............................. 326

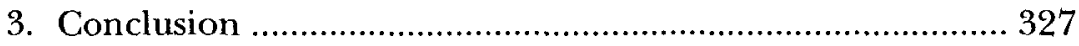

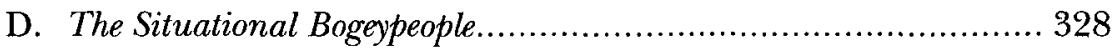

1. The Communism Bogeyman ............................................ 329

2. The Personal-Responsibility Bogeyman............................. 332

3. The Paternalism Bogeyman ............................................... 336

4. Summary: The Bogeypeople as Response to, and

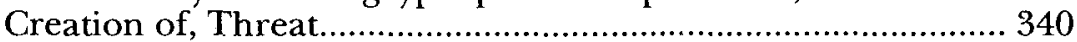

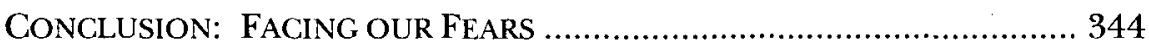




\section{INTRODUCTION TO AN INTRODUCTION}

This Article contests some of our most reassuring self-perceptions and offers a new way of thinking about our legal theories, our laws, our institutions, and, above all, ourselves.

In lieu of a conventional, preview-heavy opening, we will begin with a suggestion that you, the reader, consider your situation. We urge you to examine the internal and external influences that may affect your experience of this Article. Uncommon advice, perhaps, in a law review article, but consider the counsel of Italian novelist Italo Calvino:

Relax. Concentrate. Dispel every other thought. Let the world around you fade....

Find the most comfortable position: seated, stretched out, curled up, or lying flat. Flat on your back, on your side, on your stomach. In an easy chair, on the sofa, in the rocker, the deck chair, on the hassock. In the hammock, if you have a hammock. On top of your bed, of course, or in the bed. You can even stand on your hands, head down, in the yoga position. With the book upside down, naturally.

....

... Stretch your legs, go ahead and put your feet on a cushion, on two cushions, on the arms of the sofa, on the wings of the chair, on the coffee table, on the desk, on the piano, on the globe. Take your shoes off first. If you want to, put your feet up; if not, put them back. ${ }^{3}$

We urge you also to consider any internal influences that may affect your reading-elements that cannot be so readily inventoried, such as your attitudes, motives, and moods. These are less easily adjusted than the lighting, but can be even more important to the reading.

Try to be aware of what you bring to this Article; be aware of how you read, why you are reading, and even that you are reading. Do you have expectations about what this Article will say or how you will feel about it? Ask yourself: What am I looking for in this Article, and why? Am I reading this because it has been assigned and I want a good grade on my final? Because I am a law professor and that is what law professors do? Because I need support for a proposition in my own article? Because a friend recommended it? Because I am snowed in and it is this or nothing? And as you react to what you read, take a moment to examine those reactions and their possible sources.

3 ItAlo Calvino, IF ON A Winter's Night a TRAVEler 3-4 (William Weaver trans., Harcourt Brace Jovanovich 1981) (1979). 
In short, try as best you can to read this Article mindfully. ${ }^{4}$ This promises to be a difficult, but revealing, process, for the situation "determine[s] our mental life and our actions" far more than most of us realize or care to believe."

\section{Setting the Stage: Two Puzzles}

Throughout most of this introductory Article, we will focus our arguments primarily on economics and law and economics. We believe, however, that the implications of our inquiry extend far beyond those domains. The tendencies we hope to elucidate find their origins in the human animal, not in any particular legal theoretic perspective. It happens that these tendencies are especially prominent in law and economics, currently the dominant theoretical paradigm for creating and analyzing legal policy. But the relevance of our thesis is not confined to one approach, or even to legalpolitical questions. All humans are more or less implicated, whether they are liberals or conservatives, legal economists or critical theorists, students or scholars, producers or consumers, elected officials or citizens. ${ }^{6}$

\section{A. The First Puzzle}

Economists usually assume that each economic actor maximizes something: consumers maximize utility... firms maximize profits, politicians maximize votes, bureaucracies maximize revenues . . . and so forth.

\section{-Robert Cooter $\mathfrak{F}^{2}$ Thomas Ulen}

I do not myself believe that many people do things because they think they are the right thing to do ... I I do not think that knowledge of what is morally right is motivational in any serious sense for anyone except a handful of saints.

-Richard Posner

${ }^{4}$ See Ellen J. LANGer, Mindfulness 62 (1989) (describing the "key qualities of a mindful state of being: (1) creation of new categories; (2) openness to new information; and (3) awareness of more than one perspective").

Banaji, supra note 1 , at 8 .

'Readers should not expect, and will not find, an exhaustive defense of many of this Article's claims and conclusions. Our goal is to establish the basic premises of our argument and the conclusions to which they lead. We hope to provide a framework for a much larger project, where we and others defend those premises and conclusions. That is the subject of numerous works now in progress, which we cite to loosely by working title.

${ }^{7}$ ROBERT COOTER \& ThOMAS Ulen, LAW AND ECONOMICS 10-11 (3d ed. 2000). 
[T] he tendency to make unwarranted leaps from acts to corresponding dispositions is perhaps the most fundamental and most common failing of social inference.

\section{-Lee Ross E Richard Nisbett}

Have you ever noticed how quick legal economists are to assume that individuals and institutions are motivated by selfish interests, usually wealth and profit? ${ }^{10}$ Have you ever been puzzled by the fact that they have not applied the same type of analysis to explain their own work and remarkable success in the marketplace of ideas? Why, in other words, has there not been "An Economic Analysis of the Economic Analysis of Law?"

When legal economists write about their movement, ${ }^{12}$ they write of its historical affiliations, distinguished members, theoretical breakthroughs, scientific methods, rapidly growing numbers, sustained dominance within legal academia, and significant influence over policy. ${ }^{13}$ Implicit in these conventional narratives of the ascension of law and economics is an abstract and idyllic model of a tournament of ideas played on a level field, out of which law and economics emerges, on the merits, as a champion legal theory. ${ }^{14}$ Such canonical accounts say nothing about the actors' motives, except insofar as they imply that the participants have a

${ }^{8}$ Richard A. Posner, Social Norms, Social Meaning and Economic Analysis of Law: A Comment, 27 J. LEGal STUD. 553, 560 (1998).

${ }^{9}$ Lee Ross \& Richard E. Nisbett, The Person and the StTuation 53 (1991).

${ }^{10}$ See, e.g., supra text accompanying note 7 (noting the basic assumptions of legal economists).

${ }^{11}$ Cf. Richard Posner, The Sociology of the Sociology of Law: A View from Economics, 2 EURO J.L. \& ECON. 265 (1995) (claiming to use sociological methodologies to analyze and criticize sociological legal theories, but failing to apply the same methods to an analysis of Law and Economics).

${ }_{12}^{12}$ By "legal economists," we mean scholars in economics departments and, more commonly, in law schools who apply neoclassical economics to law and law-related issues.

${ }^{13}$ See generally COOTER \& ULEN, supra note 7, at 3 (identifying law and economics as useful to lawmakers when evaluating policy); RICHARD A. POSNER, ECONOMIC ANALYSIS OF LAW 21-22 (4th ed. 1992) (providing a history of the law and economics movement) [hereinafter POSNER, ECONOMIC ANALYSIS OF LAW]; RICHARD POSNER, Frontiers OF Legal THEORY 1-2 (2001) [hereinafter PosNer, FRONTIERS] (examining the contributions of other disciplines to the understanding and improvement of law, including economics); Richard Posner, Some Uses and Abuses of Economics in Law, 46 U. CHI. L. REv. 281 (1979) [hereinafter Posner, Uses and Abuses] (explaining the applications and incorrect uses of law and economics).

${ }^{14}$. See infra text accompanying notes 66-81 (describing widely held presumptions regarding the "marketplace of ideas"). 
magnanimous desire to advance scientific knowledge and, perhaps, social welfare through normal, well-functioning, neutral processes.'

For example, in his famous exchange with Professor Whitford, who was not a legal economist, on the enforceability of consumer product warranties, George Priest, one of the founding fathers of law and economics, wrote: "Our objectives ... are similar: to identify policies that, other things equal, will reduce the seriousness and frequency of injuries suffered by consumers." ${ }^{16}$ Priest went on to explain that Whitford, like other scholars who wrote on this topic, relied on arguments lacking in social scientific rigor and born of feelgood intuition and emotion. Of the former, Priest wrote: "Professor Whitford's criticism . . . rests upon a misunderstanding of the nature of scientific reasoning." 17 Of the latter, Priest declared:

If I have distorted the approach of the exploitation theorists, it is "distortion" that comes from the sharpened focus of any careful, scientific study. Upon closer view, a flat world becomes round, and the Martian canals are shown to be illusions. The brilliant and moving calls of Professor Kessler in 1943 and of Professor Leff in 1970 to the attack on incompletely bargained contracts provoked sympathy in many of us in the contracts field. Their ideas have dominated our thinking about contractual relations, especially between manufacturer and consumer, and have transformed the law of products liability. Unfortunately, the suppositions upon which their ideas are based are unsupported by the evidence. The time has come for a new view of the world.

Regardless of what one thinks about the strength of Priest's arguments or the reliability of his conclusions, the point is that Priest clearly sees himself as a (winning) participant in a neutral process of

15. See, e.g., W. Kup Viscusi, SMoking: MAKING The RISky DECision 14 (1992) ("By adopting a policy approach that utilizes the choice process to promote market competition for safer cigarettes, we could better foster individual health and welfare."); George L. Priest, Can Absolute Manufacturer Liability Be Defended?, 9 YALE J. ON REG. 237, 263 (1992) ("The great virtue of the economic approach to the study of the law is that it attempts to isolate data that bear on conflicting theories to allow a discerning reader to judge between them. I encourage [my critics] to turn their prodigious energies to the discovery of such data."); cf. Posner, supra note 11, at 275 ("I am sure that economic analysts of law would be . . . generous to any sociologists of law who wanted to borrow some of the theoretical or empirical tools of economics to illuminate sociological topics.").

${ }^{16}$ George L. Priest, Comment, The Best Evidence of the Effect of Products Liability Laat on the Accident Rate: Reply, 91 YAl. L.J. 1386, 1386 (1982).

${ }^{17}$ Id.; see also id. at 1388 ("Whitford misconceives the nature of scientific inquiry.").

${ }^{18}$ Id. at 1400 (footnotes omitted). 
generating knowledge about a topic that will save lives and reduce injuries. This type of claim to the principles of science-neutral testing of hypotheses against meaningful, hard empirical data-has been extremely common among legal economists, particularly in response to critics or potential critics.

To return to the puzzle: why don't legal economists analyze themselves through the same models they apply to everyone else? Why don't they explain their success in economic terms-the predictable consequence of selfishly motivated, self-aggrandizing scholars seeking to maximize their wealth, influence, or reputations? We have an answer and, perhaps surprisingly, it is an answer that is less about highlighting a contradiction than it is about locating an underlying consistency.

Simply stated, legal economists are human ${ }^{19}$ and, being human, they are subject to biasing cognitive tendencies. Among the most fundamental biases is what social psychologists have appropriately named the fundamental attribution error. ${ }^{20}$ Our proclivity is to underestimate the role of situational influences, and to overestimate the influence of individual dispositions in explaining people's behavior. ${ }^{21}$ "[W]e tend to look for the person in the situation more than we

${ }^{19}$ We do not mean to suggest that the humanity of legal economists should come as news. We mean only to point out the obvious, and then to take its implications seriously. While some critics have demonized or dehumanized legal economists, we believe that this is wrong in fact and as a critical tactic. See, e.g., David Glenn, Calculated Risks: Harvard Professor Says Smokers Know Exactly What They're Doing, CHRON. OF Higher Educ., May 31, 2002, at A14 (reporting economist W. Kip Viscusi's account of someone reacting to him as if he were "Darth Vader"), available at http://chronicle.com/free/v48/i38/38a01401.htm.

${ }^{20}$ See infra Parts II, V.C (describing in greater detail much of the social psychological evidence regarding this attributional bias); see also SUSAN T. FISKE \& SHFlley E. TAYloR, SOCIAl COGNITION 67-86 (1991) (discussing the fundamental attribution error, defined as a "bias in social perception" whereby a person's behavior is attributed to "her own dispositional qualities, rather than to situational factors"); Ziva Kunda, Social Cognition: MAKIng SENSE OF PeOPle 430 (1999) (noting that participants in psychological studies routinely make the fundamental attribution error by "underestimat[ing] the extent to which behavior is shaped by the constraints of the situation and overestimat[ing] the extent to which it is shaped by people's underlying dispositions"); ROSS \& NISBETT, supra note 9, at 4 ("People's inflated belief in the importance of personality traits and dispositions, together with their failure to recognize the importance of situational factors in affecting behavior, has been termed the 'fundamental attribution error."); supra quotation accompanying note 9. See generally Daniel T. Gilbert \& Patrick S. Malone, The Correspondence Bias, 117 PSYCHOL. BLLL. 21 (1995) (providing an intellectual history of the fundamental attribution error-or correspondence bias-and a description of some of its causes and limits).

${ }^{21}$ KUNDA, supra note 20, at 429. 
search for the situation that makes the person." ${ }^{22}$ That is true even though "human behavior is much more under the influence of situational variables than we usually recognize or are willing to admit." ${ }^{23}$

That tendency, like numerous other interpretive biases, is partially the result of the mind's propensity to conserve scarce resources. ${ }^{24}$ It is often easy to see a person's role in bringing about a particular event, but it takes a good deal of thought to understand how the situation may have wielded influence. ${ }^{25}$ A more general description of this phenomenon is that the mind tends to downplay the role of complexifying context and overplay the role of salient behavior. "Background factors, social context, roles, or situational pressures that may have given rise to the behavior are ... relatively pallid and dull and unlikely to be noticed in comparison to the dynamic behavior of the actor." ${ }^{26}$

A second powerful influence over human cognition stems from the fact that people tend to arrive at conclusions they are motivated to reach: "[M]otivation may affect reasoning through reliance on a biased set of cognitive processes: strategies for accessing, constructing, and evaluating beliefs.... [M]otivation can be construed as affecting the process of reasoning: forming impressions, determining one's beliefs and attitudes, evaluating evidence, and making decisions." 27

${ }^{22}$ Philip G. Zimbardo \& Michael LeipPe, The Psychology of ATtTtude CHANGE AND SOCIAL INFLUENCE 93 (1991).

${ }^{23}$ Id. Daniel Gilbert and Patrick Malone also note that:

Three decades of research in social psychology have shown that many of the mistakes people make are of a kind: When people observe behavior, they often conclude that the person who performed the behavior was predisposed to do so-that the person's behavior corresponds to the person's unique dispositions-and they draw such conclusions even when a logical analysis suggests they should not.

Gilbert \& Malone, supra note 20, at 21.

${ }^{24}$ Other cognitive biases with related origins include well-known heuristics such as availability and hindsight bias.

${ }^{25}$ See FISKE \& TAYLOR, supra note 20, at 67 (identifying the "fundamental attribution error" as a tendency "to attribute another person's behavior to her own dispositional qualities, rather than to situational factors"). For other possible or partial explanations of the fundamental attribution error, see infra Parts II, VI.C.

${ }^{26}$ FISKE \& TAYLOR, supra note 20, at 67.

${ }^{27}$ Ziva Kunda, The Case for Motivated Reasoning, 108 PSYCHOL. BULL. 480, 480 (1990). 
One key motivation-central to "one of the most influential social psychological theories" -is the desire to see ourselves in selfaffirming ways. ${ }^{29}$ People tend to view themselves as well-intentioned and good, and will often engage in fairly dramatic cognitive adjustments to maintain that self-image. ${ }^{30}$ Moreover, individuals engage in the same kind of motivated reasoning regarding the institutions, groups, and situations with which they identify. In those contexts, however, the tendency is often referred to as the "ethnocentric" or "group-serving" bias or, more popularly, as jingoism, racism, sexism, heterosexism, and so on. ${ }^{31}$ The first lesson of motivated reasoning, whatever its manifestation, is that we humans tend to hold beliefs and reach judgments and conclusions that we desire, and we vastly underappreciate that tendency - particularly in ourselves.

When those sorts of human tendencies are taken seriously, the initial puzzle begins to lose its mystery. The puzzle is simply an expression of the larger human inclination to see disposition where situation is largely controlling and to do so in a way that is selfaffirming. Legal economists view others as dispositionally-typically selfishly-motivated because they can plausibly infer such information from people's conduct. And the dispositions-which legal economists typically call "preferences"-behind that conduct are thereby "revealed." Or it at least appears that way to legal economists, given the influence of the fundamental attribution error. Legal economists, likewise, see themselves (and others in their movement) as dispositionally driven, but their own purposes are presumed less crass, in part because their personal sense of themselves does not "reveal" such motives, and in part because they are motivated to attribute their successes and their competitors' concomitant failures to dispositional, not situational, forces. ${ }^{32}$

${ }^{28}$ KUNDA, supra note 20 , at 3.

${ }_{29}$ Id. at $220-23$.

${ }^{30}$ Id.; see also Jon Hanson \& David Yosifon, The Situational Character: A Critical Realist Perspective on the Human Animal (unpublished manuscript, on file with authors) (reviewing key studies and summarizing evidence on role of motivation).

${ }^{31}$ See Hanson \& Yosifon, supra note 30 (describing group-affirming motive); see also FISKE \& TAYLOR, supra note 20, at 80-81 (noting that the terms "ethnocentric" or "group-serving bias" refer to "the tendency of in-group members to attribute internal causes to positive in-group behavior and negative out-group behavior and to attribute negative in-group behavior and positive out-group behavior to external causes").

${ }^{32}$ See infra text accompanying notes 106-10 (discussing the actor-observer bias). 
It is not contradiction, then, but consistency that begins to suggest the more illuminating dimension of this puzzle. Legal economists presume a dispositional account of behavior, both in their understanding of economic actors and institutions as selfish, and in their view of themselves as relatively selfless. ${ }^{33}$ Social psychology, however, has demonstrated that seemingly dispositional actions are very often more accurately identified as situational reactions. Since economists consistently rely on dispositionist attributions, they may be consistently wrong, both as to others and as to themselves.

The point-and this is a big one-is that even though individuals and institutions may behave as if their goal were to maximize wealth, such behavior may actually reflect the social stage of interactions (the situation) more than it does the dispositions of the actors. Moreover, legal economists have failed to take situation into account in their understanding of their own success, both individually and as a school of thought. This tendency, we believe, has blinded us alllegal economists, their admirers, and their critics.

The first puzzle thus yields a glimpse of a central claim of this Article: Legal economists are correct to presume the profound influence of the profit motive over the behavior of individuals and institutions in our society, but are mistaken to locate that influence dispositionally rather than situationally. The latter possibility-that situation accounts not only for the behavior that legal economists analyze, but also for the success of their movement-brings us to a second puzzle.

\section{B. The Second Puzzle}

Have you ever noticed that many of the most prominent legal scholars actively reject the tenets of law and economics in their teaching and writing? And have you ever wondered about the fact that the criticisms that such scholars have advanced are rarely, if ever, acknowledged-much less rebutted-by legal economists? And, in light of all that, have you ever wondered why law and economics is nevertheless commonly (and we think correctly)

${ }^{33}$ In responding to these observations, we suspect that many legal economists would stress that they too are moved by selfish dispositions to advance their own interests, financial and otherwise. Our point is that they seem not to begin with that presumption and build from there, but instead experience themselves and their ideas as marching beneath the pennant of scientific truth and, in all cases, take a dispositionist view of their own (and others') behavior. 
described as the dominant legal theoretic approach? It may be helpful to describe this puzzle in greater depth.

In a 1996 survey of the most cited law review articles published from 1982 to $1991,{ }^{34}$ scholars taking the critical approach-critical legal studies, critical race theory, and feminism-vastly outpaced those taking a law and economics approach, forty-three to twelve, respectively. ${ }^{35}$ From its origins, law and economics has been subject to powerful and sustained criticisms from a diverse group of distinguished legal academics ${ }^{36}$-including, among many others, Bruce Ackerman, ${ }^{37}$ Jules Coleman, ${ }^{38}$ Ronald Dworkin, ${ }^{39}$ Grant Gilmore, ${ }^{40}$ Mark Kelman, ${ }^{41}$ Duncan Kennedy, ${ }^{42}$ Frank Michelman, ${ }^{48}$

${ }^{34}$ Fred R. Shapiro, The Most-Cited Law Review Articles Revisited, 71 CHI.-KENT L. REV. 751 (1996).

Id. at 751-59.

${ }^{36}$ Cf. LAWrence M. Friedman, A History OF AMERICAN LAw 693 (2d ed. 1985) ('The 'law and economics' school was widely attacked as right-wing and excessively narrow; but it had gained, by the 1980s, a significant place in legal teaching, thought, and research.").

${ }^{37}$ See, e.g., BRUCE ACKERMAN, RECONSTRUCTING AMERICAN LAW 45 n.16 (1984) ("[S]upporters and opponents rightly suspect that there is more to law and economics' than disinterested science ... ."); Bruce A. Ackerman, Law, Economics, and the Problem of Legal Culture, 1986 DuKE L.J. 929, 929-34, 946 (1986) (arguing that legal academics need to adapt their rhetoric to subsume law and economics and thereby "put law and economics in its place").

${ }^{38}$ See, e.g., Jules L. Coleman, Markets, MORals AND the LAw 67-150 (1988) (criticizing several branches of "the new law-and-economics" school); Jules L. Coleman, The Economic Analysis of Law, in ETHICs, ECONOMICS, AND THE LAw: Nomos XXIV 83, 100-01 (J. Roland Pennock \& John W. Chapman eds., 1982) (critiquing the notion of efficiency central to the law and economics approach); Jules L. Coleman, Efficiency, Utility, and Wealth Maximization, 8 HOFSTRA L. REV. 509, 526-40 (1980) (evaluating and rejecting Posner's concept of "wealth maximization"); Jules Coleman, The Normative Basis of Economic Analysis: A Critical Review of Richard Posner's The Economics of Justice, 34 STAN. L. REV. 1105, 1106 (1982) (book review) (arguing that "neither of Posner's arguments, nor any plausible available arguments, justify pursuing certain versions of efficiency").

39 See, e.g., Ronald M. Dworkin, Is Wealth a Value?, 9 J. Legal STUd. 191, 191 (1980) ("In this essay I consider and reject a political theory about law often called the economic analysis of law."); Ronald Dworkin, Why Efficiency? A Response to Professors Calabresi and Posner, 8 HOFSTRA L. REV. 563, 563 (1980) (criticizing "economists of law who contemplate trade-offs" between justice and efficiency).

40 See, e.g., Grant GILMORE, THE AgES OF AMERICAN LAW 100 (1977) ("So far as we have been able to learn, there are no recurrent patterns in the course of human events; it is not possible to make scientific statements about history, sociology, economics-or law.")

${ }^{41}$ Kelman writes:

$[\mathrm{M}]$ uch of the concrete institutional study done in the Law and Economics movement, particularly by those whose work has been readily integrable into mainstream law classroom teaching, is biased, not because of an inevitable 
Dierdre McCloskey, ${ }^{44}$ Martha Nussbaum, ${ }^{45}$ Rick Pildes, ${ }^{46}$ Margaret Radin, ${ }^{47}$ Jeanne Schroeder, ${ }^{48}$ Joe Singer, ${ }^{49}$ and Mark Tushnet. ${ }^{50}$

Indeed, at the same time that legal economists were proclaiming the strengths and dominance of their approach, prominent critics were claiming to reveal some of its fundamental flaws and

social theoretical tilt but rather either because the people doing the work explicitly and substantively favor certain traditional right-wing positions that they have argued for rather disingenuously or because, in their frenzied desire to demonstrate the possibility of an economistically governed utopia, they distort or deny the insuperable difficulties legal institutions would have in overcoming the problem of "otherness," the problem that selfish people will inevitably harm others, no matter how we try to channel their selfishness.

MARK KelmaN, A GUIDE TO CRITICAL LegAL STUdiES 151 (1987); see also Mark Kelman, Consumption Theory, Production Theory, and Ideology in the Coase Theorem, $52 \mathrm{~S}$. CAL. L. REV. 669, 673 (1979) (arguing that the Coase Theorem "is simply wrong as a purportedly empirical hypothetical about whether liability rules would affect substantive activity as well as distribution").

${ }^{42}$ See, e.g., Duncan Kennedy, Cost-Benefit Analysis of Entitlement Problems: A Critique, 33 STAN. L. REV. 387, 387-88 (1981) (arguing that "liberal law and economics" is incoherent when applied to the whole system of private law rules).

${ }^{43}$ See, e.g., Frank I. Michelman, Ethics, Economics, and the Law of Property, in ETHICS, ECONomics, AND THE LAW: Nomos XXIV 3, 3-4 (J. Roland Pennock \& John W. Chapman eds., 1982) (asserting that the presumptive efficiency thesis is false); Duncan Kennedy \& Frank Michelman, Are Property and Contract Efficient?, 8 HOFSTRA L. REv. 711, 714 (1980) (arguing that "the efficiency of private property and free contract cannot be deduced from the sole factual supposition of rational maximizing behavior").

${ }^{44}$ See, e.g., Donald N. McCloskey, The Rhetoric of Law and Economics, 86 MICH. L. REV. 752, 753-54 (1988) (presenting law as a primarily rhetorical realm where arguments dominate that are at odds with the mathematical and logical approach of economics). Donald McCloskey subsequently changed names to Deirdre McCloskey.

${ }^{45}$ See, e.g., Martha C. Nussbaum, Flawed Foundations: The Philosophical Critique of (a Particular Type of Economics, 64 U. CHI. L. REV. 1197, 1198 (1997) (arguing that philosophical arguments cast doubts on the foundations of law and economics theory).

${ }^{46}$ See, e.g., Richard H. Pildes, The Unintended Cultural Consequences of Public Policy: A Comment on the Symposium, 89 MICH. L. REv. 936, 936-40 (1991) (explaining that public policy requires more than a simple cost-benefit analysis).

47 See, e.g., MARGaret Jane Radin, Contested Commodities 1-15 (1996) (critiquing the universal commodification of important aspects of human life).

${ }^{48}$ See, e.g., Jeanne L. Schroeder, The End of the Market: A Psychoanalysis of Law and Economics, 112 HARV. L. REv. 483, 491 (1998) ("I do not believe law can be reduced to even the most sophisticated economics .... It is my judgment [that] ... the ideal of the perfect market is... inadequate to the task of making concrete legal policy recommendations.").

${ }^{49}$ See, e.g., Joseph William Singer, Something Important in Humanity, 37 HARV. C.R.C.L. L. REV. 103, 105-08 (2002) (criticizing welfare economics for discounting fairness as a factor in normative analysis).

${ }^{50}$ See, e.g., Mark Tushnet, "Everything Old is New Again": Early Reflections on the "New Chicago School," 1998 Wis. L. Rev. 579, 581-82 (asserting that traditional law and economics has "become stale"). 
weaknesses. $^{51} \quad$ Legal economists rarely acknowledged, much less rebutted, those criticisms. ${ }^{52}$ Many thoughtful observers therefore anticipated the eventual, if not imminent, demise of law and economics. For example, Arthur Leff wrote in 1974: "[O]ne would be forced to conclude that this kind of 'scientific' study is . . . as an attempt to present a total picture, ultimately doomed." ${ }^{53}$ By 1980 , Mort Horwitz wrote that the law and economics movement had "'peaked out' as the latest fad in legal scholarship." as to predict that "[f]uture legal historians will need to exercise their imaginations to figure out why so many people could have taken most of this stuff so seriously.,

Outsiders' predictions were not altogether different from those of insiders. Early on, even some legal economists admitted to being surprised by their success. As Judge Posner, in a loose version of our second puzzle, testified, "economics has an uphill fight in law, being disliked both as politically conservative and methodologically radical. This makes its success . . . all the more striking. ${ }^{, 56}$

And yet despite that evidence, those criticisms, those predictions, and that surprise, there is no dispute that law and economics has long been, and continues to be, the dominant theoretical paradigm for understanding and assessing law and policy. Not only is law and economics not a faddish habit of the past, but in the twenty years

51 See C. Edwin Baker, Starting Points in Economic Analysis of Law, 8 HOFSTRA L. REv. 939, 948-53 (1980) (asserting that "Posner's wealth-maximization standard has seemed normatively ungrounded" and that "Posner's inability to identify normatively appropriate starting points leaves him unable to demonstrate that his wealth-maximization ... criterion is either appealing or workable"); James R. Hackney, Jr., Law and Neoclassical Economics Theory: A Critical History of the Distribution/Efficiency Debate, 32 J. Socio-ECON. 361, 370-79 (recounting various critiques of law and economics scholars' focus on wealth-maximization as the basis for evaluating societal utility); Duncan Kennedy, Law-and-Economics from the Perspective of Critical Legal Siudies, in 2 THE NEW PALGRAVE DICTIONARY OF ECONOMICS AND THE LAw 465, 471 (Peter Newman ed., 1998) (criticizing law and economics theorists for "manipulating the apparently value neutral, technocratic discourse of efficiency to support their preferred outcomes").

52 See generally Ronald Chen \& Jon Hanson, Distribution Versus Efficiency: Missing the Taste of the Pie (May 19, 2003) (unpublished manuscript, on file with authors) (describing history of "distribution versus efficiency" debate and some ways in which legal economists have avoided or postponed addressing profound criticisms of their approach).

${ }^{53}$ Arthur Allen Leff, Law and, 87 YALE L.J. 989, 1007-08 (1978).

${ }^{54}$ Morton J. Horwitz, Law and Economics: Science or Politics?, 8 HOFSTRA L. REv. $905,905(1980)$.

\footnotetext{
${ }^{55}$ Id.

${ }^{56}$ Posner, supra note 11, at 274.
} 
since Horwitz's prognostication, it has become even more entrenched among lawmakers, judges, policy shapers, and academics. ${ }^{57}$ And, as we highlight, lay versions of the theory have been gaining ground in our culture as a whole. As one critic laments, " $[t]$ he law and economics movement is quite strongly entrenched in the law schools, and is more powerful there than any of the other social sciences." Marc Galanter and Mark Edwards, proponents of the "competing" law and society approach to legal theory, concede that "the flourishing of law and economics [is] undeniable," that "[e]conomic analysis of law... has transformed American legal thought," success in the legal academy and in the judiciary." Ackerman has described law and economics as "the most important development in legal scholarship of the twentieth century."

Numerous critics have displayed less equanimity in acknowledging the dominance of law and economics, accusing its adherents of ruthless "imperialism." Ju Judge Posner dismisses such

${ }^{57}$ Richard Posner's seminal book, Economic Analysis of Law, supra note 13, is now in its sixth edition. The fifth edition, published in 1998, recently won Harvard Law School's prestigious Ames Prize. Press Release, Harvard Law School, Judge Richard Posner Presented 2003 Ames Prize (Mar. 7, 2003), at http://www.law.harvard.edu/ news/2003/03/07_ames.php. In fact, law and economics has its own Nutshell and two encyclopedias devoted to it. JEFFREY L. HARRISON, LAW AND ECONOMICS IN A NUTSHELl (2d ed. 2000); ENCYClOPEDIA OF LAW AND ECONOMICS (Boudewijn Bouckaert \& Gerrit De Geewst eds., 2000); The NEW Palgrave DictionaRy of ECONOMICS AND THE LAW (Peter Newman ed., 1998).

${ }_{58}$ J.S. Sterling, The State of American Sociology of Law, in DEveloping Sociolocicy OF LAW: A WORLD-WIDE DOCUMENTARY ENQUIRY 805, 809 (V. Ferrari ed., 1990).

${ }^{59}$ Marc Galanter \& Mark Alan Edwards, Introduction: The Path of the Law Ands, 1997 WIS. L. REV. 375, 378.

in Id.

${ }^{61}$ Id. at 381 .

${ }^{62}$ COOTER \& Ulen, supra note 7, at 2.

${ }^{63}$ See W. Bradley Wendel, Mixed Signals: Rational-Choice Theories of Social Norms and the Pragmatics of Explanation, 77 IND. L.J. 1, 29-30 (2002) (stating that "scholars in other disciplines often object to the imperialist tendencies of economic analysis, because of this tendency to translate the explanatory terms employed by humanistic and social science disciplines into a few concepts that are deemed admissible in economics, such as 'preferences' and 'expected utility'). This characterization is not new. See, e.g., ECONOMIC IMPERIALISM: THE ECONOMIC METHOD APPLIED OUTSIDE THE FIELD OF ECONOMICS, at vii (Gerard Radnitzky \& Peter Bernholz eds., 1987) (attempting to show that economics can explain the behavior of living systems, despite critics who accuse economists of "disciplinary imperialism"); DAVDD M. KREBS, A COURSE IN MICROECONOMIC THEORY 9 (1990) ("Economists are well-known among social scientists as imperialists in the sense that economists attempt to reduce everything to economic notions and paradigms."). 
accusations as so much "[p]rofessional envy." And who wouldn't be jealous? After all:

Economic analysis of law has grown rapidly, has become the largest, most pervasive interdisciplinary field of legal studies in the history of American law, has palpably influenced the practice of law and judicial decisions, has launched lucrative consulting spin-offs, has spawned courses and textbooks in economic analysis of law, has influenced legislation (economic analysts of law played an important role in the deregulation movement), has made it de rigueur for law schools of the first and second ranks to have one or more economists on their faculty, has seeded a number of its practitioners in university administration and the federal judiciary, and has now crossed the Atlantic and begun making rapid gains in Europe. ${ }^{64}$

In short, regardless of how different scholars feel about it, there is no contesting the fact that law and economics is currently the undisputed champion of the putative legal-theoretic competition.

So here, again, is the second puzzle: How is it that a theory that is the subject of so much skepticism and criticism among legal academics, and that seems to have been rejected (or at least, not embraced) by huge segments of that community, has become the dominant theoretical paradigm for understanding and assessing law and policy?

That puzzle begins to come together when one understands that scholars, as humans, are motivated to believe that the institutions with which they have a strong affiliation are just ${ }^{65}-a$ motivation that may be particularly intense in this case, given that the legal academy is an institution to which academy members have committed their professional lives and upon which their legitimacy is largely based. Absent undeniable evidence to the contrary, scholars so motivated assume that the success or failure of a theory reflects the outcome of a reasonably well-functioning marketplace or tournament of ideas. Success there, like evolutionary or market success, is thought to reflect a meritocratic selection process. ${ }^{66}$

${ }^{64}$ Posner, supra note 11, at 275 (citations omitted); see also POSNER, FRONTIERS, supra note 13, at 35 ("It is not merely an ivory-towered enterprise, especially in the United States, where the law and economics movement has influenced legal reform in such fields as antitrust law, the regulation of public utilities and common carriers, environmental regulation, the calculation of damages in personal injury suits . ...").

${ }^{65}$ See Hanson \& Yosifon, supra note 30 (discussing motivations relating to an individual's group and system affiliations).

${ }^{(16}$ To be clear, we do not believe that perceptive critical scholars (such as Mort Horwitz) consciously think to themselves that the playing field of legal theory is a purely meritocratic one. Our point is that even system-sensitive critical legal scholars 
Such a faith is implied in many legal theoretic histories. Robert Cooter and Thomas Ulen, in their authoritative text, Law and Economics, ${ }^{17}$ attribute the success of law and economics to its practitioners identifying "a vacant niche in the "intellectual ecology" of legal theory and then "rapidly fill[ing] it." ${ }^{, 68}$ Thomas Ulen recently expanded on that survival-of-the-fittest metaphor, boasting:

Law and economics has been one of the most successful innovations in the legal academy in the last century. This intellectual revolution began modestly in the 1960s and 1970 s with a few important and innovative articles and a comprehensive, masterful text that showed the possibilities of the field. Then, in the 1980s the field exploded into respectability and prominence-becoming a regular course in the curricula of the best law schools, a vibrant legal research style that figured in a torrent of important books and articles, a force that transformed many faculty from exclusive practitioners of traditional doctrinal research to a more social-science-oriented research, and a substantial justification for important public policy changes. By the early 1990s, economic analysis suffused a modern legal education, even one devoid of an explicit course in law and economics.

Writing generally about economics, George Stigler explains: "Economics is the only reasonably well-developed social science... in that it has an extensive, operable, tested theoretical system." ${ }^{70}$ Posner beats the same drum when he proclaims that the work of "anthropologists, sociologists, psychologists, political scientists, and other social scientists ... is insufficiently rich in theoretical or empirical content to create serious competition for the economists." " Elsewhere, he makes the point more concretely:

There is a dearth of arresting hypotheses to set off against the Coase Theorem, the Hand Formula, the efficiency theory of the common law,... the economics of property rights versus liability rules, the

implicitly reveal an unexamined trust in current institutional arrangements (or perhaps situational pressures discouraging the articulation of distrust), as evinced by the fact that such biases are rarely even hinted at in writing about what moves current intellectual trends in legal academia.

${ }^{67}$ COOTER \& ULEN, supra note 7.

${ }^{68} I d$. at 3 .

69 Thomas S. Ulen, Firmly Grounded: Economics in the Future of the Latv, 1997 WIS. L. REV. 433, 434 (footnotes omitted).

${ }^{70}$ GeORGe J. STIGLer, MEMOIRS OF AN UNREgulated ECONOMist 8 (1988).

${ }^{71}$ POSNER, ECONOMIC ANALYSIS OF LAW, supra note 13, at 26; see also Posner, supra note 11, at 273 ("The sheer modesty . . of American sociology of law has hurt the field in its competition with critical legal studies, feminist jurisprudence, political theory, economic analysis of law, and even law and literature for a place at the legal-studies high table."). 
activity-level theory of strict liability,... and the myriad of other concepts, many counterintuitive, that have made economic analysis of law intellectually exciting. ${ }^{72}$

When explaining their success, legal economists rely not just on proud descriptions of methods, discoveries, and insights, but also on the legacy of intellectual giants, from Jeremy Bentham and Adam Smith to Gary Becker and George Stigler. ${ }^{73}$ The internal histories of the emergence of law and economics thus focus on the "great ideas" and "great men" of the movement, as if Coase and Copernicus played analogous roles in advancing science. ${ }^{75}$ Even if that is an overstatement, it is patently clear that legal economists see themselves as the rightful winners of a fair and effective process-a success that is measured largely in terms of real-world influence and without reference to the serious criticisms of their approach.

Professor Horwitz, though no doubt disappointed with the outcome, also seemed to view the rise and fall of ideas and theories as part of a fair competition, or at least that seems an obvious

${ }^{72}$ Posner, supra note 11, at 273. Elsewhere, Judge Posner argues that law and economics has benefited from "[r]apid increases in recent decades in the scope and rigor of microeconomics (due partly to the increased incorporation of game theory into economics)." POSNER, FRONTIERS, supra note 13, at 4.

${ }^{73}$ Posner has been repeating the same basic historiographical thumbnail sketch of the movement in his writings for decades. See, e.g., POSNER, FronTIERS, supra note 13 , at 31 ("What I try to do... in this chapter is to anchor a brief description of the field by reference to two of its most illustrious progenitors, Jeremy Bentham and (briefly) Gary Becker...."). For other Posnerian renditions of this sketch, see, for example, Posner, Uses and Abuses, supra note 13, at 281-84 (1979), where he discusses the role of Jeremy Bentham, Gary Becker, and others in the development of law and economics. The same story unfolds in his chapter on the history of law and economics in his ECONOMIC ANALYSIS OF LAW, supra note 13, at 21-28.

${ }^{74}$ Cf. JULIE A. NELSON, FEMINISM, OBJECTIVITY AND ECONOMICS, at xi (1996) ("The mainstream academic and professional discipline of economics ... is built around distinctly masculine-based notions...."); Marianne A. Ferber, The Study of Economics: A Feminist Critique, 85 AM. ECON. REV. 357 (1995) (describing the malecentric bias contained in economics scholarship); Julie A. Nelson, The Siudy of Choice or the Study of Provisioning? Gender and the Definition of Economics, in BEYOND ECONOMIC MAN: FEMINIST Theory and ECONOMICs 23, 33 (Marianne A. Ferber \& Julie A. Nelson eds., 1993) ("Feminist theory suggests that the Cartesian divisions between rationality and embodiment, and between man and nautre, reflect a masculinist and separate view of the world ...."); Diana Strassman, Not a Free Market: The Rhetoric of Disciplinary Authority in Economics, in BEYOND ECONOMIC MAN: FEMINIST THEORY AND ECONOMICS, supra, at 54, 56-65 (using "stories" to illustrate the present narrowness of explanatory accounts in economics, which is due to the exclusion of the woman's perspective when formulating theories).

${ }^{75}$ See supra text accompanying notes 16-18 (quoting George Priest for his claim that law and economics, more so than other fields of legal scholarship, is grounded in scientific reasoning). 
inference to draw from his prediction about the imminent demise of law and economics. ${ }^{76}$ And Horwitz is by no means the only noneconomist exhibiting such faith. Indeed, it seems to be widespread in legal academics, as revealed by the fact that unfairness or bias in the marketplace of ideas is rarely discussed among its participants-even among those scholars whose work is built on identifying and describing such unfairness and bias in other institutions. ${ }^{77}$ Thus, while scholars have not always explicitly claimed that theoretical dominance implies theoretical superiority, such an inference is manifested in the legal economists' boasting and the critics' collective (and now largely frustrated) expectation that law and economics would pass quickly.

A closer look at the details of legal theoretic discourse reveals yet another nuance to the pattern. Legal economists attribute their success in the tournament to internal or dispositional factors. They seem to view their methods and insights, perhaps even their intellectual capacity, as simply superior to those of their competitors.

That dispositional perspective is amplified when economists criticize their competitors. Not only are outsiders deficient methodologically, they are, as our "just world" ${ }^{\text {"78 }}$ requires, also dispositionally deserving of their fate. Posner, for example, claims that some

${ }^{76}$ See supra text accompanying notes 54-55 (recounting Horwitz's prediction that law and economics would be only a short-lived "fad" in legal academia).

${ }^{77}$ For example, at two Harvard Law School panel discussions on the future of progressive legal theory, panelists had little to say about the underlying sources of, or possible solutions to, the fact that progressive legal scholarship has had comparatively little influence over legal theory or policy while law and economics has grown dominant. See Ari Z. Weisbard, Professors Debate Law, Economics, Harv. Crimson, Mar. 20, 2002, http://www.thecrimson.com/article.aspx? ref=180698 (recounting a progressive panelist's statement that "our institutions are being reformed everyday" by law and economics); Press Release, Harvard Law School, HLS Faculty Panel to Explore Future of Progressive Legal Scholarship (Feb. 22, 2002), at http://www.law.harvard.edu/news/2002/02/22_scholarship.php (describing the participants and sponsors of two panels discussing progressive legal scholarship). Panelists included distinguished progressive scholars with an acute awareness of legal theoretic trends and historical sensitivity such as Christine Desan, Kent Greenfield, Janet Halley, David Kennedy, Duncan Kennedy, Mort Horwitz, Frank Michelman, and Joe Singer. In our view, the lack of a theoretical explanation for these trends reflects an implicit (and, we think, unexamined) faith on the part of even the most institutionally and politically sensitive scholars in the academic process as basically fair and self-correcting. One goal of this project is to provide an alternative approach to assessing legal theoretic trends.

${ }^{78}$ See Hanson \& Yosifon, supra note 30 (providing a more detailed discussion of the "just world hypothesis" and "system-affirming motives"); infra notes 215, 635, and 686 and accompanying text (briefly discussing related motives). 
competitors may have fared better if only they were not so spiteful about their losses and, so unwilling "to pick up the analytic techniques and models of economic analysis and use them in their own work." According to Posner, "no one likes to retool with the methods of a rival discipline; it is a confession of defeat." ${ }^{80}$ The source of the competitors' failure is, in Posner's account, not in the situation of the competition, but in the dispositions of the participants. And it is not just any disposition, but the disposition of selfishness-the very disposition that motivates the agents of legal economists' models. And it is also, in Posner's view, the disposition of spite and smallness-the very sort of qualities that psychologists have shown that we are motivated to see in "out groups" and to deny in our own groups, and that consequently enable us to feel that the misfortunes of "others" are warranted. ${ }^{81}$

Consequently, there are two ways in which the largely uncontested "tournament of ideas" notion reflects the fundamental attribution error. First, as we just described, competitors are presumed to win or lose because of dispositional factors. Second, the operation and dynamics of the tournament itself is presumed to be independent of broader situational influences. The metaphor of a tournament or marketplace highlights the presumption that competition on the merits is the driving force and that the victor is determined through successful competitive engagements, full stop. Any forces exogenous to the tournament are rarely identified, much less systematically analyzed.

Again, it is not contradiction, but consistency, that suggests the more revealing aspects of this second puzzle. Both legal economists and their critics presume a dispositionist account of scholarly behavior. But again, social psychology instructs us that seemingly dispositional actions are often more accurately understood as situational reactions. The consistent dispositional attributions, therefore, may be consistently wrong. A more complete solution to this puzzle, however, must await the balance of this Article.

We named this Part "setting the stage," not simply because it sets the stage for the balance of the Article, but also because it is

${ }^{79}$ Posner, supra note 11 , at 274.

Id.

${ }^{81}$ See Hanson \& Yosifon, supra note 30 (discussing that tendency in greater detail and more general social psychological findings regarding inter- and intra-group motivations); infra notes 689-90 and accompanying text (summarizing the human tendency to see bias in others that we do not see in ourselves). 
intended to begin to illuminate the power of staging over acting. The stage is not simply the place where independent, dispositional actions occur, as is so commonly, so humanly, assumed. The stage is itself an unseen participant-one that shapes, transforms, sometimes determines, and almost always influences, the behaviors of the visible characters. If that is correct, legal scholars and policymakers need to ascertain how the stage is set, who has the power to set it, and what the purpose of the staging is. We all need to be attentive to the situation.

\section{BRiEf INTRoduction to the Situational Character}

\section{A. Seeing the Actors}

Tastes are the unchallengeable axioms of a man's behavior: he may properly (usefully) be criticized for inefficiency in satisfying his desires, but the desires themselves are data.

\section{- Gary Becker and George Sligler}

I find it difficult now to identify the motives for many things I have done . . . . I do not have a good answer to the question of my own behavior . . . . My memory has a strange way of selecting its contents.

\section{- George Stigler ${ }^{83}$}

In our view, legal theory and the law ought to be informed by as realistic a vision of humanity as our learning can muster. This Section begins to formulate such a vision through some of the central lessons of social psychology. The bulk of this effort must await separate articles. ${ }^{84}$

${ }^{82}$ George J. Stigler \& Gary S. Becker, De Gustibus Non Est Disputandum, 67 AM. ECON. REv. 76, 76 (1977).

${ }^{83}$ STIGLER, supra note 70 , at 132, 133, 146.

${ }^{84}$ See, e.g., David Arkush \& Jon Hanson, Law and Emotion (unpublished manuscript, on file with authors) (describing the role and influence of emotion, affect, and feelings, and assessing their relevance for law and legal theory); Chen \& Hanson, supra note 52 (focusing on role and effects of schemas, scripts, stereotypes, and other knowledge structures and their relevance for law and legal theory); Ronald Chen \& Jon Hanson, The Illusion of Law I: The Legitimating Schemas of Modern Policy and Corporate Law (May 31, 2003) (unpublished manuscript, on file with authors) (describing the biased schemas of modern policymaking and corporate law and the interests they serve) [hereinafter Chen \& Hanson, Illusion of Law I]; Jon Hanson, Ana Reyes \& Daniel Schlanger, Law and Attribution (unpublished manuscript, on file with authors) (examining how people make attributions of causation, responsibility, and 
Suppose you are walking down the street, on your way to class, when a man in a white coat comes up behind you, jabs a gun into your spine and barks "get into that building." Inside the building, you find yourself in a small room where the gunman explains that you will be shot unless you flip a switch (labeled "DANGER: SEVERE SHOCK-XXX-450 volts") on some sort of electrical box which is attached by wires to an electric-chair contraption in which another man is strapped. The gunman informs you that "although the shock can be extremely painful to the person in the chair, it can cause no permanent tissue damage." Meanwhile, that person is squirming, sweating, and imploring you not to flip the lever. He seems almost as scared as you are and is saying something about heart trouble and pleading to be released. The gunman cocks his pistol, aims the barrel at your temple, and tells you: "You have no other choice, you must go on."

Despite this scene's surreal qualities, you believe everything about it, including that the gun pointed at your head is real and that its holder is ready to use it. What would you do?

We suspect that many of you would flip the lever, as we probably would. And we suspect that even those of you who would not would still sympathize with and hold relatively blameless anyone who did. The situational pressure is simply too great to withstand. The power of the gun is unmistakable, and the "choices" to enter the building and to flip the lever are hardly choices at all, for the disposition of the person who makes them seems so clearly constrained by the situation as to render the results nearly determined.

Now, suppose you are strolling across your favorite university campus when you are approached by a clipboard-toting, labcoated graduate student who is recruiting participants for an ongoing psychological experiment testing learning techniques. You agree to take part, and follow the graduate student into a building where you meet the professor running the study and another person, who, like yourself, has agreed to participate. You draw lots and find that in the experiment you will be the "teacher," and your fellow

blame, and describing the relevance of attribution theory for law and legal theory); Hanson \& Yosifon, supra note 30 (providing a fulsome overview of the social psychological and social cognition literatures, and, based on that, offering an alternative conception of the human animal to the one imagined in law and legal theory, and considering some of the implications of that new conception for law and legal theory). 
volunteer will be the "learner." The professor explains that he will read a list of pairs of associated words to the learner, after which he will read one word from the pairs as a prompt for the learner to supply the correct associated word. If the learner fails to provide the correct word, you, as the teacher, are to flip a switch that will shock him. With each incorrect answer, the strength of the shock will increase by 15 volts. You follow the professor into an adjacent room where you watch as the learner is strapped into a chair and electrodes are attached to his body. Then you move back to the first room where the professor begins the experiment. Very soon into the procedure, the subject gets an association wrong. Do you flip the switch?

Perhaps you do. Now the wrong answers continue to come. With each mistake you increase the voltage, and you begin to hear the learner moaning in pain. Poised at 150 volts, the learner exclaims that his heart is bothering him. When you reach 210 volts, he demands to be released, saying he refuses to answer any more questions. At 300 volts, he is screaming in agony. After 330 volts, the learner's room becomes silent. The professor continues to ask questions and announces that continued silence will be interpreted as a wrong answer, bringing another shock. You look at the control panel and see that the next level reads "DANGER: SEVERE SHOCK-XXX -450 volts." You hesitate, and the professor demands, "You have no other choice, you must go on." Do you flip the switch? Would you have made it to this point in the study?

If you are like most people, you have almost certainly answered a resounding "no!" to those questions. And if you think others would respond to the scenario similarly, you would expect them to refuse to go along with the experiments as well. And you would not be alone.

College students asked to evaluate such a proposed experiment estimated that, on average, most people would go to 135 volts before refusing to go on, and they said that only one in a hundred would go all the way to end of the scale-450 volts. ${ }^{85}$ Professional psychiatrists surveyed about the same proposed experiment predicted that only one in a thousand-"the sadists"-would go all the way. ${ }^{86}$

${ }^{85}$ See ZIMBARDO \& LeIPPE, supra note 22, at 67-68 (1991) ("Most said that no one would go all the way to 450 volts.").

${ }_{86}$ Id. at 65-74 (summarizing Stanley Milgram's obedience experiments); see also STANley Milgram, ObediEnCE TO AuTHORITY 27-31 (1974) [hereinafter MILGRAM, OBEDIENCE TO AUTHORITY] ("Each one of the 110 respondents sees himself disobeying the experimenter at some point."); Stanley Milgram, Some Conditions of Obedience and 
We humans do not understand ourselves well.

The scenario described above-the one with the graduate student and not the one with the gun-was the basis of a series of actual experiments that Stanley Milgram, a pioneer in the field of social psychology conducted at Yale University beginning in the early 1960 s. $^{87}$ In the actual experiment, however, the flipped switches did not actually shock the learner. ${ }^{88}$ The responses that the teacher heard were scripted-a fact unknown to the teacher. ${ }^{89}$ Milgram's expectations matched those of the college students and psychiatrists who he surveyed beforehand. ${ }^{90}$ But out of the first forty teacher subjects he tested, twenty-six of them (sixty-five percent) went all the way to 450 volts. ${ }^{91}$ And that was only the beginning of a long series of studies revealing the disturbing "banality of evil."."

By now the reason for the experimental results should be clear: situation, like an invisible hand, moves us. ${ }^{93}$ Milgram performed this

Disobedience to Authority, 18 HUM. REL. 57, $72-73$ (1965) [hereinafter Milgram, Some Conditions of Obedience] ("The psychiatrists predicted that most subjects would not go beyond the ten th shock level [150 volts] ....").

${ }^{87}$ See Milgram, Some Conditions of Obedience, supra note 86 , at 60 ("Pilot studies ... were completed in the winter of $1960 . ")$.

${ }^{88}$ See Stanley Milgram, Behavional Study of Obedience, 67 J. ABNORMal \& SOC. PSYCHOL. 371, 373-74 (1963) (explaining the basic design of Milgram's experiments).

${ }^{89}$ See id. at 372 (explaining that in most versions of the experiment the "learner's" responses were tape recorded and played over a sound system in the "teacher's" room).

${ }^{90}$ See Zimbardo \& LEIPPE, supra note 22, at 68 ("Milgram himself foresaw little total obedience.").

${ }^{91}$ See Milgram, Obedience to AUthority, supra note 86 , at 60 tbl.3 (identifying these numbers as resulting from a base-line condition in which the "learner" responded with more than just cries of anguish, including voicing concerns of a heart problem).

92 See generally HaNNAH ARENdT, EichmanN in JERUSAlEM: A REPORT ON THE Banality OF Evil (1994); DANiel Jonah Goldhagen, Hitler's Willing EXECUTIONERS: ORDINARY Germans AND THE Holocaust (1996); ERVIN STAUb, The Roots of Evil: The Psychological and Cultural Origins of Genocide (1992); Philip G. Zimbardo, The Psychology of Evil, 5 EYE ON PSI CHI 16 (2000), http://www.psichi.org/pubs/articles/article_72.asp.

${ }_{93}$ As Milgram learned in his experiment:

With numbing regularity good people were seen to knuckle under the demands of authority and perform actions that were callous and severe. Men who are in everyday life responsible and decent were seduced by the trappings of authority, by the control of their perceptions, and by the uncritical acceptance of the experimenter's definition of the situation, into performing harsh acts... 
experiment hundreds of times using many different variations. ${ }^{94}$ By manipulating the situation, Milgram was able to increase or decrease conformity on the part of the teachers. For example, when it was not the teacher administering the shock himself, but rather a peer operating at the teacher's instruction, more than ninety percent of subjects administered the maximum shock. ${ }^{95}$ When an ordinary person rather than a scientist was demanding that the shocking continue, however, far fewer teachers went to 450 volts. ${ }^{96}$ The sixtyfive percent full compliance observed repeatedly at Yale shrunk to forty-eight percent when the study was moved off campus and purportedly run by "Research Associates of Bìidgeport."

The vast discrepancy between ex ante predictions about the likely behavior of subjects in these experiments and their actual behavior reveals a central lesson of social psychology-namely, the profound ways in which situation influences our behavior. ${ }^{98}$ The naive predictions themselves reveal the gross extent to which we underestimate the power of the situation and wrongly presume that behavior is motivated by disposition. ${ }^{99}$

... A substantial proportion of people do what they are told to do, irrespective of the content of the act and without limitations of conscience, so long as they perceive that the command comes from a legitimate authority.

Milgram, Some Conditions of Obedience, supra note 86, at 74-75.

${ }^{94}$ Milgram conducted at least twenty-one different variations on the initial experiment. See Milgram, ObEDIENCE TO AUTHORITY, supra note 86, at 207 n.6 ("[Nervousness] data [of the subjects] are available for twenty-one experimental conditions ....").

${ }^{95}$ See id. at 119, 121-22 (concluding that "any factor that will create distance between the subject and the victim[] will lead to a reduction of strain on the participant and thus lessen disobedience").

See id. at 93-97 (finding that despite authority "hovering in the background," experiments in which an ordinary man gave the orders resulted in a "sharp drop in compliance" to twenty percent administering the maximum shock).

Id. at 68-69.

${ }^{98}$ The discrepancy also reveals the extent to which even psychologists frequently fail to anticipate how situation will move their subjects. See Jerry Fodor, Why We Are So Good at Catching Cheaters, 75 CoGNition 29, 32 (2000) ("When subjects appear to behave peculiarly in an experimental task, that is not infrequently because they are sensitive to a material [] variable that the experimenter has failed to notice.").

99 Milgram's research reflects what many, including Milgram, noticed about Nazi Germany: the ease with which situational influence can lead humans to engage in atrocious, morally reprehensible, individual acts. Recent primary research indicates that "ordinary men"- those who previously led regular, civilized lives—overwhelmingly accepted the Nazi regime's call to genocide despite an explicitly available "choice" to evade the action. See CHRISTOPHER BROWNING, ORDINARY MEN 1-3, 55-57 (HarperPerennial 1998) (1992) (reporting how a Nazi battalion commander in World War II Poland allowed "any of the older men who did not feel up to the task" of 
As Milgram's experiments help demonstrate, unobserved (though observable) situation can be as potent as observed situation. And when it is unobserved situation that moves us, we experience it as dispositional consent.

Insofar as economics, and law and economics, have been challenged by critics, most debate has taken place over the extent to which people are rational. Economists tend to assume that the "rational actor model" is reasonably accurate, or that its inaccuracies do not, for one reason or another, threaten their conclusions substantially. ${ }^{100}$ The critics tend to either roll their eyes at the obvious absurdity of the rational actor model or, more carefully, provide evidence to support a conclusion that the rational actor model is flawed and should be adjusted to take into account the irrational features of the typical human actor. In our view, both perspectives miss the far more significant assumption behind the rational actor model: that people are dispositional actors. As the Milgram experiments so powerfully demonstrate, it is our situations-far more than we realize, and often far more than our dispositions-that move us. We are, in essence, not rational actors, but "situational characters."

\section{B. Missing the Stage}

We are too ready to read personality and character traits into the behavioral drama and too resistant to see stage settings as the basis for the action.

-Philip G. Zimbardo $\mathcal{F}^{2}$ Michael Leippe

participating in a massacre to "step out" and be given an alternative assignment); $i d$. at 64-65 (describing how during one execution in the Polish woods "anyone who could not take it any longer could report" and be excused); id. at 74 (reporting that despite the opportunity to drop out, less then twenty percent of the Nazi policemen evaded the killing of 1500 people-an entire town). But see id. at 65-70, 75 (relating the stories of German policemen who chose not to kill, several of whom felt no need to impress their comrades because of financial security and a lack of career military ambitions). The author of Ordinary Men, Christopher Browning, dispositionalized the massacre by focusing on those who avoided the situational influence-or responded to a less prominent situation-despite the glaring fact that so few managed to do so.

${ }^{100}$ See Hanson \& Yosifon, supra note 30 (reviewing responses of economists and legal economists to social psychological evidence that conflicts with the rational actor model).

${ }^{101}$ ZIMBARDO \& LEIPPE, supra note 22, at 93. 
All the world's a stage. . And all the men and women merely players. . . .

-William Shakespeare ${ }^{102}$

The "situational character," introduced in this Article and fleshed out in a companion article ${ }^{103}$ and in other works, ${ }^{104}$ is meant not to reconstruct, but rather to retire the basic rational actor model of law and economics (including its chief competitors such as the behavioral actor, the boundedly rational actor, the satisficing actor, and the autonomous agent of classical liberalism). Our goal is not, in other words, to offer an alternative dispositionist ${ }^{105}$ account, but rather to develop an approach to legal theory that conceptualizes people's behavior more accurately in the locus of situation.

We thus introduce the situational character: an individual who does not act with total freedom (even if she does sometimes act extemporaneously) and who does not often choose her stage. She instead finds herself, and we as legal scholars find her, already in action on a given stage, among other characters, with dialogue and plot proceeding apace around her, and subject to the powerful (if less visible) influence of scripts, props, backdrops, and directors. To be sure, such a character will often behave as if she is a dispositional actor, but alter the stage, the script, and so on, and you will see the pervasive role of situation as the actor's behavior conforms to it.

Consider the following thought experiment:

Your plane, a Boeing 747, is reaching cruising altitude in your flight from Logan to O'Hare, and the pilot turns off the "Fasten Seatbelt" sign. You recline in your aisle seat for a catnap when the elderly and somewhat feeble gentleman next to you stands and politely asks to get by. You move quickly into the aisle to aid his passage and then return to your seat as he makes his way slowly to the back of the plane to the lavatory-about one-eighth of the length of the plane. You don't rebuckle your seatbelt because you expect him to return shortly and you want to be prepared to again move into the aisle so that he can reclaim his seat.

${ }^{102}$ WILliaM SHAKESPEARE, AS YOU LIKE IT act 2, sc. 7.

103 See Hanson \& Yosifon, supra note 30.

${ }^{104}$ See sources cited supra note 84.

${ }^{105}$ By "dispositionist" or "situationist," we mean to indicate the attributional perception, and by "dispositional" and "situational" we mean to indicate the attributional truth of the matter. Thus, describing people as situational dispositionists is one way of saying that they are subject to the fundamental attribution error. 
Ten minutes pass, and you begin to worry because the elderly gentleman seemed a little unstable. Still, you are reluctant to meddle and possibly embarrass him or yourself. When another five minutes have passed, you decide to alert a flight attendant of your concerns. As you reach for the call button, the man returns, apparently no worse for wear. You jump out to let him in, and you both slide into your seats. You breathe a slight sigh of relief that he is fine after all, and that you did not have to press the button.

Now, without re-reading any portion of the preceding paragraphs, estimate the distance that the old man traveled between leaving and returning to his seat.

If you are like most people we asked about this scenario, you estimated close to thirty feet. A more accurate estimate, however, would be roughly 1000 times greater than that-approximately 150 miles. In other words, most people see the man moving within the plane, but miss his situation, the plane itself. ${ }^{106}$ But even the few who see the plane tend to miss the movement of the Earth-a failure that made Copernicus, one who did notice, the butt of ridicule, and Galileo, another who saw what others were missing, a prisoner. And even those great astronomers did not perceive, just as most of us today do not, the immense currents of the solar system, the galaxy, and the universe. Indeed, when one takes those additional situational forces into account, the old man moved, in his visit to the bathroom, something closer to 350,000 miles. $^{107}$

${ }^{106}$ Of the thirty-three people we asked, twenty-four of them provided answers of between zero and one hundred feet. Nine gave answers that revealed that they considered the movement of the plane: more than fifty miles. But of those nine, seven indicated that they considered that movement because they were looking for the "trick," and that it took them some time to figure out the second answer. It bears mentioning that even the respondents in the first group appeared to be looking for the trick, asking questions about what they had missed, but were still unable to perceive the plane's movement when asked how far the man had "traveled" in fifteen minutes. Within the seemingly fixed environment of the cabin, one individual's movement was far more salient than the (forgotten) progress of the plane itself.

${ }^{107}$ The Earth's average orbital velocity is 18.5 miles per second. See Scott Wilber, How Many Miles Does the Earth Travel in Space Each Day?, Physlink.com: Physics \& ASTRONOMY ONLINE, at http://www.physlink.com/Education/AskExperts/ae548.cfm (last visited Oct. 25, 2003) (stating that the "entire solar system, including the Earth, moves through the cosmic background ... for a total of 32 million miles per day"). In one minute, the elderly man travels 1110 miles due to the Earth's orbital velocity; in fifteen minutes, he travels 16,650 miles. Factoring in background movement $-22,222$ miles per minute-results in 350,000 miles in fifteen minutes. 


\section{The Bounds of Dispositionism}

We have already summarized some of the "evidence that people are inclined to offer dispositionist explanations for behavior instead of situationist ones, and that they make inferences about the characteristics of actors when they would do well to make inferences instead about the characteristics of situations ...."108 We have also suggested that this fundamental attribution error has not spared the professional and credentialed minds of economists and legal economists-hence, our repeated emphasis on the fact that they too are human.

But, if we humans are subject to a tendency to see disposition where situation is largely controlling, a critical question emerges as to the strength and expansiveness of that tendency. Of course, this is a question for which no precise answer can be given. But it is nevertheless a crucial issue for legal theory, and one that cannot be papered over by implausibly presuming near-total dispositionism. Some clarifying light can be shed on the matter by separating it into two sub-questions. First, at what point and to what degree do lay people and economists begin to see situation and to take it into account? In other words, what are the limits to our dispositionismhow fundamental is it? Second, to what extent do disposition and situation actually move us? Put differently, how fundamental an error is our dispositionism? The first question is about how we perceive what we see, and the second question is about how accurate our perceptions are.

\section{How Fundamental Is Our Dispositionism?}

Regarding the first question, our gun-to-the-head example ${ }^{109}$ makes clear that our dispositionism does occasionally give way to situationism. The example is particularly apt because it appears that we rarely see situation unless the situation is thrust upon us in the form of another hard-to-miss actor such as a person wielding a gun. ${ }^{110}$

${ }^{108}$ Ross \& NisBETT, supra note 9, at 125.

${ }^{109}$ See supra Part II.A (suggesting that a threat of serious bodily harm would likely cause one to inflict pain on another despite a disposition against such an action).

${ }^{110}$ There are exceptions to those basic patterns. Most notably, when making attributions about ourselves we often are more likely to attribute the cause of bad outcomes or behavior to exterior situational influences. For example, if we do poorly on an important test, we may be quick to complain about the distractions in the testing 


\section{a. Economic incentives}

Even a very obvious, controllable, and tangible situational influence-money-is commonly overlooked in favor of dispositionist explanations of behavior. The effects of financial incentives on lay people tend to be understood in terms of stable dispositional proclivities. This lesson is rendered explicit by experiments in social psychology.

In one such study, a first group of subjects (the "observers") were asked to monitor and later draw conclusions about the conduct of a second group of subjects (the "volunteers") as part of a study on decision making." ${ }^{\text {II }}$ After describing a fictitious study to the subjects, the experimenter announced that before they began the experiment, she "happen [ed] to have sort of a real decision for [them] to make." cial supporters of the college's "Human Development Institute" were gathered in town for the weekend, and the Institute was seeking students who would help with entertainment and campus tours for the spouses of these businesspeople. The real experiment, of course, was underway. Some subjects were offered $\$ 0.50$ per hour and some were offered $\$ 1.50$ (or some amount closer to $\$ 3$ and $\$ 9$, respectively, in 2003 values). Just twenty-four percent of the low-payment subjects volunteered, while sixty-eight percent of the high-payment subjects did so. ${ }^{13}$ Volunteering was therefore correlated with the amount of money offered, hardly a shocking result.

environment or a biased professor who grades unfairly. Conversely, when things go well for us we have a tendency to attribute the cause to our own dispositions-our intelligence, diligence, etc.-rather than situational influences. Those patterns in the actor-observer bias, as the phenomenon has been dubbed by social psychologists, echo part of our basic claim here, which is that our behavioral attributions are often motivated. See Emily Pronin et al., Understanding Misunderstanding: Social Psychological Perspectives, in HeuRistics AND BIASES: THE PSYCHOLOGY OF INTUITIVE JUdGMENT 636 , 653-65 (Thomas Gilovich et al. eds., 2002) (reviewing social psychological findings concerning the actor-observer bias); see also FISKE \& TAYLOR, supra note 20, at 72-75 (discussing actor-observer bias). Social psychologists have identified other limits to our dispositionism. See infra text accompanying notes 411-41 (discussing cultural influences over dispositionist and situationist attributions). Of course, even when we attribute causation to situation, we often only recognize a tiny portion of the situation. See also infra text accompanying notes 140-45 (describing other limitations to our ability to appreciate the role of situation).

${ }^{11}$ Richard E. Nisbett et al., Behavior as Seen by the Actor and as Seen by the Observer, 27 J. PERSONALITY \& SOC. PSYCHOL. 154, 155 (1973).

${ }_{112} I d$. at $155-56$.
$I d$. at 157 . 
More revealing findings, however, came out of the second part of the experiment. "Observers," who had been privy to all elements of the first part of the study, were asked about their perceptions of the volunteers' reasons for agreeing or declining to assist the Institute over the weekend. The observers apparently attributed the differences in volunteering to the stable dispositions of the individual subjects, rather than to the amount of money that each was offered in the situation. Asked "[h]ow likely do you think it is that [the subject] would also volunteer to canvass for the United Fund?," observers responded that those who had volunteered in the present experiment would be substantially more likely to volunteer for the United Fund than would those who had not presently volunteered, regardless of how much they had been offered." "Observers were apparently misled by the actor's behavior, assuming it reflected a dispositional tendency to volunteer rather than a response to a suitably compensated 'job opportunity." "115

This study suggests the depth of our dispositionism. It can run deeper than any intuitive belief in the selfish or profiteering nature of human behavior; we think people are the way they are, irrespective of the influences under which they act at any moment. We are prone to dispositionism even where situational factors are visible, countable, and widely acknowledged to be a source of incentives and influence. Of all the non-human, non-threatening situational factors, it is difficult to think of one more obvious and unmistakable than cash. And yet, even when money is the clear motive, we still tend to see disposition.

This is one place where economists part ways with the rest of us, though as argued in the next subsection, not nearly so far as it might initially appear. The self-interested, rational actor of many economic models acts pursuant to one primary situational factor-money-in the forms of prices and incomes. An economist would not miss the implied upward-sloping supply curve in the experiment just described. The volunteer ratios would be explained immediately and solely by the situational distance between $\$ 0.50$ and $\$ 1.50$.

\section{b. The limits of economists' situationism}

One should not be fooled by this fleeting attributional accuracy, for it is just a consequence of the otherwise dispositional assumptions

\footnotetext{
114 Nisbett et al., supra note 111 , at $156-57$.

${ }^{115}$ Ross \& NiSBETT, supra note 9 , at 127.
} 
behind the rational actor model. It is actually the important similarity between the economist and the non-economist as dispositionists that is most striking.

As we have already suggested, the reason that economists see the situational role of money is because of their preliminary assumption that people are dispositionally motivated to pursue little else. Close inspection reveals that economists actually provide an unjustifiably anemic version of their favored situational factor, as their models allow for only a fraction of the situational force of price. For example, a fundamental assumption of legal economists, one that quietly makes possible much of their analysis, is that a person's willingness to pay equals her willingness to accept for the same item. That is, a person would be willing to pay as much for a widget as that person would be willing to accept in payment from another party for selling that same widget. That assumption is, for example, central to the Coase Theorem's instruction that well-functioning markets will yield allocatively efficient outcomes.

Yet, even if one ignores the growing evidence from economic behavioralists that willingness to pay tends to be significantly lower than willingness to accept, ${ }^{116}$ such a starting place entirely disregards the role of external situation. More specifically, a "basic principle of economics" 117 that assets tend to "gravitate toward their most valuable uses if voluntary exchange-a market-is permitted"118 ignores the fact that a person's "willingness to pay," will to a great degree reflect that person's "ability to pay." In other words, the basic principle of economics treats situation (ability to pay) as disposition (willingness to pay). Richard Posner describes this translation of situational constraints into dispositional tendencies in the introduction to his seminal law and economics text:

Suppose that pituitary extract is in very scarce supply relative to the demand and is therefore very expensive. A poor family has a child who will be a dwarf if he does not get some of the extract, but the family cannot afford the price and could not even if they could borrow against the child's future earnings as a person of normal height .... A rich family has a child who will grow to normal height, but the extract will add a few inches more, and his parents decide to buy it for him.

${ }^{116}$ See, e.g., Daniel Kahneman et al., Experimental Tests of the Endowment Effect and the Coase Theorem, 98 J. POL. ECON. 1325, 1325 (1990) (declaring that "[c]ontrary to theoretical expectations, measures of willingness to accept greatly exceed measures of willingness to pay").

${ }_{117}$ POSNER, ECONOMIC ANALYSIS OF LAW, supra note 13, at 10.

${ }^{118} I d$. 
In the sense of value used in this book [Economic Analysis of Lazu], the pituitary extract is more valuable to the rich than to the poor family, because value is measured by willingness to pay; but the extract would confer greater happiness in the hands of the poor family than in the hands of the rich one.

As this example shows, the term efficiency, when used as in this book to denote that allocation of resources in which value is maximized, has limitations as an ethical criterion of social decisionmaking.... Although no effort will be made in this book to defend efficiency as the only worthwhile criterion of social choice, . . . it is an important criterion. In many areas of interest to the economic analyst of law,... it is ... the main thing that students of public policy worry about. ${ }^{\mathrm{H} 19}$

In short, economists are situationally sensitive in only the narrowest sense-taking into account the way in which price might influence people's actions based on their willingness to pay, but refusing to look at the situational backdrop to that disposition. ${ }^{120}$ As the Posner quotation exemplifies, economists do not typically go very far to justify that situational blindness. ${ }^{12}$ But it is a blindness that arguably implicates even the most central features of their theory.

Indeed, it may be that same type of situational influence (ability to pay as limited by "budget constraints" or prices) and not the presumed dispositional forces (rational ranking of preferences) that puts the "down" in the downward-sloping demand curve, the crown jewel of economic theory. ${ }^{122}$ As Nobel Laureate Gary Becker taught forty years ago:

Negatively inclined market demand curves result not so much from rational behavior per se as from a general principle which includes a wide class of irrational behavior as well. Therefore, households can be

119 Id. at 13 .

${ }^{120}$ There are arguably other minor ways in which economists take into account situational considerations. For instance, they sometimes take into account the role of collective, as compared to individual, decisions or decisions regarding uncertain outcomes. But even then, their analyses are otherwise based on dispositionist assumptions. A group of people is usually assumed to act like a set of dispositionally motivated individuals who are making a choice, and little or no adjustment is made to consider the situational influence of even various group dynamics.

${ }^{221}$ When pushed, they instruct those who see it otherwise that such "distributional" concerns are not properly the province of either economists or legal rules. See Chen \& Hanson, supra note 52 (recounting Posner's argument that the economic analysis of law does not take in account income distributional considerations).

${ }^{122}$ See, e.g., COOTER \& ULEN, supra note 7 , at 23 (treating as axiomatic the downward-sloping demand curve-i.e., the notion that "when the price of $x$ goes up, the amount of $x$ that the consumer will purchase goes down, and vice versa"). 
said to behave not only "as if" they were rational but also "as if" they were irrational: the major piece of empirical evidence justifying the first statement can equally well justify the second ....

$[\mathrm{T}]$ he change in opportunities resulting from a change in relative prices also tends to produce a systematic response, regardless of the decision rule. In particular, the fundamental theorem of traditional theory-that demand curves are negatively inclined-largely results from the change in opportunities alone and is largely independent of the decision rule. ${ }^{123}$

Not only utility maximization but also many other decision rules, incorporating a wide variety of irrational behavior, lead to negatively inclined demand curves because of the effect of a change in prices on opportunities. ${ }^{124}$

Hence the market would act as if "it" were rational not only when households were rational, but also when they were inert, impulsive, or otherwise irrational. ${ }^{125}$

Indeed, the most important substantive result of this paper is that irrational units would often be "forced" by a [situational] change in opportunities to respond rationally. For example, impulsive households would tend to have negatively inclined demand curves because a rise in the price of one commodity would shift opportunities toward others, leaving less chance to purchase this one even impulsively. Other irrational households would likewise tend to have negatively inclined demand curves, irrational firms negatively inclined demand curves for inputs, and irrational workers positively inclined supply curves to occupations. ${ }^{126}$

Strikingly, despite Becker's demonstration that downward-sloping demand curves do not imply rational behavior, many subsequent economists (particularly legal economists) have ignored or trivialized it. $^{127}$ The idea that situation is central and disposition is peripheral

${ }^{123}$ Gary S. Becker, Irrational Behavior and Economic Theory, 70 J. POL. ECON. 1, 4 (1962).

${ }^{125}$ Id. at 5.
${ }^{126} \quad I d$. at 7.
$I d$. at 12.

${ }^{127}$ Richard Posner is one of the few legal economists to address it. See Hanson \& Yosifon, supra note 30 (reviewing Richard Posner's discussion and dismissal of the issue). Posner recently ridiculed Ronald Coase for suggesting that the insight might be taken seriously. See RICHARD A. POSNER, Overcoming LAw 442 (1995) ("Could Coase believe that some cognitive or psychological defect prevents us from moving up the ladder of preferred alternatives in the manner that I described? That misfiring brain cells make us disregard opportunity cost or fail to disregard sunk costs? Unlikely."). Very recently, however, behavioral economists have identified several ways in which arbitrary anchors can provide the illusion of stable preferences and how there 
has no purchase, given what economists seem to "know" about their world (as confirmed by their human vision and, tautologically, by the shape and slope of the demand curves they have "seen"). ${ }^{128}$ It is as though legal economists, like the rest of us, are so swept up by the play that they forget that they are watching one and come to believe that the characters in it are internally, dispositionally motivated. Becker's point has been regarded as a move in a logic game; it is treated as a bizarre, if strictly speaking correct, theoretical insight. ${ }^{129}$ His point is stripped of its power as the human figures are caricatured as "irrational" actors and the more revealing depth of the insight is not pursued: situation is often more potent than we acknowledge, exerting a greater influence over our actions than disposition.

Besides the narrow treatment of price and budget, the other major exception to economists' dispositionism is, as for the rest of us, the case in which someone acts in response to a significant threat (usually of force) posed by another person-prototypically a bullet to the brain. Robert Cooter and Thomas Ulen, in their highly regarded law and economics text, provide a fairly conventional description of when situation should be considered in the law of contracts:

[S] ometimes one of the parties to a bargain faces a dire constraint.

A dire constraint leaves the decision-maker with little or no choice.

Contract law treats dire constraints differently ....

Law prohibits people from making threats such as, "Work for me if you want your sister to come home safely from school ....,"130

Then, at the conclusion of their analysis, they ask the reader to explain the efficiency argument against enforcing the following arrangement: "Suppose that person $A$, while aiming a gun at person $B$, invites $B$ to write a check." ${ }^{\text {131 }}$ As such hypotheticals illustrate,

can be "stable demand curves without stable preferences". See generally Dan Ariely, George Loewenstein \& Drazen Prelec, Coherent Arbitrariness: Stable Demand Curves Without Stable Preferences, 118 Q.J. ECON. 73 (2003).

${ }^{128}$ See, e.g., PoSNEr, supra note 127, at 441-42 (acknowledging the first point, then trivializing it through brief tautological assertions).

${ }^{129}$ See id. at 442 ("Becker's argument is that since consumers have limited budgets, even irrational consumers will on average purchase less of a good when [the] price rises, because the consumers' resources will become depleted sooner.").

${ }_{130}^{130}$ COOTER \& ULEN, supra note 7 , at 261.
Id. at 263 . 
situation is easy to see, if not impossible to miss, when it is brandishing a revolver. ${ }^{132}$

Along with those scenarios, Cooter and Ulen offer some less dramatic examples, such as a crew threatening to walkout midway through a chartered fishing voyage in an effort to extract higher wages from their captain. ${ }^{139}$ But even examples that do not involve violent threats still involve "threats." 134 And those threats are made clear by one or more dispositionally motivated human actors seeking to force one party to act contrary to his or her interests absent the threat. In other words, only an extremely narrow range of situational factors count-those of dispositionally bad actors. Cooter and Ulen's lesson is that constraints less "dire" than the sort indicated in their examples are ignored in contract law, and properly so from an economic perspective. ${ }^{13}$

But these exceptions do not reveal a true sensitivity to situation; they expose only the tiny and predictable exception to dispositionism that proves the rule. Indeed, these departures flow from the very same current that creates the more general phenomenon-the fundamental attribution error-to which they are exceptions. That current, recall, originates from our cognitive tendency to "see" salient actors and features and to miss the rest. ${ }^{136}$ The general result is that we tend to attribute a person's actions to her free choices because we do not see the influence of situation. However, when the situation takes the form of a threatening actor, we see that "situation" and alter our conclusion regarding how free, in fact, the first actor's

${ }^{132}$ Revealingly, even in conditions of unmistakable situational duress, economists sometimes see a person's submission as properly understood as voluntarily and dispositionally motivated, albeit inefficient. For instance, Judge Posner writes:

A points a gun at B saying, 'Your money or your life.' B is very eager to accept the first branch of this offer by tendering his money. But a court will not enforce the resulting contract. The reason is not that $B$ was not acting of his own free will. On the contrary, he was no doubt extremely eager to accept A's offer. The reason is that the enforcement of such offers would lower the net social product, by channeling resources into the making of threats and into efforts to protect against them.

POSNER, ECONOMIC ANALYSIS OF LAW, supra note 13, at 116.

${ }^{133}$ COOTER \& ULEN, supra note 7 , at 263.

${ }^{134} I d$. at 262 ("Bargaining, which involves demands and offers, is opposite from coercion, which involves threats.").

${ }^{135}$ See infra text accompanying notes 550-614 (discussing other legal theorists and the law's treatment of similar issues).

${ }^{136}$ See supra text accompanying notes 21-26 (explaining that the fundamental attribution error is a function of numerous factors, including the dominant role that human action generally takes in our causal construal processes). 
choices were. Put differently, a person is seen to give up her seat for an 800-pound gorilla, not by free choice, but because of the half-ton of hairy, menacing situation. If she gives up her seat for an elderly person or a parent holding a child, in contrast, suddenly it is her kind disposition that dominates the field, eclipsing situation.

In sum, there is little or no place in economists' models for situational influences other than prices or narrowly defined threats. It is not just the inability of poor parents to afford pituitary extract for their children that the economic approach ignores; it is also the myriad of situational influences that Milgram's studies and countless other social psychological studies have exposed, and that economists have yet to see, much less explain. ${ }^{137}$ It is also the countless situational influences that invisibly regulate us all-as they would the impoverished dwarf in Posner's example whose future earnings presumptively would be less than those of an affluent person of normal height. ${ }^{198}$ Thus, economists exclude most of the vast range of situational influences in their analyses, and provide no explanation for privileging guns and money over the situational factors that they, like the rest of us, mostly ignore.

\section{c. Some situation behind our dispositionism}

Social psychologists have discovered that our day-to-day dispositionism goes still further. When we observe a person's behavior, we tend to first characterize that person in terms of her disposition. Only then do we begin to correct our characterization and take into account some of the situational variables that may have shaped her behavior. ${ }^{139}$ For instance, when we observe someone who is acting nervously, we automatically infer that the person is a nervous person. If we then discover that the person was talking about her intimate life, we might adjust our initial inference to take

${ }^{137}$ See, e.g., supra notes 86-99; infra notes 148-54, 180-81, 192, 242, 489-91, 616-34 (describing some of the situational manipulations in Milgram's studies and closely related studies, and how they influenced behavior and expectations). See generally Hanson \& Yosifon, supra note 30 (providing an overview of situational influences).

138 See supra text accompanying notes $119-20$ (presenting the pituitary extract example).

${ }^{13}$ Daniel T. Gilbert, Thinking Lightly About Others: Automatic Components of the Social Inference Process, in Unintended THOUGHT 189, 193 (James S. Uleman \& John A. Bargh eds., 1989). 
that situational feature into account. We might, in other words, drop or doubt our inference that she is dispositionally a nervous person. ${ }^{14}$

While initially inferring character and temperament from people's behavior is an automatic process, correcting those initial inferences to account for the situation requires effort. ${ }^{141}$ We must expend cognitive resources to correct our initial dispositional impressions. And if our cognitive resources are being utilized because we are, say, preoccupied, tired, or intoxicated, then we will be less able to correct our dispositional inferences about people's behavior to account for the situation. Consequently, we will inaccurately attribute a person's behavior to her disposition rather than the underlying situation. ${ }^{142}$ Put differently, our situations influence the extent to which we take into account other people's situations-a tendency discussed at greater length below. ${ }^{143}$

More troubling still, "even when we appreciate the impact of the situation, want to correct our inferences for it, and have the cognitive resources necessary for doing so, we may still fail to make sufficient corrections." ${ }^{\prime \prime 4}$ The dispositional attribution that we initially and automatically make acts as an anchor on the adjustments that we allow for situational factors. "Our ultimate conclusions about a person may remain contaminated by our initial inferences about this person's character even if we consider these inferences unwarranted and attempt to rid ourselves of this contamination." 145

140 KUNDA, supra note 20 , at 431.

141 Gilbert, supra note 139, at 193-94.

${ }^{142} I d$. at 194 (finding empirical support for the hypothesis that a perceiver who is distracted is more likely to engage in dispositional thinking than a perceiver who is not "cognitively busy"); KUNDA, supra note 20, at 431 ("When we are preoccupied, tired, intoxicated, or in a hurry, and so unable to devote careful thought to making sense of others, we may fail to correct our impressions for situational constraints even if we understand these constraints."); see also Timothy D. Wilson \& Nancy Brekke, Mental Contamination and Mental Correction: Unwanted Influences on Judgments and Evaluations, 116 PSYCHOL. BULL. 117, 127-28 (1994) (citing this as an example of the fundamental attribution bias and explaining that we often attribute a person's behavior to certain traits or attitudes--i.e., disposition-implied by such conduct).

${ }^{14.3}$ See infra text accompanying notes 415-56 (discussing the role of culture); infra Part VI.C-E (discussing some of the situational influences behind our culture).

${ }^{144}$ KUNDA, supra note 20, at 431-32; see also George A. Quattrone, Overattribution and Unit Formation: When Behavior Engulfs the Person, 42 J. PERSONAlity \& Soc. PSYCHOL. 593, 600-01, 604-06 (1982) (reviewing two experiments demonstrating that there may be circumstances in which observers overattribute behavior to situational causes while adjusting insufficiently for information about an actor's dispositions).

${ }^{145}$ KUNDA, supra note 20, at 432; see also Wilson \& Brekke, supra note 142, at 12728 (characterizing "the tendency to attribute people's behavior to their underlying dispositions" as a "failure" of the "unacceptable process"). 


\section{How Fundamental an Error Is Our Dispositionism?}

As the previous subsection suggested, considerable evidence reveals that our dispositionism runs very deep. ${ }^{146}$ But even if most of us, including legal economists, are hard-core dispositionists, there is a second, related question regarding the extent to which dispositionism is wrong: That is, just how influential is situation vis-àvis disposition? How much like a play are the settings in which humans actually find themselves and observe others?

It is difficult to read about Milgram's experiments and the reactions to them without strongly suspecting that the human presumption is exactly inverted; that what we do not see dominates the little that we do see. That suspicion would, in our view, be generally correct. But since those early studies, social psychologists have managed to get a better measure of that inversion, a sample of which we will highlight here.

When we introduced Milgram's famous experiments, we asserted that most readers would, like us, predict that they themselves would not have carried out the instructions to shock a fellow experimental subject at high voltages. Most readers surely would have predicted ex ante that the vast majority of others would not have gone through with it either, just as the lay people and psychologists surveyed by Milgram before his experiment predicted. ${ }^{147}$ This divergence between the common sense prediction and the actual behavior, we indicated, was due to the erroneous presumption that people behave dispositionally rather than situationally. In fact, the situational features were central, leading many to shock their fellow subjects despite having an otherwise normal or benign character. ${ }^{148}$ Once one is familiar with Milgram's experiments, it would seem difficult to deny his central claim - that situation played a major role in causing the subjects to perform as they did.

And yet, social psychologists have found that even when exposed to the Milgram study, people continue to conclude that the subjects were motivated dispositionally and thus miss the power of the

${ }^{146}$ See KUNDA, supra note 20, at 432-41 (providing a fascinating review of additional types of evidence of the fundamental attribution error).

${ }^{147}$ See supra notes 85-86 and accompanying text.

148 See ZimbaRdo \& LEIPPE, supra note 22, at 70 (dismissing the argument that Milgram's subjects were somehow "bad apples" by pointing out that the experimental "results were the same: meek obedience to unjust authority" across a wide demographic subject population). 
situation even when it is made explicit. For example, social psychologist Martin Safer showed students Milgram's film, Obedience, ${ }^{149}$ which portrays the dynamics of the situational forces operating in Milgram's experiments. One week later, Safer provided his students with a description of the control experiment where the subject or "teacher" was free to choose the shock level on his own, without any direction by the experimenter to increase the voltage after each wrong answer. ${ }^{150}$ Safer then asked the students to make certain predictions, including the average shock level set by the teachers in the control experiment and the percentage of teachers choosing the maximum shock level. ${ }^{151}$

Even after seeing the film of the obedience experiment and the situational pressures of the experiment, Safer's students still believed that disposition was driving the teachers and would do so even in other situations, including that in which they were given no orders from the experimenter. When comparing the students' forecasts to the actual results of the control experiment, Safer's students significantly overestimated both the average shock level set by the teachers and the number of teachers who chose the maximum amount of shock absent the most significant situational forces of the original obedience experiment. ${ }^{152}$ In other words, Safer's students persisted in believing that the teachers in Milgram's original experiment were motivated by stable disposition rather than the situation of the experiment. ${ }^{159}$

This, of course, completely contradicts the findings of the ex ante surveys in which people drastically underestimated the amount of

149 OBEDIENCE (Stanley Milgram 1969).

${ }^{150}$ Martin A. Safer, Attributing Evil to the Subject, Not the Situation: Student Reaction to Milgram's Film on Obedience, 6 PERSONALITY \& SOC. PSYCHOL. BULL. 205, 205-06 (1980).

${ }_{152}^{151} I d$. at 206.

${ }^{152} I d$. at 207.

${ }^{153}$ Id. at 208. In Milgram's movie about the experiments, only one of the many subjects is shown flipping the final switch, even though a majority of those participating did so. OBEDIENCE, supra note 149. According to folk wisdom among social psychologists, that is because the subjects who went that far did not want to be shown on film doing so, presumably because they felt that their actions reflected badly on their dispositions. In other words, it appears that even the subjects interpreted what happened in largely dispositionist terms. As revealed in one subject's reflections one year after the experiment, subjects and their family members construed the experiment as revealing dispositionism: "As my wife said, '[y]ou can call yourself Eichmann.' I hope I can deal more effectively with any future conflicts of values I encounter." MILGRAM, OBEDIENCE TO AUTHORITY, supra note 86, at 54. 
shocking that would occur with situational pressures present. The contradiction again reveals the underlying consistency of the stubborn command of our dispositionism. Even when the power of the situation was made explicit, "subjects continued to interpret behavior in terms of presumed dispositions, rather than recognizing the crucial role that Milgram's particular situation had played in producing his disturbing demonstration." ${ }^{, 154}$ Our dispositionism runs deep, despite the fact that situation often runs deeper.

In another classic demonstration of this phenomenon, subjects were asked to read a short essay on "Castro's Cuba" and to judge the true attitude of the writer toward Castro. The subjects were informed that the essay was a prepared answer to an examination question, in which some exam takers were asked to criticize Castro's Cuba and other exam takers were asked to defend it. Subjects thus understood that the writer of any exam had little choice with respect to the position he or she took regarding Castro's Cuba. Surprisingly, many of the subjects nevertheless associated the writer's true attitude (disposition) toward Castro with the content of the essay. If the writer wrote a pro-Castro essay as (situationally) directed, many subjects concluded that the writer was privately (dispositionally) proCastro, and vice versa. ${ }^{155}$ Thus, even when situational influences should be obvious and even when people are watching what is tantamount to a play, humans still tend to overestimate the role of disposition.

Consider another exemplary experiment. In this one, college students participated in a simulated quiz game and were randomly assigned to either of two roles: contestant or questioner. ${ }^{156}$ Questioners were asked to compose general-knowledge queries to be posed to the contestants, and the contestants were instructed to answer as many of the questions as they could..$^{157}$ The situational

${ }^{154}$ Ross \& NISBETT, supra note 9, at 132.

155. See Edward E. Jones \& Victor A. Harris, The Attribution of Attitudes, $3 \mathrm{~J}$. EXPerimental SOC. PSYCHOL. 1, 4-8 (1967). Jones and Harris observed similar results in a second experiment that had the subjects draw dispositional inferences based on hearing an opening statement in a debate. Id. at 8-14.

${ }^{156}$ Lee D. Ross et al., Social Roles, Social Control, and Biases in Social-Perception Processes, 35 J. PERSONALITY \& SOC. PSYCHOL. 485, 485-94 (1977). In a separate experiment, observers of the simulated quiz game exhibited the same dispositional bias as the contestants. Thus, even though the observers were aware of the situational advantage of the questioners, the observers nonetheless ranked the questioners as more generally knowledgeable than the contestants. Id. at 490-91.

${ }^{157}$ Id. at $489-94$. 
advantage of the questioners is clear, given that they could draw from their areas of personal expertise, while contestants were forced to answer questions on unfamiliar topics. Therefore, it should not have been surprising that contestants could only give a small percentage of correct answers. Yet, when it came to estimating the intelligence of the two groups, the situational advantage was forgotten: both questioners and contestants grossly underappreciated the situational benefit of being a questioner. As a result, both groups ranked the questioners as more generally knowledgeable than contestants. In other words, the game was perceived as a fair measure of general knowledge, and the failure of contestants was attributed to disposition. ${ }^{158}$ Put differently,

${ }^{158}$ This study (and the many like) it would be, if they were well known, a favorite among law students and anyone else on the business end of the Socratic method. $C f$. LaNi Guinier et Al., Becoming Gentlemen: LAW SCHOOl and INSTITUtional CHANGE 28 (1997) (noting that many women are alienated by the use of the Socratic method, especially in the first year of law school); Lani Guinier et al., Becoming Gentlemen: Women's Experiences at One Ivy League Law School, 143 U. PA. L. REv. 1, 6-59 (1994) (describing in detail the results of the study discussed in Guinier's book).

In another important study, a group of subjects was asked to divide a set of their peers into two categories: those the subjects thought would be likely to contribute to a food drive, and those they believed would be unlikely to contribute. Ross \& NisBeTT, supra note 9, at 132. Half of each group-the "most likely" and the "least likely" - was then sent a personalized letter asking for a specific food donation, including a map of where to deliver the item. $I d$. The other half of each group received a generic form letter requesting only a general food donation, and with no map. Id.

The study confirmed both the prevalence of dispositionism and the dominance of situation in determining actual conduct. The subjects who selected the "most likely" and "least likely" groups predicted that dispositional ascriptions, not the type of letter received, would determine who would actually donate food. Id. at 133 . Specifically, subjects predicted that disposition (the type of person) would be nearly five times more influential than situation (the type of letter). But when the letters were sent and the food was collected, it turned out that the influence of situation was over four times greater than the influence of disposition-those who received personal letters with a map were much more likely to donate food. Id. Of course, even that figure overstates the role of disposition, because even those seemingly "dispositional" influences may be explained in part by situational influences beyond the channeling effect of the letter. In any event, the subjects tended to see what mattered least and miss what mattered most.

\begin{tabular}{|c|l|c|c|}
\hline \multirow{4}{*}{ SITUATION } & \multicolumn{3}{|c|}{ DisPOSITION } \\
\cline { 2 - 4 } & & Most Likely & \multicolumn{1}{|c|}{ Least Likely } \\
\cline { 2 - 4 } & Channeling Letter & $83 \%$ predicted/ & $17 \%$ predicted/ \\
& & $42 \%$ actual & $25 \%$ actual \\
\cline { 2 - 4 } & Non-Channeling & $80 \%$ predicted/ & $16 \%$ predicted/ \\
& Letter & $8 \%$ actual & $0 \%$ actual \\
\hline
\end{tabular}


participants saw the players and missed the playing field, thus presuming that it was level.

Finally, consider the following experimental inquiry into the social-psychological lessons of the classic Christian parable of the Good Samaritan. In the biblical version of the story, Jesus, in response to questioning by a lawyer about the meaning of neighborliness, tells of a man mortally wounded and left on a road by thieves. ${ }^{159}$ The man was passed first by a priest, who saw the hurt man but did not stop to help him. Next, a Levite (a priest's assistant) passed the man, saw him, but continued on without stopping. Finally came a man from Samaria-a Samaritan. He saw the wounded man and "was moved to pity. He went up and bandaged his wounds... brought him to an inn, and looked after him there." ${ }^{160}$ Having told this story, Jesus turns to the lawyer and asks, "Which of these three do you think was neighbor to the man who fell into the hands of the robbers?" that the Samaritan was the neighborly one, hence earning the dispositional moniker the "Good Samaritan."

Social psychology, however, instructs that situation may provide a better explanation for the conduct of the characters in this tale, as it does in so much of our social life. This is not merely conjecture; it has been subject to experiment. ${ }^{163}$ Princeton Theological Seminary

Subjects predicted that eighty-three percent of the "most likely" group would donate if they received the detailed channeling information, and that eighty percent of the "most likely" group would donate if they received the general letter. Id. Subjects further predicted that only seventeen percent of those deemed "least likely" would donate if they received the letter with the channeling information, and that sixteen percent of the group would donate if they received the general request. Id. In other words, the subjects expected that the different letters would have virtually no effect, but that the different "types" of recipients would have an immense effect. The predictions failed: only four percent of subjects donated food in the nonchanneling condition (none of the "least likelies" and eight percent of the "most likelies"), while thirty-three percent donated food in the facilitory condition (twentyfive percent of the "least likelies" and forty-two percent of the "most likelies."). Id. As the authors of the study noted, " $[t]$ he situational variables proved more important than the relevant actors' dispositions-more important, at least, than any dispositions salient to their peers." Id.

${ }^{159}$ Luke 10:29-37.

${ }^{160}$ Id. 10:33-34.

${ }^{161}$ Id. 10:36.

${ }^{162}$ Perhaps revealingly, the phrase is not found in the biblical tale at all; rather, it has come down to us through dispositional interpretations of the parable.

${ }^{163}$ See John M. Darley \& C. Daniel Batson, From Jerusalem to Jericho: A Study of Situational and Dispositional Variables in Helping Behavior, 27 J. PERSONALITY SOC. PSYCHOL. 100, 100-08 (1973). 
students were asked to prepare a brief extemporaneous talk that would be recorded in a nearby building. ${ }^{164}$ The experiment thus neatly managed to have its subjects parallel the priestly vocations of the characters in the biblical tale. Some of the students were told to discuss possible jobs for seminary students, while the others were told to discuss the parable of the Good Samaritan. ${ }^{165}$ After informing them about their respective talks, the experimenter told some of his subjects, "Oh, you're late. They were expecting you a few minutes ago. We'd better get moving." students were given the high-hurry situational condition. Another group of subjects was given an intermediate-hurry situational condition. This group was told, "The assistant is ready for you, so please go right over." ${ }^{\text {167 }}$ Finally, for a low-hurry situational condition, the experimenter told the remaining subjects, "It'll be a few minutes before they're ready for you, but you might as well head on over."

Along the route between the two buildings was a man, the experimenter's undisclosed confederate, "slumped in a doorway, head down, eyes closed, not moving[, coughing, and groaning]."169 Only ten percent of the seminarians who had been told they were running late (the high-hurry situational condition) stopped to help the ailing man, and only forty-five percent of the seminarians who were pressed for time (the intermediate-hurry situational condition) offered help. ${ }^{170}$ In contrast, among those who were not pressed for time (the low-hurry situational condition), sixty-three percent offered to help. ${ }^{171}$ Again, a minor situational manipulation produced a major behavioral difference. Perhaps most indicative of the power of situational influence is that several of the seminarians who were pressed for time and who were to speak on the parable of the Good Samaritan "literally stepped over the victim" on the way to give their talks. ${ }^{172}$

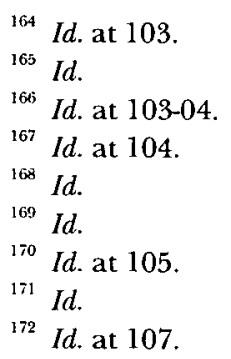


What about dispositions? Before the experiment began, the seminarians filled out a survey, answering a variety of questions about themselves. ${ }^{173}$ For example, the seminarians were asked whether their interest in religion stemmed primarily from a desire to assure their own personal salvation or whether it was primarily related to their desire to help others. ${ }^{174}$ Such dispositional self-ascriptions had "virtually no role in determining whether the subject stopped to help." Af5 After analyzing psychological evaluations of their forty subjects, the experimenters found that the only significant variable that correlated with "helping behavior" was time, a situational factor. ${ }^{176}$ The fact that some of the seminarians were to speak on the parable of the Good Samaritan, thereby raising the salience of dispositional helping norms, did not significantly affect helping behavior in the students. ${ }^{177}$

Taken together, these experiments help bring into relief the profound power of situation over human action. They also reveal that such influences are usually left unexamined in our daily lives, in our stories, and in our theories about what moves people. There was little evidence of a "good seminarian" or a "bad seminarian," but there was much evidence of "situational seminarians." The difference between the priest who passes on and the Samaritan who stops may be more a function of a bad or good situation than of a bad or good disposition. ${ }^{178}$

We humans tend to perceive disposition as dominating situation even though evidence from social science strongly suggests the reverse; this is, again, the fundamental attribution error. The objective here is not to prove or to claim that disposition plays no role in our behavior, or even that it does not sometimes play a very important role. Rather, the objective is to make clear what social science reveals about just how surprisingly slight that role is most of the time-at least as compared to what most of us believe and,

${ }^{173} I d$. at 102.

${ }^{174} I d$.

${ }^{175}$ Ross \& NISBETT, supra note 9 , at 131.

176 Darley \& Batson, supra note 163, at 104-06.

${ }^{17}$ Id. at 107; see also Hanson \& Yosifon, supra note 30 (discussing a related portion of this experiment).

${ }^{178}$ See also Milcram, OBEdience TO Authority, supra note 86, at 205 ("[T] he social psychology of this century reveals a major lesson: often, it is not so much the kind of person a man is as the kind of situation in which he finds himself that determines how he will act."). 
perhaps, want to believe. ${ }^{179}$ Readers may, as we do, take some reassurance from the fact that ten percent of the hurried seminarians did stop to assist the ailing man, despite their perceived time crunch. But again, it is easy to miss even the profound situational influence wielded in that experiment by the groaning, slumped elderly man. Settings with less compelling situational pressures for help are likely to yield even less "goodness." Indeed, a disheartening finding is that, in the many versions of Milgram's studies, not a single subject ever went to check on or assist the learner whom they believed was being shocked, despite the learner's protests and ultimate silence during the "experiment" and despite the teacher's own concern about hurting the learner. ${ }^{180}$ Why not? A good guess would be that offering such aid was somehow not situationally scripted. ${ }^{181}$

\section{Some Sources of Dispositionism}

Why do we see what isn't and fail to see what is? We have already discussed several reasons. First, part of the answer stems from the fact that human actions dominate the field in our causal attributions-we see what is most obvious and salient, and tend to miss the rest. ${ }^{182}$ Perhaps that would not be such a problem were we not so inclined to believe in the accuracy of our vision-that we see all there is to see, and that what we miss does not exist. Second, even when there are situational features that we might recognize as influential, we make dispositional attributions automatically, while our situational adjustments require cognitive effort-meaning that dispositionism is the default inference, mutable only when our minds

${ }^{179}$ See infra text accompanying notes 193-95, 393-401, 454-56, 638-81 (suggesting some of the ways in which dispositionism may be linked to the motive to affirm ourselves, our groups, and our systems); supra note 110 (describing our tendency to attribute cause to situation when doing so is self-affirming).

${ }^{180}$ ZIMBARDO \& LEIPPE, supra note 22, at 73-74.

${ }^{181}$ Without a model of action, our feelings of upset and our desire to help often lead to no action. Milgram discussed the frustration of a specific "teacher" as such:

This subject did not want to shock the victim, and he found it an extremely disagreeable task, but he was unable to invent a response that would free him from [the experimenter's] authority. Many subjects cannot find the specific verbal formula that would enable them to reject the role assigned to them by the experimenter. Perhaps our culture does not provide adequate models for disobedience.

Milgram, Some Conditions of Obedience, supra note 86, at 67.

182 See supra text accompanying notes 21-22. 
are not otherwise occupied. ${ }^{183}$ Third, even then our automatic dispositional attributions will contaminate the adjustments for situations that we do have the cognitive energy to make. ${ }^{184}$ As significant as those reasons are, there is more to consider.

To comprehend the robustness of dispositionism, it is necessary to understand that the causal ambiguities that fog our experiences allow, and often encourage, it. As Lee Ross and Richard Nisbett have argued at length, our dispositionism often appears to be confirmed in the evidence we encounter in our daily lives. ${ }^{185}$ That is true in part because we tend to see what we expect to see, and, particularly in Western culture, disposition is the general expectation. ${ }^{186}$ We will return to both of these points below. ${ }^{187}$ For now it is enough to say that our construals of what we experience (or of our memories of what we have experienced) are far more malleable in service of our expectations than we recognize.

But even if we were seeing what "is," our dispositionist theory of human conduct will tend to be confirmed by the evidence we encounter, though our interpretation of that evidence is often fundamentally wrong. We constantly see people behaving in ways consistent with our assumptions about their personality traits, and we often conform our own interactions with them based on those dispositional accounts. Our predictions are confirmed, however, not because dispositions are in fact stable, but because situations so often are:

In the course of ordinary experience, we rarely have a chance to observe the same people in radically different roles or situations in a way that would test fairly the cross-situational consistency of their geniality, generosity, or ability to delay gratification. Nor do we systematically vary our own behavior, or our status and circumstances, or the nature of our relationships with others, to determine how their responses might change as a result. ${ }^{188}$

And even if "the many situations in which we observe our acquaintances are quite diverse, they all share an important

${ }^{183}$ See supra notes $141-43$ and accompanying text.

184 See supra notes $144-45$ and accompanying text.

${ }^{185}$ Ross \& NISBETT, supra note 9 , at $145-58$.

${ }^{186}$ See infra text accompanying notes $418-52$; see also KUNDA, supra note 20 , at 442 (asserting that Western culture's emphasis on personality traits leads to the expectation that human behavior will be consistent across different situations).

${ }^{187}$ See infra Part VI.C.

${ }^{188}$ Ross \& NISBETT, supra note 9, at 147-48. 
element-our presence." ${ }^{189}$ What we see and what we expect to see operate as self-fulfilling, situational forces on those we are observing ${ }^{190}$-our dispositionism is part of the situation. As Ross and Nisbett explain, none of this implies that dispositionism is correct; it implies only that people will experience dispositionism as a reasonably reliable heuristic for predicting behavior. Because the people we observe will tend to behave as if they are motivated by disposition and not situation, the data we collect will appear to confirm our flawed dispositionist conception of the humans we are observing:

It is precisely the confounding of person and situation that allows people to be well served by their naive dispositionism. When we predict that the behavior of professors will be professorial, that the behavior of dictators will be dictatorial, that the behavior of servants will be servile ... it makes little difference whether we do so because we are aware of the impact of the respective roles, because we have made stereotyped judgments about the types of individuals who occupy such roles, or because we have taken role-prescribed behavior at face value and ascribed corresponding personality traits to the actor. In each case, the performances we observe more often than not will confirm our predictions... provided that no other powerful situational factors suddenly intrude.

In all those ways, our dispositionism is shielded from having to regularly confront unambiguously anomalous evidence.

189 KLNDA, supra note 20 , at 442.

${ }^{190}$ See id. at 442-43 (summarizing the "considerable amount of evidence [that] suggests that our expectations of others can be self-fulfilling").

${ }^{191}$ Ross \& NisBETT, supra note 9, at 150 . Briefly below, and in some detail in Hanson \& Yosifon, supra note 30 , we discuss other motives that amplify our dispositionism. See infra notes 193-94, 393-401, 454-56, 638-81 and accompanying text (highlighting some of the connections between motivation and dispositionism). Research in system legitimation theory, for example, suggests that when we perceive our social systems to be under threat-as in periods of social instability-we exhibit a heightened tendency to dispositionalize out-groups and individuals within out-groups, blaming their stable character traits for the threat, and missing situational factors that may be the real cause of the threat. See, e.g., John T. Jost, Outgroup Favoritism and the Theory of System Justification, in COGNITIVE SOCIAL PSYCHOLOGY 86, 101 (Gordon B. Moskowitz ed., 2001) (noting that "the presence of an ideological threat directed against the national system increases stereotypic differentiation" between inside groups and outside groups). 


\section{E. The Fundamental Interior Attribution Error (or, Getting Ourselves Wrong)}

We all wear glasses that carry a date in time and the name of some geographic area, and with even the keenest of vision these glasses allow us to see only limited distances and partial motion of our world.

$$
\text { -George Stigler }{ }^{192}
$$

The upside-down causal ascriptions behind the fundamental attribution error are also explained by a more subtle, though as we've emphasized is often the case, no less important understanding of the human animal. Appreciating its significance requires distinguishing between two types of fundamental attribution error. The first is the sort that we have been discussing since opening the Article and that social psychologists have in mind when they use the term. We will call this the exterior fundamental attribution error. When humans look at any setting and make causal attributions, certain key features of that setting - the observable actions of individuals-exert disproportionate influence over their evaluations. They see what is easy to see and tend to miss what is not. Thus, observers give little or no weight to the fact that Milgram's shock box had many switches instead of just one-a distinction that most social psychologists now recognize was likely influential. All the observers see is the teacher shocking (or, if they are imagining themselves in the teacher's role, not shocking) the learner.

The theoretic primacy of dispositionism also reflects what we call the interior fundamental attribution error. That error, which is analogous to its exterior counterpart, is the tendency to "see" and attribute a powerful causal role to certain salient features of our interior that exercise comparatively little causal influence over our behavior while, at the same time, failing to see those interior features that are highly influential. Those salient features of our interior that we see, in turn, make possible (if not likely) a theory of ourselves in which dispositions play a role-usually the dominant role-in our behavior. We are primed by our felt interior experience to see dispositions and to overlook a potentially more significant influence-the situation. In that way, the interior fundamental attribution error contributes significantly to the exterior fundamental attribution error.

${ }^{192}$ STIGLER, supra note 70, at 219. 
In a companion article, we describe what many peopleparticularly those of us in the West-"see" when we look into our interiors: above all, we "observe" ourselves thinking, perceive that we have preferences, experience our "wills," and see our actions, which we attribute to that salient combination of thought, preferences, and will. ${ }^{193}$ Again, that myopic vision of our interiors, just like our vision of our exteriors, is fundamentally distorted by our oversight of many far more important influences that elude our conscious awareness.

The bulk of our companion article is devoted to bridging -though only loosely-that gulf and examining the implications of the fundamental interior attribution error. More specifically, that article describes at length how causal attributions, motives, emotions, visceral factors, implicit attitudes, knowledge structures, affiliations and group memberships, and behavior itself invisibly influence our more visible cognitions, attitudes, and actions. It explains how the desire to see ourselves, the groups and institutions with which we identify, and our world in self-affirming ways, has an immense effect on how we construe our environs and ourselves, including our own interiors. ${ }^{194}$ In doing so, the companion article helps to clarify how the interior and exterior fundamental attribution errors combine to render "axiomatic, though generally implicit, in many modern Western cultures," the beliefs that:

- Actions are freely chosen.

- Choices imply a preference.

- Preferences are stable over time.

- Preferences implicate the identity of the self.

- Outcomes are mostly controllable.

- People are responsible for (and hence the self is implicated in) the choices they make and the resulting outcomes.

- Smart (good) people make good choices whose outcomes they are happy with. ${ }^{195}$

\footnotetext{
${ }^{198}$ See Hanson \& Yosifon, supra note 30.

${ }^{194} I d$.
}

${ }^{195}$ Alan P. Fiske et al., The Cultural Matrix of Social Psychology, in 2 THE HaNdBoOK OF Social PSYCHOlogy 915, 939 (Daniel T. Gilbert et al. eds., 4th ed. 1998). 
Those axioms are implicit for most of us, and, as this Article and our next illuminate, they define the starting points for most scholars and policymakers. Indeed, neoclassical economists have built their theory around a formal version of those basic axioms. According to conventional economic assumptions, a person's preferences can be inferred from that person's choices-the latter reveal the former. ${ }^{196}$ As illustrated in this Article and its companion, the starting points of dominant legal theories are unrealistic and are based on fundamentally inaccurate visions of humanity.

\section{A BRIEF INTRODUCTION TO CRITICAL REALISM}

[T] he search was on, from World War II onwards, for a new method to replace the deductive approach of the late nineteenth century with some criterion for judicial lavmaking other than open-ended, contextualized policy analysis, one that would be plausibly non-political.

-Duncan Kennedy ${ }^{197}$

The life of the law has not been logic: it has been experience.

-Oliver Wendell Holmes ${ }^{198}$

In light of evidence about how real humans actually behave, most conventional legal theories, which are based primarily on dispositionist premises, seem suspect. By way of an alternative, therefore, this Section introduces critical realism-the legal theoretic approach hinted at above, named and cursorily defined here, and employed in this Article and in others to follow. ${ }^{199}$

Because terms like "critical" and "realism" have been widely used to describe a variety of legal-theoretic approaches, and because they have been infused with a variety of meanings, we begin by offering a loose, simple explanation of what we hope to capture by the phrase "critical realism."

${ }^{196}$ See COOTER \& UlEN, supra note 7 , at 348 (explaining economists' use of directly observable choices to impute the decision maker's unobservable preferences); Hanson \& Yosifon, supra note 30 (summarizing revealed preference theory and the dispositionist assumptions of economics and law and economics).

${ }^{197}$ Kennedy, supra note 51 , at 468.

198 Oliver Wendell holmes, JR., The Common Law 1 (Little, Brown \& Co. 1946) (1881).

${ }^{199}$ For a sample of these works, see manuscripts cited supra note 84.

${ }^{200}$ We are not the first to employ the term "critical realism." In fact, legal scholars have previously formulated several variants of the phrase, though none of 
them have adopted quite the meaning that we intend. Morton Horwitz, for example, used the term to denote an approach within the tradition of American legal realism that emphasized the practical political applications of legal theory. See MORTON J. HORWITZ, THE TRANSFORMATION OF AMERICAN LAW, 1870-1960: THE CRISIS OF LEGAL ORTHODOXY 209-10 (1992). Horwitz distinguishes "critical" realists from "constructive" realists, who he describes as having been more dedicated than critical realists to "subordinat[ing] political and moral passion to social science expertise" in the study of law. Id. Horwitz characterizes this brand of critical realism as a predecessor to the critical legal studies movement. Id. at 270-71.

More recently, a few contemporary scholars have adopted the term "critical realism" to describe their own approach to legal scholarship. Ruben J. Garcia has employed the phrase to name his work, which, in the tradition described by Horwitz, is aimed simultaneously at a critical and a political agenda. See Ruben J. Garcia, New Voices at Work: Race and Gender Identity Caucuses in the U.S. Labor Movement, 54 HASTINGS L.J. 79, 117 (2002) (presenting his project as one that embraces a "'critical' view of the endemic nature of racism and sexism in society but seeks to be 'realistic' about potential legal reform programs in light of contemporary realities and the limits of legal change").

Howard Engelskirchen employs another modern variant of "critical realism" that is concerned more particularly with analyzing the "generative structures or mechanisms at work in nature and society that cause the manifest phenomena of our natural and social world." Howard Engelskirchen, Consideration as the Commitment to Relinquish Autonomy, 27 SETON HALl L. REv. 490, 500 (1997). While part of our endeavor shares in that basic effort, our approach differs dramatically from that of Engelskirchen in two ways. First, he emphasizes that he "want[s] to distinguish sharply . . . between the genesis of human actions, lying in the reasons, intentions and plans of people, on the one hand, and the structures governing the reproduction and transformation of social activities, on the other." Id. at 508 (quoting RoY BHASKAR, THE POSSIBILITY OF NATURALISM 35 (2d ed. 1989)). Second, he "rel[ies] on the fact that the market economy in which we live is characterized by the private autonomy of its agents." Id . at 510. As will become clear, if it is not already, we do not adopt either of these premises.

Finally, Anthony Fejfar has undertaken still another version of critical realism based on the work of Bernard J. F. Lonergan, a knowledge theorist within the philosophy of science tradition. See Anthony J. Fejfar, Insight into Lauyering: Bermard Lonergan's Critical Realism Applied to Jurisprudence, 27 B.C. L. REV. 681, 682 (1986) (presenting Lonergan's theory that knowledge is rooted in "affirmations which are made on the level of judgment," a presumption that serves as the foundation of Fejfar's approach). According to Fejfar, "critical realism envisages a system which is flexible enough to deal with the human world as it actually exists in the concrete and particular." Id. at 717. Fejfar has also employed concepts from developmental psychology in his critical realist approach, particularly with respect to a study on the concept of corporate voluntarism. See Anthony J. Fejfar, Corporate Voluntarism: Panacea or Plague? A Question of Horizon, 17 DEL. J. CoRP. L. 859, 863 (1992) (analyzing corporate voluntarism from the perspective of liberal rationalist, critical rationalist, and critical realist "horizons" to determine the extent to which one's point of view impacts one's analysis of the subject).

As described in the text, we derive our notion of critical realism from our understanding of the American legal realist tradition and the critical legal studies movement. Our use of the term is meant to signal our intention to incorporate the best of what we find in each of these traditions, but in a manner that we hope advances legal theory in ways that differ from both of them. We have not been 


\section{A. "Realism"}

By "realism" we mean, first, to suggest that our approach is a descendent of American legal realism and to claim allegiance to the basic assumptions and attitudes that its other descendents, including law and economics ${ }^{201}$ and law and society, claim. The theoretical foundation of the legal realist tradition includes "a 'scientific outlook' that posits a knowable world out there beyond the text, a world whose workings are not transparent and which invite exploration to discern their deeper and truer contours." ${ }^{202}$ This tradition of realism has been driven by the desire to "explain legal realities" through a commitment to the belief that "legal scholarship (and law) will be enriched by the application of science." ${ }^{203}$ The "science" of this tradition is a social science, for the realist is committed to the consequentialist belief that "the meaning of law resides in its effects on human well-being (variously conceived)

directly informed by, nor have we attempted to directly engage, the notions of critical realism employed by the scholars whose use of the term we have noted here, though we have little doubt that some of our work and some of theirs are mutually supportive in significant ways.

We also want to distinguish our "realism" from that employed in international relations theory, where the word "realism" has come to be associated with a somewhatstylized school of thought focusing almost exclusively on states. Theorists of this school assume states to be rational, unitary, and functionally identical in their desire to maximize "power" and their unwillingness to subject themselves to international institutions except where it serves self-interested, power-maximizing goals. See, e.g., Anne-Marie Slaughter, Liberal International Relations Theory and International Economic Law, 10 AM. U. J. INT'L L. \& POL'Y 717, $721-24$ (1995) (defining and discussing "realism" in the context of international relations theory). This dispositionalizing brand of realism intentionally downplays the role of non-state actors, ideology, and countless other factors, holding that a simplified, state-centric view is the most useful heuristic for understanding the operation of international relations. Thus, in international relations theory, realism at times becomes somewhat detached from reality; perhaps ironically, other theories purporting to be more realistic often define themselves in opposition to "realism." See id. at 724-31 (describing "institutionalism" and "liberalism" as alternatives to "realism" in international relations theory). By contrast, the kind of realism articulated in this project differs substantially in that its basic principles are an openness to rethinking traditional starting principles and a willingness to question familiar heuristics in light of empirical observations.

${ }^{201}$ But see POSNER, supra note 127, at 3 (criticizing legal realism and downplaying its relationship to law and economics).

${ }^{202}$ Galanter \& Edwards, supra note 59, at 377. For an overview of the development and historical significance of American legal realism, see HORWTZ, supra note 200, at 169-92 (1992).

${ }^{203}$ Galanter \& Edwards, supra note 59, at 377. 
rather than in its formal characteristics." ${ }^{204}$ Perhaps most importantly, legal realists believe that their task is not only important, but promising; the history of realism has been advanced under "a conviction that knowledge derived from [its] undertaking can promote greater felicity by modifying social arrangements." ${ }^{205}$ We will return to this discussion of realism, but we first want to briefly explain the "critical" side of critical realism.

\section{B. "Critical"}

By "critical," we mean to suggest that our theory is also a descendent of critical legal studies and other post-modern approaches to law, such as feminist legal theory and critical race theory. ${ }^{206}$ To be critical, we believe, means to have (as we do) serious reservations about how "knowable" our world is, about the existence of truly neutral, apolitical social sciences and legal doctrines, and about the independence of judges, scholars, and other reputedly neutral actors and institutions from the influence of existing allocations of power.

We do not see any necessary contradiction between the "realism" leg and the "critical" leg of our approach, and it is in part our belief that a successful legal theory must stand on both legs that motivates this project. Social scientists are never free from the deep biases that shadow human thinking, and they should therefore be continually self-critical and suspicious of the "knowledge" they produce. Nevertheless, social science done well can help us understand those biases and limitations, and, in turn, their influence over our theories and institutions. Such insights can assist us in better understanding our social arrangements and in improving overall well-being.

Holmes believed that the life of the law is experience, and so it may be, but to make sense of and to guide that life, legal scholars, among others, should be skeptical of how that experience is construed. Legal analysis, in other words, should begin with a critical examination of our experience and our perceptions of that experience. So critical realism is dedicated to gaining knowledge

204 Id.

$205 \mathrm{Id}$.

${ }^{206}$ For an overview of the meaning and significance of the critical legal studies movement, see ROBERTo MANGABEIRA UNGER, THE CRITICAL LEgal STUdies MOVEMENT 5-42 (1986). Although Galanter and Edwards might disagree, see Galanter \& Edwards, supra note 59, at 377-78, we consider critical legal studies and other critical schools to be as much the heirs of legal realism as law and economics, if not more. 
about our world through scientific inquiry and theoretical analysis, while simultaneously seeking to unearth and understand the myriad biases that render suspicious the "knowledge" that our inquiries and theories produce. ${ }^{207}$

\section{What Is So Critical About Realism?}

We have been moving in a direction in which we have an increasingly limited control over our own lives, and that movement has been nourished by a series of arguments which, quite simply, are untrue.

\section{- Milton Friedman ${ }^{208}$}

With that, we can describe a second, even more important facet of what we mean by "critical realism." For reasons that were suggested above and will become more evident below, we believe that, to best promote human understanding and well-being, legal theories must be anchored in a reality-based understanding of human thinking and behavior. Realism, we think, is critical. To be realists, on this telling, means to begin with real humans and to build models from there, rather than to begin with models and then view and interpret humans through them. The distinction may be better understood by contrasting our approach with what we do not mean by realism, and by describing and distinguishing among the quasi-realistic commitments that some legal scholars have recently made.

In a related article, we detail the justifications that economists offer for dispositionism in economics and the extent to which economic and legal-economic theorists have, in the name of realism, begun to relax some of the traditional assumptions behind the basic rational actor model. ${ }^{209}$ As we conclude in that article, there is no compelling justification for the various shades of unrealism of economics and law and economics, which are more or less premised

${ }^{207}$ In important ways, we understand our admittedly loose and ambiguous epistemology to resemble that of positionality, which "acknowledges the existence of empirical truths, values and knowledge, and also their contingency," Katharine $T$. Bartlett, Feminist Legal Methods, 103 HARV. L. REV. 829, 880 (1990), and "sets an ideal of self-critical commitment whereby I act, but consider the truths upon which I act subject to further refinement, amendment, and correction." Id. at 883.

${ }^{208}$ Milton Friedman, Economic Myths and Public Opinion, NEWSWEEK, Jan. 1976, reprinted in BRIGHT PROMISES, DISMAL PERFORMANCE: AN ECONOMIST'S PROTEST 60, 75 (William R. Allen ed., 1983) [hereinafter BRIGHT PROMISES].

${ }^{209}$ Hanson \& Yosifon, supra note 30. 
on the same fundamental attribution error that distorts all human reasoning. ${ }^{210}$ In this Article, we want to focus briefly on just one of the more common justifications offered for eschewing a realistic account of the human animal. It seems that a key reason why legal economists have been so unwilling to get real about human nature has to do with a somewhat amorphous, but nonetheless powerful fear, that realism is dangerous.

\section{Facing Our Fears of Reality}

For example, in an article devoted to considering the implications of cognitive psychology for existing products liability laws, Professors Henderson and Rachlinski generally assume that consumers are dispositional, if cognitively biased, actors. However, they conclude their article by briefly acknowledging the possibility that stable preferences may not in fact underlie consumer "choices":

The notion that manufacturers distort consumer risk-perception assumes that there is some natural and appropriate risk-benefit assessment from which manufacturers lead consumers astray. If we take seriously the psychological proposition that all preferences are constructed, then there is no magical correct level of risk that consumers should endure. ${ }^{211}$

Their point seems to be that if policymakers were to take seriously that possibility, then policy theory as we know it would be rendered largely meaningless. We may agree with that claim. But Henderson and Rachlinksi's closing observation highlights a troubling and common unwillingness-even among cognitive psychologists like Rachlinski-to confront the reality that the available evidence reveals. If the implications of cognitive psychology are as drastic as Henderson and Rachlinski suggest they might be, then why highlight those implications only in a concluding comment, rather than beginning with them? And why would Henderson and Rachlinski largely ignore those implications in reaching definitive policy prescriptions throughout their article (and work)? $?^{212}$

${ }^{210} I d$.

${ }^{211}$ James A. Henderson, Jr. \& Jeffrey J. Rachlinski, Product-Related Risk and Cognitive Biases: The Shortcomings of Enterprise Liability, 6 ROGER WILLIAMS U. L. REV. 213, 258 (2000).

${ }^{212}$ It is not as if Henderson and Rachlinski's policy analysis has no real-world influence. Henderson, as a leading academic scholar and teacher, a busy litigation consultant and expert, and one of the Chief Reporters for the Third Restatement of 
Likewise, numerous psychology-sensitive scholars emphasize the influence of context or situation when downplaying the relevance of social psychological insights for policy, but then ignore the behavioral implications of context in applying the theoretical model of law and economics to policy analysis. ${ }^{213}$ One important reason for this tendency, we suspect, is that these scholars are human, and we humans want our world to make sense. ${ }^{214}$ We do not easily relinquish a model of behavior or a vision of ourselves that provides us with a feeling of predictability, manageability, and control, or that allows us to maintain positive self-conceptions. We are afraid of letting go of comforting, if false, images of our world and of ourselves. ${ }^{215}$ And that fear, like most, can be manipulated and exploited.

Like Henderson and Rachlinski, Samuel Issacharoff concludes his review of behavioralist literature by emphasizing the need for "humility" among those who apply its insights. He does not dispute many of behavioralism's findings; instead, he worries about their application. As he sees it, individualism and autonomy are themselves threatened by what behavioralism demonstrates, a threat that counsels caution:

[Behavioralism's insights] cannot possibly translate into a justification for greater constraints on individual decision making. Bounded rationality should not become the pretext for the imposition of an overarching regulatory structure on individuals .... [I]t would indeed be ironic if greater insight into the complexity of human decision making became the justification for taking the freedom to decide, even imperfectly, from those very individuals. ${ }^{210}$

Issacharoff implies that if a more accurate understanding of human behavior interferes with our preferred conception of who we

Torts, has had as much real-world influence on tort law as virtually any other living person.

${ }^{213}$ See, e.g., Jennifer Arlen, Comment: The Future of Behavioral Economic Analysis of Law, 51 VAND. L. REV. 1765, 1765-68 (1998) (arguing that while behavioral psychologists' findings undermine rational choice theory, their resulting understanding of human behavior is too uncertain to formulate a credible alternative to the conventional law and economics framework).

${ }^{214}$ See Hanson \& Yosifon, supra note 30.

215 See id. (reviewing evidence of such motives from social psychology and related fields). For other examples of this propositions, see MELVIN J. LERNER, THE BELIEF IN A JUST WORLD: A FUNDAMENTAL DELUSION (1980); John T. Jost et al., Non-Conscious Forms of System Justification: Implicit and Behavioral Preferences for Higher Status Groups, 38 J. EXPERIMENTAL SOC. PSYCHOL. 586 (2002).

${ }^{216}$ Samuel Issacharoff, Can There Be a Behavioral Law and Economics?, 51 VAND. L. REV. 1729, 1745 (1998). 
are, then the former must yield. Beware of those who challenge the basic economic model, no matter how unrealistic it may be, he seems to argue, for their apparent realism may be mere pretextual cover for the imposition of an "overarching regulatory structure." those who interfere with your "individual decision making," for what is at stake is your "freedom to decide." ${ }^{218}$

Posner brings Issacharoff's closeted bogeyman out into the open. In responding to Jolls, Thaler, and Sunstein's important work on behavioral economics, ${ }^{219}$ he writes, again in a concluding paragraph:

I wish to consider briefly [behavioral economics'] possible normative implications. On the one hand, the picture of the human being that [Jolls, Sunstein, and Thaler] draw is one of unstable preferences and (what turns out to be related), infinite manipulability. If you give a worker childbirth coverage, she'll like it (endowment effect); but if you don't give it to her, she'll dislike it (more precisely, won't pay for it in lower wages) .... If you describe the threat of breast cancer to a woman in one way, she'll want a mammogram, but if you describe it another although logically equivalent way, she won't. It seems then that the politically insulated corps of experts that [Jolls, Sunstein, and Thaler] favor would be charged with determining the populace's authentic preferences, which sounds totalitarian. On the other hand, ... [t] the expert, too, is behavioral man. Behavioral man behaves in unpredictable ways. Dare we vest responsibility for curing irrationality in the irrational?

In our view, Posner misrepresents Jolls, Sunstein, and Thaler's far more nuanced and restrained normative prescriptions. (Rest assured, they never proposed a Bureau of Authentic Preferences.) But, for our purposes, it is enough to point out the method by which Posner seeks to persuade his readers. More vividly than the others, he seems to be stoking-and perhaps revealing his own-fear by embracing the very phenomena that he is attempting to have us disregard. He accepts the influence of the framing and endowment effects, while at the same time suggesting that their very invocation raises the specter of totalitarianism or a "confederacy of dunces."

217 Id.

218 Id.

${ }^{219}$ Christine Jolls et al., A Behavioral Approach to Lau and Economics, 50 STAN. L. REV. 1471 (1998).

${ }^{220}$ POSNER, FRONTIERS, supra note 13 , at 286-87. 


\section{Thinking the Unthinkable}

Legal economists often take pride in the fact that they are willing to reach the conclusions that their theories yield, no matter how unpopular or unconventional they may be. To them, that willingness helps prove that they are neutral scientists. ${ }^{221}$ "Should the sale of babies be made legal?" Richard Posner asks. "The idea strikes most people as bizarre and offensive... . However, economists like to think about the unthinkable, so let us examine in a scientific spirit the objections to permitting the sale of babies for adoption."222 Posner acts as if he is broad-minded, compelled by principles of good science to apply his paradigm in all settings no matter how much non-economists disagree with his result.

But this habit of ending articles with a caution to readers about the perils of taking seriously a realistic account of human behavior (as noted in the previous subsection) reveals a different picture. These are not the words of social scientists pursuing truth wherever it leads them. Rather, these are more the words of a fundamentalist preacher warning members of his flock to avoid having their minds polluted or confused by anyone who would argue that dinosaurs once roamed the earth or that our species "evolved." These, more broadly, are the words of someone guarding, for himself and his audience, the comfort and reassurance of a worldview that faithfully yields familiar, easy, and agreeable answers.

There is far more at stake than whether or not preferences are manipulable or what products liability law should be. These scholars seem worried about the threat posed to an entire school of thought and to their ability to generate credible conclusions using the methods of that school. They also seem worried about the threat posed to an entire socioeconomic system that is built on the same basic dispositionist assumptions that they refuse to challenge. Their implicit warning to readers is to close their minds, because otherwise something between chaos and communism will surely be loosed upon us. Because we are human, taking seriously evidence that thoroughly challenges our worldviews, our frames of reference,

${ }^{221}$ Richard A. POSNer, ECONOMiC ANalysis of LAW 141 (3d ed. 1986); $c f$. POSNER, ECONOMIC ANALYSIS OF LAW, supra note 13, at 25 ("Economic analysis of law has aroused considerable antagonism, especially but not only among academic lawyers who dislike the thought that the logic of the law might be economics.").

${ }^{222}$ POSNer, ECONOMIC ANALYSIS OF LAW (3d ed.), supra note 221, at 141. 
our theories, and our systems, is truly "think[ing]... the unthinkable." ${ }^{223}$

Our biggest problem with this sort of scare tactic is not that there is no truth to it. If, as the evidence suggests, preferences are unstable, constructed, and manipulable, this should give rise to concern about the legitimacy of our systems, about our being manipulated, and even about our being subjected to some form of totalitarianism. The bogeyman that law and economics scholars seek to keep at bay may be real. But relying on models that ignore that possibility does not make the evidence or its repercussions go away, any more than lying motionless under a blanket would provide a defense against an authentic monster. Hiding our heads as a defense tactic succeeds only when the danger is just in our heads.

If we are anything close to infinitely manipulable, as Posner conjectures, ${ }^{224}$ or if all preferences are "constructed," as Henderson and Rachlinski hypothesize, ${ }^{225}$ then the "free choice" that scholars presume to be reflected in our behavior (and claim to want to protect) may be an illusion. We may already be in the grips of a bogeyman-a situation closer to the totalitarian nightmare than inadequately realistic models enable us to see.

This returns us to one of our main themes: if situation is far more influential than we realize, then the dispositions that we assume are primary to the human experience may be largely an illusion. Social scientists should be committed to examining the implications of what we know to be true, no matter how much we want to deny it, and rejecting what we know to be false no matter how much we want to embrace it. That is what is critical about realism.

\footnotetext{
${ }^{223} I d$.

${ }^{224}$ See supra quotation accompanying note 220 .

225 See supra quotation accompanying note 211.
} 


\section{Faith or Social Science?}

[F]indings ought not to be judged by the level of comfort they provide about acceptable views of human nature or the personal comfort the findings afford. . . It is not surprising when a lack of synchrony between our view of ourselves as unbiased ("I am a morally good person") and evidence of ourselves as biased ("I am not a morally good person") controls assessments of the finding of such discrepancies on the part of laypeople; it is a bit embarrassing when the same is possibly true of scientists themselves.

-Mahzarin R. Banaji ${ }^{226}$

We are now ready to return to our earlier discussion of law and economics and Posner's claims regarding the dominance of that approach. $^{227}$ In describing his commitment to objectivity and empiricism, a commitment that is shared (at least implicitly) by most legal economists, Posner has written earnestly of the need to employ the scientific method. In one of his early articles, for example, he wrote:

As biology is to living organisms, astronomy to the stars, or economics to the price system, so should legal studies be to the legal system: an endeavor to make precise, objective, and systematic observations of how the legal system operates in fact and to discover and explain the recurrent patterns in the observations-the "laws" of the system.

Nearly two decades later, he wrote similarly about the aspirations of the approach he helped found:

To me the most interesting aspect of the law and economics movement has been its aspiration to place the study of law on a scientific basis, with coherent theory, precise hypotheses deduced from the theory, and empirical tests of the hypotheses. Law is a social institution of enormous antiquity and importance, and I can see no reason why it should not be amenable to scientific study. Economics is the most advanced of the social sciences, and the legal system contains many parallels to and overlaps with the systems that economists have studied successfully.

${ }^{226}$ Mahzarin R. Banaji, Implicit Attitudes Can Be Measured, in THE NATURE OF REMEMBERING 137 (Henry L. Roediger III et al. eds., 2001).

${ }_{227}$ See supra notes $56,64,71-72$ and accompanying text.

${ }^{228}$ Richard A. Posner, Volume One of The Journal of Legal Studies-An Afterword, 1 J. LEGAL STUD. 437, 437 (1972).

${ }^{229}$ Richard A. Posner, Foreword to EsSAYS IN LAW AND ECONOMICS 5, 5 (Michael Faure \& Roger Van den Bergh eds., 1989). 
And recently, he has written about the concomitant need to dismiss the work of those who do not operate accordingly:

The rotation of the moons of Jupiter was anomalous in medieval cosmology because each planet (other than the earth, which was not considered a planet, but instead the center around which the planets revolved) was thought to be fastened to a crystalline sphere, which the moons would have collided with in their rotation. The anomaly could be dispelled by assuming that the sphere was permeable, or by assuming (as Cardinal Bellarmine did in his famous dispute with Galileo) that the telescopic observations that had disclosed the rotation of Jupiter's moons were a deceit by the devil. Whichever route was taken, the amended theory would not generate any predictions about planetary satellites; all it would predict was that whatever would be, would be. ${ }^{230}$

Posner's message is clear: the scientific approach should be embraced, and those theories grounded in little more than faith or non-falsifiable assertions should be rejected, particularly when they compete with a viable social scientific theory.

And it is purportedly based on that Galileo-like self-image that Posner has asserted that "the economic theory of law seems the best positive theory of law extant." ${ }^{231}$ It is simply "rich[er] in theoretical and empirical content" than any of its competitors. ${ }^{232}$ And Posner's views are held at least implicitly by most legal economists. So, for example, Cooter and Ulen "can say that economics provides a behavioral theory to predict how people respond to changes in laws," and that this behavioral "theory surpasses intuition, just as science surpasses common sense." "233

We wholeheartedly agree with the general case for relying on the scientific method. But, for the reasons we have provided, we reject the claim by legal economists that the dominance of law and economics has much to do with its theoretical and empirical content or their loyalty to the scientific method-at least in the way they suggest. Legal economists have missed, among other things, that

${ }^{230}$ POSNER, FRONTIERS, supra note 13, at 264.

231 Richard A. Posner, The Economic Approach to Lawv, 53 TEX. L. REV. 757, 774 (1975).

${ }^{232}$ Id.

${ }^{233}$ COOTER \& ULEN, supra note 7, at 3; see also Mark Klock, Are Wastefulness and Flamboyance Really Virtues?: Use and Abuse of Economic Analysis, 71 U. CIN. L. REV. 181, 252-53 (2002) ("I predict that the future of law will be characterized by less commentary arguing that economic analysis is inappropriate and more reliance on alternative economics models...."). 
they have unconsciously adopted, not the scientific approach of Galileo, but the faith-based approach of Cardinal Bellarmine. ${ }^{234}$

It is the economists who resist seeing or taking seriously what others are revealing, through the scientific method, about what moves us. ${ }^{235}$ And they are doing so based on a theory that has been falsified (or is non-falsifiable) and, which, therefore, is based, at bottom, on an evidence-blind intuition or faith. Although Posner and other legal economists do not stoop to warning readers about the "devil" being behind the heretical visions of social psychologists, they do, as we have noted, commonly raise the specter of a close cousin: "the totalitarian bogeyman." 236

\section{Some Presuppositions of Critical Realism}

What we do and do not mean by "critical realism" will become clearer below. But before introducing one of its important implications, it may be helpful to summarize several strong presumptions or axioms that we intend critical realism to build upon-principles that we have suggested in our discussion to this point:

- First, we-scholars and non-scholars alike-do not understand ourselves well, and certainly not as well as we think we do.

${ }^{234}$ See Maurice A. Finocchiaro, Introduction to THE Gallleo AFFAIR 1, 30 (Maurice A. Finocchiaro ed. and trans., 1989) [hereinafter THE GALILEO AFFAIR] (noting that Bellarmine rejected Copernican theory because it conflicted with the scriptures) .

${ }^{235}$ Our claim is not that law and economics is totally devoid of social science; far from it. But where social science does play a role, economic legal theory rarely generates clear answers to problems. For example, there is still considerable debate about what the most efficient liability rule is in tort law, despite the fact that this is one of the oldest, most discussed issues in law and economics. See, e.g., Richard S. Markovits, The Allocative Efficiency of Shifting From a "Negligence" System to a "Strict Liability" Regime in Our Highly-Pareto-Imperfect Economy: A Partial and Preliminary Third-Best-Allocative Efficiency Analysis, 73 CHI.-KeNT L. REV. 11, 133 (1998) (analyzing "efficiency of a shift from negligence to strict liability and various other standard-of-liability allocative-efficiency issues"). See generally John C. Moorhouse et al., Law and Economics of Tort Law: A Survey of Scholarly Opinion, 62 ALB. L. REv. 667 (1998). There is, in other words, considerable scholarly debate about most areas of law, even where efficiency is accepted as the law's underlying normative goal. This is where the social scientific features of law and economics take place-a competition among legal economists offering different efficiency-oriented stories and, where possible, different empirical evidence to support their views. Thus, with respect to the application of the basic theory to various social and policy issues, social scientific methods are welcome. With respect to the basic theory and its underlying axioms, in contrast, social scientific methods are disallowed.

${ }^{236}$ See supra text accompanying notes 221-23. 
- Second, the process of developing theories or models is a human one and is therefore subject to all sorts of biases and unperceived influences. It is largely for that reason that the impressions and models-informal and formal-that we legal scholars have created to help us understand ourselves tend to be flawed and self-serving.

- Third, we cannot hope to make sense of our institutions or ourselves until we better understand how humans go about trying to make sense of themselves and their institutions. To develop a theory that is free of, or at least less distorted by, such biases, it is necessary to more closely examine both the process that yields those biases and the biases themselves.

- And, fourth, a promising way to understand human cognition and behavior is to begin with those schools of thought and those institutions that are devoted to understanding human cognition and behavior. In this Article, we look primarily to one such source, social psychology, ${ }^{237}$ but we will also look briefly at what market practices can teach us about ourselves.

It is by bringing these principles together with the lessons taught by social psychology and markets that critical realism provides unique and, for many, unsettling insights about who we are, why we behave as we do, and what we should do about it, if anything.

${ }^{237}$ By "social psychology," we include not only the traditional field of research that goes by that name, but also numerous related fields, including social cognition, cognitive neuroscience, and cognitive psychology. For accessible overviews of the history of relationships between the various fields, see FISKE \& TAYLOR, supra note 20, at 1-18; KUNDA, supra note 20, at 1-7. 


\section{BRIEF INTRODUCTION TO POWER ECONOMICS}

Most Marxists... [believe] politics is but a reflection of the underlying economic order. The bourgeoisie, and especially the large corporations, will acquire and use the power of the state to protect and enhance their interests. . . .

But many non-Marxist scholars also doubt that the government will regulate an industry over the objections or against the interests of business. This view, held chiefly . . . by certain economists, does not arise out of any conviction that the historically formed interests of the dominant social class always find expression in the prevailing political structure, but rather out of the assumption that individual behavior can best be understood by assuming that it is rationally self-interested. Indeed, most economists find the Marxist argument murky and unconvincing precisely because it lacks any psychological theory that would explain how class position determines individual behavior.

-James Q. Wilson ${ }^{238}$

It's true that if you had concentrated power in the hands of an angel he might be able to do a lot of good, as he viewed it, but one man's good is another man's bad. The great virtue of a market capitalist sociely is that, by preventing a concentration of power, it prevents people from doing the kind of harm which concentrated power can do.

- Milton Friedman ${ }^{299}$

It is certainly the case that many Nazi concentration camp guards led blameless lives, both before and after their horrible service. To explain such complicity, therefore, we must assume the existence of a specific social and situational context that could induce ordinary people to commit extraordinarily evil deeds.

- Ross $\mathcal{E}^{2}$ Nisbett $^{240}$

\section{A. Power}

Think back to our example of the gunman who commands you to flip a switch that will deliver a violent electric shock to a pleading victim. $^{241}$ That is an example of power, as we mean it in this Article. Power is the use of situational devices (like guns) to influence

${ }^{238}$ James Q. Wilson, The Politics of Regulation, in THE POLITICS OF REgulation 357, 357-58 (James Q. Wilson ed., 1980).

${ }^{239}$ Milton Friedman, Is Capitalism Humane?, in BRIGHT PROMISES, supra note 208 , at 83,89 .

${ }^{240}$ Ross \& NiSBETT, supra note 9 , at 53.

${ }^{241}$ See supra text accompanying notes $84-85$. 
people's choices and to weaken the effect of their dispositions in order to achieve some goal. This sort of power is often viewed as illegitimate; offers of "your money or your life" are unacceptable negotiation tactics. Governmental regimes that rely on such power to exact obedience are typically labeled authoritarian. Particularly in America, we respect only actions that are consensual and the actions and institutions that reflect the autonomous choices of those involved-hence, our culture's celebration of democracy and capitalism. As we hope readers have begun to see, however, situation can have enormous consequences for our behavior, even when there is no gun to our head. Stanley Milgram's groundbreaking experiments demonstrate the incredible power of situation over our actions. People delivered what they believed were dangerous and painful shocks to fellow humans simply because of the situational pressures of a seemingly benign psychology experiment. That is frightening. But perhaps more frightening is that even after learning about Milgram's experiment, most of us still have little appreciation for the power of situation. ${ }^{242}$

${ }^{242}$ If members of the law school community believe they are immune to the power of situation, they should consult Steven Hartwell's study of students at the University of San Diego. Steven Hartwell, Moral Development, Ethical Conduct, and Clinical Education, 35 N.Y.L. SCH. L. REV. 131 (1990). Hartwell set up an experiment in the guise of a clinical class exercise. Id. at 142 . Each student was to individually advise litigants in a small claims court, although Hartwell was available in the next room for consultation. Id. Unknown to the students, each "litigant" presented her student-advisor with an identical problem: how best to make her case in a rent dispute. Id. As Hartwell recounts, "I told each student to advise the client to lie under oath that she had paid the rent. When students asked for clarification, I uniformly responded . . my advice is that, if your client wants to win her case, then you must tell her to perjure herself." Id. The idea was for students to feel the "pull between loyalty to authority... and prescribed ethical conduct." Id. Like the evaluators in Milgram's initial experiment, Hartwell predicted that the students would uniformly "reject my advice and refuse to tell their client[s] to lie." Id. And, like Milgram's evaluators, he was surprised to find out how wrong he was. "Although many of the twenty-four participating students grumbled either to me or to the client about my proffered advice, twenty-three told their client to perjure herself." Id. at 142-43.

A more famous example of the power of situation over students (although not law students) was demonstrated in a classic experiment conducted at Stanford University, in which students took on the roles of "prisoner" or "guard" in a realistic prison environment. Craig Haney et al., Interpersonal Dynamics in a Simulated Prison, 1 INT'L J. CRIMINOLOGY \& PENOLOGY 69 (1973). Although the students had been specifically chosen for their apparent emotional maturity, within only a couple of days the "guards" began to demonstrate extreme cruelty toward the "prisoners." Id. at 80-81. On the other side, several of the "prisoners" experienced severe emotional depression, while others were prompted to rebel. Ultimately, the experiment had to be cancelled less than a week after it began. Id. Rather than showing dispositional consistency 


\section{Power Blindness}

[The] systematic simucturing of institutions to reflect the viewpoint and position of those in power is most often invisible.

- Martha Chamallas ${ }^{243}$

There is reason to suspect that in our daily lives, we routinely overlook the power of our situations. As social psychology teaches, situational factors are cognitively hidden (often in plain sight), easily camouflaged and naturalized as mere background. Put differently, in most situations there is no gun, only an invisible hand and the seemingly consensual, choice-driven behavior of individuals. Perhaps that is what political scientists Herbert Kaufman and Victor Jones were driving at when they wrote:

There is an elusiveness about power that endows it with an almost ghostly quality. It seems to be all around us, yet this is "sensed" with some sixth means of perception rather than with the five ordinary senses. We "know" what it is, yet we encounter endless difficulties in trying to define it. We can "tell" whether one person or group is more powerful than another, yet we cannot measure power. It is as abstract as time yet as real as a firing squad. ${ }^{244}$

This is an insight of critical realism. As the quotation indicates, it is hard to think of anything more "real" than power. And, yet, despite its undeniable existence, the mechanisms of power are often hidden, ghostlike, in the setting. Hidden there, they tend to be disregarded, literally overlooked.

Legal economists have reacted to the elusiveness of this realism characteristically and understandably-they have ignored it. ${ }^{245}$ For the most part, economic thinking has no place for the concept of power. A perusal of the indices of the major law and economics texts, for example, yields no references to the word-except when

across environments, the students' behavior corresponded with situational cues and roles.

24.3 MARTha Chamallas, InTROdUCtion to Feminist Legal TheORY 16 (1999).

${ }^{244}$ Herbert Kaufman \& Victor Jones, The Mystery of Power, 14 PUB. ADMIN. REV. 205, 205 (1954); see also ROBERT DAHL, WHO GOVERNS? 90 (1961) ("One who sets out to observe, analyze, and describe the distribution of influence in a pluralistic democracy will . . . encounter formidable problems.").

${ }^{245}$ Economics does occasionally take power into account in exceptions that prove the rule. See, e.g., supra text accompanying notes 130-34 (recounting Cooter and Ulen's examples of economic threats); infra text accompanying notes 267-80 (describing Stigler's "shallow capture" theory). 
coupled with the word "market."246 Moreover, many economic presuppositions, such as the presumed autonomy of choice-making agents, implicitly remove the role of power from the analysis. If one type of "autonomy" is given, then there is no place for the sort of power illustrated in Milgram's experiment to emerge. ${ }^{247}$ The subjects of the experiment chose to engage in the experiment. They could have stopped; they could have walked out, but they didn't. Obviously, they were made better off by shocking the other agents to the fullest extent possible. Economic models are as blind as we are to situational forces.

This problem of "unrealism" in law and economics has been largely unrecognized by even its critics. ${ }^{248}$ That may be partially because the failure, like the problem, is hard to see. And in the rare instance where legal economists have acknowledged that their models disregard power, they use it as a basis for claiming that their power-blind approach is superior to competing theories. Thus, Richard Posner admonishes sociologists for incorporating power in their work given that the concept is "difficult to operationalize." ${ }^{249}$

\section{Looking for Power}

We have three problems with Posner's rationale for ignoring power. First, what good is a theory that ignores a force so potentially influential that it is actually called "power," purely for the sake of maintaining an operable model? "Power economics," an element of

${ }^{246}$ When economists speak of "market power," they generally use the term to refer to a firm's control of a significant share of a particular market. Often the term is associated with monopoly practices, as when a firm enjoys such "market power" that it can reduce output and raise prices without experiencing a total loss of sales to competitors. See, e.g., W. KIP VISCUSI ET AL., ECONOMICS OF REGULATION AND ANTITRUST 164 (3d ed. 2000) ("Generally speaking, the market power of a firm is the ability to raise price without suffering a significant decline in demand. This is typically measured by the price elasticity of the firm's demand curve.").

${ }^{247}$ See supra text accompanying notes 85-91 (recounting Milgram's obedience experiments).

${ }^{248}$ The law and traditional legal education also have no place for the concept of power. Critical theories represent an important exception inasmuch as they have influenced law and legal education. For instance, feminist legal scholarship has been particularly attentive to the operation of power dynamics in law and related social institutions. See, e.g., Bartlett, supra note 207, at 849-62 (summarizing and discussing feminist legal scholarship about relationships between power, gender, and social institutions).

${ }^{249}$ Posner, supra note 11 , at 272. 
critical realism, is committed to starting with power and developing our understanding or model of human behavior from there.

Second, any obstacle in operationalizing the concept of power may reflect the unrealistic starting presumptions of legal economists more than the inherent difficulty of incorporating power into a viable social scientific theory. Were economists more committed to understanding human behavior, they would be better able to model it. The ghostly quality of power, we hope to show, is less in the object and more in the lens. Change the lens and power is more likely to come into focus and will sometimes be as obvious as a gun to the head. This leads to our third point.

The clear message of Milgram's experiments is that situation influences us. But Milgram's decades-old findings serve as just one example of a much larger situation. "Social psychology has by now amassed a vast store of such empirical parables." 250 The deeper implication of those experiments is that situation can be managed, shaped, arranged, and constructed to influence us in ways that we do not anticipate or appreciate. Situation is thus a source and vehicle of power. Milgram, after all, designed and created the situation in his laboratory. Unfortunately the pursuit of academic or scientific knowledge is not the only motive that might shape the scenery that surrounds and moves us.

\section{B. Economics}

And here is where the economics of "power economics" comes into play. What we know about the situational character makes clear that people's behavior is influenced by situational factors. Thus, the ability to influence the situation is also the ability to influence people's behavior. Such power can be profitable. Because power is valuable to those who wield it, and insofar as power can be exercised through (invisible or, at least, unobserved) situational variables, those variables are themselves manipulable. And because those variables are manipulable, profit-driven agents will compete to control or influence them and, in turn, the people and institutions that tend to be blindly moved by them. More succinctly, once situation is understood as the locus of influence, it follows that situation will trade like mousetraps and widgets.

${ }^{250}$ Ross \& NiSBETT, supra note 9 , at 4. 
Market actors will exert power-whether or not they are aware of it-because of the situational pressures of the market. If profit can be made by influencing the situation, we predict that it will be. Market competitors will, to survive in the long run, "discover" precisely which situational manipulations most efficiently influence us and how. Market actors who fail to manipulate situational variables effectively will sooner or later be supplanted by those who do.

If there is uncertainty regarding the precise workings of powerthe particular mechanisms by which situational influence is wielded-that is a problem of description, not of economics. The market will discover those workings and exploit them. Because market actors will, indeed must, attend to the operation of power, legal economists have no excuse, even on operational grounds, for ignoring it. Market forces guarantee the exercise of power through situational manipulation-that is the essence of power economics. ${ }^{25}$

\section{Some Implications of Power Economics}

More than when I first wrote these pages, I am now impressed with the role of power in economic life-and with the great if largely innocent service of the conventional economic instruction in concealing it.... [The moderm business firm's] influence and power extend to politicians, Presidents and the Pentagon. This power would be much more remarked and resisted were it not for the social conditioning of economics and its instruction. The latter contends that all producers-all business firms and corporations, from the smallest to the largest, from the comer drugstore to Exxon and General Motors-are substantially subordinate to the impersonal authority of the market. So matters are presented in all reputable economic discussion... Power is much enjoyed, and its economic and political exercise can also be pleasingly remunerative. Nothing serves it better than a theology that disguises its exercise.

-John Kenneth Galbraith ${ }^{252}$

251 For an earlier statement of power economics, though not by name, and for considerable evidence from consumer-product markets confirming our claims, see Jon D. Hanson \& Douglas A. Kysar, Taking Behavioralism Seriously: The Problem of Market Manipulation, 74 N.Y.U. L. REV. 630 (1999) [hereinafter Hanson \& Kysar, Taking Behavioralism Seriously I]; Jon D. Hanson \& Douglas A. Kysar, Taking Behavioralism Seriously: Some Evidence of Market Manipulation, 112 HARV. L. REV. 1420 (1999) [hereinafter Hanson \& Kysar, Taking Behavioralism Seriously II]; Chen \& Hanson, Illusion of Law I, supra note 84; see also infra text accompanying notes 393-414 (illustrating how commercial interests have, through situational manipulations, promoted dispositionism).

${ }_{252}$ JOHN KENNETH GALBRAITH, THE AFFLUENT SOCIETY, at xiv (4th ed. 1984). 
What we know from economics is that markets will eventually discover and exploit profit-enhancing opportunities for power. Economics also helps us predict that the market actors who will exploit those opportunities most successfully will be those with the greatest wealth and willingness to pay. Large corporations meet those criteria because they amass extreme amounts of wealth ${ }^{253}$ and possess the overriding, narrow interest in profit maximization. ${ }^{254}$

${ }^{253}$ Comparing the 2001 Gross National Income of all nations with the 2001 total revenues of the Global Fortune 500 companies helps bring this into relief. For example, Wal-Mart's 2001 revenues ( $\$ 219.8$ billion) were greater than those of eightfive countries combined. Home Depot had greater revenue ( $\$ 53.6$ billion) than Hungary ( $\$ 49.2$ billion). The Gap had greater revenue ( $\$ 13.8$ billion) than Bulgaria ( $\$ 13.2$ billion). Toys "R" Us $(\$ 11.0$ billion) had greater revenue than Kenya ( $\$ 10.7$ billion). The revenue of the $\$ 500$ company, a Japanese construction firm called Takenaka, surpassed ninety-four countries. In fact, the sum of the revenues of the Global 500 firms ( $\$ 14$ trillion) accounts for forty-five percent of the total world GDP (\$31.3 trillion). Compare WORLD BANK, 2003 WORLD DEVELOPMENT INDICATORS (describing the 2001 gross national income of each nation), with The Global 500: The World's Largest Corporations, ForTune, July 22, 2002, at F-1 to F-10 (listing the gross revenues of the five hundred largest corporations).

${ }^{254}$ Cf. Hanson \& Kysar, Taking Behavioralism Seriously II, supra note 251, at 14671553 (providing a case study of how the tobacco industry, based on shared interest, managed to manipulate consumer perceptions, preferences, and behavior in order to increase profits). With exceptions that we will explore in future research, corporations tend to behave as if their sole-or, at least, primary-goal is to maximize profits. See, e.g., Chen \& Hanson, Illusion of Law I, supra note 84. That is true not because corporations have dispositions, but because of a confluence of stable and significant situational factors. Most importantly, firms participate in a number of market competitions-for products, for capital, for managers, for labor, and for acquisitions of firms themselves. All of these markets work to winnow out those firms and managers that do not effectively profit maximize. Firms have charters and bylaws, situational restraints that typically set profit-maximization as the firm's stated goal, and they operate within a legal environment that places, according to most corporate law scholars, fiduciary duties on managers to maximize profit.

Moreover, the situational characters who work within firms face strong cultural norms to maximize profits and are given extensive training in business schools or by the firms themselves. The American business culture promotes the idea that "business is business" and considerations other than profit are irrelevant to decisions. For a history of the basic scripts of business and corporate, see id. Together, these and other situational forces push firms (and the situational characters who occupy them) to behave "as if" maximizing profit. Of course, those situational forces are limited, and corporations and their managers do not always behave in profitmaximizing ways. Still, most scholars agree that, at least in the long run, the situational imperatives of profit and the dispositions and situations of corporate managers combine to push corporations firmly towards profit-maximizing conduct. It bears noting that our interpretation of firms as situationally motivated, at least in the long run, to behave as if they are profit-maximizing is conventional among corporate law scholars. See id.; HENRY HANSMANN, THE OWNERSHIP OF ENTERPRISE 23 (1996) (explaining why it is reasonable to assume that firms will, over time, tend toward profit-maximizing, or cost-minimizing, practices); cf. Milton 
Power economics predicts that we are living within an ongoing Milgram experiment, in which we, the subjects, perceive our acts to be free and dispositionally motivated, but in which the experimenters-large business entities-wield far greater influence over our movements through situational manipulations than we tend to recognize. As in Milgram's experiment, we predict and report, in our common sense views and formal theories, that we are largely immune to such situational manipulations. Power economics predicts that the totalitarian bogeyman is invisible but real, and that we commonly behave as if there is a gun to our head.

Of course, very often market actors compete against each other for situational supremacy. In a previous work, one of us (with Doug Kysar) has examined the battle for prime placement of products in supermarket aisles. ${ }^{255}$ Placement at eye level sells, and someone has got to be on the bottom. In those cases, competition for situation is often a zero-sum game.

But there are other situational factors that help all firms: for example, the Muzak that wafts over the entire supermarket and has been found to increase overall purchasing. ${ }^{256}$ In the same manner, competing firms within industries often act in ways that further their shared interests ${ }^{2.57}$ or even join forces when their collective self-interest is at stake. ${ }^{258}$ All firms share a broad goal of profit maximization. This leads to secondary shared interests in promoting markets, preventing profit-restricting regulation, and, most importantly for our argument here, supporting a concept of human

Friedman, The Methodology of Positive Economics, in ESSAYS IN POSITIVE ECONOMICs 3, 21-22 (1953) (examining the hypothesis that individual firms behave as if they were seeking rationally to maximize profits).

${ }^{255}$ See Hanson \& Kysar, Taking Behavioralism Seriously II, supra note 251, at 1448.

${ }^{256}$ See id. at 1445 (describing how marketers manipulate consumers' "mood states").

${ }^{257}$ See generally Jon D. Hanson \& Douglas A. Kysar, Taking Behavioralism Seriously: A Response to Market Manipulation, 6 ROGER WILliams U. L. REV. 259, 337-370 (2000) [hereinafter Hanson \& Kysar, Taking Behavioralism Seriously III] (describing reasons why firms tend not to engage in activities that increase consumer risk perceptions).

${ }^{258}$ For one very recent example, competing automakers joined together this year in a lawsuit challenging California's strict fuel emission standards. See Bob Egelko, California, Bush Spar over Clean Air Rules: Appeals Court Ponders Block on Emissions Standards, S.F. CHRON., Feb. 14, 2003, at A8. For other examples of firm cooperation in self-interest, see Hanson \& Kysar, Taking Behavioralism Seriously II, supra note 251, at 1467-1502 (describing tobacco industry's response to industry-wide threats); Hanson \& Kysar, Taking Behavioralism Seriously III, sutpra note 257, at 361-66 (describing how even competitive industries often manage to cooperate to advance their shared interests). 
behavior that serves profit-maximizing interests. Because commercial interests-particularly corporate entities-are incredibly wealthy and powerful forces in society, when they work in complementary ways, they can have far-reaching effects on how we view society, justice, and ourselves. ${ }^{259}$

Power economics predicts that situation is sold to the highest bidders through largely unseen market processes. Corporate entities manipulate situation to influence our conduct and dispositional self-conceptions, thereby building their wealth and increasing their power. ${ }^{260}$ The analogies undergirding our conclusions in this section may appear to be loaded. By likening situational forces to a gun, it may appear that we have likened market forces to a gunman. Indeed, we have. We are thinking the unthinkable. Posner's bogeyman reigns, but he rules from where Posner and others have least looked for him-that is, outside of us, or at least out of our sight, in the situation.

This talk of power may look like the product of some pretty radical thinking. However, one can instead see our thesis as nothing more than the careful application of the logic unhesitatingly embraced by many of academia's most conservative scholars. Here, again, is where the economics of "power economics" plays a role. We are making the same assumptions as neoclassical economists about how markets work, but we add a more realistic account of the humans involved in that process. And, as will become clear in the next Section, we also accept the conventional economic presumptions with respect to the way regulatory processes operate -indeed, in some ways, we take that understanding more seriously than economists have.

${ }^{259}$ As will become clear below and in our future work, it is not necessary that corporate decision makers make conscious decisions to cooperate with others for corporations to be acting in complementary ways toward shared goals. See infra Part VI.B (providing evidence of how dispositionism has been promoted by commercial interests).

${ }^{200}$ See id. 


\section{BRIEF INTRODUCTION TO DEEP GAPTURE}

\section{A. Shallow Capture}

One cannot mention regulatory agencies without adding the observation that, of course, such agencies are likely to be 'captured' by the interests they are supposed. to regulate. To suggest that matters are any different from this is to mark oneself as hopelessly naïve, or even disingenuous.

-James Q. Wilson ${ }^{261}$

The basic story of regulatory capture has become so well known-indeed, such a truism-that we think it appropriate to begin as Steven Croley began his recent retelling: "You've heard all of this before."262

Because no one wants us to rehearse the details yet again, and because we also value efficiency, we will base our introductory overview on the brief rendition offered by an extremely credible source. In his Memoirs of an Unregulated Economist, ${ }^{263}$ George Stigler describes how he came to the work central to his winning the Nobel Prize in Economics. ${ }^{264}$ According to Stigler, prior to his work, academic economists writing about state policies commonly offered their advice on "what [the government] should do, or refrain from doing." Th5 "They published their normative conclusions naively believing that governments, charged with enhancing the public welfare, would readily heed sound prescriptions. But after "two centuries" of being disregarded on issues like free trade, Stigler and a few other economists came to believe that government officials were not very interested in the "truths" of economics. ${ }^{266}$ It was time to "undertake the different and more fundamental task of explaining

${ }^{261}$ James Q. Wilson, Introduction, in THE POLITICS OF REGULATION, supra note 238, at ix.

${ }^{262}$ Steven P. Croley, Public Interested Regulation, 28 FLA. ST. U. L. REV. 7, 9 (2000).

${ }^{263}$ STIGLER, supra note 70.

${ }^{264}$ Also significant was Stigler's work on the "economics of information." See generally George J. Stigler, The Economics of Information, $69 \mathrm{~J}$. POL. ECON. 213 (1961) (calling on economists to pay more attention to the importance of information, for example, in ascertaining market price); George J. Stigler, $A n$ Introduction to Privacy in Economics and Politics, 9 J. LEGAL STUD. 623 (1980) (demonstrating how economic analysis illuminates choices in favor of privacy and the concealment of information).

265 STIGLER, supra note 70, at 114.

${ }^{266}$ Id. at $114-15$. 
what states actually do, of discovering what are the forces that determine which policies will actually be adopted by a government., ${ }^{267}$

Stigler began that undertaking (much of it with co-author Claire Friedland) by examining "the actual effects of economic regulations." 268 By understanding the effects of regulation, he believed he could infer something about the forces that created the regulation. Through empirical testing unlike any that had previously been conducted, ${ }^{269}$ he discovered that several prominent regulatory policies of the $1960 \mathrm{~s}$-including the regulation of electricity rates and the SEC's "elaborate review of the prospectuses for new security issues"-were not having the effects or yielding the benefits that ostensibly motivated them. ${ }^{270}$ To be sure, the regulations were creating benefits. The problem was that those benefits were accruing to the wrong recipients. For instance, the beneficiaries of electricityrate regulation were large commercial customers instead of consumer households. ${ }^{271}$ Additionally, the effect of the SEC reviews was to inhibit competition and raise the public's costs.

From these and similar findings, the now-dominant conception of regulation emerged: the "general theory of the behavior of governments" ${ }^{272}$ is that "groups possessing political influence use the political process effectively to increase their incomes. ${ }^{\text {n273 }}$ According to the "economics of regulation," as this approach was initially dubbed, ${ }^{274}$ causal relationships and the direction of influences are the

${ }^{267}$ Id. at 114. Reflecting the immodesty that seems to characterize those who employ this approach, see supra text accompanying notes 71-75, Stigler went out of his way to add that it was "economists [who] initiated the theoretical study of the actual, in contrast to the desired, functions of the state," because "[o]f all the social scientists, only economists possess a theoretical system to explain social behavior." STIGLer, supra note 70 , at 115 .

${ }^{268}$ STIGLER, supra note 70 , at 115.

269 Id. at $117-18$.

270 Id. at $116-17$.

${ }^{271}$ Id. at 116; see also George G. Stigler \& Claire Friedland, What Can Regulators Regulate? The Case of Electricity, 5 J.L. \& ECON. 1, $7-8$ (1962) (describing how commercial customers benefited from regulation).

${ }^{272}$ STIGLER, supra note 70 , at 118.

273 Id. at 120.

${ }^{274}$ Stigler, like many of his contemporaries, eschewed an anthropomorphic view of the state and, true to the tenets of his discipline, looked for answers under the assumptions that governments are made up of individual people who are rational actors, and who therefore behave according to the very same principles, and in response to the same sorts of incentives, that motivate market participants. What they assumed was true of private choice, Stigler and his contemporaries assumed was also true of "public choice" (the name given to the now-immense field of research that, 
reverse of what had been supposed. The seemingly autonomous administrative agency is, upon inspection, captured, ${ }^{275}$ and the seemingly constrained industries are liberated and enriched. Consequently, the industry tail wags the regulatory dog. As Stigler laments, "no matter how disinterested the goal of public policy, the policy is bent to help politically influential groups at the cost of the less influential." ${ }^{, 276}$ And the problem is not just that for every winner, there are losers-the real kicker is that the winners often win less than the losers lose. ${ }^{277}$ Regulation is, in a word, inefficient. ${ }^{278}$

The finding that industries tend to benefit from regulation led to another question for Stigler: "Why are some industries and activities regulated by the state, and not others?" significant developments that emerged from this dismal perspective on regulation was a set of insights regarding the sources of political influence-or, as we would put it, power. As Stigler recounts, economists could explain, for example:

[W] hy smaller groups do better than large in the political arena. [First, $t$ ] he smaller group is more cohesive: It is easier to organize the small group, collect funds for lobbying, and keep it informed. There are only about 70,000 beekeepers concentrated in a few western states (yes, there is a federal program for them) but millions of occasional consumers of honey. And secondly, it pays each member of a small group to invest resources in politics, because the payoff will be larger. Each beekeeper gets hundreds of times as much out of the federal program as each taxpayer loses. ${ }^{280}$

Such insights regarding how groups of individuals could effectively coordinate their behavior in pursuit of common interests were more the product of some of Stigler's contemporaries than of

for the most part, has a similar premise). See supra text accompanying notes $303,314-$ 17 (discussing dispositionism of regulators).

${ }^{275}$ This is not meant to imply that the people who run agencies are captured by the process. According to the basic theory, their interests are advanced by the quid pro quo inherent in the process. See George Stigler, The Theory of Economic Regulation, 2 BELLJ. ECON. \& MGMT. SCI. 3, 12-13 (1971) (arguing that regulators may not antagonize regulated firms because they want to keep their options open for a high-paying job with a firm upon departing the regulatory agency).

${ }^{276}$ STIGLER, supra note 70, at 119.

277 Id. at $118-20$.

278 This was one of several ways in which neoclassical economics was attempting to demonstrate how good regulatory intentions tend to create unintended (i.e., inefficient) consequences. For an overview, see Milton Friedman, BRIGHT PROMISES, supra note 208 , at $127-28$.

${ }_{280}^{279}$ STIGLER, supra note 70 , at 118.
Id. at 119. 
Stigler himself. ${ }^{281}$ But before leaving our discussion of Stigler, a few observations are in order regarding his important contributions.

Look carefully at the structure of Stigler's work-at least as we have summarized it. Stigler was challenging a long-held conventional wisdom that governments and their agencies create beneficial regulations. Underlying that conventional wisdom was the supposition that regulatory processes were fair and that regulators were dispositionally motivated to serve the public interest. Stigler's challenge to those suppositions was initiated by his discovery that, in fact, a sanguine view of our regulatory institutions had no empirical basis and that, if anything, those institutions' actions were counterproductive to their espoused goals. To explain the phenomenon, Stigler looked to the outside influences on regulators and described how different groups were able to exert power over the regulators. Thus, Stigler contested the reassuring conventional wisdom that our institutions are neutral and well-functioning and rejected the idea that the stated goals of regulators are controlling. He did so by downplaying dispositional factors and emphasizing situational factors. ${ }^{282}$ By taking situation seriously, he raised the issue of power inasmuch as situations are largely defined by allocations and dynamics of power. As Stigler and many others writing in this area have taken for granted (without ever actually using the term), power is central.

In this way, Stigler's work on the economics of regulation provides a paradigmatic example of power economics. We believe that this Article finds confirmation in the fact that Stigler and other economists stopped there-why, in other words, neoclassical

281 See, e.g., MANCUR OLSON, THE LOGic OF COLleCtive ACTION: PUblic GoOdS AND THE THEORY OF GROUPS 53-57 (1971) (discussing the effectiveness of small groups); RUSSEll HARDIN, COLlective ACTION 42-45 (1982) (reviewing Olson's analysis of the correlation between group size and effectiveness). This topic of what interests will be best able to influence regulation is central to power economics and our theory of deep capture. We hope to return to it in much greater detail in future works. In any event, we hope readers might begin to see its relevance for questions far broader than simply administrative regulation.

${ }^{282}$ This is not to say that Stigler and other scholars, did not still see an important-we think too important-role for dispositions. The work he began initiated a great deal of scholarship that assumed that regulators were dispositionally inclined to be captured. See, e.g., George J. Stigler, Can Regulatory Agencies Protect the Consumer?, in THE CITIZEN AND THE STATE: ESSAYS ON REgulation 178, 181 (1975) (arguing that regulators and regulation have often failed to protect the public interest relative to the interests of the regulated industry because "the logic and basic forces of regulation ... dictate what type of men ... will typically be appointed" and emphasizing dispositional factors). 
economics has not evolved into to power economics and why capture theory has not evolved in to deep capture theory.

\section{B. Deep Capture: An Historical Example}

I, Galileo [Galilei], ... seventy years of age, arraigned personally for judgment, kneeling before you Most Eminent and Most Reverend Cardinals InquisitorsGeneral against heretical depravity in all of Christendom, . . . swear that I have always believed, I believe now, and with God's help I will believe in the fuiure all that the Holy Catholic and Apostolic Church holds, preaches, and teaches.... I have been judged vehemently suspected of heresy, namely of having held and believed that the [S] un is the center of the world and motionless and the [E]arth is not the center and moves.

Therefore, desiring to remove from the minds of Your Eminences and every faithful Christian this vehement suspicion, rightly conceived against me, with a sincere heart and unfeigned faith I abjure, curse, and detest the above-mentioned errors and heresies, . . . and I swear that in the future I will never again say or assert, orally or in writing, anything which might cause a similar suspicion about me... .

- Galileo Galilei ${ }^{283}$

With the foundation of shallow capture in place, we can now build upon it, or dig beneath it, to introduce deep capture. To catch your first glimpse of the phenomenon, recall the Galileo story. We argued, in a flip of Posner's version of the story, that it was Galileo who was committed to realism and Bellarmine who, like legal economists, was wed to an unrealistic, reductionist model. ${ }^{284}$

Let us push the analogy further. Galileo was, for most of his life, devoted to the idea that humans could, through methods of observation, discover and make sense of the natural order. ${ }^{285}$ He was committed to basing theories about our world and the place of it in the universe on all the evidence and clues available for human inspection, even if doing so challenged widely held self-affirming and

${ }^{283}$ Galileo's Abjuration of June 22, 1633, in THE GALILEO AFFAIR, supra note 234, at 292, 292.

See supra text accompanying notes $230-36$.
28.5 In 1611 , Galileo described his research methodology this way:

Over a period of two years now, I have tested my instrument (or rather dozens of my instruments) by hundreds and thousands of experiments involving thousands and thousands of objects, near and far, large and small, bright and dark; hence I do not see how it can enter the mind of anyone that I have simple-mindedly remained deceived in my observations.

DANIEL J. BOORSTIN, THE DISCOVERERS 316 (1983). 
faith-based beliefs about the Earth's centrality in the universe. ${ }^{286}$ Recall that Galileo lived at a time when most people believed themselves to inhabit a stationary world. The intellectual establishment of the Renaissance, controlled to a large degree by the Catholic Church, perceived human knowledge as a fundamentally static thing. ${ }^{287}$ Certain environmental features seemed obvious: the Earth was not moving, and the Sun was rotating about the earth. The validity of those notions was bolstered by everyday experience and found confirmation in several biblical texts, and in the basic assumption that heaven reigned above the Earth and hell below. ${ }^{288}$

${ }^{286}$ Galileo had, in his lesser-known work in mechanics, divined the truth of Copernicus' revelations long before his invention of the telescope. GIORGIO DE SANTILlana, THE CRIME OF Galileo 5-6 (1955). But Galileo was aware of how Copernicus had been mocked and marginalized for expressing those views and thus opted to wait until he had compelling proof before endorsing Copernican ideas. Id. at 11 . In a letter to Kepler, Galileo remarked:

Like you, I accepted the Copernican position several years ago and discovered from thence the causes of many natural effects which are doubtless inexplicable by the current theories. I have written up many reasons and refutations on the subject, but I have not dared until now to bring them into the open, being warned by the fortunes of Copernicus himself....

Id. The telescope provided Galileo with what he thought would be "irrefutable proof to any man in good faith," id., or, with what we might describe as evidence so irrefutable as to pierce the ambiguity supporting the then-conventional view.

${ }^{287}$ At the same time, it is important to note that the Catholic Church was not an institution that inherently spurned logic and empirical study. Its guiding philosophy, Scholasticism, represented an attempt to wed divine revelation, buttressed by faith, to Aristotelian logical deduction. Id. at 56-57. Thus, the Church had no problem with, and actually encouraged, Aristotelian science that generally limited itself to the basic study of the natural world. Id.

What the Church (and with it, most of European society) valued above all else, however, was not creativity but authority. Hence, the intellectual establishment inhabited, and later critiqued, by Galileo was in many ways profoundly backwardlooking, in the sense that the "the progressive nature of human knowledge" was entirely alien to it. William R. SHEA, Gal.ileo's INTEllectual ReVOlution: MiddLe PERIOD, 1620-1632, at 31 (1972). Traditional science and philosophy were rooted in the insights of the Bible and the work of Ancient Greek thinkers (notably Aristotle). Scholars were to approach such authorities, not as advocates of debatable propositions, but as bodies of revealed truth from whom added insights could then be gained via the process of deductive reasoning. See PIETRO REDONDI, GalileO: HERETIC 52, 54-55 (Raymond Rosenthal, trans., Princeton Univ. Press 1987) (1983) ("Nature-the Aristotelian professors of philosophy said-has spoken through the mouth of Aristotle.").

${ }^{288}$ See, e.g., Psalms 103:11 ("For, as high as heaven is above the [E] arth...."); Matthew 11:23 ("[W]ill you be exalted to the skies? No, brought down to the depths!"). 
Galileo, informed by the work of fellow astronomical realist Copernicus, ${ }^{289}$ was interested in exploring and studying elements of our planet and the celestial bodies whirling "above" it for hard-to-see clues into the reality of celestial dynamics. Mathematics and a telescope both provided critical lenses through which he could get a better view. ${ }^{290}$

Using these tools, Galileo helped to turn the dominant Aristotelian model of the universe, and our place in it, on its head. ${ }^{291}$

${ }^{289}$ Galileo wrote of Copernicus' dedication to realism:

And so he began to investigate what the system of the world could really be in nature, no longer for the sole convenience of the pure astronomer, whose calculations he had complied with, but in order to come to an understanding of such a noble physical problem; he was confident that, if one had been able to account for mere appearances by means of hypotheses which are not true, this could be done much better by means of the true and physical constitution of the world.

Galileo's Considerations on the Copernican Opinion (1615), in THE GALILEO AFFAIR, supra note 234 , at 70,74 (1989).

${ }^{290}$ Galileo stated that:

"Philosophy is written in this grand book the universe, which stands continually open to our gaze ... But the book cannot be understood unless one first learns to comprehend the language and to read the alphabet in which it is composed. It is written in the language of mathematics, and its characters are triangles, circles, and other geometric figures, without which it is humanly impossible to understand a single word of it ...."

Dava SOBEL, GallLEO'S DAUghter 16 (1999) (quoting Galileo's The Assayer, in Stillman Drake, Galileo (Oxford Univ. Press, 1996) (1980)).

Galileo's use of mathematics is crucial. The notion of scientific empiricism was not, in and of itself, offensive to the Aristotelian mindset embraced by the Church. Yet, in contrast to Aristotle's relatively simplistic system that relied entirely on concrete observations that human beings could make with their own senses, Galileo posited a framework of analysis that was just as abstract and theoretical as that of the Scholastics. See REDONDI, supra note 287, at 52-53 (describing the intricate process of deciphering The Assayer). In doing so, Galileo saw himself as a kind of "philosopher of nature," whose work was every bit as important to the project of understanding Creation as that of the moralist or the theologian. Id. at 53. Thus, to the established intellectual and religious hierarchy, Galileo's ideas were deeply threatening.

${ }^{291}$ Neither Galileo nor Copernicus was the first to discover the basic astronomical insights that later made each of them famous. Indeed, many of the early "discoveries" associated with the origins of modern science had been, in other cultures, long known. As Dick Teresi recently summarized:

$[T]$ he ancient Indians, long before Copernicus, knew that the [E]arth revolved around the [S] un and, a thousand years before Kepler, knew that the orbits of the planets were elliptical; the Arabs invented the observatory and named most of our popular stars; the Chinese mapped the sky; and the Amerindians noted important events with daggers of light or optical snakes that thrill us to this day.

Dick Teresi, LOST DisCoveries: The ANCIENT RoOTS OF MOdern SCIENCE-From THE Babylonians to the Maya 92-93 (2002). The belief that Copernicus or Galileo 
It is important to note, however, that the Aristotelian model (as enhanced through Ptolemy's refinements) ${ }^{292}$ provided an adequate "as if" theory, for most purposes. ${ }^{293}$ Through theory and observation, Galileo removed the Earth from its stable center, around which the Sun was revolving, and placed the Sun at the immovable center of the Earth's rotations. Put differently, by studying our astronomical situation more closely, Galileo discovered our astronomical fundamental attribution error: attributing the movement of the celestial situation to the centrality and fixity of the Earth instead of attributing our own movement, like that of the other heavenly bodies, to the celestial situation. Galileo did not provide absolute proof for his challenging worldview, although he believed the telescopic observations were sufficient to overturn the geocentric model. What he did provide was a refined theory and new observations-such as the discovery of four moons orbiting Jupiter, the phases of Venus, and an exegesis of the tides-that strongly

discovered that the Earth circled about the Sun is tantamount to saying that Columbus discovered South America. It is accurate only from an ethnocentric vantage point, a problem that plagues many of our presumed accuracies. See supra text accompanying notes 28-30 (explaining the social psychological findings that people tend to view themselves in self-affirming ways and make mental adjustments to preserve that self-image).

${ }_{202}$ Aristotle originally proposed that all celestial bodies were immutable perfect spheres, the Earth being fixed at the center. See SOBEL, supra note 290, at 170-71 (describing the geocentric Aristotelian world view in contrast to the views of Salviati, Galileo and others). Ptolemy reasoned that this must be so, since "if the [E] arth were not at the center of the stellar sphere, we should not be able to always see half of this sphere; but we do see it..." Galileo's Reply to Ignoli (1624), in THE Galile. AFFAIR, supra note 234 , at 154,168 . When one looks at two fixed stars opposite each other, such that one rises when the other sets, this shows that the part of the sky above the Earth is equal to the part below, and consequently that each is a hemisphere, and, since this phenomenon is observable for all horizons, that the Earth is at its center. See id. at 168-69 (explaining the basis for Ptolemy's reasoning). Galileo called the argument "beautiful and worthy of Ptolemy" but pointed to the (now obvious) alternative explanation that "if we let this sphere be still and let the terrestrial globe turn on itself (as Copernicus does), then regardless of where it is placed the same thing will happen to the two fixed stars, namely their simultaneous rising and setting." Id.

${ }^{293}$ See Albert Van Helden, Ptolemaic System, at http://es.rice.edu/ES/humsoc/ Galileo/Things/ptolemaic_system.html (last visited Oct. 31, 2003) ("Ptolemy was able to account for the motions of heavenly bodies within the standards of observational accuracy of his day. The idea was to break down the complex observed planetary motion into components with perfect circular motions."). 
suggested that the astronomical situation was far more influential than the then-dominant geocentric view allowed. ${ }^{294}$

We want to push this analogy even further. Despite Galileo's compelling evidence that the Earth revolved around the sun, he appeared to have been wrong. To be sure, we might look today and judge that he was (comparatively) right, after all. But forget for a moment the revival and celebration of Galileo's pre-abjuration views, beginning in the eighteenth century, and temporarily ignore his stature today as a father of modern science. ${ }^{295}$ Instead, imagine yourself living in early seventeenth-century Italy. It is Bellarmine's view-informed by biblical passages, religious authorities, popular perceptions, experience, and naked-eye observations-which confirms your intuitions and the formal positions of the most powerful groups and institutions in Italy. ${ }^{296}$ And it is Galileo, not Bellarmine,

${ }^{294}$ Of course, Galileo's theory was more complicated than the geocentric view and consequently left many questions unanswered. Among other problems, a heliocentric Earth, without gravity (a concept which was unavailable at the time) could neither rotate nor revolve without sending its occupants flying. The fact that most of the Earth's objects seemed fairly secure (with the exception of the tower in Pisa) was a major reason that he (incorrectly) turned to the tides for support of his view. See SOBEL, supra note 290, at 75 (outlining the problems with Galileo's theory that the principle of gravity, then undiscovered, would have explained).

Legal economists justify eschewing realism in the name of maintaining a theory that is falsifiable. As the Galileo story indicates, however, there are major problems with that justification. First, there is no reason to believe that the more realistic a model, the less falsifiable it is. That much is clear from Posner's own example of the debate between Galileo and Bellarmine. See supra text accompanying note 230. Bellarmine's theory was clearly neither realistic nor falsifiable. Second, even if more realistic theories are less falsifiable, that fact does not justify ignoring reality. Absent a meta-rule explaining how realism and falsifiability are to be traded off (again, assuming that there is such a tradeoff), identifying the problem does not identify how the tradeoff should be resolved. Thus, Posner's claim seems to be a makeweight argument against realism. Furthermore, if Posner's position is that his theory is superior because it is falsifiable, then he needs to acknowledge that it has, indeed, been thoroughly falsified (or been rendered, by his defenses, non-falsifiable). As we discuss elsewhere, many previous economic theories have been falsified, including those that resemble the simplistic models of law and economics. See Hanson \& Yosifon, supra note 30 (discussing biology's theory of "spontaneous generation" and economists' theories of intertemporal choice, revealed preference, and assumptions of "perfect information" and "stable preferences" have been more or less falsified."); Hanson et al., supra note 84 (arguing that Posner's positive theory of tort law has been falsified or is non-falsifiable, and provides an alternative positive theory of tort law).

${ }^{295}$ Albert Einstein himself dubbed Galileo "the father of modern physics-indeed of modern science altogether." SOBEL, supra note 290, at 326.

${ }^{296}$ As expressed in the Papal Condemnation of June 22, 1633 :

That the [S] un is the center of the world motionless is a proposition, which is philosophically absurd and false and formally heretical for being explicitly contrary to Holy Scripture; 
who recants and renounces his earlier "findings" and opinions. Chances are that you, that we, would have believed Galileo was a heretic and never doubted the process that "proved" him to be one. From this perspective, Bellarmine was obviously right, and Galileo, clearly wrong.

So how could one of the greatest scientists of all time be so wrong? The answer is obvious, indeed it is one of the reasons that the story is so well known: the scientific community was not sufficiently insulated from powerful institutions with a stake in scientific outcomes. ${ }^{297}$ More concretely, because Galileo's work was threatening to the Catholic Church and its teachings, and because of the Church's encompassing power, Galileo was under intense pressure-indeed, was ultimately convicted by the inquisitors-to "restate" his views on the structure of the universe. ${ }^{298}$ Galileo's recantation was the result, not of scientific observation, but of religious persecution and the very real threat of a horrible death. ${ }^{2.99}$ The situational forces behind Galileo's "restated" views are thus unmistakable. Galileo made his recantation decision with the equivalent of a gun to his head. Of course, as we have argued

That the [E] arth is neither the center of the world nor motionless but moves even with diurnal motion is philosophically equally absurd and false, and theologically at least erroneous in the Faith.

Sentence of June 22, 1633, in THE GALILEO AFFAIR, supra note 234, at 287-88.

297 The adherence to the Ptolemaic model by university professors was a recurrent theme in Galileo's attempt to bring forth evidence to support the Copernican view. Professors from Pisa to Bologna to Padua rejected the telescope: Magini, professor of astronomy in Bologna, promised the new planets would be "extirpated from the sky." DE SANTILLANA, supra note 286, at 9.

${ }^{298}$ Daniel Boorstin nicely summarizes the sweeping threat of Galileo's findings to the fabric of conventional theological and philosophic understandings of the universe:

Each of his simple observations shook another pillar of the AristotelianPtolemaic universe. Now, with his very own eyes, Galileo had seen fixed stars beyond his capacity to count them (Was the Universe infinite?). He had seen that the moon was not more perfect in shape than the earth itself (Was there perhaps no difference, after all, between the substance of celestial bodies and that of the Earth?). The Milky Way then proven to be simply a mass of countless stars (Was there nothing, after all, to the Aristotelian theory of celestial exhaltations? Were heavenly processes not essentially different from those on Earth?).

BOORSTIN, supra note 285 , at 320 .

${ }^{299}$ See SOBEL, supra note 290 at 4, 171 (describing how Dominican friar Giordano Bruno was burned at the stake in 1600 in Rome for asserting heliocentric views of the world, a fact of which Galileo was aware). 
throughout this Article, such situational pressures are rarely so obvious.

This can all be expressed, somewhat stylistically, in Stiglerian terms. In recanting, Galileo was "captured" by the Church much like, say, the now defunct Civil Aeronautics Board was once said to be captured by the airline industry. ${ }^{300}$ He claimed to be saying what he believed "with sincere heart and unfeigned faith," ${ }^{301}$ independent of any pressure from the Church, when in fact he was serving the Church's interests, despite his own beliefs.

\section{Deep Capture: History Repeating Itself}

[T]here have been opened up to this vast and most excellent science, of which my work is merely the beginning, ways and means by which other minds more acute than mine will explore its remote cormers.

- Galileo Galilei ${ }^{302}$

\section{Some Deep Implications of Shallow Capture}

In identifying the phenomenon of capture, Stigler and his contemporaries obliterated the once-conventional view of regulation. They refuted the naive presumption that had long been protected behind the ambiguous (and, therefore, easily defended) concept of "the public interest," and provided a far more realistic (albeit disturbing) account of the sources and effects of regulation. Regulation was "caused" less by public-spirited and well-advised regulators and more by the situational constraints imposed upon them by competing economic entities, with the most powerful entities wielding the most influence. In other words, Stigler, identified and substantially overtumed what might be called the regulatory fundamental attribution error. The older "public interest" regulatory theory maintained a kind of dispositionist view of a constant figure, evaluating influences, measuring public welfare, and

${ }^{300}$ See generally Bradley Behrman, Civil Aeronautics Board, in WILSON, supra note 238 , at 75 .

${ }^{301}$ Galileo's Abjuration of June 22, 1633, in The Galileo AfFaIR, supra note 234, at 292, 292.

Galileo Galilei, Two New Sciences 153-54 (Henry Crew \& Alfonso De Salvio, trans., Macmillan 1914) (1638). 
making decisions accordingly. ${ }^{303}$ Regulatory theory essentially rested on a view of the regulator as a rational actor whose stable preferences were in the public interest. By studying the regulator's actions and ignoring the regulator's words, economists like Stigler were able to see new patterns and surmise some of the situational influences that generated them.

But Stigler's work barely breaks the surface of situationism and identifies only a very shallow form of capture. When one takes seriously the power of the situation-exterior and interior ${ }^{304}$-one can begin to understand the potential depths of capture. There are several ways in which capture is likely to run much deeper than Stigler, or others applying and advancing his insights, have recognized.

\section{The Depth of Capture}

Again, returning to Galileo's story may help make evident what is invisible in our midst. First, as the Catholic Church's efforts revealed, there are other capture-worthy and capturable institutions and individuals beyond merely administrative regulators. Recall that Galileo had no official regulatory authority either in the state or in the Church. What he had was a certain level of public legitimacy, and therefore power, as a renowned scientist. ${ }^{305}$ His theories, evidence, and conclusions were important as a confirmation of, or challenge to, the "truth" of the Church's teachings. ${ }^{306}$ As a result, Galileo's positions were well worth capturing. Similarly, today any institutions or individuals capable of influencing existing wealth and power distributions will be subject to the pressures of capture. In this sense, Stigler and those who subscribe to his theory are, like the public-interest theorists they replaced, far too shallow.

If administrative regulators are vulnerable to the forces of capture by certain interests, as most everyone agrees they are, then

${ }^{309}$ See STIGLER, supra note 70 , at $114-15$ (asserting that recent theories on government behavior no longer attribute public policies to the suggestions of informed economic advisors, but rather characterize policies as a response to pressure from interested parties who aim to benefit from them).

${ }^{304}$ See supra Part II.E (briefly describing "interior" and distinguishing it from "exterior").

${ }^{305}$ See SOBEL, supra note 290, at 6-7 ("Galileo found himself lionized as another Columbus for his conquests ....").

${ }^{306}$ Id. at 11-12 (describing Galileo's complex relationship with religion and the Catholic Church). 
the likelihood of a deeper capture seems undeniable. There is nothing special about administrative regulators-except, perhaps, the general concern that they may be captured. Virtually every other institution in our society seems just as vulnerable. After all, contemporary scholars and commentators have rarely even considered, much less taken seriously, the problem of deep capture. Given that nescience, one would expect other institutions to be constructed without heed to the dynamics of capture. In a world without foxes, a farmer will not guard the hen-house. And because deep capture occurs situationally-outside of view by, and with the induced consent of, the captured-any loss of eggs will either go unnoticed or will be perceived as natural and just.

There is a second general way in which traditional capture theory is too shallow. To see this, it is necessary to look deeper than the behavior of the captured institutions and individuals. Beneath the surface of behavior, the interior situation of relevant actors is also subject to capture. Indeed, much of the power of deep capture comes from the fact that its targets include the way that people think and the way that they think they think.

The Catholic Church would have been far less troubled by Galileo, we suspect, if he had not been writing and publishing his ideas broadly in an attempt to persuade others to reject thenconventional wisdom. ${ }^{307}$ Eschewing the scientific conventions of his day, Galileo published many of his discoveries not in Latin but in Italian. He was committed to altering the opinions of people in his society, not simply to recording his measurements for a narrow scientific audience. ${ }^{308}$ It was the danger Galileo posed to the Church's basic knowledge structures-which were embraced by most of the intelligentsia and lay people of the time-that led forces, including vested academic interests, to urge the Church to literally

${ }^{307}$ Galileo was well-known and well-liked by prominent Catholics, including the Medicis and Pope Urban VIII. DE SaNTILlana, supra note 286, at 118, 160-62. Thus, the pressure applied by the Inquisitors might have been reduced had Galileo attempted only to persuade fellow professors or the Church hierarchy. By taking his case to the Italian prelates, princes, gentlemen, and men of business, however, and by writing in Italian rather than Latin, Galileo presented a significant challenge to the Church. See Mario Biagioli, Galileo, Courtier: The Practice of Science in the CULTURE OF ABSOLUTISM 33-37 (1993) (analyzing Galileo's use of patronage relationships as a source of power throughout his career).

${ }^{308}$ See BoORSTIN, supra note 285, at 323-25 (describing Galileo's campaign to "interest literate laymen in this new way of thinking"). 
capture Galileo. ${ }^{309}$ Galileo's work went beyond offering a simple challenge to established propositions such as geocentric cosmology; it advocated an entirely different intellectual and moral approach, one that aimed to discredit the "cult" of tradition. ${ }^{310}$ Thus, when Galileo advanced heliocentricism, as he did in his famous letter to the Grand Duchess Christina, he did so in the context of a more comprehensive rejection of the view of knowledge as nothing more than a set of preordained revelations:

[W] ho wants the human mind put to death? Who is going to claim that everything in the world which is observable and knowable has already been seen and discovered? ... one must not, in my opinion ... block the way of freedom of philosophizing about things of the world and of nature, as if they had all already been discovered and disclosed with certainty. Nor should it be considered rash to be dissatisfied with opinions which are almost universally accepted ....

The message that common sense notions should be challenged was deeply threatening to the Catholic Church of the seventeenth century, which defined faith as it had since the Middle Ages-as obedience to the teachings of religious authorities. The highest crime an individual could commit was that of heresy-the word itself deriving from the Greek word hairesis, meaning "choice."

${ }^{309}$ Following the guilty verdict, at which time he was seventy years old, Galileo was imprisoned in his own home for the remainder of his life. Like so many radicals before and after him, Galileo continued his work while imprisoned, smuggling out of captivity two books for publication under an assumed name, which would ultimately become the basis for the theory of dynamics and gravity developed by Sir Isaac Newton. Boorstin notes that Galileo's imprisonment was mitigated somewhat before his death:

Eventually the Pope allowed him the companionship of a young scholar, Vincenzo Viviani, who reported Galileo's death on January 8, 1642, a month before his seventy-eighth birthday. "With philosophic and Christian firmness he rendered up his soul to its Creator, sending it, as he liked to believe, to enjoy and to watch from a closer vantage point those eternal and immutable marvels which he, by means of a fragile device, had brought closer to our mortal eyes with such eagerness and impatience."

Id. at 326-27.

${ }^{310}$ See REDONDI, supra note 287 , at 501.

${ }^{311}$ Galileo's Letter to the Grand Duchess Christina (1615), in THE GallLeO AFFAIR, supra note 234 , at $87,96-97$.

${ }^{312}$ BERNARD HAMILTON, THE MEDIEVAL INQUISITION 13 (1981). Heresy extended far beyond the act of challenging the Church's central theological teachings; any intellectual project that called into question the Church's fundamental intellectual authority was subject to censure. Thus, Cardinal Bellarmine condemned the Copernican cosmology as heretical not only (or principally) because it ran afoul of a few passages in the Bible, but because it stood in sharp contrast to a fundamental Aristotelian law of physics, which said that "the [E]arth, insofar, as it is the greatest 
to prevent the wider populace from realizing that a "choice" existed, Galileo had to be silenced.

Those in power thus captured the institutions and individuals that threatened their dominant position, including an individual scientist capable of altering ideas or knowledge in a way that might weaken their power. They did so through a process intended to suggest that Galileo freely chose his recantation and resultant silence. Galileo, wisely, did not proclaim that he was being forced to recant under the threat of death; he stated instead that he was trying to clarify the possible confusion that his errors had created and make clear that he, upon reflection, "abjure[d], curse[d], and detest[ed] the above-mentioned errors and heresies...."313 The Church thus applied situational pressure to generate the appearance of "dispositional" recantation. And the people at that time, inasmuch as their knowledge structures and understanding of the world were influenced by the Church, and insofar as the Church managed to squelch other ideas or knowledge structures, were also deeply captured.

Understanding that capture is directed at both our exteriors and interiors clears up some confusion and debate in the shallow capture literature. When Stigler's evidence of capture emerged, economists, political scientists, and public choice theorists got busy trying to identify the precise mechanics of the regulatory black box that Stigler mostly ignored. True to form, they began with the rational actor model of human behavior and sought to explain capture as the consequence of the self-interested, maximizing dispositions of individual regulators. ${ }^{914}$ Yet, while simple formulations have given way to increasingly elaborate ones, ${ }^{315}$ public-choice theory is still dogged by the fact that it is unrealistically "cynical" (meaning that the assumed dispositions of regulatory actors are perceived to be

weight, tends naturally to that natural point which is the center." REDONDI, supra note 287, at 39. Because the Church had accepted Aristotle as the final authority on the laws of nature, all others were bound to do the same. Id.

${ }^{313}$ Galileo's Abjuration of June 22, 1633, in THE GALILEO AFFAIR, supra note 234, at 292 .

314 This is yet another example of the tendency to infer dispositions from actions. See supra text accompanying notes 150-78 (describing several experiments in which participants tended to overestimate the role of disposition even when situational influence should be obvious).

315 See, e.g., Donald P. GReEn \& IAN Shapiro, Pathologies of Rational Choice Theory: A Critique of Applications in POlitical SCIENCE 47-71 (1994) (analyzing the failure of traditional rational choice theory to explain voter turnout). 
unrealistically selfish). After all, many governmental actors and regulatory agents often claim, and actually seem to be, motivated by the public interest and try to act that way; ${ }^{316}$ that is, many regulators' actions appear more consistent with their ideological beliefs than with a narrow conception of self-interest. ${ }^{317}$

The problem with shallow capture is not that it cannot always explain the part played by the dispositions of regulatory actors, but rather that it takes dispositions so seriously in the first place. Deep capture makes clear that people's intentions and beliefs may have little to do with their behavior and that, insofar as they do, those intentions and beliefs are part of what interests compete to capture.

When Catholic astronomers of the seventeenth century stated that they believed, as most profoundly did, that the Earth was at the center of the universe, deep capture was at work. Their astronomy was part of a larger, interconnected set of truths taught to them in seminary and reinforced at many turns-some seen, some unseen -in their society. Similarly, lay people had no reason to dispute those truths and faced situational influences just as powerful, despite being less visible, as the gun to the head or fire to the feet that Galileo experienced. That a regulator may act out of ideological dispositions no more implies that she is free from capture than the changing lengths of shadows on a summer afternoon implies that the sun is revolving around the Earth.

${ }^{316}$ See, e.g., Mark Kelman, On Democracy-Bashing: A Skeptical Look at the Theoretical and "Empirical" Practice of the Public Choice Movement, 74 VA. L. REV. 199, $217-23$ (1988) (arguing that shifts in public policy demonstrate that public leaders are not motivated purely by self-interest); see also DANIEL A. FARBER \& PHILIP P. FRICKEY, LAW AND PUBLIC CHOICE: A CRITICAL INTRODUCTION 31 (1991) (describing evidence that "one factor in how a legislator votes is simply that legislator's view of the public interest").

${ }^{317}$ See FARBER \& FRICKEY, supra note 316, at 24-25, 28-33 (discounting the public choice theory as the sole explanation for legislators' actions). In such circumstances, the literature sometimes accommodates such ideological behavior by treating it as a manifestation of self-interest. See generally Joseph P. Kalt \& Mark A. Zupan, Capture and Ideology in Law and Economics, 74 AM. ECON. REV. 279 (1984); James B. Kau \& Paul H. Rubin, Self-Interest, Ideology, and Logrolling in Congressional Voting, 22 J.L. \& ECON. 365 (1979). Instead of pursuing the analytic inquiry that this increasingly non-falsifiable definition of self-interest would entail, scholars relying on it typically just move on, leaving the dispositionist rational actor whole and ready to be employed for the next analysis. A critical realist approach places the exploration of the nature of preference formation, and the location of its influences, at the start of an analytic inquiry, instead of avoiding it as an unfortunate impasse to simple, if unrealistic, analyses and seemingly clear policy conclusions. 
The question that should be asked is not: "Who among the regulators is corrupt or so selfishly motivated as to disregard the 'public interest?" The question that should be asked is: "Who among us is the most powerful and most capable of deeply capturing our exteriors and interiors and, even, of capturing what we mean by the "public interest?"”

\section{The Invisibility of Capture}

By "deep capture," then, we are referring to the disproportionate and self-serving influence that the relatively powerful tend to exert over all the exterior and interior situational features that materially influence the maintenance and extension of that powerincluding those features that purport to be, and that we experience as, independent, volitional, and benign. Because the situation generally tends to be invisible (or nearly so) to us, deep capture tends to be as well.

This raises the question: if deep capture is so hard to see, then why is it so obvious in the Galileo example? There are several reasons. To begin with, at the time, we doubt that it was so visible. We suspect that few observers saw anything untoward or illegitimate about Galileo's inquisitorial experience or any reason to doubt the "knowledge" that it produced. ${ }^{318}$ The situational pressures that, to us, were glaringly excessive during the Inquisition were probably not perceived as excessive at the time. ${ }^{319}$

The situational forces confronting Galileo may be easier for us to see now because we live in a radically different environment. We are looking at another generation of people in another country

${ }^{318}$ Cf. REDONDI, supra note 287, at 303 (suggesting that news of Galileo's condemnation, although greeted "by a salvo of Aristotelian criticism," did not rise above the level of "routine academic skirmishes"). Galileo's trial itself was, of course, a hidden proceeding-a series of private interrogations that the world did not learn about until after the fact. Id. at 326 .

${ }^{319}$ Such situational pressures are less likely to be visibly employed today. The fact that burning people at the stake is now considered to be an unacceptable violation of human rights does not mean that blatant situational force is no longer used to elicit the appearance of free, voluntary action. The still-significant problem of "forced confessions" is just one of many possible examples of that phenomenon. See Jim Dwyer \& Kevin Flynn, New Light on Jogger's Rape Calls Evidence into Question, N.Y. TIMES, Dec. 1, 2002, at Al (discussing recent evidence that the convictions in the Central Park jogger rape case were based on confessions that likely were coerced); Susan Saulny, Convicions and Charges Voided in ' 89 Central Park Jogger Attack, N.Y. Times, Dec. 20, 2002, at A1 ("[L]awyers for three of the men ... contend that the confessions were coerced by the police."). 
whose situational worldviews we reject and whose victim, Galileo, we revere. $^{320}$ They are "them," and Galileo is "us." People are motivated to attribute bad outcomes to in-group members. ${ }^{321}$ The contrast is heightened by the historical construction of the event as a lesson on the horrors of the Inquisition and the dangerous distortions that result when religion is allowed to dominate (or, we might say, "capture") science. The role of disposition and deep capture in the Galileo story is, today and to us, conspicuous, almost palpable. But seeing our own situation and its deep capture is not.

\section{Learning from History}

For some of the same reasons that it is difficult to convince people that they would have been influenced by the situational cues in the Milgram experiment, ${ }^{322}$ it is nearly impossible to convince people that they live in, and are part of, a deeply captured world. To make our preliminary case, therefore, we will attempt to demonstrate that the situation today is very similar to the situation that existed in Galileo's Italy. Because the existence of deep capture is easy to see and accept there, by observing it, we may be better able to see and accept deep capture now. Perhaps by seeing that we are subject to a parallel influence over a parallel issue, we may be able to more clearly see ourselves, not in the heroic Galileo, but in the complacent and complicit adherents of the common sense of his day, or even in the reactionary Bellarmine.

\section{a. Institutions to deeply capture}

The first parallel is the existence of an institution or collection of institutions with immense wealth and power and, thus, both the ability and desire to influence exterior and interior situations to enhance those advantages. In the Galileo story, that collection of

320 The rehabilitation of Galileo as an object of reverence was not accomplished until the nineteenth century, when his cause was taken up by radicals like Auguste Comte who portrayed him as a "martyr of the religion of humanity." REDONDI, supra note 287 , at 321 . Today, Galileo is depicted in a similar-if not somewhat anachronistic-light as a great crusader for scientific fact against the superstitious monolith that was the early modern Catholic Church. As the Indigo Girls sing, "Galileo's head was on the block, the crime was looking up the truth." INDIGO GIRLS, Galileo, on RITES OF PASSAGE (Sony Music Entertainment 1992).

321 See Hanson \& Yosifon, supra note 30 (describing some phenomenon between groups); supra note 110 (discussing actor-observer bias).

${ }^{322}$ See supra text accompanying notes 86-100 (outlining the Milgram experiment). 
institutions is, for the sake of simplicity, often treated as an individual actor under the heading of "the Catholic Church" or "the Vatican." Today, we hypothesize that the institutions with the means and the motive to engage in deep capture are large corporations. ${ }^{393}$ In virtually any present metric and manner of understanding power, corporations easily qualify as immensely powerful.

Let us start with corporations' immense wealth, a fundamental component of power in our market economy. As is so often emphasized by legal economists, resources have a tendency through market processes to move to those who value them most, as measured by relative willingness to pay. ${ }^{324}$ Willingness to pay, of course, is heavily determined by ability to pay. No institutional actor controls as much wealth in so concentrated a fashion in our society today as do corporations and those individuals with an important stake in promoting the power of corporations. ${ }^{325}$ Thus, valuable resources (including influence over the situation) tend toward those with the greatest ability to pay-that is, corporations.

Large corporate interests have several other power advantages beyond their wealth-advantages that likely help them to amass that wealth in the first place. For instance, like Stigler's beekeepers, ${ }^{326}$ they enjoy a common single interest and thus an advantage in the competition to influence-an assertion that finds considerable support in the shallow capture literature. ${ }^{327}$ Insofar as each corporation is devoted to the single goal of profit maximization, they are, even as they compete in the marketplace, collectively committed

${ }^{323}$ Of course, there are many dimensions of power, many of them overlapping. We believe that this theory also predicts the operation of power in other social institutions and along other dimensions and sources of power, including species, gender, race, ethnicity, sexual orientation, age, and physical attractiveness.

${ }^{324}$ See supra text accompanying notes $117-21$ (discussing the ways in which measuring value by willingness to pay highlights a disposition while overlooking an important situational element-namely, ability to pay).

${ }^{325}$ See supra note 253 (providing evidence of the wealth controlled by corporations). Corporate interests, to be sure, are not without competitors, such as churches, foundations, nonprofit organizations, labor unions, trial attorneys, aggregations of consumers, and individual consumers. In subsequent work we hope to examine the relative power of such institutions vis-à-vis corporations, and also the ways in which all of those institutions are themselves targets of deep capture by large commercial interests.

${ }^{326}$ See supra text accompanying note 280 (describing beekeepers' advantages over honey consumers in influencing beekeeper regulations).

${ }^{327}$ See supra Part V.A (summarizing that literature) 
to a uniform regulatory end: the creation and maintenance of a world that maximizes profit opportunities. ${ }^{328}$

Moreover, corporations are-in part because of market processes-profoundly effective at uncovering and exploiting the most efficient and reliable means of influencing people and institutions, a pursuit that will extend through situational influences. ${ }^{929}$ Advertising, marketing, lobbying, and public relations are only the most obvious activities that corporations have refined in their profitmaximizing pursuits. Even those practices are largely obscured by our dispositionism and largely invisible in our theories ${ }^{330}$-an obscurity that renders them all the more effective. In future work, we hope to describe those practices in more detail. For now, our point is that the situation of market competition has led corporations to become far more expert at manipulating situational factors than other institutions or individuals have had the need or wherewithal to accomplish.

Finally, the livelihood or economic well-being of the majority of our population is perceived to depend directly or indirectly on the health of corporations-individually and collectively. For example, many people work for corporations, many people invest in corporations, and, more generally, the overall health of the economy, in which most of us feel we have a significant stake, is perceived to depend on the collective health of corporations. Corporate scholars Henry Hansmann and Reinier Kraakman, for instance, recently described the expanding base of shareholders as follows:

Stock ownership is becoming more pervasive everywhere. No longer is it confined to a small group of wealthy citizens. In the United States, this diffusion of share ownership has been underway since the beginning of the twentieth century. In recent years, however, it has accelerated substantially. Since the Second World War, an ever-

${ }^{328}$ See supra text accompanying notes $257-59$ (briefly describing shared commercial ends); Chen \& Hanson, Illusion of Law I, supra note 84 (analyzing the schemas of corporate law and how it benefits corporate interests)

${ }^{329}$ See Hanson \& Kysar, Taking Behavioralism Seriously I, supra note 251, at 724-43 (describing and predicting methods by which manufacturers manipulate consumers); Hanson \& Kysar, Taking Behavioralism Seriously II, supra note 251, at 1428-1501 (illustrating consumer manipulation tactics, including those used by the tobacco industry).

${ }^{330}$ See Hanson \& Kysar, Taking Behavioralism Seriously I, supra note 251, at 725 ("[S]cholars... have failed to see that manufacturers can take advantage of such manipulability." (emphasis omitted)); Hanson \& Kysar, Taking Behavioralism Seriously II, supra note 25l, at 1548-49 (describing "Viscusi's failure to consider how the industry itself might have influenced consumer risk perceptions and preferences"). 
increasing number of American workers have had their savings invested in corporate equities through pension funds. Over the same period, the mutual fund industry has also expanded rapidly, becoming the repository of an ever-increasing share of nonpension savings for the population at large.

This is not just an academic point. President George W. Bush has been emphasizing this theme repeatedly in the wake of corporate debacles since he took office. In response to Enron revelations, for instance, he explained:

The reason that a single bankruptcy can cause so much concern in America is that more Americans than ever have invested their money in public corporations. Today, about 80 million Americans own stock, either individually or through their pension plans. This is one of the causes for the expansion in personal wealth over the past 20 years. This has been an incredibly positive development for America. Stock ownership allows citizens from all walks of life to own a part of the economy and to share in its growth. The people who run public companies owe a special obligation to these investors, many of whom have put their savings and future security on the line. ${ }^{339}$

The widespread sense that our collective welfare turns importantly on the wealth and success of corporations empowers corporations. It does so by giving the general population a stake in the health of those institutions that are already the most wealthy and influential in our culture. As Hansmann and Kraakman put it:

No longer do labor and capital constitute clearly distinct interest groups in society. Workers, through share ownership, increasingly share the economic interests of other equity-holders. Indeed, in the United States, union pension funds are today quite active in pressing the view that companies must be managed in the best interests of their shareholders.

${ }^{331}$ Henry Hansmann \& Renier Kraakman, The End of History for Corporate Law, 89 GEO. L.J. 439, 452 (2001) (citations omitted).

${ }^{332}$ President George W. Bush, President Outlines Plan to Improve Corporate Responsibility, Remarks at Malcolm Baldrige National Quality Award Ceremony (Mar. 7, 2002), available at http://www.whitehouse.gov/news/releases/2002/03/200203073.html; see also President George W. Bush, President Reiterates Call for Corporate Responsibility, Remarks to Employees of America II Electronics (Mar. 8, 2002), 2002 WL 14547111 ("We've got thousands of citizens who own shares of publicly held companies, many in pension plans, mutual funds, a lot of them direct ownership. And this country must hold corporate CEOs-CEOs of publicly held companies, to the highest of high standards."), available at http://www.whitehouse.gov/news/ releases/2002/03/20020308-4.html.

${ }^{333}$ Hansmann \& Kraakman, supra note 331, at 452. 
In this way, according to Hansmann and Kraakman, "a public shareholder class" has developed into "a broad and powerful interest group in both corporate and political affairs across jurisdictions" promoting corporate interests. ${ }^{334}$

\section{b. Fundamental attribution errors}

The second major parallel between our world and Galileo's is the existence of a widely held attributional intuition that is false, but generally viewed as a "truth"-and an obvious one at that. At that time, it was about what, if anything, moved the Earth and the celestial bodies "above" it. Now, it is about what moves us and our institutions. ${ }^{395}$

\section{c. Incentives to deeply capture}

The third parallel is that in our world, too, those in power have a stake in maintaining the apparent veracity of that "truth" and, thus, in heavily promoting it. Instead of the Catholic Church sustaining geocentricism and dismissing Galileo's observations regarding the role of astronomical situation, today, in our world, it is large corporate interests promoting dispositionism and dismissing observations regarding the influence of exterior and interior situations on behavior.

\section{i. The stakes of geocentricism}

To the Catholic Church, maintaining an allegiance to the biblical account of astronomical structure, no matter how logically dubious, was extremely important. Although Galileo himself saw no tension between his scientific findings and his Catholic faith, ${ }^{396}$ portions of

${ }^{834} I d$.

${ }^{335}$ Note that in both cases, the attributions are self-affirming. We like to see ourselves as thinking, free actors, and we like to think of our Earth as being placed, apparently by God, at the center of the universe.

${ }^{396}$ Galileo wrote that:

$[\mathrm{T}]$ hough the Scripture cannot err, nevertheless some of its interpreters and expositors can sometimes err in various ways... [ [N] ature is inexorable and immutable, and she does not care at all whether or not her recondite reasons and modes of operations are revealed to human understanding ....

... [T] $]$ herefore, whatever sensory experience places before our eyes or necessary demonstrations prove to us concerning natural effects should not in any way be called into question on account of scriptural passages whose 
the Catholic hierarchy saw in his discoveries the direct contradiction of several theological tenets. ${ }^{337}$ In their eyes, such weakened links threatened to destroy a whole chain of logic upon which the Church relied. ${ }^{338}$

The insistence on intellectual conformity in scientific and philosophical subjects was intimately connected to the Church's reaction to a far more fundamental challenge to its authority, that of the Protestant Reformation. That Galileo was linked in the minds of many Catholic Church leaders to the Protestant Reformation is ironic, since Galileo probably objected to the Protestant's literal interpretations of the Bible, if not their reformist spirit, even more than he did to Catholic orthodoxy. ${ }^{339}$ At the same time, Protestantism seemed to be advancing the same kind of challenge to core Catholic beliefs that Galileo's scientific approach posed to Aristotelian naturalism. ${ }^{840}$ On a broader level, at its inception, Protestantism was fundamentally anti-authoritarian in the sense that its leaders, beginning with Luther, encouraged the radical decentralization of religious authority and the rationalization

words appear to have a different meaning, since not every statement of the Scripture is bound to obligations as severely as each effect of nature.

Correspondence from Galileo to Castelli (Dec. 21, 1613), in THE Galileo AfFair, supra note 234 , at $49,49-50$.

${ }^{337}$ In 1546, at the Fourth Session of the Council of Trent, Church leaders launched the Counter-Reformation, declaring that:

$[\mathrm{N}]$ o one relying on his own judgment shall, in matters of faith and moral pertaining to the edification of Christian doctrine... presume to interpret [the Holy Scriptures] contrary to that sense which holy mother Church, to whom it belongs to judge of their true sense and interpretation, has held and holds, or even contrary to the unanimous teachings of the Fathers.

Maurice A. Finocchiaro, Introduction to THE GALILEO AFFAIR, supra note 234; see also id. at 11-12 (summarizing the political background of the Counter-Reformation).

${ }^{398}$ As one scholar of Galileo has noted:

Bellarmine's logic is relentless. If God is the author of Scripture, everything in the Bible is true, whether it is essential to salvation or merely a piece of accidental historical information. And his reason for this is of crucial importance. "It is necessary to believe them because they were zuritten." . . This truth condition, which is certainly not limited to only Bellarmine's presentation, was clearly destined to clash with Galileo's scientific standard of truth.

Richard J. BlackWell, Galileo, Bellarmine, AND the Bible 32 (1991).

339 Cf. DE SANTILlana, supra note 286, at 326-27 (noting that Galileo was an "anticlerical Catholic," not a Protestant).

${ }_{340}$ See REDONDI, supra note 287, at 209 (describing the Protestant challenge to the Catholic doctrine of transubstantiation). 
of scriptural interpretation. The result was a more personal, individualized experience and interpretation of the scriptures. To the Catholic hierarchy, this was the work of the devil. And maintaining a strict biblical understanding of astronomy was of critical importance in their broader battle against diabolical corruption of Church dogma. ${ }^{341}$

\section{ii. The stakes of dispositionism}

Similarly, today, large corporate interests have a great deal at stake in maintaining and promoting a dispositionist worldview. As we argued earlier, it is possible to speak of a "corporate interest" in maximizing profit not because corporations are dispositionally motivated, but because there are robust and stable situational pressures encouraging corporations to act "as if" they want to pursue that end. ${ }^{342}$

${ }^{341}$ The battle was not played out merely in the minds of Europeans-great armies also were clashing on European soil. On the eve of Galileo's trial, the Thirty Years War (1618-1648) was going extremely badly for the Catholic side. In 1632, the Protestant King of Sweden, Gustavus Adolphus, broke through the armies of the Catholic Holy Roman Emperor in Germany and advanced on Italy. He probably would have crossed the Alps and marched on Rome itself but for his own untimely death that same year. See id. at 231. It was at this time, in February of 1632, that Galileo published The Dialogue, in which he called into question the entire framework of Aristotelian cosmology advanced by the Church. See DE SANTILlanA, supra note 286 , at $38,186$. (acknowledging dispute between Galileo and Aristotelians and citing 1632 as the date of publication). So it was that Galileo slammed into an entire framework of intellectual, spiritual, and political power and authority that already felt itself to be under attack. Consequently, the Pope was in no mood to be indulgent, especially since Bellarmine had forbidden Galileo to advance heliocentrism in 1616. In response to a plea by the Tuscan ambassador for lenience, the Pope supposedly "exploded in anger," saying that in his "perverse material," Galileo had, "dared enter where he should not, into the most grave and dangerous subjects that one could possibly raise at the moment." REDONDI, supra note 287, at 256.

Had Galileo and his discoveries come earlier, at a time when the Catholic Church was not losing power and influence, his findings and ideas might have met a more hospitable audience. Indeed, it was not until well into the twentieth century and the current Pope's tenure that the Church apologized for silencing Galileo. See William D. Montalbano, Earth Moves for Vatican in Galileo Case, L.A. TIMES, Nov. 1, 2002, at A3 ("The Roman Catholic Church has admitted to erring ... in formally condemning Galileo Galilei for entertaining scientific truths it long denounced as against-theScriptures heresy."); Alan Cowell, After 350 Years, Vatican Says Galileo Was Right: It Moves, N.Y. Times, Oct. 31, 1992, at Al ("More than 350 years after the Roman Catholic Church condemned Galileo, Pope John Paul II [will] rectify one of the Church's most infamous wrongs-the persecution of the Italian astronomer and physicist for proving the Earth moves around the Sun.").

${ }^{342}$ See supra text accompanying notes 248-51 (noting the situational pressures on market actors to maximize profits); see also Hansmann \& Kraakman, supra note 
And, in a similar vein, just as one can speak of corporations' individual interests, one can also speak of their shared or collective interest. Although corporations are often in direct competition with one another, they share a collective interest in maximizing profitswhich translates to an interest in maximizing available markets and minimizing profit-reducing regulation. Phenomena such as trade associations for lobbying, industry- and sector-wide advertising and public relations, and illegal collaborative activities such as pricefixing, evince these shared interests amongst competitors. ${ }^{343}$ Coordinated lobbying efforts for policy initiatives like NAFTA ${ }^{344}$ and for one-or-another political candidate, ${ }^{345}$ demonstrate a shared corporate interest across markets. But corporations share an interest in more than just promoting, for example, global trade policy. They also share a deeper interest in promoting certain perceptions of global trade policy, and of many other issues that can influence their common pursuit of profits. It is our contention that a dispositionist worldview benefits both individual corporations and the shared corporate interest, and that corporations therefore individually and jointly will act situationally to promote it. Because this claim is a major feature of our larger thesis, and because defending it is somewhat complex, it will be the topic of a separate article. ${ }^{346}$ We urge the reader to accept, or at least suspend disbelief in, this claim until we can flesh it out and (we hope) thoroughly substantiate it. For now, we will only cursorily highlight portions of that article.

One important reason that corporations have a stake in dispositionism is that it is the dispositionist perspective that largely justifies their profit-seeking behavior as socially beneficial. If consumers are assumed to be dispositional-that is, if they act according to a stable set of preferences that only they can access directly-then it plausibly follows that the best way to maximize

331, at 441-42 (describing the "interests" of institutions-profit maximization); Chen \& Hanson, Illusion of Law I, supra note 84 (describing those situations in detail).

${ }^{349}$ See also supra notes 256-60 and accompanying text (making a related point and providing some evidence in support).

${ }^{344}$ See Coalition of Business Interests is Mobilizing Support for NAFTA, 10 Int'l Trade Rep. (BNA) 314, at 314-15 (Feb. 24, 1993) (reporting that a coalition of business interests comprised of over a thousand organizations was lobbying in support for NAFTA).

${ }^{345}$ See David R. Lagasse, Undue Influence: Corporate Political Speech, Power and the Initiative Process, 61 BROOK. L. REv. 1347, 1385 (1995) (describing the collaborative creation of the Business Roundtable as a corporate lobbying organization).

${ }^{346}$ See Jon Hanson, Adam Wright \& David Yosifon, The Situational Stakes of Dispositionism (unpublished manuscript, on file with authors). 
welfare is to allow consumers to satisfy their preferences through free-market transactions. It is through free markets that otherwise invisible preferences are satisfied (and revealed) through mutually beneficial transactions that enhance overall social welfare. As profitmaximizing entities, corporations act to maximize social welfare by serving consumers' supposed dispositional preferences. Profit is the substantiation of those welfare-enhancing transactions and is therefore, by definition, good. In short, profit-maximizing corporations act in the public interest. ${ }^{347}$

A dispositionist worldview is similarly valuable to the corporate interest because it helps minimize profit-reducing regulation. Markets, which allow the free exercise of dispositions, are understood as more responsive to consumer preferences than regulators who lack good information and the appropriate incentives. The dispositionist presumption translates to a presumption against regulatory intervention even against visible harms, for the actors involved are presumed to be choosing the inevitable risks that gave rise to those harms. Regulatory intervention is warranted only in circumstances in which markets demonstrably fail to respond to consumer dispositions-for instance, when consumers clearly lack information or when a transaction creates significant negative externalities. But, even in the presence of such market imperfections, calls for regulation may be rebutted on the grounds that imperfect markets might be preferable to imperfect regulations. Expressions like "the nirvana fallacy" and "the law of unintended consequences" have been coined to capture this fallback defense of markets. ${ }^{348}$

Dispositionism also helps support common arguments for why regulators cannot be trusted. Regulators, like the rest of us, are presumed to be motivated to satisfy their self-interest, ${ }^{349}$ an end that is often in tension with their purported goal of serving the public interest. Regulators are often depicted as concerned with job security, career advancement, and larger budgets, as well-meaning but ill-informed bunglers, or as zealous intermeddlers seeking to note 84

${ }^{347}$ Aspects of this script are described in Chen \& Hanson, Illusion of Law I, supra

${ }^{948}$ See Melvin Aaron Eisenberg, Bad Arguments in Corporate Law, 78 GEO. L. J. 1551, 1551-52 (1990) (discussing the use of the Nirvana Fallacy to defend markets); Kenneth Sanney, Cyberjacking, Mousetrapping, and the FTC Act: Are Federal Consumer Protection Laws Helping or Hurting Online Consumers?, 3 VAND. J. ENT. L. \& PRAC. 221, 233 n.40 (2001) (defining the law of unintended consequences and discussing its invocation).

${ }^{349}$ See supra text accompanying notes 7, $303 \& 314$. 
impose their visions of society upon otherwise free consumers. Such dispositions are likely to lead to wrongful interference in free choices and, consequently, inefficient outcomes-the apparent dispositional mechanism behind Stigler's findings.

Another benefit of dispositionism is that it helps to preserve and legitimate the status quo, in which corporations are the wealthiest and most powerful entities. Dispositionism places consumers, not corporations, in the driver's seat. Corporations are viewed as competing to fulfill consumers' desires in a fair competition; they are viewed as having no role in creating or influencing consumers' behavior. If consumers are unhappy with one or another outcome of that competitive process, they are rebuffed with the observation that the process is fair and that consumers have no one but themselves to blame. If consumers claim not to like a given market outcome, they can be told to change their consumption choices, reexamine their perceived preferences, or take it up with their fellow consumers.

In addition, corporations gain in innumerable ways from the general human tendency-reflected in the fundamental attribution error-to attach disproportionate weight to what we see and to see only a small, salient subset of our environs and interiors. This phenomenon has many manifestations that tend to benefit large commercial interests. For example, when the situation is not obvious (as is generally the case), people believe they are acting autonomously when they are actually responding to unseen situational cues. Not only do they miss the situational influence, they don't believe there is a situational influence. Consumers are like competitors in a sprint, who, not seeing the track, presume that it is flat and fair. The runners measure their dispositions-talent and drive-according to the outcome of the race, without regard to its situation. In such a setting, corporations can camouflage their situational manipulations behind reassurances that those subject to them are, in fact, dispositionally moved. That same tendency permits corporations to attribute particularly egregious corporate activities to the dispositions of the handful of human actors involved or the rather unique corporate disposition (culture) of one corporation, and not to larger situational influences that might implicate, say, all corporations or all of corporate law.

Galileo's conflict with the Church was not a neutral scientific debate. It had profound implications for power-who would have it and how it would be wielded-in seventeenth-century Europe. Similarly, the divide between dispositionism and situationism is not 
an academic point. It has profound implications for the distribution of power in our society. Large corporations have a stake in a dispositionist worldview because it helps them create and maintain vast situational power. Indeed, by promoting a lopsided worldview, based on individual stable preferences and autonomous individual choices, corporations can actually curtail individual autonomy and alter perceived preferences. That is possible, we assert, because of dispositionism.

\section{The Deep Capture Hypothesis}

The universal spirit of the laws, of every country is always to favor the strong against the weak and those who have against those who have not. This difficulty is inevitable, and it is without exception.

-Jean Jacques Rousseau ${ }^{350}$

The twentieth century has been characterized by three developments of great political importance: the growth of democracy, the growth of corporate power, and the growth of corporate propaganda as a means of protecting corporate power against democracy.

-Alex Carey ${ }^{351}$

All of the key elements are in place. As with Galileo's capture, today we have an extremely powerful institutional force with an immense stake in maintaining, and an ability to maintain, a false, though intuitive, worldview. ${ }^{852}$ Our basic hypothesis (and prediction) is that large commercial interests act (and will continue to act) to capture the situation-interior and exterior-in order to further entrench dispositionism. Moreover, they have done so largely undetected, and without much in the way of conscious awareness or collaboration. Hence, large corporate interests have, through

${ }^{350}$ JEAN-JACQUES RouSSEAU, EMILE 236 (Allan Bloom trans., Basic Books 1979) (1762).

35. AlEX CAREY, TAKING THE RISK OUT OF DEMOCRACY: CORPORATE PROPAGANDA VERSUS FREEDOM AND LIBERTY 18 (Andrew Lohrey ed., 1995).

${ }^{952}$ It is important to note that the deep capture prediction that large commercial interests will wield disproportionate influence over "knowledge" is not limited to simply dispositionism and dispositionist tendencies. We use dispositionism as an extremely important example of pro-commercial "knowledge." For other examples, see Chen \& Hanson, Illusion of Law I, supra note 84 (describing the deeply-captured schemas of policymakers and corporate law). 
disproportionate ability to control and manipulate our exterior and interior situations, deeply captured our world.

This is a hypothesis that finds support not just in the axiom of history repeating itself, although the lessons of history do indeed provide significant support. And it is a hypothesis that follows from more than just laboratory and field experiments of social psychology, although that literature alone should be sufficient to reverse our current presumptions. ${ }^{35.9}$ The deep capture hypothesis is also the logical extension of several basic economic insights, including those associated with capture theory and market theory-informed by a realistic understanding of the human animal (or situational character). The question remains, however, whether such a provocative, counterintuitive hypothesis finds much support in the various institutions that shape our exterior and interior situation.

\section{SOME EVIDENCE OF THE DEEP CAPTURE HyPOTHESIS}

The deep capture hypothesis is too provocative to leave totally undefended, but covers too vast a set of institutions to adequately defend here. Much of the remainder of this Article, therefore, will be devoted to providing a sample of observations that provide support for our framework. The sample is intended to foster open minds in our readers (if not to thoroughly destabilize existing dispositionist worldviews) until we can return with a more fulsome defense of, and more compelling evidence for, our claims.

Here, we will attempt to show that history is, as usual, repeating itself-that we live in a world much like that of Galileo. ${ }^{354}$ The dispositionist worldview, which is so valuable to the most powerful institutions in our culture, is widely accepted in our population as common-sensical, even though that view is, according to the best available evidence, fundamentally lop-sided. Furthermore, those powerful institutions use their power to advance that view by actively promoting it themselves, by rewarding others who do so, and by seeking to penalize or delegitimate those who challenge it. Again, further evidence regarding (1) precisely how dispositionism is incorrect, (2) exactly how dispositionism serves large commercial interests (and not the public interest), and (3) how, in practice, deep capture occurs are the topics of research now in progress.

${ }^{353}$ See Hanson \& Yosifon, supra note 30.

${ }^{354}$ See supra pp. 307-12 (describing Galileo's struggle against the intellectual establishment of the Renaissance). 
In this Article, we are, like Stigler was, initially concerned with just the consequences of (de)regulatory actions. Unlike Stigler, however, we look less at who benefits from particular regulatory changes and more at what the regulators say, for it is in framing their regulations and in assuming one or another vision of the human being that they reveal their dispositionism. Furthermore, we define "regulation" far more broadly than Stigler did, to include, as we believe his analysis should have, all institutions that could possibly influence the fortunes of large commercial interests. ${ }^{355}$ In this Part, we will touch on only a few of those.

\section{A. Some Shallow Evidence of Deep Capture}

Experience should teach us to be most on our guard to protect liberty when the government's purposes are beneficial. Men born to freedom are naturally alent to repel invasion of their liberty by evil-minded rulers. The greater dangers to liberty lurk in insidious encroachment by men of zeal, well-meaning but without understanding.

-Justice Louis Brandeis ${ }^{\mathbf{3 5 0}}$

First, we will consider the view of human beings adopted by the sort of administrative regulatory institutions that Stigler and his cohorts did focus on. Take, for example, the Federal Communications Commission (FCC) and Chairman Michael Powell's ${ }^{357}$

${ }^{355}$ See supra text accompanying notes 305-17 (explaining why Stigler's shallow capture theory and evidence have far deeper implications than he appreciated).

${ }^{\$ 56}$ Olmstead v. United States, 277 U.S. 438, 479 (1928).

${ }^{357}$ Michael Powell, son of Colin Powell, was appointed by President Clinton to the Commission in 1997 and was designated Chairman by President Bush in 2001. Since joining the FCC, Powell's deregulatory rhetoric has coincided with wide-ranging deregulatory action. It may be helpful to highlight a few of the key deregulatory actions of the FCC within the past several months. On February 20, 2003, the FCC voted to eliminate regulations that required the Bell telephone companies to lease broadband Internet access to competitors at discounted rates. Jonathan Krim, FCC Delivers Mixed Vote on Competition: Phone Giants Prevail on High-Speed Internet, WASH. PosT, Feb. 21, 2003, at A1. On May 15, the FCC voted to eliminate a 40-year-old standard that restricted the leasing of airwaves. The new regulation allows airwaves license-holders to work out leasing deals without prior FCC approval. Yuki Noguchi, FCC to Let Companies Sublease Airwaves, WASH. POST, May 16, 2003, at E5. On June 2, the FCC relaxed regulations that limit the cross-ownership of newspapers and television stations. Frank Ahrens, FCC Eases Media Ownership Rules: Party-Line Vote Clears Way for More Consolidation, WASH. POST, June 3, 2003, at A1. The FCC regulation would combine two cross-ownership rules-one preventing newspaper and broadcast station ownership in the same city and another limiting radio and TV station ownership in the same market-into a single rule that would lift most current 
conception of consumers and the corresponding presumptions about markets and regulation:

I am committed to building policy that is centered around market economics. At times, this foundation of my thinking is often questioned as being somehow anti-consumer. In a television interview, the question goes something like this: "Many consumer groups express grave concern that your laissez-faire approach will harm consumers. They say you are out of touch with consumers and living in an ivory tower. What say you?"

I am always a little puzzled by this question, for the premise of it has been so thoroughly discredited in this nation and in countries around the world that it should be beyond challenge. Market systems, far from being the bane of consumers, have unquestionably produced more consumer welfare than any other economic model devised by mankind. How is it that anyone can argue that the pro-market policies of the United States have not yielded enviable productivity in our economy, jobs for our citizens, a higher standard of living than nearly any other country in the world, and a tradition of innovation and invention that has brought new products, tools and services to our citizens?

A well-structured market policy is one that creates the conditions that empower consumers:

It lets consumers choose the products and services they wantwhich is their right as free citizens.

....

It allows market forces to calibrate pricing to meet supply and demand. Consumers get the most cost-efficient prices and enjoy the benefits of business efficiencies.

The result for consumers is better, more cutting edge products, at lower prices.

Contrary to the classic bugaboo that markets are just things that favor big business and big money, market policies have a winning record of delivering benefits to consumers that dwarfs the consumer record of government central economic planning. Thus, if you are

restrictions. Frank Ahrens, FCC Plan to Alter Media Rules: Spurs Growing Debate, WASH. POST, May 28, 2003, at A1 [hereinafter Ahrens, FCC Plan]. The plan would substantially raise the number of television stations a company may own and allow a company to reach up to $45 \%$ of the national audience, up from $35 \%$. It would also relax a ban on newspaper and broadcast cross-ownership in local markets. Mark Wigfield \& John R. Wilke, FCC Plan Draws Fire: Senators Introduce Bill to Keep Current Media-Ownership Limits, WALL ST. J., May 14, 2003, at B4. The decision has met with strong resistance. Senators and House Representatives both sponsored bills that would return the cap on television ownership to 35\%. Frank Ahrens, FCC Rule Fight Continues in Congress: Opponents of Ownership Consolidation Also Plan Legal Strategy, WASH. PosT, June 4, 2003, at E1. In fact, on September 16, the Senate voted 55 to 40 to override all of the new media ownership rules. Frank Ahrens, Senate Votes to Block FCC Media Rules, WASH. POST, Sept. 17, 2003, at A14. The White House has refused to back down. Id. 
truly committed to serving the public interest, bet on a winner and bet on market policy. ${ }^{358}$

Thus, Powell views consumers as "free citizens," who should therefore be allowed to "choose the products and services they want." And, according to that conception of consumers, free choice should be enabled through "market systems," which are the best mechanism ever "devised by mankind" for "delivering benefits to consumers," "empower[ing] consumers," and thereby producing "more consumer welfare." $"$;:9

There are other noteworthy features of Powell's remarks. For example, Powell frames his goals in terms of serving the "public interest," but this is the same type of assertion that Stigler claimed could not be trusted. ${ }^{360}$ And certainly this "trust" issue has been raised. $^{361}$ But Powell reassures critics by claiming that deregulation tends toward the "public interest:" "In capital[ist] economies," he writes, "the central premise is that the interests of producers (i.e., money-makers) and consumers need not diverge, but, in fact, can be synchronous. $^{362}$ That may be true, but it is equally true that a

358 Michael K Powell, Chairman, Federal Communications Commission, Consumer Policy in Competitive Markets, Remarks Before the Federal Communications Bar Association, at http://www.fcc.gov/Speeches/Powell/2001/spmkp106.html (June 21, 2001).

${ }^{359}$ Id.; see also Stephen Labaton, Policy Defeat Puts F.C.C. Chief in Awkward Spot, N.Y. Times, Feb. 22, 2003, at C1 ("Powell ... has set an ambitious agenda of relaxing or removing many regulations that have limited the nation's largest media conglomerates from becoming bigger or entering new markets.").

${ }^{360}$ See supra text accompanying notes 282, 303 (describing Stigler's critique of the supposed neutrality and public spirit of regulatory agencies).

${ }^{361}$ At a three-hour hearing on June 4, 2003, before Republican Senator John McCain's Committee on Commerce, Science and Transportation, many senators expressed criticism over several of Powell's FCC decisions, most prominently the vote to allow broadcast networks to buy more television stations. See, e.g., Frank Ahrens, Senators Attack FCC Rules: Most on Oversight Panel Sign on to Revise Changes, WASH. POST, June 5, 2003, at E4 ("'It looks for all the world like you could not or would not stand up to corporate interests ....") (quoting Democratic Senator Byron L. Dorgan); id. ("Where in the world do you find the grounds for 45 percent?") (quoting Democratic Senator Ernest F. Hollings).

${ }^{362}$ Powell, supra note 358. Much of Powell's rhetoric is based on the idea that regulations inhibit innovations that would directly benefit the public. In defending the vote to allow airwaves license-holders to lease without prior FCC approval, Powell said, "'[o] ur decision unlocks value trapped for too many years in a regulatory box." David Ho, FCC Votes to Let Cell-Phone Firms Lease Airwaves, PHILA. INQUIRER, May 16, 2003, at C2 (quoting Powell). He added that the decision "'will expand spectrum access for innovators and entrepreneurs, increasing the number and variety of wireless applications available to consumers." Id. (quoting Powell). 
central premise behind regulation is that the interests of producers and consumers sometimes do diverge. As if to respond to that potential criticism, Powell takes a page from Stigler's scholarly agenda, writing:

I am the first to admit that deregulation for its own sake is not responsible policy. What is good policy is to carefully examine rules to determine if they are actually achieving their stated purposes, or if, instead, they are, in fact, denying consumers value by impeding efficient market developments that these consumers would welcome. Regulations are not innocuous simply because they are promulgated in the name of consumers. No matter how worthy the purpose, rules that constrain markets can, in fact, deny or delay benefits to the consuming public. ${ }^{363}$

Stigler himself could hardly have said it better. If you want to be sure that regulations (or deregulations) actually serve the public interest, then look at their effects. Thus, Powell's vision of consumers, like that of virtually all of the country's most prominent regulators, appears to be very close to the one that George Stigler complained regulators generally lacked.

But our hypothesis is that shallow capture is still a problem, in part because the advantages favoring large business interests in the competition for regulatory influence have not changed, even if the

Powell sees the recent move to deregulate cross-ownership rules as similarly bolstering the public interest by expanding consumer choice. According to Powell, in situations where a corporation has received a waiver to own both a newspaper and a television station in the same city, the result has been better local news coverage. Ahrens, FCC Plan, supra note 357, at A1. In addition, he has suggested that network owned-and-operated television stations typically produce more local news than those not owned by networks. Id. In his words, it "has become more difficult to simply assert that an ownership restriction is essential to promoting diverse viewpoints where so many outlets and owners thrive ...." Associated Press, FCC to Vote on Media Ownership Rules, SAN DIEgo UNION TRIB., Mar. 28, 2003, at C2 (quoting Powell).

Powell also justifies the cross-ownership changes by claiming they help support public-interest programming. In his view, if cable continues to eat away at broadcast, public-interest programming will be jeopardized because cable channels are under no FCC obligation to provide such programming. Ahrens, FCC Plan, supra note 357. Allowing media companies to buy more stations, which typically return profits of 20 to $30 \%$, would help ensure continued free, over-the-air public-interest broadcasting to the roughly $15 \%$ of viewers who do not have cable or satellite television. Id.

Although Powell has described public-interest programming as necessary, he is uncomfortable with the FCC deciding what it should be. "II you're using the government will to impose "castor oil" or "eat your vegetables" programming, you'd better be a little bit concerned that you're going to allow three of five unelected officials to unduly impose what they prefer to see on TV."' Id. (quoting Powell).

${ }^{363}$ Powell, supra note 358 . 
conceptions of consumers, markets, and regulations have. Thus, the same evidence that, to many scholars, might constitute proof of the absence of shallow capture, strikes us as evidence of deep capture -the faith in pro-market, anti-regulation dispositionism. ${ }^{36}$

${ }^{364}$ While our main emphasis in this Article is on how corporations indirectly capture the way we see and understand the world, we do not mean to suggest that corporations are not expending a great amount of energy on directly influencing regulators as well. In anticipation of the FCC's recent decision on how Bell telephone companies lease lines to competitors, " $[t]$ he Bells spent hundreds of millions of dollars in a furious lobbying campaign to convince Congress and the FCC that they could not be expected to push broadband out into rural areas, or invest in new, advanced networks, if they were forced to then lease them to rivals." Krim, supra note 357, at A1. Moreover, between 1999 and 2002, the top twenty-five media companies spent $\$ 82$ million on lobbying the FCC and Congress and contributed $\$ 26.7$ million in individual, PAC, and soft money donations. Ctr. for Responsive Politics, Tracking the Payback: Media Ownership, at http://www.opensecrets.org/payback/issue.asp?issueid $=$ MO1\&CongNo=108 (last visited Oct. 16, 2003).

One of the main forces behind the FCC's recent decision to relax regulations that limit the cross-ownership of newspapers and television stations was Victor Miller, a media analyst at Bear Stearns. Coincidentally, Bear Stearns has banking and underwriting relationships or has rated stocks in at least fifteen media companies directly affected by the FCC's proceedings. Mark Wigfield, Bear Stearns Analyst Helps FCC Reshape Ownership Rules, WALL ST. J.. June 2, 2003, at C1. Yet, the media ties do not appear to have resulted in Miller's advice being discounted. According to Susan Eid, Counsel to the FCC Chairman, Miller "'is enormously helpful as you sort through the economic issues and financial issues in the industry." Id. (quoting Eid). In the words of Eid, "'His analysis is rock-solid." Id. (quoting Eid).

Miller's example highlights a general trend. "Wall Street's views have become increasingly important at the FCC since the 1996 Telecommunications Act began substituting market competition for regulation as the best way to ensure that the nation's airwaves are used in the public interest." Id. Today, the FCC appears to rely heavily on non-governmental private data for a range of critical regulatory factors such as "ownership, audience reach and cable subscribers." John Dunbar, Ctr. for Pub. Integrity, A Penchant for Secrecy: Why is the FCC So Determined to Keep Key Data from the Public?, at http://www.openairwaves.org/telecom/report.aspx?aid=18 (May 22, 2003). A more general reliance on corporations, analysts, and investors in policy making has led some critics to question the neutrality of the regulatory process. Between September 2002 and June 2003, the nation's top broadcasters had over seventy face-toface meetings with FCC officials behind closed doors. Bob Williams, Ctr. for Pub. Integrity, Behind Closed Doors: Top Broadcasters Met 71 Times With FCC Officials, at http://www.publicintegrity.org/dtaweb/report.asp? ReportID=526\&L1=10\&L2=10\&L3 $=0 \& L 4=0 \& L 5=0$ (May 30, 2003).

The closed-door sessions, which are officially called ex parte meetings, are allowed under FCC rules. The meetings are not recorded, nor are the participants required to keep detailed minutes of the sessions. Non-FCC people who participate in the meetings are supposed to file a notice of the session by the end of the following day. The notice is supposed to include a summary of what was discussed.

Id. During that same period, the FCC met with two major consumer groups only five times. Id. Faced with this heavy lobbying, even Powell has begun to question the benefits of an increasingly close relationship with interest groups: "I do think . . that 
sometimes it gets out of hand.... I often think that we need time to do our work rather than hear pitches." Id. (quoting Powell).

But then as bad as "pitches" are, they may not be as troubling as the "perks" passed on to FCC employees in recent years by big business. The Center for Public Integrity reports that companies and industry groups paid $\$ 2.8$ million over the past eight years for 2,500 trips by agency officials. Bob Williams \& Morgan Jindrich, Ctr. for Pub. Integrity, On the Road Again-And Again: FCC Racks up $\$ 2.8$ Million Travel Tab with Industries They Regulate, at http://www.openairwaves.org/telecom/report.aspx?aid=15 (May 22, 2003). Ninety-eight of the trips were to London, which is not even in the FCC's jurisdiction. Id. The biggest sponsor happened to be the National Association of Broadcasters. Id.

There are still other unsettling statistics concerning the "revolving door" between industry and regulators. For example, before coming to the FCC, Powell worked at the law firm of O'Melveny \& Myers LLP, of which the GTE Corporation was a major client. GTE later merged with Bell Atlantic to form Verizon, the largest local phone company in the United States, but Powell never recused himself from participating in deliberations or votes relating to either company. Nathaniel Heller, Ctr. for Pub. Integrity, New FCC Chairman Had Big Telephone Player as a Major Client, at http://www.public-i.org/dtaweb/report.asp?ReportID=135\&L1=10\&L2=70\&L3=15 $\&$ L4=0\&L5=0\&State $=\&$ Year $=2001$ (Feb. 13, 2001). To be sure, his actions appear to have been within the letter of the law. The Code of Federal Regulations requires only a one-year cooling-off period. 5 C.F.R. $\$ 2635.502$ (b) (1) (iv) (2003). However, one wonders how well his actions comport with the spirit of that law. Since the time Powell took office through the present, Verizon has had many regulatory issues before the FCC, relating from cell phones to the Internet. And in his role as Commissioner, Powell has often taken the pro-Verizon position, bemoaning what he sees as the harsh "interconnection and market-opening requirements" imposed on GTE and others. Id.

Passing through that same door, but in the opposite direction, Dorothy Attwood quit her job last year as chief of the FCC's Wireline Competition Bureau and two months later was working at SBC Communications, guiding the telecom company through the FCC policies on local telephone competition that she helped draft. John Dunbar, Ctr. for Pub. Integrity, The FCC's Rapidly Revolving Door, at http:// www.public-i.org/dtaweb/report.asp? ReportID=510\&L1 =10\&L2=10\&cL3=0\&L4=0\&L5 $=0$ (Feb. 19, 2003) [hereinafter Dunbar, FCC's Rapidly Revolving Door]. Attwood was not a minor player. As Powell stated several months before Attwood departed, "She has played an integral role in the FCC's implementation of the Telecommunications Act of 1996, and in shaping our policies in the transition to a more competitive telecommunications environment." Press Release, Federal Communications Commission, Powell Announces Changes in Wireline Competition Bureau 1, at http://hraunfoss.fcc.gov/edocs_public/attachmatch/DOC-223658Al (June 21, 2002). Yet, according to the letter of the law, she was not senior enough to fall under the "cooling-off period" ban. 5 C.F.R. \$ 2637.204 (2003). Since she began at SBC, Attwood has met with FCC officials, including Powell's senior legal advisor, four times. Dunbar, FCC's Rapidly Revolving Door, supra.

Attwood and Powell are not anomalies. In fact, over the last decade, several dozen FCC workers have crossed the busy threshold from regulated industry to regulator or the other way around. Id. Some have taken to straddling the worlds on both sides of that threshold. Former FCC Chairman Richard Wiley is now a senior partner at the lobbying firm of Wiley, Rein \& Fielding LLP. Steven Weiss, Interview: Richard Wiley, CAPITAL EYE (June 2, 2003), at http://www.capitaleye.org/inside.asp?ID=85. He often appears on the so-called eighth floor of the FCC to lobby key decision makers on behalf of media clients like Belo Corporation, Clear Channel, and Gannett. Id. 
Not everyone is turning a blind eye to the matter. On June 13, 2003, Senator McCain proposed a reauthorization bill that would give the FCC greater authority to regulate and limit the "revolving door" influence on the agency. Statement by Senator John McCain on the Federal Communications Commission Reauthorization Act of 2003 (June 13, 2003), available at http://www.senate.gov/ commerce/newsroom/ printable.cfm?id=205012. To decrease the influence of the media industry, the bill would bar top staffers from lobbying for one year after leaving the FCC. See id. (recounting the various elements of the reauthorization bill). It would also bar companies and other interest groups from paying travel expenses of FCC officials for flights to nongovernment sponsored conferences, meetings, and events. Id.

Unfortunately, these remedies may not ultimately solve the regulatory capture dilemma because they do not go far enough. They do not acknowledge the problem that people perceive the playing field as reasonably level even when it is not. In the debate leading up to the recent changes in media ownership rules, former FCC Chairman Riley saw a fair tournament of ideas between consumer groups and media corporations: "[A] lot of players have gotten onto the field and are participating in the process at the commission. So there's a lot of lobbying, pro and con." Weiss, supra. In his opinion:

Money may permit you to get in the door, but I don't think it buys people's votes. Members of Congress are elected because they have strong viewpoints and they're very well-informed people. I don't think they're bought and sold quite as effectively or quite as much as people allege in the campaign finance area.

Id. That he once ran the agency, he believes, is largely irrelevant:

Decisions of the commission are made on the merits. I don't want to put myself or other former commissioners down, but it's what you're bringing in there in terms of the merits that is going to win cases at the FCC. I truly believe that. Hopefully people who know the commission process can help their clients sort through it, but ... I don't think anybody rolls over because a former chairman or former commissioner comes in.... I've won some, I've lost some, and I think that's true of other lawyers around town.

Id.

We do not claim that there is no competition for regulatory influence, or that all commercial interests will always agree on every regulatory policy, or that one side of the competition will always win. There does appear to be a playing field, and, as these examples illustrate, the competition over regulatory policy can be robust. See Stephen Labaton, F.C.C. Chief Talks of Frustration and Surprise, N.Y. TIMES, Sept. 22, 2003, at C1 (describing the competing interests in regulatory policy). The existence of a competition, however, is not proof of a fair, meritocratic process, as Wiley seems to suggest. It is still possible to predict which groups will be advantaged or disadvantaged by the playing field and the rules of the game. And that is the stuff of shallow capture. Furthermore, and this is a major theme of this Article, there are ways of conceptualizing human actors, markets, and regulations in a way that is broadly procommercial. As we have argued, the dispositionist perspective that frames the discussions and debates about regulatory policy itself tends toward pro-market and anti-regulatory policies. That is part of what we mean by deep capture.

Consider the following metaphor: In Major League Baseball, there are thirty teams, which compete not just on the field in games, but also off the field in recruiting the best players to play for their teams. While on-the-diamond competition is played on a level field, the off-the-field competition is not; the wealthiest teams have a huge advantage in recruiting top players because they can offer much higher salaries. So while there is still some competition-you still have to throw strikes and score runs- 
Finally, it is worth pointing out how Powell dismisses those who doubt that faith. ${ }^{36.5}$ He finds such apprehensions, not just "puzzl[ing],"366 but "so thoroughly discredited...that [his view] should be beyond challenge." comes from the fair competition that is presumed to have occurred in the global marketplace of political-economic systems, a competition that led to the "winning record" of markets and a "higher standard of living [in the United States] than nearly any other country in the world." ${ }^{368}$ The not-very-hidden implication is that those who don't embrace his views are favoring a turn toward "central economic planning," perhaps even communism. ${ }^{369}$ Powell, in other words, dismisses what he calls "the classic bugaboo that markets... favor big business and big money" ${ }^{\text {"70 }}$ by raising the familiar specter of the totalitarian bogeyman. ${ }^{371}$

off-the-field situational advantages have tremendous impacts on on-the-field outcomes. In 1999, for example, all eight teams that made the playoffs were among the top ten highest salaried teams in the league. Although the tenth-highest salaried team made the playoffs and the fourth-highest did not, none of the twenty lowest salaried teams made it. In the 1999 World Series, the team with the league's highest payroll, the New York Yankees, defeated the team with the league's third-highest payroll, the Atlanta Braves. While there is a playing field, the playing field is not level, and the situation of the playing field affects outcomes. See Lani Canfield Fisher, October is For the Rich, $19 \mathrm{~J}$. COSMIC BASEBALL ASs'N (2000) (describing the payroll figures for major league teams and their relationship to post-season appearances), at http://cosmicbaseball.com/ jcba19_octo.html.

${ }^{365}$ Powell's convictions as to the righteousness of deregulation are unflappable. After being challenged by those calling for more public input into the FCC's changes to media ownership rules, Powell retorted: '‘You don't govern just by polls and surveys ... We have to exercise difficult judgments and abide by the law. If all of our rulemaking was just a case of put them out and take a referendum, things would be a lot easier." Ahrens, FCC Plan, supra note 357 at A1 (quoting Powell). "I have had to make peace with myself, to know myself, to know with every fiber of my being and intellect and faith with the law that this is the right answer, at least in the short term. .. Though it's not the popular answer." Frank Ahrens, FCC Set to Vote on Easing Media Ownership Rules, WASH. POST, June 2, 2003, at A6 (quoting Powell).

${ }^{366}$ Powell, supra note 358.

${ }^{367}$ Id.

${ }^{368}$ Id.

${ }^{369} I d$.

${ }^{370}$ Id.

${ }^{371}$ Powell is quite adamant in this respect:

I don't know of another economic system in the history of the world that's produced as much consumer welfare for its citizenry as American capitalism has. You name to me the state central plan system that better served the maximum consumer welfare of its citizens as the free market did in American stock capitalism? I think that's the penultimate conclusion of the end of the 20 th Century that not only did democracy prevail, as a social value and 
A look at the Federal Trade Commission (FTC), whose "efforts are directed toward stopping actions that threaten consumers' opportunities to exercise informed choice, ${ }^{\not 72}$ is similarly revealing. The current FTC Chairman, Timothy Muris, seems to share Powell's preference for free markets, and for all the same reasons. In 1980, for instance, Muris wrote (with a co-author) that

[t] he relatively unregulated marketplace has significant advantages in allocating resources and promoting consumer welfare. The market tends to minimize waste by permitting continuous individual balancing of economic costs and benefits by consumers and producers. In addition, greater productive efficiency and more innovation result from the reliance on market incentives. Competitive markets also reduce the need for central collection of information; their price signals allow producers and consumers to respond quickly to change. Finally, competitive markets tend to decentralize power and make decisions that are fair in the sense of being impersonal. For these reasons, reliance on the market should be the norm.

More recently, he has supplemented that pro-market view by emphasizing the need for certain types of regulatory interventions in

political value, but the capital economy prevailed as the leading environment for the welfare of citizens and for the ferment of innovation and revolution.

Transcript of Conversation Between FCC Chairman Michael K. Powell and Sam Donaldson at the NAB 2001 Convention 4 (Apr. 24, 2001), available at http:// www.fcc.gov/Speeches/Powell/2001/spmkp102.pdf.

${ }^{372}$ Fed. Trade Comm'n, Vision, Mission $\mathcal{E}$ Goals, at http://www.ftc.gov/ftc/ mission.htm (last updated June 17, 1999).

${ }^{373}$ Kenneth W. Clarkson \& Timothy J. Muris, Constraining the Federal Trade Commission: The Case of Occupational Regulation, 35 U. MIAMI L. REV. 77, 81 (1980) (citation omitted). The FTC made a similarly revealing statement in 1978:

The public policy of this country favors the existence of free markets to the maximum extent possible. While the complexity of the modern economy often necessitates a departure from free market organization, as a general proposition a market-perfecting solution to a perceived problem is preferable. There should be a heavy burden of proof on those who would opt for a different form of economic organization ....

Advertising of Ophthalmic Goods and Services, 43 Fed. Reg. 24,001 (June 2, 1978). Former FTC Commissioner Thomas B. Leary stated that, "consumer freedom implies the right to buy in open markets ...." Thomas B. Leary, Freedom as the Core Value of Antitrust in the New Millennium, 68 ANTITRUST L.J. 545, 553 (2000); see also Thomas B. Leary, Commissioner, Federal Trade Commission, The Federal Trade Commission and the Defense of Free Markets, Remarks Before the David T. Chase Free Enterprise Institute, Eastern Connecticut State University (Oct 7, 2002) [hereinafter Leary, Defense of Free Markets] (describing how the FTC is devoted primarily to protecting the freedom of sellers to sell and buyers to buy what they choose and the role of efficiency-oriented scholars in promoting that now-conventional view of the FTC), available at http://www.ftc.gov/speeches/ leary/willimantic.pdf . 
markets. In 1991, for instance, he wrote that "[o]ne of the crucial roles for government, as we are seeing in Eastern Europe, is to define and allocate property rights." ${ }^{374}$ And although he acknowledges the need for certain types of regulation when a market fails, he cautions that

it is important to talk about the concept of market failure with care because the issue is failure compared to what. In the real world, institutions are imperfect, both government institutions and market institutions. It makes no sense to compare an imperfect reality to a hypothetical perfection. A vast literature exists on government failure, as large as or larger than the literature on market failure.

With that caution, Muris appears to be emphasizing the work of, among others, George Stigler, for Muris goes out of his way to stress that

[g]overnment agencies are not run by philosopher kings who descend from Olympus to protect us. Instead, government agencies are, themselves, governed by rules that constrain what they can do, and they are run by individuals who are striving to advance or succeed, just as we all are. These constraints and incentives will influence how an agency acts in the public interest. ${ }^{376}$

Muris also describes how FTC regulation of advertising has moved from protecting industry members from competition toward serving consumers by encouraging competition.

Again, the chairperson of a major federal regulatory institution seems to embrace the dispositionist case for markets-as does the

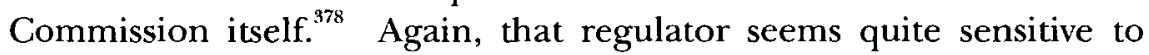

${ }^{374}$ Timothy J. Muris, Economics and Consumer Protection, 60 ANTrTRUST L.J. 103, 104 (1991).

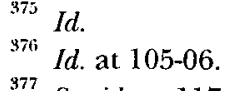

${ }^{377}$ See id. at 117 (contrasting the competition-motivated FTC enforcement in the $1950 \mathrm{~s}$ and 1960s with the consumer-oriented policy that developed in the 1970s).

${ }^{378}$ See, e.g., H.R. REP. NO. 98-156, pt. 1, at 37 (1983) ("Normally we expect the marketplace to be self-correcting, and we rely on consumer choice-the ability of individual consumers to make their own private purchasing decisions without regulatory intervention-to govern the market."); Leary, Defense of Free Markets, supra note 373, at 5 (describing the "New Learning - an efficiency-orientated view of antitrust [as], today, mainstream competition law"). According to Leary: 
the insights of shallow capture theory. And, again, we would conclude that, insofar as Chairman Muris fails to consider the role of exterior and interior situation, his views and, indeed, his position at the FTC, evince deep capture.

We could continue in this vein at some length, but for everyone's sake, we will stop here. ${ }^{380}$ In the following Section, we aim to dig a little deeper and provide some illustrative examples of how other "regulators," from courts to hard-hitting news networks, reflect and contribute to deep capture.

Although we may differ on the facts of individual cases, all of my [FTC] colleagues agree that the objective is to maximize efficient outcomes. We all start in the same place and we are all trying to do the same thing. This broad consensus is a great demonstration of the power of ideas and, in my view, has made an immense contribution to consumer welfare.

Id.

${ }^{879}$ Although we were unable to find much of his writing, it is widely understood that Hal Stratton, Chair of the Consumer Product Safety Commission has similar, strong pro-market, anti-regulation presumptions. See, e.g., New Mexico Attomey General Stratton Repudiates NAAG's Horizontal Guidelines, ANTITRUST \& TRADE REG. REP., Issue No. 1314, at 869-70 (May 7, 1987) (describing Stratton's objection that the merger guidelines proposed by the National Association of Attorneys General ("NAAG") "needlessly impose government regulation in the market place" in a way that "unnecessarily interfere[s] with market forces" and "that will prejudice both legitimate business reorganization and consumer welfare"); Hal Stratton, Attorneys General in State of Collusion, WALL ST. J., June 10, 1988, at 22, col. 4 (attributing NAAG's movement in this direction to "[s]ome ambitious, high-profile attorneys general [that] ... are using the cover of 'consumer protection' to impose their own anti-business, progovernment-regulation views on the entire nation and are bypassing the legislative process to put in place 'enforcement guidelines' that Congress itself refuses to pass"). One critic complains that Stratton

inhabits a world in which government has no right to tell business what to do, a world where consumer choices are the best marketplace regulators, a world in which product-liability lawsuits stifle innovation. This would be the same world in which consumer products never are unsafe, only used incorrectly by careless people. In other words, a fantasy world.

Editorial, From Bad to Worse, THE BLADE (Toledo), Nov. 28, 2001, available at http://www.toledoblade.com/apps/pbcs.dll/article?Date=20011128\&Category=OPINI ON02\&ArtNo $=111280045 \&$ Ref $=A R$.

${ }^{380}$ For a different but complimentary analysis of the pro-market and antiregulation schemas of policymaking, see Chen \& Hanson, Illusion of Law I, supra note 84. 


\section{B. Some Less Shallow Evidence of Deep Capture}

The myth that holds that the great corporation is the puppet of the market, the powerless servant of the consumer, is, in fact, one of the devices by which its power is perpetuated.

\section{-John Kenneth Galbraith ${ }^{381}$}

Consider briefly courts. Consider, for instance, the 1979 dispositionist language of then-Chief Judge Irving Kaufman of the Second Circuit:

$[\mathrm{N}]$ o one can determine with any reasonable assurance whether one product is "superior" to another. Preference is a matter of individual taste. The only question that can be answered is whether there is sufficient demand for a particular product to make its production worthwhile, and the response, so long as the free choice of consumers is preserved, can only be inferred from the reaction of the market. ${ }^{382}$

Kaufman, in now-common fashion, treats the market as little more than a highly responsive conduit of stable, exogenous consumer preferences. The preferences and free choices of the consumers come first, and the success or failure of the product comes second, depending on its ability to satisfy those preferences. ${ }^{383}$ More recently, Judge Frank Easterbrook has expressed a similar deference to markets, adding that, with respect to reducing at least some kinds of personal injury risks, courts should defer to the incentives of the marketplace rather than attempt to fashion judgemade incentives. As he puts it, market incentives, "[i]mperfect as they are, ... work better than the alternatives the legal system can offer." ${ }^{384}$ In this vein, too, we could go on. After all, like Judge Easterbrook, many of the most prominent and influential judges today made their careers as academics devoted to promoting the dispositionist views of law and economics and libertarianism, including: Judge Ralph Winter, Judge Stephen Williams, Justice

381 JOHN KENNETH Galbraith, THE AGE OF UNCERTAINTY 258-59 (1977).

382 Berkey Photo v. Eastman Kodak Co., 603 F.2d 263, 287 (2d Cir. 1979).

383 Thus, "in its advertising, a producer is ordinarily permitted, much like an advocate at law, to bathe his cause in the best light possible." Id.

${ }^{384}$ Carroll v. Otis Elevator Co., 896 F.2d 210, 217 (7th Cir. 1990) (Easterbrook, J., concurring). 
Stephen Breyer, Justice Antonin Scalia, and, of course, Judge Richard Posner. Moreover, some who did not begin as academics nonetheless rose to fame and influence in significant part because hard-core dispositionism was central to their judicial identity, such as Judge Alex Kozinski, Judge Michael Luttig, and Justice Clarence Thomas. Indeed, at this moment in history, it is difficult to imagine that any federal judge will be appointed or promoted who does not substantially embrace the hard-core dispositionism promoted by President Bush, his advisors, and the Federalist Society, which now has immense influence over the judicial selection process. ${ }^{385}$

Dispositionism, as we have already indicated ${ }^{386}$ and will return to below, also dominates legal academia. For instance, when, in the mid-1980s, the American Law Institute (ALI) amassed a large, somewhat representative, ${ }^{887}$ cast of influential tort scholars to assess the tort system and to recommend possible reforms, those scholars began their substantial work by embracing dispositionism. In their words:

Utilitarian theorists . . accept as a factual premise that people are generally the best judges of what actions will maximize their own utility. This premise implies that society should strive to let states of affairs be determined by the choices of the individuals affected rather than by public decision makers.

We reject hard paternalism here both because we find it unpersuasive and because we think that most Americans do not accept

985 See Martin Garbus, A Hostile Takeover: How the Federalist Society is Capturing the Federal Courts, AM. PROSPECT, Mar. 2003, at A16 (discussing the increasing influence of the Federalist Society on both legal and non-legal affairs). By 2001 the Federalist Society had become so powerful that President George W. Bush felt comfortable eliminating "the longstanding role in the evaluation of prospective judges by the resolutely centrist American Bar Association (ABA), whose ratings had long kept extremists and incompetents off the bench. Today the Federalists have more influence in judicial-selection than the ABA ever had." Id. The group's efforts have also been directed beyond judicial appointments and clerkships through "publications, strategy sessions and panel discussions." Id. at A17. With millions of dollars of backing from pro-market organizations such as the John M. Olin Foundation, the Federalists have attacked individuals and agencies who attempt to regulate business, and have celebrated those espousing dispositionism. Id. at Al6.

386 See supra Part I.B.

${ }^{387}$ See James A. Henderson, Jr., Revising Section 402A: The Limits of Tort as Social Insurance, 10 TOURO L. REv. 107, 114-15 (1993) (describing the committee membership as "a balanced representation of well-known plaintiffs" lawyers and wellknown defendants' lawyers"). 
it. Hence, we suppose that, presumptively at least, consumers should choose the accident level.

The idea that consumers "choose the accident level," might strike some readers as an unfamiliar notion. Few of us are conscious of having much influence over, much less selecting, the accident level. But what the ALI Reporters are indicating, of course, is that through decentralized individual choice, a collective determination or variety of determinations is made by consumers. The belief that consumers best know their own interests and, through choice-based behavior, are best able to act on that knowledge, is sometimes known as consumer sovereignty-the normative principle that the ALI Reporters explicitly endorsed. ${ }^{389}$

The ALI Reporters' terms are revealing (not to mention, constraining) ${ }^{390}$ "Hard paternalism" conjures up notions of considerable governmental interference-something akin to central planning. ${ }^{391}$ In underscoring the rejection of such an approach by "Americans," the Reporters seem again to be implicitly using the shadow of the then-freshly fallen Soviet Union as an important justification for embracing pro-market dispositionism and rejecting any alternative.

Whether the ALI Reporters were in fact making such an analogy, we (and perhaps they) cannot know. But we do know that legal scholars have been explicit in making just that comparison. For example, in a recent article, Robert Lande writes:

An optimal level of consumer choice, which has elsewhere been termed "consumer sovereignty" is the state of affairs where the consumer has the power to define his or her own wants and the ability to satisfy these wants at competitive prices. The concept of consumer choice even embodies some implicit notions about the rights of the individual in the broader society; it is implicitly part of the Western world's response to Marxism and the other totalitarianisms of the Twentieth Century.

388 ALI, 1 ENTERPRISE RESPONSIBILITY FOR PERSONAL. INJURY: REPORTERS' STUDY 205-07 (1991) (citation omitted).

${ }^{389}$ See id. at 204-08 (justifying their commitment to consumer sovereignty).

${ }^{390}$ See id. at 203-32 (illustrating the ALI Reporters' use of the common, though false, dichotomy between a "pure" market solution and "hard paternalism").

${ }^{391}$ See id. at 207 (noting that according to hard paternalism, "people do not have preferences so much as they have "interests" and that "the state should choose the legal rule that is in the citizens' real (rather than their subjectively perceived) best interest").

${ }^{392}$ Robert H. Lande, Consumer Choice as the Ultimate Coal of Antitrust, 62 U. PITT. L. REV. 503, 503 (2001) (citations omitted). 
Again, the belief in dispositionism appears to be motivated, at least in part, by a fear that any other belief would place us on a slippery slope toward totalitarianism.

But there is more to it than that. If one looks beyond the legal reporters and law reviews, one will encounter many other, far less formal, "regulatory" institutions that seek to promote dispositionism. In these contexts, the goal seems to be to present to consumers a vision of ourselves that we want to hold-a self-affirming image that we are not being moved by the situation. For example, Fidelity Investments tells us:

You are not the kind of investor who blindly reacts to each and every new market condition. You're informed. You're involved. You're focused.

Being in control of your financial future has never been more important.

THERE ARE BULLS AND BEARS. BUT YOU ARE A THINKING ANIMAL. ${ }^{399}$

In other words, you, unlike all the other animals on the planet, are uninfluenced by situation. You think, you prefer, you choose, and you thereby enjoy dispositional control of your life.

Advertisers do not mind casting the shadow of those unAmerican totalitarian regimes to drive the self-affirming dispositionist point home. For instance, one cable news network recently placed this ad:

${ }^{393}$ Fidelity Investments, Advertisement, N.Y. TimEs, July 14, 2002, $\$ 1$, at 15 . In light of recently burst bubbles and other corporate debacles, it is unsurprising that other strategies include actually emphasizing cognitive quirks. A recent TIAA-CREF advertisement reads:

Economist Robert Shiller wonders why we have such faith in the utter rationality of markets when we can be kinda, you know, irrational. Bad judgment, lousy information, half-baked strategies-there are times when money brings out the worst in people. That's why Professor Shiller's retirement dollars are invested with a company whose level-headed thinking stands out in a world where impulse and intuition are bucking intelligence and insight.

Teacher's Ins. \& Annuity Ass'n-Coll. Ret. Equities Fund, Advertisement, ATLANrIC MONTHLY, Jan./Feb. 2003, at 84-85. Thus, the ad encourages those with doubts in their own rationality to trust the rationality of a dispositionalized institution and the benevolence of privatized paternalism. The company is our agent (or friend) looking out for our interests and avoiding the pulls of our flawed disposition (here portrayed as "irrationality"). The ultimate message is that the rational dispositional choice of investors can correct for the flawed dispositional choice of investments: you + TIAA-CREF = rational dispositional actor. 
What makes America... America? It's the freedom to have an opinion ... the freedom to speak your mind... [W] e know you can think for yourself. When it comes to covering the news, we don't have an agenda... and don't take orders from anyone. Just like every American. Just like you. America's News Channel MSNBC. ${ }^{394}$

The point seems to be not just that Americans are situationally independent (able to think what they want to think and speak what they want to speak), but also that MSNBC is uninfluenced by outside forces.

MSNBC's competitor, FOX News Channel, takes the dispositionist view a step further and credits its own success to the free-choice-making dispositions of its viewers:

Thanks to the American people. You've made FOX News Channel the most watched, most trusted name in news. As active participants in the American experience, you ensure a free and fair press for all.

We Report. You decide.

And:

For the 3 out of 4 Americans who believe the news is biased, we present something quite rare: a news network dedicated to providing fair and balanced coverage. It's cable news for the independent thinker, 24 hours a day.

This practice of portraying the consumer as nobody's fool is extremely widespread. According to some analysts, two of the most common themes of cigarette advertising historically were "choice" and "autonomy." "397 The Marlboro Man, as we will highlight below, was nothing if not free and autonomous. And this imagery was not exclusive to men. The demise of the taboo against women smoking,

${ }^{394}$ MSNBC, Advertisement, N.Y. TIMES, Apr. 12, 2002, at A11.

${ }^{995}$ FOX News Channel, Advertisement, N.Y. TIMES, Jan. 21, 2003, at C3.

${ }^{396}$ FOX News Channel, Advertisement, N.Y. TIMES, Sept. 15, 1997, at D16. But cf. Bill Carter \& Jim Rutenberg, Fox News Head Sent a Policy Note to Bush, N.Y. TIMES, Nov. 19, 2002, at A27 (describing claims of connections between FOX News and the Republican Party); Jim Rutenberg, Cable's War Coverage Suggests a New "Fox Effect" on Television Journalism, N.Y. TIMES, Apr. 16, 2003, at B9 (asserting that FOX News "casts aside traditional notions of objectivity [and] holds contempt for dissent"); Matt Wells, TV Watchdog Checks Claims of Bias on Murdoch Channel, GUARDIAN (London), May 8, 2003, at 5 (explaining investigation in the United Kingdom into the alleged bias of FOX News).

${ }^{397}$ See WORLd HEALTH ORG., WOMEN AND TOBACCO 4-5 (1992) (noting that the early twentieth century witnessed the beginning of public smoking by women as they sought to assert their newfound emancipation; this habit increased greatly during World War II as women contributed to the war effort and smoking became associated with working, independence, emancipation, and patriotism). 
and the concomitant doubling of potential cigarette consumers, was reinforced by a clever public relations campaign devised by Edward L. Bernays. $^{398}$ To cap off that campaign, Bernays enlisted the cooperation of feminist Ruth Hale to organize a contingent of ten cigarettepuffing women to walk down New York's Fifth Avenue in the 1929 Easter Parade. The feminists' involvement was billed and reported as an act of protest and a call for equality. ${ }^{399}$ And the cigarettes were, themselves, described as "torches of freedom." American Tobacco managed, through public relations, to promote smoking in the name of liberation and autonomy. A look at Virginia Slims' more recent advertising campaign slogans from 1968 until today reveals that the beat goes on: "You've Come A Long Way, Baby," "It's a Woman Thing," "Find Your Voice," and "See Yourself as a King." 401

The similarity of "seeing yourself as a king" and "consumer sovereignty" is hard to miss and may not be an accident. The message not only encourages consumers to purchase cigarettes, it also suggests some of the larger possible stakes that commercial interests have in dispositionism. After all, if the consumer is king, then it is hard to justify making manufacturers pay for simply following orders. And this ability to place responsibility squarely on consumers-to say in a tort case, for instance, that they "assumed the risk" of their actions-has been fundamental to the tobacco industry's success in selling a product believed to cause more than 440,000 premature deaths per year in the United States alone. ${ }^{402}$

${ }^{398}$ See LARRY TYE, THE FATHER OF SPIN: EDWARD L. BERnays AND THE BIRTH OF Public Relations ch. 2 (1998) (discussing Bernay's efforts in the 1920s and 1930s to encourage women to smoke); see also CASSANDra TATE, CigaretTE Wars: THE TRIUMPH OF "THE LITTLE WHITE SLAVER" 105-17 (1999) (describing how such efforts reinforced, but did not initiate, cigarette smoking by women, and describing many of the situational-social, political, and economic-forces that were more influential).

${ }^{399}$ See Stuart Ewen, Overrated and Underrated: Public Relations Campaign, АM. HERITAGE, May/June 2000, at 77, 77-78 (describing and quoting Bernays's conception of the campaign); Steve Craig, 'Torches of Freedom': Themes of Women's Liberation in American Cigarette Advertising 8 (Feb. 25, 1999) (noting that the campaign sought to distinguish cigarettes as "explicit symbols of a woman's defiance of traditional social norms"), available at http://www.rtvf.unt.edu/people/craig/pdfs/torches.PDF.

${ }^{400}$ Ewen, supra note 399.

401 See Campaign for Tobacco-Free Kids, Warning: Smoking is a Women's Issue, at http://tobaccofreekids.org/reports/women/ (last modified May 31, 2002) (describing the tobacco industry's historical targeting of women and girls).

${ }^{402}$ See Jon D. Hanson \& Kyle D. Logue, The Costs of Cigarettes: The Economic Case for Ex Post Incentive-Based Regulation, 107 YALE L.J. 1163, 1171 (1998) (describing the long-time trend of holding smokers responsible for their resulting health problems); 
Thus, an important reason that sellers might embrace and encourage dispositionism is their hope of shifting responsibility and avoiding costly regulation or liability. ${ }^{403}$

A recent Pfizer Forum advertisement echoed that message: "Medical professionals must help patients understand that in return for greater power, control, and choice over the services and treatments they receive, they must bear greater responsibility for their own care." ${ }^{.404}$ The pharmaceutical company's message, which comes at a time when it seems to be facing growing threats of liability, ${ }^{405}$ taps into a well-established human tendency: where we see the ingredients of autonomous, volitional, preference-satisfying disposition, we place responsibility. ${ }^{406}$

see also Ctrs. for Disease Control \& Prevention, Annual Smoking-Attributable Mortality, Years of Potential Life Lost, and Economic Costs: United States 1995-1999, 51 MORBIDITY \& MORTALITY WKLY REP., Apr. 12, 2002, at 300 (reporting the 440,000 figure and noting that smoking continues to be the leading cause of preventable death in the United States).

${ }^{403}$ See Jon D. Hanson \& Douglas A. Kysar, The Failure of Economic Theory and Legal Regulation, in SMOKING: RISK, PERCEPTION, AND POLICY 229, 253-54 (Paul Slovic ed., 2001) (describing how the cigarette industry adopted just that strategy and its success).

${ }^{404}$ Liz Kendall, Pfizer Forum, Advertisement, Improving Healthcare by Empowering Patients, ECONOMIST, July 13, 2002, at 10 (explaining that patients can and should take on more responsibility regarding their own healthcare).

405 See Editorial, No Access to Law, 9 MULTINAT'L MONITOR (June 1988) (describing lawsuits and settlements over a heart valve produced by Pfizer), at http://multinational monitor.org/hyper/issues/1988/06/mm0688_03.html; Elisa Odabashian, Consumer Union, Concealed Danger: Who Is Really Behind the Bid to Kill the California Corporate Criminal Liability Act, at http://www.consumersunion.org/products/pfizerwc900.htm (Apr. 24, 1996) (suggesting that Pfizer has lobbied against a California liability statute in order to avoid criminal sanctions and further fines).

${ }^{406}$ We feel it is important to reemphasize that we intend only to scratch the surface of the evidence for, and mechanisms of, deep capture in this Article. Future work, much of it well in progress, will flesh out the many ways that dispositionism benefits powerful interests, particularly large commercial interests, and the mostly situational mechanisms - both abstract and practical - of deep capture.

On a similar note, we recognize that our small sample of evidence has the potential for bias, as we have searched for evidence to support our hypothesis and have postponed any attempt to consider contrary evidence or to talk much about overall trends. Still, at this point, we do not believe that the trends that we are suggesting are all that controversial. For an overview of some of the relevant trends, see Chen \& Hanson, Illusion of Law I, supra note 84. With those who would claim that our examples are on the extreme side of the dispositionism spectrum, we might agree but would argue that they represent the vast bulk of the most influential policymakers and policy theorists today. In any event, we believe that those who do not occupy that extreme are nonetheless fairly described as dispositionists. For evidence supporting that claim, see Hanson \& Yosifon, supra note 30 ; infra Part VII 
And so we see countless instances of groups latching on to consumer sovereignty in order to meet the threats of heightened regulation and liability. Take, for example, the Center for Consumer Freedom, "a nonprofit coalition supported by restaurants, food companies, and consumers working together to promote personal responsibility and protect consumer choices." ${ }^{.407}$ The group is one of several created by Berman and Company, a public relations firm headed by Richard Berman, whose numerous projects have been heavily funded by the tobacco, alcohol, and restaurant industries. ${ }^{408}$ The Center for Consumer Freedom has, among other things, published and broadcast numerous advertisements purporting "to stand up for common sense and personal choice" seems to mean, stereotypes and dispositionism. In one advertisement, the group warns:

YOU ARE TOO STUPID ... to make your own food choices. At least according to the food police and government bureaucrats who have proposed "fat taxes" on foods they don't want you to eat. Now the trial lawyers are threatening class-action lawsuits against restaurants for serving America's favorite foods and drinks. We think they're going too far. It's your food. It's your drink. I $t$ 's your freedom. ${ }^{410}$

To those suggesting that the food industry is partially responsible for the obesity epidemic, ${ }^{411}$ the Center for Consumer Freedom maintains its hard-line dispositionism: "We need individual solutions for individual problems. And the best individual solution is personal responsibility." ${ }^{412}$ And just behind that dispositionism lurks the totalitarian bogeyman. Richard Berman, for instance, describes those with whom he disagrees as

${ }^{407}$ See Ctr. for Consumer Freedom, What is the Center for Consumer Freedom?, at http://www.consumerfreedom.com/main_faq.cfm (last visited Oct. 15, 2003).

408 See Ctr. for Media \& Democracy, ActivistCash.com/Center for Consumer Freedom, IMPROPAGANDA REV. (last visited Oct. 15, 2003) (claiming that Berman receives advice and funding from industry representatives), at http://www.prwatch.org/improp/ ddam.html.

${ }^{409}$ Ctr. for Consumer Freedom, supra note 407.

${ }^{410}$ Ctr. for Consumer Freedom, Advertisement, U.S. NEWS \& WORLD REP., May 27, 2002 , at 21.

411 See, e.g., Kelly Brownell \& Katherine Battle Horgen, Food Fight: ThE INSIDE STORY OF THE FOOD INDUSTRY, AMERICA'S OBESTTY CRISIS AND WHAT WE CAN DO ABOUT IT (2003).

${ }^{412}$ Ctr. for Consumer Freedom, Obesity: Individual Problem Demands Individual Responsibility, at http://www.consumerfreedom.com/headline_detail.cfm?HEADLINE ID=1962 (June 11, 2003). 
aggressors [who] are a blend of self-anointed "food police" activists; overzealous public health "experts" who'd like to raise our children for us; advocates of "Twinkie taxes"; lawmakers who use the cudgel of government to appear "enlightened" enough to be re-elected; and, yes, those trial lawyers who smell a payday where most of us just smell dinner. $^{413}$

And to underscore the point, the Center for Consumer Freedom labels a recent book criticizing the food industry's role in contributing to the obesity epidemic as a "Big Brother' Manifesto."

\section{Some Cross-Cultural Evidence of Deep Capture}

My research has led me to the conviction that two utterly different approaches to the world have maintained themselves for thousands of years. These approaches include profoundly different social relations, views about the nature of the world, and characteristic thought processes. Each of these orientations-the Western and the Eastern-is a self-reinforcing, homeosiatic system. The social practices promote the worldviews; the worldviews dictate the appropriate thought processes; and the thought processes both justify the worldviews and support the social practices.

-Richard E. Nisbett ${ }^{415}$

The previous Sections provided a sample of evidence suggesting that various regulatory institutions are, indeed, highly dispositionist. This evidence should not be surprising, given that social psychologists have demonstrated that we humans tend to see the world dispositionally. So, although the evidence might be consistent with our deep capture hypothesis and might well reveal a major cause for concern, it may only evince a shared cognitive illusion-a worldview that emerges solely from forces outside of anyone's control.

An important implication of deep capture is that our dispositionism is, at least in this market-oriented culture, more

${ }^{413}$ Richard Berman, All-out Assault by Food Cops: When Will it End?, USA TODAY, Aug. 15, 2002, at A13; see also Richard Berman, Beef Against Fast Food Could Lead to Economic Indigestion, BOSTON HERALD, June 21, 2003, at 16 ("Laugh now if you must, but this is serious business. How long before parents are criminally accountable for allowing their kids to be obese? How long before restaurants post width scales at the fast-food counter similar to the height scales on amusement park rides?").

${ }^{414}$ Ctr. for Consumer Freedom, Would You Take Dietary Advice from this Man?: Kelly Brounell's "Big Brother" Manifesto, at http://www.consumerfreedom.com/article _detail.cfm?ARTICLE_ID=125 (Aug. 26, 2003). For a look at the supposed "manifesto," see BROWNELL \& HORGEN, supra note 411.

415 RICHARD E. NISBETT, THE GEOGRAPHY OF THOUght: HOW ASIANS AND WESTERNERS THINK DIFFERENTLY... AND WHY, at xx (2003). 
profound than it would otherwise be. Corporations exercise their enormous power over situation to encourage and reinforce dispositionism because it is valuable to them. This presumes that the basic contours of our outlook are malleable, that even dispositionism is not stable but is subject to situational influence.

A question thus emerges as to whether dispositionism reflects anything more than our hardwiring as humans-a shared interior situation. The answer seems to be that it does. As we have already indicated, dispositionism varies somewhat across contexts. Thus, exterior situation matters too. Social psychologists have begun looking more specifically at the significance of culture. In a revealing study by Takahiko Masuda and Richard Nisbett, for example, students at Kyoto University and the University of Michigan were shown animated underwater scenes containing images of various undersea objects, such as rocks, small fish, plants, and a "focal fish." fish was larger, brighter and faster moving than the others-the sort of characteristics that would, according to conventional understandings, make them more salient to the observer. ${ }^{417}$ After viewing the scenes, students were asked to describe what they saw. Predictably, American students spoke immediately of the focal fish (e.g., "a trout, moving off to the left") and only later added references to its surroundings. ${ }^{418}$ The Japanese students, on the other hand, tended to begin by describing the context (e.g., "It looked like a pond"). ${ }^{419}$ During the course of their descriptions, students from both universities made roughly equal references to the focal fish, but the Japanese participants made over sixty percent more references to contextual elements and twice as many references to relationships with inanimate aspects of the environment (e.g., "the big fish swam past a rock"). ${ }^{420}$

According to Nisbett, such evidence confirms the hypothesis that members of some cultures are more inclined to take in the world as if through a wide-angle lens, whereas members of other cultures tend to see the world as if through a zoom. ${ }^{421}$ Nisbett argues that this

${ }^{416}$ NiSBETT, supra note 415, at 89-92; Takahiko Masuda \& Richard E. Nisbett, Attending Holistically Versus Analytically: Comparing the Context Sensitivity of Japanese and. Americans, 81 J. PERSONAlity \& SOC. PSYCHOL. 922, 924-25 (2001).

${ }^{417}$ Masuda \& Nisbett, supra note 416, at 924.

418 NiSBETT, supra note 415 , at 90 .

41.9 Id.

${ }^{420} I d$

491 Id. at 89. Recognizing the differences between self-conceptions in the East and in the West has long been a theme in both anthropology and philosophy. See 
distinction across cultures has ancient roots and may even help explain why the Chinese made connections that Aristotle and Galileo, with their telescopic vision, missed:

The Greeks' focus on the salient object and its attributes led to their failure to understand the fundamental nature of causality. Aristotle explained that a stone falling through the air is due to the stone having the property of 'gravity.' But of course a piece of wood tossed into water floats instead of sinking. This phenomenon Aristotle explained as being due to the wood having the property of 'levity'! In both cases the focus is exclusively on the object, with no attention paid to the possibility that some force outside the object might be relevant. But the Chinese saw the world as consisting of continuously interacting substances, so their attempts to understand it caused them to be oriented toward the complexities of the entire 'field,' that is, the context or environment as a whole. The notion that events always occur in a field of forces would have been completely intuitive to the Chinese. The Chinese therefore had a kind of recognition of the principle of 'action at a distance' two thousand years before Galileo articulated it. They had knowledge of magnetism and acoustic resonance, for example, and believed it was the movement of the moon that caused the tides, a fact that eluded even Galileo. ${ }^{422}$

Thus, the tendency goes beyond perception of non-human objects and is revealed as well in how "Easterners" and "Westerners" conceptualize and construe social contexts. ${ }^{423}$

KUNDA, supra note 20, at 515, (noting that anthropologists have long explored cultural differences in self-perception and social understanding) (citing CULTURE THEORY: ESSAYS ON MIND, MIND SELF, AND EMOTION (Richard A. Schweder \& Robert A. LeVine, eds. 1984)); see also Clifford Geertz, The Impact of the Concept of Culture on the Concept of Man, in NEW VIEwS OF THE NATURE OF MAN (J. Platt ed. 1966). For a collection of Geertz's influential writings on cultural anthropology, see THE INTERPRETATION OF Cultures: SElected ESSAYS by ClifFord GeERTZ (1973). More recently, social psychologists have begun to demonstrate and examine the difference. One of their key discoveries is, as we will review in this Section, that dispositionism varies across cultures. See generally KUNDA, supra note 20, at 515-60 (comparing differences in social cognition amongst different cultures, and in particular between Easterners and Westerners).

${ }^{422}$ KUNDA, supra note 20, at 21-22.

${ }^{423}$ We recognize and apologize for the breadth of these categories. To date, the distinctions by social psychologists have rarely been refined much past those of "Easterners" and "Westerners." Still, as broad and inadequate as those two categories may be, they represent a key advance over the nearly complete lack of categories that otherwise exists in many social scientific theories and lay theories of human actors. And that criticism, we confess, applies to much of social psychology and to virtually all of this Article, which too frequently speak of "human" tendencies-as if there is just one relevant category of humans as revealed through studies of mostly college students. This practice is particularly striking in light of the fact that, as we'll describe, the work comparing "Easterners" and "Westerners" has demonstrated significant cross- 
The evidence about cultural variations in dispositionism provides some additional support for our hypothesis that humans are both "individually" and "culturally" dispositionist, but it may go further. It suggests that dispositionism is greatest where the situational influence of large corporate interests has likely been greatest.

Recall the fundamental attribution error that is at the heart of dispositionism fallacy-the tendency to miss the influence of situation and to overstate the power of disposition in understanding one's own and other people's behavior. Earlier, we described the centrality of that bias to human perception and experience. ${ }^{424}$ Crosscultural comparisons, however, indicate that the fundamental attribution error may be more fundamental in Western societies than it is in other societies. ${ }^{425}$ People in Asia, for example, appear to be less prone to see disposition than are Westerners. ${ }^{426}$ The "focal fish" experiment provides some support for that conclusion. This disparity

cultural differences. See infra text accompanying notes 425-50; see also NISBETT, supra note 415, passim (providing evidence of how groups in different parts of the world not only think about different things, but actually think differently). Future work will likely yield a more refined understanding of how we conceptualize our worlds and of how those conceptualizations reflect and influence those worlds.

Additionally, we may find that much of the cognitive processes and emotions that social psychologists have understood as involuntary may be somewhat malleable. That, at least, was a recurring theme at a very recent two-day conference and discussion entitled, Mind and Life XI: Investigating the Mind: Exchanges Between Buddhism and the Biobehavioral Sciences on How the Mind Works, (held at MIT, Sept. 13-14, 2003, and cosponsored by the McGovern Institute at MIT and the Mind and Life Institute, and attended by, among others, Daniel Kahneman, Daniel Gilbert, and the Dalai Lama). For an overview of the conference and materials, see, Mind \& Life Inst., Mind and Life XI: Investigating the Mind, at http://www.investigatingthemind.org/index.html (last visited Nov. 22, 2003). For a brief account of some of the exchanges and dynamics that led to the conference and research that has been initiated in reaction to previous, related conferences and discussions, see Stephen S. Hall, Is Buddhism Good for Your Health?, N.Y. TIMES MAG., Sept. 14, 2003, at 46.

The problem is not just that the category "human" is too broad. In fact, it may also be too narrow. We suspect that our conceptions of other animals will demonstrate that "humans"-there we go again-are unique in fewer ways and to a lesser degree than "humans" have historically tended to believe. For recent general accounts along those lines, see JEFFREY MOUSSAIEFF MASSON \& SUSAN MCCARTHY, WHEN ELEPHANTS WeeP: The Emotional lives of ANimals (1995); George Page, Inside the ANimal MiND (1999).

${ }^{424}$ See supra text accompanying notes 86-107 (discussing various studies that reveal the persuasiveness of the fundamental attribution error).

${ }^{425}$ See KUNDA, supra note 20, at 525-33 (discussing several studies that compare Western and Eastern paradigms about dispositional and situational attribution); NISBETT, supra note 415, at 123-27 ("Westerners tend to assume that events are caused by the object and Asians are inclined to assign greater importance to the context.").

${ }^{426}$ KUNDA, supra note 20, at 526-27, 529-32. 
has been demonstrated in numerous experiments, including variations of the famous pro-Castro, anti-Castro speech experiment highlighted above. ${ }^{427}$

In the basic version of that study, recall, subjects who knew that a student had been instructed to write and deliver a pro-Castro speech nevertheless thought that the views the student expressed in her speech were representative of her true dispositional beliefs. ${ }^{428}$ The same dispositionist mistake appeared when the study was conducted with a group of East Asian subjects-that is, subjects at first overstated the role of disposition in the students' speeches. ${ }^{429} \mathrm{~A}$ number of similar studies have documented this basic commonality between Westerners and Easterners in the tendency to overstate disposition. ${ }^{40}$ Social psychologists therefore do believe that dispositionism, in its most basic form, is a widely shared human tendency. ${ }^{43}$

Differences begin to emerge, however, when the basic design of the experiment is altered to highlight the role of the situational pressure even more prominently to subjects-by, for example, placing the subject in the target's shoes and requiring her to write an essay that takes a particular stance. American subjects continue to exhibit the fundamental attribution error in significant proportions, while East Asians become far more likely to acknowledge the role of situation in the speeches they hear. ${ }^{432}$ This variation in dispositionism has recurred in several studies comparing Eastern to Western subjects. ${ }^{493}$ Such cross-cultural differences in the power of

${ }^{427}$ Id. at 532-33 (concluding that "East Asians are more likely than North Americans to pick up on cues pointing to the importance of situational constraints"); see also Eric D. Knowles et al., Culture and the Process of Person Perception: Evidence for Automaticity Among East Asians in Correcting for Situational Influences on Behavior, 27 PERSONALITY \& SOC. PSYCHOL. BULL. 1344, 1348-54 (2001) (discussing an experiment that asked students from the United States and Hong Kong to characterize the attitude of a speaker, based on the speaker's speech about a political issue). For our earlier description of the Castro experiments, see supra text accompanying note 155 .

428 See supra text accompanying note 155.

${ }^{429}$ KUNDA, supra note 20, at 532 .

${ }^{430} I d$. at 525-32 (discussing several studies focusing on the dispositional tendencies of Westerners compared to non-Westerners); NISBETT supra note 415, at 125 (explaining that "the illusion is sufficiently powerful that even East Asians are susceptible").

${ }^{4.31}$ KUNDA, supra note 20, at 532; Fiske et al., supra note 195, at 915, 930-33; Knowles et al., supra note 427, at 1354.

${ }^{432}$ KUNDA, supra note 20, at 532; NISBETT supra note 415, at 125.

${ }^{433}$ KUNDA, supra note 20 at 525-32; Fiske et al., supra note 195, at 930-33. Other studies have yielded more specific evidence of the contours of cultural difference and 
the fundamental attribution error suggest that, although dispositionism may be universal, the degree of dispositionism varies across cultures. ${ }^{434}$ Overall, the findings suggest that dispositionism is itself subject to situational influence, a reality that helps to make deep capture possible.

Another dimension to these cross-cultural experiments confirms that hypothesis. In a number of studies, people who are from the East but living in the West exhibit an outlook that falls between the strong dispositionism seen in Western subjects and the weaker dispositionism seen in Eastern subjects. ${ }^{435}$ A compelling explanation

how it manifests in broader outlooks and motivations. One study of American and Japanese subjects, for example, compared self-enhancement biases in Western and Eastern subjects. Groups of American and Japanese subjects were asked to provide a list of examples of situations that they felt had enhanced their self-esteem, and others that they felt had diminished it. See Shinobu Kitayama et al., Individual and Collective Processes in the Construction of the Self: Self-Enhancement in the United States and SelfCriticism in Japan, 72 J. PERSONALITY \& SOC. PYSCHOL. 1245, 1249-54 (1997); see also KUNDA, supra note 20, at 542-47 (summarizing Kitayama's experiments). The researchers then took a list of four hundred responses culled from both groups and administered the list to new subjects, again comprised of American and Japanese subjects. Id. at 544 . The subjects were asked to select the situations that they felt were applicable to themselves, and how their self-esteem had been affected by the situation. Id. The results revealed strikingly different self-perceptions between the American and Japanese subjects. American subjects exhibited a more pronounced self-serving bias, claiming that a higher proportion of the self-enhancing situations applied to themselves than did the Japanese subjects. So significant was that tendency among Westerners that it held true even for self-enhancing characterizations that had been provided by the earlier Japanese subjects; that is, Americans were more likely than Japanese subjects to claim that those characterizations applied to themselves. Id. at 546-47.

The self-enhancement tendency is one aspect of the broader dispositionist character that social psychology has documented in Western society. See supra text accompanying notes 194-95; see also Hanson \& Yosifon, supra note 30 . The results of the above study, and others like it, suggest that the tendency to see oneself as interacting with the world as a stable dispositional actor is more pronounced in individuals in Western society than it is among people in the East. Related studies, for example, demonstrate that self-enhancement biases are less prevalent in the East than in the West. See KUNDA, supra note 20, at 538-43 (recounting a study that suggested Canadians demonstrate a greater self-enhancing bias than do Japanese).

${ }^{434}$ "All these studies point to the same conclusion. Westerners tend to view social behavior as driven by internal, stable dispositions such as traits and attitudes. In contrast, Easterners tend to view social behavior as determined by the individual's interpersonal relations, roles, circumstances, and cultural milieu." Id. at 531.

${ }^{435}$ See id. at 540 (describing studies that show that Asian Canadians' dispositionist tendencies fall somewhere between the dispositionist tendencies of Asians and those of European Canadians). In the self-enhancement study discussed above, see supra note 433, Japanese subjects living in the United States were less prone to selfenhancement than American subjects, but more prone than Japanese subjects living in Japan. KUNDA, supra note 20, at 546. Another study found that Canadians of 
for these findings is that when subjected to different situational influences-that is, different cultures-people develop differences in how they perceive behavior. ${ }^{436}$ In other words, situation, not dispositional factors such as biology or race, makes the difference. And importantly for our deep capture thesis, the Western cultural situation appears to drive people into a deeper dispositionism and away from situationism. Undoubtedly, differences in basic outlook remain among the many subcultures within Western society. ${ }^{437}$ The general patterns, however, are reasonably clear that dispositionism is stronger in the West than in the East, and that the situational influences of Western culture powerfully alter outlooks toward dispositionism. ${ }^{438}$

The evidence suggesting a greater sensitivity in Eastern society than in Western society to situational influences over behavior at first appears to challenge explanations of the fundamental attribution error that are rooted in the mechanics of human perception. In our earlier discussion we stressed, as have social psychologists, that one reason for the fundamental attribution error is the relative facility of seeing individual behavior compared to the situational influences that may give rise to it. ${ }^{439}$ Our limited perceptual and cognitive resources focus on what is stark and miss what is subtle. Therefore, we see the person who would administer painful shocks to a testsubject as dispositionally bad or sadistic, rather than account for the myriad of situational influences that help account for that behavior. ${ }^{440}$ Notably for our thesis, social psychologists have not abandoned the basic perceptual explanation of the human tendency to overstate

Asian heritage exhibited self-enhancing biases at rates lower than those registered by European Canadians, but higher than those that were seen in Japanese subjects living in Japan. Steven J. Heine \& Darrin R. Lehman, The Cultural Construction of SelfEnhancement: An Examination of Group-Serving Biases, $72 \mathrm{~J}$. PERSONALITY \& SOC. PSYCHOL. 1268, 1278 (1997).

${ }^{436}$ See KUNDA, note 20 , at 540 ("Canadians of Asian heritage who may be assumed to absorb Asian culture at home while being exposed to North American culture everywhere else show[] some but not total adoption of Western cultural patterns.").

${ }^{437}$ See id. at 549-56 (describing studies on differences in outlook between people in the Northern and Southern United States).

${ }^{438}$ Of course, it should be recognized that cross-cultural social psychology is a nascent field; findings are at this point preliminary, and more will be learned about differences between the social psychologies of different cultures as this field grows. See KUNDA, supra note 20, at 547-49 (cautioning that the work in this area is at an early stage and therefore "not conclusive").

${ }^{439}$ See supra text accompanying notes 19-23, 139-45, 182-96 (defining the fundamental attribution error and describing some of the causes).

${ }^{440}$ See supra text accompanying notes 86-99 (discussing the Milgram experiments). 
dispositionist explanations of behavior. Indeed, this basic perceptual account explains the baseline of similarity seen in the cross-cultural Castro speech experiments. ${ }^{441}$

According to social psychologists, the ultimate divergence in the commitment to dispositionist explanations is a product of the difference in the two cultures' lay theories of the relationship between individuals and society. ${ }^{4+2}$ In the West, the perceptual foundation of the fundamental attribution error is surrounded by lay

${ }^{441}$ Supra notes 425-31 and accompanying text; see also David M. Buss, Human Nature and Cullure: An Evolutionary Psychological Perspective, 69 J. Personality 955, 968 (2001) (acknowledging a universal human nature, and recognizing that the human mind contains many complex psychological mechanisms that are selectively activated, depending on cultural contexts).

${ }^{442}$ Cf. KUNDA, supra note 20 , at 537-38 (concluding that maintaining and enhancing one's self-esteem, [which is linked to dispositionism], is more important in Western cultures than in Eastern cultures because of differing views on the relation between the individual and society). The Japanese legal system seems to reflect elements of their lay theories, which focus on the role of the individual as interdependent with the collective. See, e.g., Koichiro Fujikura, Administering Justice in a Consensus-Based Society, 91 MICH. L. REV. 1529, 1541-42 (1993) (discussing the position of Hamilton and Sanders that in Japanese society "those who insist on their legal rights may be seen as free riders, exploiting the collective benefit, and modern legal reforms in Japan can be interpreted as a "process of constant adjustments to thwart the corrosive impact of litigious free riders on a nonlitigious legal order"') (quoting V. LeE HAMILTON \& JOSEPH SANDERS, Everyday Justice: RESPONSIBIlity aNd THE INDIVIDUAL IN JAPAN AND THE UNITED STATES 193 (1992)); V. Lee Hamilton \& Joseph Sanders, Punishment and the Individual in the United States and Japan, 22 LAw \& SOC'Y REV. 301, 304 (1988) (suggesting that in Japan, "the individual is seen as operating in networks and contexts ... [so] sanctions for wrongdoing are influenced by individuals' embeddedness in roles"); Erik W. Ibele, Govermment Regulation of Technology Licensing in the Pacific Rim: The Legacy of Industrial Policy, 15 WIS. INT'L L.J. 299, 301 (1997) (noting that the "collective focus is evident in the language of Article I of the Japanese Patent Law which states, 'the purpose of this Law shall be to encourage inventions by promoting their protection and utilization so as [sic] to contribute to the development of industry'") (quoting Tokkyoho [Patent Law], Law No. 121 of 1959, art. 1, translated in [VI Japan] EHS Law Bull. Series No. 6850A, at SA-A 2 (1994)); Mark A. Levin, Essential Commodities and Racial Justice: Using Constitutional Protection of Japan's Indigenous Ainu People to Inform Understandings of the United States and Japan, 33 N.Y.U. J. INT'L L. \& POL. 419, 48488 (2001) (discussing the conception of individualism in Japan and how that outlook has shaped interpretation of the American-influenced, individualistically-worded constitution); Glenn Theodore Melchinger, For the Collective Benefit: Why Japan's New Strict Product Liability Law is "Strictly Business," 19 U. HAw. L. REV. 879, 931 (1997) (arguing that Japan's new products liability scheme may seem toothless by our standards because it takes the cost of social conflict into account); Masumi Anna Osaki, Comment, A Look at Damage Awards Under Japan's Trademark Law and Unfair Competition Prevention Law, 8 PAC. RIM L. \& POL'Y J. 489, 492 (1999) ("Traditional collectivist values that frown upon personal gain have contributed to the inadequate enforcement of individual intellectual property rights in Japan ... [and have] traditionally resulted in limited awards...."). 
theories of the self as an autonomous, free, dispositionally stable individual. ${ }^{443}$ In this fashion, the fundamental attribution error serves to confirm the dispositional worldview for Westerners. On the other hand, cultures in the East entertain lay theories that portray the individual as situated in an array of interdependent social relationships in which roles, rather than individual actors, are emphasized. ${ }^{44}$ Social psychologists, thus, attribute to culture the fact that Eastern subjects appear to correct more easily for the fundamental attribution errors received from basic perceptual cues than do Western subjects. ${ }^{45}$ That explanation finds support in a number of cross-cultural studies. For instance, individuals who have been "multiply enculturated"- that is, exposed extensively to two or more cultures-can be situationally primed to activate the causal schemas characteristic of either culture. In one study, students in Hong Kong were shown one of the following: Western images (such as a cowboy on a horse), Eastern images (such as a dragon), or neutral images (such as a landscape). ${ }^{446}$ Afterwards, when making causal attributions, subjects in the first group were most dispositionist, subjects in the second group were most situationist, and those in the control group fell in between. ${ }^{447}$ Studies by developmental psychologists have found that Eastern and Western children exhibit common fundamental attribution errors and, unlike their parents, Eastern children do not correct for those errors when situational constraints 30 .

${ }^{443}$ See supra text accompanying notes 194-95; see also Hanson \& Yosifon, supra note

${ }^{444}$ See KUNDA, supra note 20, at 537-38 (noting that Eastern cultures tend toward the notion that individuals are highly interdependent with others in society). But see Yohtaro Takano \& Eiko Osaka, An Unsupported Common View: Comparing Japan and the U.S. on Individualism/Collectivism, 2 ASLAN J. SOC. PSYCHOL. 311, 316-30 (1999) (reviewing empirical studies comparing conceptions of individualism and collectivism in the two nations, and finding that the standard view, which holds that Japanese are more collectivist than Americans, is based on flimsy grounds and might be attributable to the fundamental attribution error).

${ }^{445}$ See supra notes 416-23 and accompanying text (reviewing experiments that illustrate this hypothesis).

${ }^{446}$ Ying-yi Hong, et al., Bringing Culture out in Front: Effects of Cultural Meaning System Activation on Social Cognition, in PROGRESS IN ASIAN SOCIAL PSYCHOLOGY 139, 141-46 (Kwok Leung et al. eds., 1997).

447 Id at 146. Researchers have discovered the same situational sensitivity to cultural primes on the part of Asian Americans. See Kaiping Peng \& Eric Knowles, Culture, Education, and the Attribution of Physical Causality, 29 PERSONALITY \& SOC. PSYCHOL. BULL. 1272, 1279-83 (2003) (demonstrating that culturally instilled folk theories affect Chinese Americans' interpretations of physical phenomena). 
are highlighted. ${ }^{448}$ Having not yet learned the situational lay-theories that their culture provides, their perceptions appear to rest on the limitations that give rise to the fundamental attribution error in Easterners and Westerners alike. ${ }^{449}$

It is important to note that Easterners' tendency to correct for dispositional overstatements is itself an unseen, subtle process. The studies revealing the relative depth or shallowness of the fundamental attribution error show that the adjustments for situation are often made automatically; they are not the result of a conscious, explicit, intentional adherence to an ideology or worldview. ${ }^{450}$ The difference in outlook, driven by cultural differences, is attributable to unseen processes, not dispositional choice. Consequently, while exterior situation helps explain the depth of our dispositionism, that influence is registered automatically, beneath our conscious control in the situations of our interiors.

The fact that situational influence determines the depth of our dispositionism is extremely advantageous to corporations, which, as we have indicated, have an interest in encouraging such an outlook. ${ }^{451}$ The capture of this outlook can be accomplished by exercising power over situation, a pursuit that is itself enabled by the strength of the dispositionist theories that support corporate power.

${ }^{448}$ See KUNDA, supra note 20, at 527 ("Cultural differences in attribution appear to emerge only in mature individuals who have been well-socialized into their culture's view of the person."); see, e.g., Joan G. Miller, Culture and the Development of Everyday Social Explanation, $46 \mathrm{~J}$. PERSONALITY \& SOC. PSYCHOL. 961 (1984) (comparing attributions of Indian Hindu children with those of American children and finding that children in the two cultures did not differ in the sorts of explanations they gave and that explanations did not begin to take culturally scripted form until adolescence).

${ }^{449}$ See KUNDA, supra note 20, at 526-27 (discussing the findings of Miller, supra note 448 , with regard to Eastern children's attribution behavior).

${ }^{450}$ See Knowles et al., supra note 427 , at 1354 ("East Asians ... have the ability to automatically correct [dispositionist] inferences in light of situational constraints.").

${ }^{451}$ See supra Part V.C.4.c.ii (arguing that a dispositionist worldview benefits corporations, both individually and collectively).

${ }^{452}$ Hence, one might expect dispositionism to grow more robust in the East, as Western corporations strive to maximize profits in Eastern markets. On the other hand, we might expect to see differing methods of deep capture in markets where dispositionism is less pronounced. Certainly, even in the West, there is evidence of corporate appeals to group identities and situationist conceptions, such as is seen in patriotic or racially identified messages. It is the situation, and not our dispositionism directly, that makes deep capture possible. If deep capture can be accomplished more effectively or more efficiently by promoting other worldviews, then such efforts may take different forms in different cultures. 


\section{Some Direct Evidence of Deep Capture}

As we just reviewed, evidence about cultural variation of dispositionism is consistent with our deep capture hypothesis in a number of ways. However, that evidence, by itself, does little to demonstrate that corporate efforts are an important cause of the heightened dispositionism of the West. Many would argue that any causal connection is actually the reverse of the one we have hypothesized. For instance, the prominence and success of commercial interests in America could well reflect the heightened dispositionism of Americans.

There is almost certainly some truth to that view. The American self-conception is one of individualism, a sibling concept of what we refer to as dispositionism. This individualism seemed to emerge without much obvious encouragement by large commercial interests and is sometimes associated with people like Henry David Thoreau, who seem anything but deeply captured. President Herbert Hoover saw individualism as the cornerstone of the American character (or disposition):

Individualism has been the primary force of American civilization for three centuries. It is our sort of individualism that has supplied the motivation of America's political, economic, and spiritual institutions in all these years. It has proved its ability to develop its institutions with the changing scene. Our very form of government is the product of the individualism of our people, the demand for an equal opportunity, for a fair chance.

The American pioneer is the epic expression of that individualism, and the pioneer spirit is the response to the challenge of opportunity, to the challenge of nature, to the challenge of life, to the call of the frontier.

In this way, Americans have long seen their individualism as both obvious $^{454}$ and the most significant factor behind their relative economic and political success. That self-affirming self-conception may, however, be yet another example of the fundamental attribution error. In our view, attributing our success to our individualist disposition misses the more significant role of our

${ }^{453}$ Herbert HoOver, AMERICAN Individualism 63-64 (1922).

${ }^{4.54}$ Of course, as we have emphasized, the fact that something is obvious does not mean it is entirely true. See BARRY ALAN SHAIN, THE MYTH OF AMERICAN INDIvidualism: The Protestant Origins of American Political Thought 21 (1994) ("Contrary to popular belief, Americans in the years surrounding the Revolution were not adherents of political individualism ...."). 
situation, which itself has fostered success and rendered more plausible our self-conception. Put differently, the American pioneer may not be "the epic expression of . . individualism," tend to presume. Rather, the individualism is as much the consequence of the existence of a valuable situation, including an immense frontier. ${ }^{436}$

${ }^{455}$ HoOvER, supra note 453 , at 63 .

456 Again, the cultural disposition of individualism may well reveal more about the situation than is commonly recognized. See supra text accompanying notes 444-49 (discussing the link between a culture's regard for individualism and that culture's tendency toward dispositionism). "The frontier" provided to those who ventured to America a chance to change their lives-an escape in some cases, an opportunity in others. By sailing West to get to America and then "going West" once here, the situation would have seemed far less constraining: gone were many of the shackles of religious persecution, population density, employment pressures, and rigid class norms. Those who survived and thrived did so perceiving they had acted according to their choices. Seemingly boundless land and natural resources, together with growing markets and changing technologies, provided many Americans with a strong perception of self-reliance and self-determination. To a large degree, that perception held true-but largely because the situation permitted it. In other words, the freedom that we attribute to the disposition of individuals may more accurately be the consequence of the options afforded by the situation in a "land of opportunity." Particularly when compared to the Old World-where famine, poverty, and political strife rendered the situation oppressive and salient-the New World would have felt to many people (particularly young, strong, entrepreneurial, free, and white men) as a land where disposition decided one's fate. Again, the frontier on which the American pioneer was permitted to venture was itself a great situational source of both perceived individualism and this country's success.

With that commentary, we have here inadvertently stumbled into the midst of a long-standing historiographical battle. The classic work that initiated that battle was written in the late nineteenth century by Frederick Jackson Turner. FREDERICK JACKSON TURNER, The Significance of the Frontier in American History (1893), reprinted in THE FRONTIER IN AMERICAN HISTORY 1 (1920). Turner challenged the thenconventional "germ theory" that the American character was a dispositional legacy of the Old World and emphasized instead the situational effects of the frontier in giving shape to a distinctly American disposition. In his words:

[T] the frontier the American intellect owes its striking characteristics. That coarseness and strength combined with acuteness and inquisitiveness; that practical, inventive turn of mind, quick to find expedients; that masterful grasp of material things, lacking in the artistic but powerful to effect great ends; that restless, nervous energy; that dominant individualism, working for good and for evil, and withal that buoyancy and exuberance which comes with freedom-these are the traits of the frontier, or traits called out elsewhere because of the existence of the frontier.

$I d$. at 37 . A century of historical analysis and debate has discredited many of the details of Turner's frontier thesis. See, e.g., Donald Worster, New West, True West: Interpreting the Region's Histomy, 18 W. HIST. Q. 141, 144-46 (1987) (rejecting the process idea central to Turner's thesis, preferring instead to define the West as a fixed geographical region). But there remains, we believe, a strong case that situation-including our interior situation, which may be motivated to see ourselves as the rugged individuals 
Be that as it may, the fact that different cultures tend to be more or less dispositionist reveals how dispositionism can itself be influenced by the situation, thus leaving the door open for deep capture. However, it does not, in and of itself, provide direct evidence of deep capture. If our culture is especially dispositionist, one would expect our legal theorists, lawmakers, and laws ${ }^{477}$ to share or reflect that fundamental bias. Similarly, one would expect advertisers to reflect that same view, by design or not, in marketing their products in America. The Marlboro Man, as a cigarettesmoking frontiersman, may reflect little more than a shared sense that he is us and we are him: autonomous, free, and unfettered,... the epic expression of individualism. ${ }^{458}$ Thus, to support the portion of the deep capture hypothesis that predicts that large commercial interests actively and sometimes consciously promote dispositionist worldviews directly, we need a different sort of evidence, a small sample of which we will highlight here.

Fortunately, providing evidence is quite simple. All one has to do is point to the hundreds of billions of dollars spent each year on advertising, marketing, and public relations. ${ }^{459}$ Large commercial entities are using and developing the sort of social psychological research of which the rest of us are either ignorant or dismissive. As one of us has argued at length (with Doug Kysar), marketing texts and marketing firms are steeped in an understanding of the powerful role of situation. ${ }^{460}$ Moreover, they use what they know (and learn from market experience) to manipulate consumer perceptions and behavior. ${ }^{461}$

that Turner idealized-plays far more of a role in defining who we are, or like to believe we are, than we recognize. Cf. JARED DIAMOND, GunS, GERMS \& STEEL: THE FATES OF HUMAN SOCIETIES 25 (1997) ("History followed different courses for different peoples because of differences among people's environments .....”).

${ }^{457}$ For examples of the influence of dispositionist presumptions on laws, see Hanson \& Yosifon, supra note 30 (examining dispositionism in contract, tort, and criminal law); infra text accompanying notes 598-614 (describing the dispositionism inherent in contract law).

${ }^{458}$ See also Bruce A. Lohof, The Higher Meaning of Marlboro Cigarettes, 3 J. POPULAR CUlTuRE 441, 447 (1969) (comparing the Marlboro image to Frederick Jackson Turner's vision of the frontier).

${ }^{459}$ See Ticker, BRILL'S CONTENT, Oct. 2000, at 33 (detailing the level of advertising expenditure in the United States).

${ }^{460}$ For a discussion of this point, see Hanson \& Kysar, Taking Behavioralism Seriously II, supra note 251 .

${ }^{401}$ For more on this idea, see id.; Hanson \& Kysar, Taking Behavioralism Seriously I, supra note 251; Hanson \& Kysar, Taking Behavioralism Seriously III, supra note 257. See 
We will not review that work here. For now, we hope it is sufficient to point out that when social psychologist Robert B. Cialdini $^{462}$ wrote his popular book, Influence: The Psychology of Persuasion, ${ }^{463}$ he devoted one of six main chapters to the Milgram experiments and their lessons for marketing. ${ }^{464}$ A review of the book in the Jourmal of Retailing raved that "[Influence] could be required, profitable 'weekend reading' for business majors." stated that "[f]or marketers, [this book] is among the most important books written in the last 10 years. ${ }^{\$ 46}$ Similarly, many other marketing-oriented writings on consumer behavior underscore the importance of situation over disposition in determining individual behavior. "An actor in a play takes his cue from a line or some other happening or event. The human mind takes its cue from its intentions and its immediate environment. Such cues can influence what we think about next." ${ }^{467}$ Such is the starting point for one influential marketing guide promising to "demystif[y] the effects of advertising and describ[e] some of the psychological mechanisms underlying them ... written primarily for those who foot the bill for advertising and those who produce advertising."

Marketing and advertising practices thus reveal the deep, though apparently unseen, irony in the advertisements that we summarized earlier. ${ }^{469}$ Advertisers commonly present to us a vision of ourselves that confirms our self-affirming, dispositionist (and non-manipulable) self-image. They do so, it would seem, in order to manipulate our perceptions and behavior. The manipulation apparently works, as revealed by their choice to continue doing so at a substantial cost.

In a way, that is our entire case in a nutshell. We are subject to influence and manipulation from sources that we do not see or do

also Hanson \& Kysar, supra note 403 (showing how tobacco manufacturers manipulate consumer perception and preferences to increase profits).

${ }^{462}$ Robert B. Cialdini is the Regents' Professor of Psychology at Arizona State University in Tempe.

${ }^{463}$ Robert B. Cialdini, Influence: The Psychology of Persuasion (rev. ed. 1993).

${ }^{464} I d$. at $208-36$.

${ }^{465}$ Roger A. Dickinson, Influence, 60 J. RETAILING, Winter 1984, at 126, 128 (book review).

${ }_{466}$ Alan J. Resnik, Influence: Science $\mathcal{E}$ Practice, 23 J. MARKETING RES., Aug. 1986, at 305, 305 (1986) (book review).

${ }_{467}$ MAX SUTHERLAND \& ALICE K. SYLVESTER, ADVERTISING AND THE MIND OF THE CONSUMER: WHAT WORKS, WHAT DOESN'T, AND WHY 17 (2d ed. 2000).

${ }^{468} I d$. at 4.

${ }^{469}$ See supra text accompanying notes 393-406. 
not consider relevant. Those with the ability to influence those sources wield immense influence over us, while we continue to believe that we are acting independently, according to our preferences. We conclude that advertising works, but deny that it works on us. ${ }^{470}$ But, to borrow one of the oldest strategies in the book, do not take our word for it-listen to what those in the industry say about what they do. For example, the Web site for Burson-Marsteller, a public relations firm, has this to say about their industry:

What makes public relations so important is that people's opinion of . . a company, or a company's products or services is to a great extent beyond that ... company's control. A public relations agency offers these ... companies the resources necessary to make today's incredibly diverse influences work for them. It accomplishes this by having messages about the . . company or company product or service communicated through a credible third party such as a trusted journalist, physician, television or radio commentator, entertainer, or influential Internet figure. In essence, a public relation agency optimizes the power of endorsement by successfully influencing those who influence a targeted audience. ${ }^{47}$

Hill and Knowlton, one of Burson-Marsteller's chief competitors and the firm responsible for designing the tobacco industry's response to evidence that smoking caused lung cancer, ${ }^{472}$ describes their role in very similar terms:

Powerful communications that make a difference[,] ... that can transform, inspire, move and educate is why we exist. This power can be accessed by our clients wherever and whenever they need it; in specialist arenas and in global campaigns; in the corridors of

${ }^{470}$ See Jean Kilbourne, Can't Buy My love: How Advertising Changes the WAY WE THINK AND FEEL 27 (1999) (“[J]ust about everyone in America still feels personally exempt from advertising's influence."); see also Emily Pronin, Daniel Y. Lin \& Lee Ross, The Bias Blind Spot: Perceptions of Bias in Self Versus Others, 28 Personality \& SOC. PSYCHOL. Bull. 369, 370-78 (2002) (summarizing several studies finding that people see motivational and cognitive biases much more readily in others than in themselves).

${ }^{471}$ Burson-Marsteller, Inc., Why You Need a PR Firm, at http://www.bm.com/ resources/why_pop.html (last visited Mar. 5, 2003) (emphasis added).

${ }^{472}$ See KAREN S. Miller, THE VOICE OF Business: Hill \& KNOWLTON AND POSTWAR PUblic Relations $121-45$ (1999) (remarking on Hill \& Knowlton's role in "promot[ing] the notion that the case against smoking has not been proved," and the later description of Hill \& Knowlton's work as "one of PR's best finger-in-the-dike jobs ever"). 
government; in the financial centers and in the minds of consumers everywhere.

Richard Berman's public affairs firm, Berman and Company, which represents the cigarette, restaurant, and alcohol industries, describes in like fashion its bold mission to "[c] hange the debate" for the sake of its clients: ${ }^{47}$

Many PR firms promise access to the media. Law firms pledge to defend their clients. Lobbying firms promise access to friendly legislators. At Berman and Company we do all this. But we go further. We change the debate. If necessary, we start the debate.

....

... Our success is based on three core competencies: credible research as the foundation for effective messages disseminated via aggressive communications.

By analyzing the way marketers, advertisers, and public relations firms view us, it is clear that we are not as dispositional as we think we are. A major sector of our economy is making a huge profit by maintaining two visions of the human animal. The public vision is often that of the dispositional, independent, rational actor. The private vision is that of the situational character, capable of manipulation through situational influence. Those with the greatest stake in perpetuating the illusion that we are dispositionists encourage, promote, and market our dispositionism, in significant part because doing so helps make the situation that much more invisible. It is largely through the unseen situation that consumers, like other individuals, institutions, and entities in our culture, are deeply captured.

From this vantage point the Marlboro Man reveals himself not as a reflection of what we-advertisers and consumers alike-all see about ourselves. Rather, he embodies that dispositionist self whom marketers want us to see, but whom they understand is almost as fictional as the Marlboro Man himself.

The Marlboro Man first saddled up in the 1950s, as part of a concerted effort by Philip Morris to attract male smokers who may

${ }^{479}$ Hill \& Knowlton, Homepage, at http://www.hillandknowlton.com/global (last visited Oct. 24, 2003).

${ }^{474}$ Berman \& Co., Homepage, at http://www.bermanco.com/ (last visited Oct. 24, 2003).

Id.; see infra text accompanying notes $483-500$ (describing in more detail the use of third-party spokespeople for credibility, and detailing some of the particular strategies and tactics used to create and maintain access to such third parties). 
have been frightened by then-fresh reports of the health risks of smoking. ${ }^{476}$ Marlboro was a filtered brand that had originally been marketed, with limited success, as a woman's cigarette behind the slogan "Mild as May." The cowboy image eventually proved the most popular of a group of potential pitchmen, including explorers, sailors, athletes and other rugged men. ${ }^{478}$ In a three-page spread in the January 1957 issue of Life magazine, ${ }^{479}$ the caption read, "The Marlboro Man speaks for himself." "In0 Introducing his Western way of life, the Marlboro Man states: "Own my own ranch ... [I] ride from one end of it to the other every day... I like the life a man leads out here . . . the good feeling of being your own boss." ${ }^{481}$ Over the next four decades, the Marlboro Man would help Marlboro become, in the words of a Phillip Morris competitor, "the most valuable brand item in the world." ${ }^{482}$ The cowboy image was so successful because it tapped into the same American ideal of the independent frontiersman that Hoover credits as the "primary force of American civilization:" ${ }^{483}$

${ }^{476}$ The tobacco industry refers to the publication of the first lung cancer reports as the "Big Scare," a transformative moment for virtually all industry practices, not just their advertising. Plaintiff's Complaint at II 68-73, Commonwealth ex rel. Fisher v. Philip Morris, Inc. (Pa. Ct. Com. Pl. Apr. 1997) (No. 2443), available at http://www.attorneygeneral.gov/ppd/tobacco/complaint.cfm; see also Hanson \& Kysar, Taking Behaviorism Seriously II, supra note 251, at 1483-87 (describing the "Big Scare" and the industry's initial concerted response). See generally Richard Doll, Cancer by the Carton, READER's DIG. (Dec. 1952).

${ }^{477}$ See Katherine M. West, The Marlboro Man: The Making of an American Image, at http://www.people.virginia.edu/ tsawyer/mman/mman.html (last visited Oct. 24, 2003) (describing the evolution of the Marlboro marketing campaign).

${ }^{478}$ Lohof, supra note 458 , at 443-44 (noting that by the early 1960 s the cowboy had surpassed these other concepts and "was promoted to supremacy"); see also Leo Burnett, Advertisement, The Marlboro Story, NEw YORKER, Nov. 15, 1958, at 41-43 (describing the marketing campaign of Marlboro in the 1950s).

${ }^{479}$ Advertisement, The Marlboro Man: What's He Like, LiFE, Jan. 21, 1957, at 7, 7-9.

Id. at 8.

${ }^{481}$. at 8-9.

${ }^{482}$ Cover Letter, MKTG. InTElligence DeP'T, Brit. AM. TOBaCco Co., How MARLBORO LED THE PACK, (1994), available at http://www.library.ucsf.edu/tobacco/ batco/OCR/100/177.txt [hereinafter BATCO REPORT]. According to the report, "Marlboro [i]s the most successful brand in the history of consumer marketing, more so even than Coca Cola, which has a higher awareness level but lower profitability.... [I]n 1993, Financial World reported that [the Marlboro Man was] the world's most valuable trademark[,] valued at $\$ 39.5$ billion." Id.

${ }^{483}$ See supra text accompanying note 453 (quoting Hoover) (discussing individualism as the cornerstone of American character). 
[T] he cowboy proved to be the advertising "Big Idea" achieving universal appeal. During the 1950 s and 60 s the popularity of American cowboy films meant that for most people the cowboy became [ $t$ ]he symbol of America and the American "dream," cutting across barriers of sex, and social and cultural divisions.

... [T] he underlying themes of adventure, freedom, independence, being in charge of your destiny, open spaces and escapism for the urban dweller have proved appealing to several generations. They still have contemporary relevance; the cowboy is an icon of sturdy independence, the kind of person who chooses to smoke, a quiet defender of free choice.

That the Marlboro Man portrays an image of "free choice" should come as no surprise. It is more than an appeal to an active American script; it also deepens that script. Of course, it also helps to sell a product that most would agree gains its appeal from almost entirely situational sources. Those sources can be either exterior situational influences, such as peer pressure, or interior situational influences, such as addiction. From that perspective, it is striking that "autonomy" and "free choice" are the banners behind which cigarettes are sold and the self-image that consumers gain from smoking them. To confirm this (incorrect) self-image, cigarette advertisers portray smoking as something we simply choose to do.

The R.J. Reynolds Tobacco Company used similar means to attract young customers to smoke Camels. As one internal memorandum put it, "Advertising will rely on clearly aspirational appeals (the me I want to be versus the me I am) to provide the motivation for target smokers to select CAMEL." ${ }^{85}$ A second RJR memorandum states:

${ }^{484}$ BATCO REPORT, supra note 482, at 7-8 (emphasis added).

${ }^{485}$ Memorandum Regarding CAMEL New Advertising Development from R.T. Caufield, R.J. Reynolds, to D.N. Iauco, R.J. Reynolds 2 (Mar. 12, 1986), available at http://legacy.library.ucsf.edu/cgi/getdoc?tid=pil75d00\&fmt=pdf\&ref=results

[hereinafter Memorandum from R.T. Caufield]. Camel's campaign had two goals. First, it attempted to convince young smokers that Camels give them the masculine ideal of "strength, authenticity and self-confidence." $I d$. at 3. "Reinforcement of masculinity is an important want among a large percentage of males and this is particularly true among less educated and younger adult males. (i.e., CAMEL's prime prospect)." Id. Second, the advertising campaign sought to

create the perception that CAMEL smokers project a non-conformist, selfconfident cool attitude which is admired by their peers.

...

Aspiration to be perceived as cool/a member of the in-group is one of the strongest influences affecting the behavior of younger adult smokers.

Personality attributes respected by target smokers and inherent in their definition of cool include a degree of rebellion or non-conformity, along 
The fragile, developing self-image of the young person needs all of the support and enhancement it can get. Smoking may appear to enhance that self-image in a variety of ways. If one values, for example, an adventurous, sophisticated, adult image, smoking may enhance ones self-image. If one values certain characteristics in specific individuals or types and those persons or types smoke, then if one also smokes he is psychologically a little more like the valued image. This self-image enhancement effect has traditionally been a strong promotional theme for cigarette brands and should continue to be emphasized. ${ }^{486}$

Again, cigarette manufacturers know exactly "who we are"-we are beings who want to believe that we are autonomous, free choosers, but who, in reality, are very susceptible to situational forces. We are especially susceptible to situations that make us feel as if we really are free choosers acting according to our own will. These advertising campaigns seek to exploit our situational weaknesses. As a result, cigarette smoking, a deadly addiction, becomes the epitome of free choice. ${ }^{487}$

As Americans, we see ourselves as particularly immune to the role of situation. We see "individualism as the primary force" in defining our institutions and our lives. In fact, we are not immune to situation, nor are we as individualistic as we suppose. The fact that profit-driven actors spend billions of dollars per year to promote a false dispositionist image of ourselves is direct evidence of both of those claims and of deep capture.

with the self-confidence to remain in control of the somewhat risky, exciting lifestyle associated with these characteristics.

Id. at 4. The irony is striking-RJR is trying to convince people they are "selfconfident non-conformists" by using advertising that situationally manipulates this very aspiration.

${ }_{486}$ Memorandum from Claude E. Teague, Jr., R.J. Reynolds, Research Planning Memorandum on Some Thoughts About New Brands of Cigarettes for the Youth Market 7 (Feb. 2, 1973), available at http://tobaccodocuments.org/rjr/5029873577368.html.

${ }^{487}$ Widely produced advertising campaigns can affect the self-images of everyone, not just those who purchase cigarettes. They reinforce our tendency to see ourselves as dispositional free choosers. RJR recognized this:

Campaigns which rely on literal depiction of smokers to communicate desired user imagery will ensure that models and situations selected are highly relevant and appealing to not only target smokers but broader demographic groups as well. Additionally, the exploratory will cover approaches which employ universal cues and symbols that effectively communicate the strategies with motivational value that transcends demographics.

Memorandum from R.T. Caufield, supra note 485, at 2. 


\section{E. Some Deeper Evidence of Deep Capture: The Puzzles Revisited}

We have reviewed a sample of the evidence indicating that procommercial dispositionism has been widely accepted as the presumptive starting place for policy analysis. Many administrative regulators, judges, and legal scholars, like most consumers-from cigarette smokers, to investors, to television-news enthusiasts-take dispositionism as the obvious truth. Implicitly, we have also reviewed one of the most common and effective strategies for promoting procommercial views. Before explicitly naming that strategy, it may be helpful to return briefly to the Milgram experiments and some variations of the rendition that we described above.

\section{The Demand for Credible Messengers}

With numbing regularity good people were seen to knuckle under the demands of authority and perform actions that were callous and severe. Men who are in everyday life responsible and decent were seduced by the trappings of authority, by the control of their perceptions, and by the uncritical acceptance of the experimenter's definition of the situation, into performing harsh acts....A substantial proportion of people do what they are told to do, irrespective of the content of the act and without limitations of conscience, so long as they perceive that the command comes from a legitimate authority.

-Stanley Milgram ${ }^{488}$

After discovering the unexpected power of the situation in his initial experiment, Milgram altered the situation in the hope of making visible some of the previously unseen influences. One of the key factors he varied was the credibility or authority of the person who gave orders to the teacher. In the basic experiment, recall that the person prompting the teacher to continue shocking appeared as a scientist, complete with a white lab coat. He seemed to have considerable knowledge and authority. When Milgram replaced that "experimenter" with an "ordinary man" to give the orders, the percentage of teachers who administered the maximum shock (450 volts) dropped from approximately sixty-five percent to twenty percent. ${ }^{499}$ Apparently, the same words were less persuasive or

${ }^{488}$ Milgram, Some Conditions of Obedience and Disobedience to Authority, supra note 86 , at 74-75.

${ }^{489}$ MilgRAM, OBEDIENCE TO AUTHORITY, supra note 86, at 93-97. As part of the experiment, when "teachers" refused to go on, the common man, in apparent disgust, would assert that he would take over administering the shocks. Id. at 97-99. The action was met with strong resistance-virtually all protested and five out of sixteen 
influential when they came from a less credible or authoritative source. In addition, when Milgram replaced the one lab-coated experimenter with two lab-coated authorities who gave contradictory orders, the complete compliance percentage dropped to zero. ${ }^{490}$ In that variation, teachers could more easily justify ending the shocking because one person with authority was encouraging them to do so. Those and other variations help make clear that the credibility of the messenger is often more important than the message itself. ${ }^{491}$

This underscores an important element of the deep capture hypothesis: the quest to promote certain ideas will include an endeavor to locate, create, and sponsor credible means of conveying those ideas. Often, those with the greatest stake in an idea have, for precisely that reason, questionable credibility when speaking on behalf of the idea. Thus, the search for an effective means of communication often includes a search for trustworthy spokespeople. The public relations firm Burson-Marsteller makes the point in just those terms when it describes its primary strategy as that of "having [one's] messages ... communicated through a credible third party" in order to "influenc[e] those who influence a targeted audience."

Berman and Company emphasizes that the "key" to its success "is getting the most credible messengers to carry the strongest messages." ${ }^{493}$ To access such credible messengers, Berman and Company developed what it calls an "academic research network:"

We commission more than a dozen major research projects each year to independent academics at leading research universities, including:

- University of Chicago

- Florida State University

- University of Texas

- Johns Hopkins University

subjects took physical action to prevent the confederate from completing the experiment. $I d$. As Milgram noted, subjects "felt free to threaten the common man and were not reluctant to criticize his judgment or personally chastise him; their attitude contrasts sharply with the deferential politeness subjects invariably displayed in other experiments, when an authority was at the helm." Id. at 97-98.

Id. at 105-07.

491 See generally CIALDINI, supra note 463, at 216-29 (describing some examples of people's willingness to obey authority and how "compliance professionals" take advantage of that willingness).

492 Burson-Marsteller, Inc., supra note 471.

${ }^{403}$ Berman \& Co., at http://www.bermanco.com/public_affairs.cfm (last visited Oct. 25,2003$)$.

${ }^{494}$ Berman \& Co., at http://www.bermanco.com/research.cfm (last visited Oct. 25,2003 ). 
- University of Wisconsin

- Massachusetts Institute of Technology

- University of North Carolina

- University of California, Los Angeles

- Boston University

- Michigan State University

The credibility of the material produced by these independent researchers is unparalleled among "brand name" trade associations, law firms, or consultants active in the public policy arena.

Berman and Company relies on several other tactics to create favorable, credible third-party messengers for its clients:

Sometimes, the best messengers are line managers from affected employers. We have more than a decade of experience building and maintaining sophisticated grassroots activation systems through which managers can have maximum impact with a minimal investment of time.

CEOs of major employers, working in teams managed by Berman and Company, repeatedly deliver powerful messages to key legislators and the White House.

Whether drawing industry allies from associations, think tanks, or the private sector, Berman and Company reaches out to potential allies on a daily basis, providing data, information, and refined messages that others use to make their cases-and ours-in the policy arena. Our clients benefit when more allies use our research and repeat our messages.

When Berman and Company publishes research from independent academics, we craft our publicity efforts so that the authors' credibility shines in the legislative spotlight.

Sometimes, uncommon allies can get more attention than "traditional" spokespersons. Our staff has developed strong ties to individuals who are often perceived as "anti-industry" but who agree with focused messages that we seek to publicize.

To aggressively disseminate the credible third-party messages, Berman and Company attempts to "design unique programs for maximum impact in the debate ... [and to] stick with the issue for as long as it takes to win." ${ }^{497}$ Those programs include creating and maintaining "web sites that constantly elicit the 'Wow!' factor from users." ${ }^{498}$ ConsumerFreedom.com, discussed above, ${ }^{499}$ is an example of that creative approach. To "change the debate," that Web site seeks to expose and resist "the Nanny Culture"- "the growing fraternity of

\footnotetext{
${ }^{495} I d$.

496 Berman \& Co., supra note 493.

497 Berman \& Co., supra note 494.

${ }^{498}$ Berman \& Co., supra note 493.

${ }^{499}$ See supra notes 407-14 and accompanying text.
} 
'food cops,' health care enforcers, militant activists, meddling bureaucrats, and violent radicals who think they 'know what's best for you" - "and protect consumer choices."

The same basic principle was at work in the Galileo story: the Catholic Church dealt with Galileo's threatening astronomical views by having its own worldview "communicated through" Galileo's recantation. ${ }^{501}$ Likewise, the principle seems to underlie Stigler's basic shallow capture message: institutions or groups with the requisite power employ the legitimacy of regulators to advance their own interests. $^{502}$

\section{The Creation of Credible Messengers}

There is a vast range of interconnected evidence (too vast to do justice to in this subsection) of pro-commercial interests investing to deeply capture the many "credible third parties" that might influence the many "targeted audiences" (including all of us) to accept pro-commercial worldviews. In this subsection we will focus on a small sample of that evidence..$^{j 03}$ Although the sample is small, it will hit close to home for much of our audience and will, we hope, strike a more direct and personal chord than the Galileo discussion may have.

Consider the world of legal scholarship. Large business interests have attempted to locate, create, and sponsor the production and dissemination of pro-commercial legal scholarship by legal scholars who have served as credible, if often unwitting, spokespeople for business ends. More specifically, consider some of the evidence regarding the goals and influence of the John M. Olin Foundation.

According to the Olin Foundation's Web site,

the general purpose of the John $\mathrm{M}$. Olin Foundation is to provide support for projects that reflect or are intended to strengthen the economic, political and cultural institutions upon which the American heritage of constitutional government and private enterprise is based. The Foundation also seeks to ... encourag[e] the thoughtful study

${ }^{500}$ Ctr. for Consumer Freedom, supra note 407.

${ }^{501}$ See supra text accompanying notes 297-314 (reviewing and evaluating Galileo's recantation).

${ }^{502}$ See supra Part V.A (summarizing Stigler's arguments and evidence).

${ }^{503}$ In work now in progress, we provide a more fulsome description of that evidence. 
of the connections between economic and political freedoms, and the cultural heritage that sustains them.

To advance that goal the Olin Foundation has, among other things, awarded tens of millions of dollars to prominent law schools for the promotion of law and economics scholarship. Over the past twenty years, Olin money has established law and economics programs, or "centers," at several prominent law schools: the University of Chicago, Yale, Stanford, Harvard, Columbia, Georgetown, Duke, the University of Michigan, the University of Pennsylvania, George Mason, and the University of Virginia. ${ }^{505}$ In 1999 , a year in which the Foundation paid out almost $\$ 20$ million in grants to organizations around the country, ${ }^{506}$ Harvard Law School's John M. Olin Center for Law, Economics, and Business was in the middle of a four-year, \$6 million grant, ${ }^{507}$ Yale Law School's John M. Olin Program in Law and Economics was in the middle of a three-year,

${ }^{504}$ John M. Olin Foundation, Inc., History and General Purposes, at http://www. jmof.org/history_purposes.html (last visited Oct. 26, 2003).

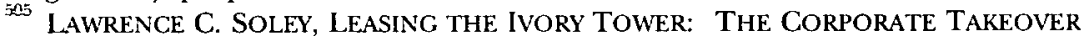
OF ACADEMIA 137 (1995); Michael L. Rustad \& Thomas H. Koenig, Taming the Tort Monster: The American Civil Justice System as a Battleground of Social Theory, 68 BROOK. L. REV. 1,76 tbl.2 (2002).

${ }^{506}$ John M. Olin Foundation, Inc., Total Grants Paid, 1999, at http://www. jmof.org/grants_1996.html (last visited Oct. 26, 2003).

507 John M. Olin Foundation, Inc., Schedule of Grants, 1999: H, at http://www. jmof.org/grants/1999h.htm (last visited Oct. 26, 2003). An Olin grant helped establish Harvard Law School's Law and Economics Program in 1985. Olin Gift Expands Law and Economics at HLS, HARV. L. BuLL., Summer 1998, at 30. Further support then led to the 1995 opening of the Olin Center at Harvard Law School, "now the world leader in educating students, training academics, and promoting scholarship in law and economics." Id. "Among [the Olin Center's] academic offerings are three economic analysis seminars, courses on the economics on regulation and antitrust, classes on law and economics and on empirical methods, and a new course, Analytical Methods for Lawyers," for which the Olin Center faculty is developing a textbook for adoption across the country. Press Release, Harvard Law School, Harvard Law School Receives $\$ 10$ Million Grant from John M. Olin Foundation, at http://www.law.harvard.edu/news/2003/05/19_olin.php (May 19, 2003) [hereinafter Harvard Law School Press Release]. Beyond the classroom, " $[t]$ he Olin Center supports more than twenty John M. Olin Fellows each year to conduct research on topics ranging from corporate governance to prenuptial agreements." Id. Much of the sponsored scholarship has involved the application of economic analysis to controversial issues, including Professor Kip Viscusi's criticism of tobacco and smoking regulation. Id.; see also VISCUSI, supra note 15, at 145 (arguing that government policy "should not be to deter smoking but to provide information concerning the variety of smoking hazards" so that consumers can make their own choice). 
$\$ 1.9$ million grant, ${ }^{508}$ and the University of Chicago Law School's John M. Olin Program in Law and Economics was in the middle of a six-year, $\$ 2.5$ million grant. ${ }^{509}$ In May 2003 , Harvard received another grant from the Olin Foundation, this time for $\$ 10$ million, "the largest foundation grant in the law school's 186-year history."

Olin money, as we will describe in more detail in subsequent work, has a significant influence not only in encouraging certain types of scholarship, ${ }^{511}$ but also in increasing the credibility of that scholarship. It establishes "centers" dedicated to law and economics theory, provides funding for journals through which law and economics scholarship can be stamped with the legitimacy of "peer review" by other legal economists, finances a series of workshops to encourage efficiency-oriented scholars to share and test their views at elite law schools, and gives scholarships and fellowships to top law students who participate in law and economics seminars and produce law and economics scholarship. ${ }^{512}$ In short, Olin money has helped to create and advance a critical mass of legal scholars, who begin with the strong dispositionist axioms of neoclassical economics, who write largely for one another and policymakers, and who view themselves (and are viewed by many others) as the only genuinely social scientific members of the legal academy.

The success of the Olin Foundation's funding of law and economics seems fairly dramatic. Professor Steven Shavell, the director of Harvard Law School's Olin Program, recently provided one measure of that achievement. Professor Shavell surveyed the academic appointments at the "top 10" law schools over the last

${ }^{508}$ John M. Olin Foundation, Inc., Schedule of Grants, 1999: Y, at http://www. jmof.org/grants/1999y.htm (last visited Oct. 27, 2003).

509 John M. Olin Foundation, Inc., Schedule of Grants, 1999: U, at http://www. jmof.org/grants/1999u.htm (last visited Oct. 27, 2003).

510 Harvard Law School Press Release, supra note 507. The gift is a testament to the great success of the Center in achieving the goals of the Olin Foundation. In the words of James Piereson, executive director of the Olin Foundation, "[t]he school has made an impressive commitment to the field of law and economics and has created a very strong program of teaching and research. We hope this gift will enable the school to build on this record of success." Id.

For a recent critique of the John M. Olin Foundation's neoconservative influence in law schools, see Rustad \& Koenig, supra note 505, at 74-77.

512 SOLEY, supra note 505, at 5-6, 140-41. Not all institutions have accepted the Olin Foundation's handouts. "A short-lived program in Law and Economics was offered at UCLA during the 1980s, but was abandoned after a curriculum committee found that the program was 'taking advantage of students' financial need to indoctrinate them with a particular ideology."' SOLEY, supra note 505, at 137, 140 (quoting UCLA curriculum committee). 
decade. $^{513}$ Of forty-three total placements, he found that, twentythree were Harvard Law School graduates, and ten of those had been Olin fellows. ${ }^{514}$ As Professor Shavell told the Boston Globe, "[i]n the long run, we're going to have a heck of an impact on who's teaching at the leading law schools, and what the students are learning., ${ }^{515}$

We would go further. The Olin Foundation and the law and economics scholarship that it has subsidized have already had "a heck of an impact." Indeed, the scholarly project that the Olin money has sponsored is the same project that is widely understood today to be the dominant paradigm for policy analysis. ${ }^{516}$ Professor Shavell has emphasized that the economic analysis of law "has changed the nature of legal scholarship, influenced legal practice, and already proven its tremendous value in policymaking and business." ${ }^{517}$ Furthermore, the Olin Foundation's Board of Trustees recently declared that their contributions have "supported a wide range of scholars and writers who significantly changed the content and direction of American academic and political discussion."

Of course, the fact that the Olin Foundation poured millions of dollars into promoting law and economics does not necessarily imply that those investments played a significant causal role in the stunning success of the now-dominant paradigm. It may be, as most of its proponents presume, that law and economics was destined for greatness solely on the merits, and that Olin money simply facilitated an inevitable process that was already underway. ${ }^{519}$

\section{a. A market test}

There are several reasons to suspect, however, that the Olin Foundation's support, combined with numerous other situational influences, has played a pivotal causal role in the success of the law and economics movement. First, the success of law and economics appears to map closely with the precise ambitions and strategies of

513 See Thomas C. Palmer Jr., The Right to Self-Destruct, BosTon SUNDAY GLoBe, Apr. 29, 2001, at D1 (discussing Shavell's work in the context of the Olin Foundation's impending dissolution).

${ }^{514}$ Id. at D3.

515 Id

${ }^{516}$ See supra text accompanying notes 57-64.

517 Olin Gift Expands Law and Economics at HLS, supra note 507, at 30.

${ }^{518}$ John M. Olin Foundation, Inc., Board Resolution (Sept. 20, 2000), available at http://www.jmof.org/wes.htm.

${ }^{519}$ See supra text accompanying notes 68-81. 
the key individuals behind the Olin Foundation: John Olin, the founder of the organization, and William Simon, its longtime president. After leaving his position as Treasury Secretary in the Nixon and Ford Administrations, Simon wrote two best-selling books that outlined his conservative and pro-commercial beliefs and his agenda for implementing them. ${ }^{520}$ Simon was a prominent, early exponent of the dispositionist, neoliberal worldview that seeks to promote private enterprise and to minimize the role of government-a worldview shared by John Olin. They also shared a belief that American universities at the time produced ideas and graduates that were dangerously antithetical to those ends. To Simon, this problem was tantamount to a war of liberty versus totalitarianism-a war with three fronts:

1. Funds generated by business ... must rush by multimillions to the aid of liberty, in the many places where it is beleaguered.

....

... [Foundations established by such funds must] serve explicitly as intellectual refuges for the non-egalitarian scholars and writers in our society who today work largely alone in the face of overwhelming indifference or hostility. They must be given grants, grants, and more grants in exchange for books, books, and more books.

2. Business must cease the mindless subsidizing of colleges and universities whose departments of economics, government, politics and history are hostile to capitalism and whose faculties will not hire scholars whose views are otherwise.

... America's major universities are today churning out young collectivists by legions, and it is irrational for businessmen to support them.

3. Finally, business money must flow ... to media which are either pro-freedom or, if not necessarily 'pro-business,' at least professionally capable of a fair and accurate treatment of procapitalist ideas, values and arguments. The judgment of this fairness is to be made by businessmen alone-it is their money that they are investing.

These are the three fronts on which to act aggressively if we are to create a sophisticated counter-force to the rising despotism. One of my own first actions on leaving the post of Secretary of the Treasury was to accept the job of president of the John N. [sic] Olin Foundation, whose

${ }^{520}$ William E. SIMON, A TIME FOR TRUTH (Berkley Books 1979) (1978) [hereinafter Simon, A Time for TRUTH]; William E. Simon, A Time for ACtion (1980). 
purpose is to support those individuals and institutions who are working to strengthen the free enterprise system.

Thus, Simon, with the support of the Olin Foundation, was trying to alter the playing field on which academic debate takes place-and trying to do so situationally. Furthermore, he understood that the dispositionism of law and economics is pro-business and that many alternative views, otherwise successful in the marketplace of ideas, are not. Simon presented American individualism, much as ad agencies presented the Marlboro Man, as the American tradition and the source of America's greatness. However, like the Marlboro Man's creators, Simon seemed to appreciate that such individualism, to be embraced as deeply as Philip Morris, Simon, and others desired, had to be heavily promoted, and reinforced if it is to be widely accepted. And he further understood that the situation can and should be manipulated by, among other things, choosing particular academics, programs, and scholarly camps to give "grants, grants, and more grants in exchange for books, books, and more books."

In light of Simon's (and thus the Olin Foundation's) probusiness mission, there is good reason to believe that the Olin Foundation's sizeable law and economics investment was money well spent. The point is strengthened when one considers that the Foundation engaged in a kind of "stage financing" of these programs: grants were intended to last for only a few years, at which point the Foundation would consider whether to renew its contribution to a particular program. ${ }^{593}$ The fact that the Founda-

${ }^{521}$ SIMON, A Time FOR TRUTh, supra note 520, at 246-50.

${ }^{522} I d$. at 247.

${ }^{523}$ We suspect that such financing arrangements may have had some influence over the kind of work that was produced under the auspices of each program, just as economists generally tend to assume that such financing arrangements can have incentive effects over those subject to them. See, e.g., Francesca Cornelli \& Oved Yosha, Stage Financing and the Role of Convertible Securities, 70 REV. ECON. STUD. 1 (concluding that venture capital financing can affect the short-term behavior of the entrepreneur); see also Paul A. Gompers, Optimal Investment, Monitoring, and the Slaging of Venture Capital, $50 \mathrm{~J}$. F1N. 1461, 1461 (1995) (“[T] he staging of capital infusions allows venture capitalists to gather information and monitor the progress of firms, maintaining the option to periodically abandon projects.").

John M. Olin, having witnessed the leftward trend of the Ford Foundation during the 1960s and $1970 \mathrm{~s}$, specified that all resources of the Olin Foundation were to be spent within one generation of his death in order to prevent its cooption. Shawn Zeller, Conservative Crusaders, 35 NAT'L J. 1286, 1290-91 (2003). Although currently allocating the remaining assets of the Foundation, with the idea of closing down by 2005, the Olin board may be making further arrangements to ensure that Olin's goals are not disappointed. In the same 
tion continued to renew many grants provides strong evidence that it believed that its investments were generating worthwhile returns in terms of encouraging pro-commercial worldviews (and discouraging alternatives) among students, academics, and policymakers. ${ }^{524}$

\section{b. Re-imagining the marketplace of ideas}

This leads to a second general reason to suspect that Olin's investments have played a critical causal role in the success of law and economics. As we noted at the outset of this Article, the dominance of law and economics is puzzling when one attempts to make sense of it without considering situational forces. Law and economics has been subject to many (largely unanswered) criticisms by extraordinarily respected legal academics, and its success seems to have surprised both its critics and some of its proponents. ${ }^{525}$ If the success of law and economics does not square easily with the idealized image of a neutral tournament of ideas, then that raises the possibility that its success reflects some largely unseen situational influences.

To advance this argument further, we ask the reader to consider how to answer the following question: which bird, species A or species $\mathrm{B}$, has been more successful in the evolutionary process of natural selection? If you are like us, we suspect that your first thought would be to compare the relative numbers of the two birds. With a little more time, you might decide that you would also like to know about relative sizes since at equilibrium the environment could probably sustain fewer large birds than small birds. Controlling for habitat needs you would seem to have a simple, but fairly accurate, measurement process.

Now let us make the question a little more concrete: which bird, the bald eagle or the chicken, has been more successful in the evolutionary process of natural selection? Shall we do the math? There are approximately 70,000 bald eagles in North America, a

statement detailing the $\$ 10$ million grant to Harvard Law School, the Center for Law, Economics and Business announced that an "external advisory committee" was being set up "to assist the faculty in guiding its programs" in the future. Harvard Law School Press Release, supra note 507. While the structure of the committee has not yet been discussed, it seems likely that one purpose of the committee will be to serve as a substitute for stage-financing.

${ }^{524}$ See supra note 510 and text accompanying note 518 (providing more direct evidence that the Foundation's leaders believe that their efforts have been successful).

${ }^{325}$ See supra text accompanying notes $35-64$. 
number that is up considerably in recent years following the bald eagle's near extinction. ${ }^{526}$ It is a little harder to know just how many chickens there are in this country at any given moment, but our rough calculations put the number somewhere between 1.75 and 2 billion. ${ }^{527}$ That means that for every bald eagle there are twenty to thirty thousand chickens.

Even discounting the figure slightly to take into account the eagle's larger size and habitat requirements, the numbers are clear: the standard farm chicken is the bald eagle's evolutionary superior. But that finding seems absurd. We know the bald eagle as our national bird, a symbol of strength and power. Eagles are extremely well adapted for survival in nature, given their superb flying, hunting, and nest-building abilities. ${ }^{528}$ For centuries, bald eagles thrived, and according to one history, they may have once numbered half a million. ${ }^{529}$

They existed along the Atlantic from Labrador to the tip of south Florida, and along the Pacific from Baja California to Alaska. They inhabited every large river and concentration of lakes within North America. They nested in forty-five of the lower forty-eight states. One researcher estimated an eagle nest for every mile of shore along

${ }^{526}$ Hope Rutledge, American Bald Eagle Information, at http://www. Baldeagle info.com (last updated Aug. 26, 2003).

597 There are two general categories of chickens: "broilers," which are raised and slaughtered for meat, and "layers," whose primary purpose is to produce eggs. Livestock, Env't \& Dev't Initiative, Poultry Production (Broilers and Layers), at http://lead.virtualcenter.org/en/dec/toolbox/Indust/IndPProd.htm (last visited Oct. 26, 2003). Approximately 8.5 billion broilers were slaughtered in the United States in 2001. Nat'L Agric. Statistics SERV., U.S. DeP'T OF AGriC., Poultry Slaughter: 2001 ANNUAL SUMMARY 2 (2002), available at http://jan.mannlib.cornell.edu/ reports/nassr/poultry/ppy-bban/pslaan02.pdf. Assuming that broilers have an industry life expectancy of approximately two months, the number of broilers existing at any one moment is something close to 1.5 billion. See Save Animals From Experiments (SAFE), Profiling New Zealand's Shameful 'Clean, Green Living', at http://www.safe.org.nz/campaigns/factory/animalprofiles.php (last visited Oct. 25, 2003). Their actual life expectancy-if they were not slaughtered-would be fifteen to twenty years. $I d$. There are approximately 337 million layers alive at any one time. Nat'l AGRic. Statistics Serv., U.S. DeP't OF AGRIC., Chickens ANd EgGs: 2002 SUMMARY 1 (2003) available at http://jan.mannlib.cornell.edu/reports/nassr/poultry/ pec-bbl/lyegan03.pdf [hereinafter NAT'L AGRIC. STATISTICS SERV., CHICKENS AND EGGS]. Adding broilers and layers together, the number of chickens alive at any one moment in this country appears to be somewhere between 1.75 and 2 billion.

${ }^{528}$ NELTJE Blanchan, Birds THAT HuNT AND ARE HuNTED 326-28 (1905).

${ }^{529}$ Hope Rutledge, History of the Bald Eagle, at http://www.baldeagleinfo.com/ eagle/eaglel1.html (last visited Oct. 25, 2003). 
Chesapeake Bay. They congregated on the lower Hudson, and were extremely abundant along the coast of Maine.

So then we have missed something. In determining that chickens are more fit than eagles to withstand nature's trials and challenges, we have ignored critical situational influences. Why are there so many more chickens than eagles? The more obvious and correct explanation is that humans value chickens in a way that they have not valued bald eagles.

Indeed, there are robust markets in both chickens and eggs. ${ }^{531}$ According to a recent industry-sponsored survey, Americans consume, on average, eighty-one pounds of chicken per year-a figure that appears to be going up and that represents "the highest percapita consumption of any of the major meats." ${ }^{532}$ They also consume approximately 260 eggs per year. ${ }^{533}$ Unsurprisingly, market pressures ensure that there are many chickens alive at any given moment.

Well, if bald eagles are so fit, why did they nearly go extinct and why are there still so few of them? The following history of the bald eagle helps to shed light on a different sort of situational influence on the bald eagles' stature than is imagined in any idealized, unrealistic "natural selection" script.

There is no single cause for the decline in the bald eagle population. When Europeans first arrived on this continent, bald eagles were fairly common. As the human population grew, the eagle population declined. The food supplies for eagles decreased, because the people hunted and fished over a broad area. Essentially, eagles and humans competed for the same food, and humans, with weapons

$530 I d$

${ }^{581}$ We have been unable to ascertain which came first.

532 Press Release, Nat'l Chicken Council \& U.S. Poultry \& Egg Ass'n, Boom in Chicken Consumption Has Room to Grow (May 1, 2000), available at http://www. eatchicken.com/statistics/pr_050100.cfm. According to John Bekkers, chairman of the National Chicken Council, one important reason for the growing "success" of chicken is its convenience. Id. "The simple fact is that chicken fits, better than any other meat, the hectic, harried, time-crunched lifestyle that so many people lead today." Id. (quoting Bekkers).

533 American Egg Board, Egg Consumption Through the Year, at http://www.aeb.org/ eggstravaganza/egg-consumption.htm (last visited Aug. 25, 2003); see also INT'L EGG Comm'n, International EgG MARket: Report No. 67 (2002) (finding per capita egg consumption in the United States was 251.8 in 2000 and 252.6 in 2001), available at http://www.internationalegg.com/html/reports/report67/ lusa.pdf. There is a striking similarity between the 252 eggs consumed per person and the 256 eggs produced by the average laying chicken. See NAT'L AGRIC. STATISTICS SERv., CHICKEN AND EGgS, supra note 527, at 1 (providing estimate for average laying chicken). 
at their disposal, had the advantage. As the human population expanded westward, the natural habitat of the eagles was destroyed, leaving them fewer places to nest and hunt, which caused the population of bald eagles to decline sharply by the late $1800 \mathrm{~s}$.

By the 1930s, people became aware of the diminishing bald eagle population, and in 1940 the Bald Eagle Act was passed. This reduced the harassment by humans, and eagle populations began to recover. However, at the same time DDT and other pesticides began to be widely used. Pesticides sprayed on plants were eaten by small animals, which were later consumed by birds of prey. The DDT poison harmed both the adult birds and the eggs that they laid. . .

More than 100,000 bald eagles were killed in Alaska from 1917 to 1953. Alaskan salmon fisherm [e]n feared they were a threat to the salmon population.

According to that history, the threat to eagles was not that they were ill-equipped to survive in nature, but that their success as a species did not appear to serve the interests of humans. Indeed, the eagles competed with human interests, including commercial interests.

As a result, the grand, and once ubiquitous, bald eagle was pushed toward extinction. Meanwhile, chickens were raised in huge numbers to meet the increasing demand for their eggs and meat. The relative success of chickens over bald eagles, then, has little to do with the survival of the fittest and a lot to do with "the survival of the tastiest" or "the survival of the profittest."

In light of that competition among birds, look again at how legal scholars tend to measure the success of various schools of thought. As we reviewed earlier, legal academics generally assume that they are competing in some neutral tournament wherein ideas evolve and good ideas become more prominent while bad ideas disappear. ${ }^{535}$ According to this view, the tournament benefits the outside world by generating and announcing the winning ideas, which are then relied upon to help make effective and desirable policy. Thus, when some ideas are more commonly accepted, are attracting larger audiences and are having more influence outside of law schools, the assumption is often that those ideas, like the bald eagle, soar above their ground-bound, clucking competitors.

But here is the problem: the competition among ideas may have much in common with the imagined competition between chickens

${ }^{534}$ Rutledge, supra note 530.

535 See supra text accompanying notes 12-18 (discussing the presumption that law and economics emerges from a level playing field in a tournament of ideas). 
and eagles. That is, in both contexts there appear to be very significant demand-side factors that help determine which ideas will be most prevalent and seemingly most successful. For reasons that we have already highlighted, the "winners" will be those ideas that are valuable to the more influential participants on the demand-side of the marketplace-specifically, pro-commercial interests.

With that in mind, consider again how legal economists measure their own success. Richard Posner writes:

Economic analysis of law has grown rapidly, has become the largest, most pervasive interdisciplinary field of legal studies in the history of American law, has palpably influenced the practice of law and judicial decisions, has launched lucrative consulting spin-offs, has spawned courses and textbooks in economic analysis of law, has influenced legislation (economic analysts of law played an important role in the deregulation movement), has made it de rigueur for law schools of the first and second ranks to have one or more economists on their faculty, has seeded a number of its practitioners in university administration and the federal judiciary, and has now crossed the Atlantic and begun making rapid gains in Europe.

Similarly, recall legal economist Thomas Ulen's brief history of the triumph of law and economics:

Law and economics has been one of the most successful innovations in the legal academy in the last century. This intellectual revolution began modestly in the 1960 s and 1970s with a few important and innovative articles and a comprehensive, masterful text that showed the possibilities of the field. Then, in the $1980 \mathrm{~s}$ the field exploded into respectability and prominence-becoming a regular course in the curricula of the best law schools, a vibrant legal research style that figured in a torrent of important books and articles, a force that transformed many faculty from exclusive practitioners of traditional doctrinal research to a more social-science-oriented research, and a substantial justification for important public policy changes. By the early 1990s, economic analysis suffused a modern legal education, even one devoid of an explicit course in law and economics.

Posner and Ulen make no mention, and seem to have no conception, of the role played by outside forces in creating the appearance of successful ideas. Posner emphasizes the "rapid

${ }^{536}$ Posner, supra note 11, at 275; see also POSNER, FRONTIERS, supra note 13, at 35 ("It is not merely an ivory-towered enterprise, especially in the United States, where the law and economics movement has influenced legal reform in such fields as antitrust law, the regulation of public utilities and common carriers, environmental regulation, [and] the calculation of damages in personal injury suits ....").

${ }_{537}$ Ulen, supra note 69 , at 434. 
growth" of the discipline just as Ulen notes the field's "explosion" in the 1980s. But neither seems mindful of possible situational contributions to that explosive growth, much less the fact that it occurred in the 1980s when the Olin Foundation began to invest significantly in sponsoring various law and economics programs. ${ }^{588}$ Posner speaks of the "spawning courses and casebooks," while Ulen comments on the "torrent of important books and articles." But neither mentions that the Olin Foundation's targeted efforts encouraged such a spawning and a torrent through "grants, grants, and more grants." Posner recognizes the "lucrative" consulting opportunities created by law and economics, without considering what makes the ideas so lucrative in the first place or what those lucrative opportunities may indicate about why the school of thought is thriving. Ulen emphasizes that law and economics provides a "substantial justification for important public policy changes,"540 and Posner highlights, more specifically, the fact that "economic analysts of law played an important role in the deregulation movement." ${ }^{, 541}$ But neither seems to notice just how valuable that justification for deregulation is to large commercial interests or how it lines up with the specific pro-market and deregulatory planks of the Olin Foundation's mission. Ulen notes that "economic analysis suffuse[s] a modern legal education," palpably influenced the practice of law and judicial decisions... [and] legislation." ${ }^{543}$ But neither considers that such profound effects might well have been the precise ambition of powerful individuals, entities, and groups in our society with the means to influence those important institutions through the situation.

In short, as we stated at the outset of this Article, there appears to be a blindness to situational influences over legal scholarship. And Posner and Ulen are by no means unusual in falling subject to this fundamental attribution error. Even the staunchest critics of law and economics rarely, if ever, consider, much less challenge, its situational advantages.

${ }^{538}$ See, e.g., SOLEY, supra note 505, at 137-40 (discussing various grants made by the Olin Foundation to programs of law and economics in the late 1980s).

${ }^{539}$ See supra text accompanying notes 521-22; SIMON, A TIME FOR TRUTH, supra note 520 , at 247 .

${ }^{540}$ Ulen, supra note 69 , at 434 .

${ }^{541}$ Posner, supra note 11, at 275.

${ }_{542}$ Ulen, supra note 69 , at 434.

${ }^{543}$ Posner, supra note 11 , at 275. 
As we have been arguing, however, the situation is often as significant as it is invisible. Where Posner, Ulen, and most legal scholars tend to see a marketplace of ideas in which supply-side participants determine the winners, we see a marketplace of ideas in which demand-side actors are wielding an immense, unseen influence over the playing field and, in turn, the winners. Where Posner, Ulen, and most other legal scholars see a neutral, fair (and perhaps even natural) competitive process separating the fit from the unfit, we see large numbers of chickens, ensconced in elaborate institutions devoted to promoting the birds' growth and productivity for a particular end-an end that has little to do with a robust and fair tournament of ideas.

We opened this Article asking why legal economists have tended not to apply their own sort of market analysis to help them understand their success. We posited several explanations, which we have expanded on slightly in this Section. Before moving on, we want to emphasize that we perceive ourselves to be providing what legal economists have not: a type of economic analysis of the economic analysis of law. The claim that legal academia is deeply captured strikes us as consonant, not only with Stigler's shallow capture theory, but also with the sort of "consumer sovereignty" arguments that inform the vast majority of legal-economic analyses.

We end this Part with several assertions. First, the deep capture of legal academia is the result of far more situational influences than just those created by the Olin Foundation's funding efforts. Second, the consequences of the deep capture of legal academia are many, varied, and immense. And, third, the deep capture of legal academia is, we believe, only a small, though important, part of a much more comprehensive web of situational influence over "regulatory" institutions in this country and, increasingly, around the world. Evidence for those assertions is, again, the subject of future work. 


\section{A Theory of AtTRIBUtional Presumptions}

I started with the belief that every person who came to the laboratory was free to accept or to reject the dictates of authority. This view sustains a conception of human dignity insofar as it sees in each man a capacity for choosing his own behavior. And as it turned out, many subjects did, indeed, choose to reject the experimenter's commands, providing a powerful affirmation of human ideals.

\section{-Stanley Milgram ${ }^{544}$}

We have argued that law and economics is highly dispositionist ${ }^{545}$ and that its success in legal academia and in policymaking has been a function of the situational demand for such a dispositionist theory. In that way, the exterior situation of the market for legal-policy theory has strongly promoted law and economics because of its generally pro-commercial dispositionist assumptions and analyses.

As we noted at the outset, however, the misbegotten attributional tendencies that we are highlighting in this Article are by no means limited to legal economists. The dispositionism of human beings is fairly universal-though the particular contours of its manifestation vary across cultures, groups, individuals, and situations. The fundamental attribution error is just that-a strong tendency in all humans to see only the most salient, moving features of our exteriors and interiors, like the sun moving across the sky, or our own behavior in a moment, and to attribute cause and agency to what we see. This urge to downplay the rest is an animalian tendency. Thus, dispositionalizing legal economists as dispositionists, while maintaining the view that the rest of us are not, would only repeat that error. We are all, because of our shared interior situation, more or less dispositionists.

It is important that we are not misunderstood. The phrase "more or less" in the last sentence is key. Our thesis is not that all of us (or that any of us) are wholly dispositionist, unable in any circumstance to recognize the possible role of the situation behind people's behavior. ${ }^{546}$ Neither do we assert that all of us (or any of us)

${ }^{544}$ Stanley Milgram, Issues in the Study of Obedience: A Reply to Baumrind, 19 AM. PSYCHOL. 848, 851 (1964).

${ }^{545}$ See supra Part I.B (introducing the idea that legal economists have overestimated the role of dispositional influences on their success).

${ }^{546}$ As emphasized above, cultural causal schemes, motives and other variables influence the degree to which groups and individuals tend to appreciate the situation. 
are wholly situational, unable to act according to our own preferences or attitudes and entirely driven by unseen forces. We believe that we are all both dispositionists and situationists in construing our world and that we are all, in fact, both dispositional and situational.

Recognizing the significance of the situation does not imply that disposition is irrelevant. Disposition often plays some role, and sometimes a quite important role, in people's behavior. Indeed, even in Milgram's famous demonstration of the power of the situation, a sizeable minority (and, in some renditions, a clear majority) of subjects refused to obey the experimenter's instructions to continue the shocking. ${ }^{547}$ Moreover, if situational considerations are substantial, stable, and consistent enough, the dispositional assumption may become a more reliable heuristic for understanding our world. ${ }^{548}$

If dispositions can in fact play a major situation-independent role in a person's behavior, or if the "as if" dispositional assumption can sometimes be justified, then the question emerges: is the fundamental attribution error really so important in legal questions, in theory, in practice, and in social debate? Should policymakers and policy theorists really concern themselves with it?

We have already begun our answer to that question in this introductory Article and will continue to do so in subsequent articles. Our answer has numerous components, including what follows here. The tendency to see disposition and overestimate its significance, while missing the situation or underappreciating its effect, is quite robust. When the situation is observed, it is usually only a small, particularly salient piece of the whole. Furthermore, the way an issue is framed-as dispositional or situational-can have an immense effect on what attributions people make about behavior. Here is

See supra text accompanying notes $415-23$ (noting corporate motivation and cultural variations in dispositionism).

${ }^{547}$ See MILGRAM, OBEDIENCE TO AUTHORJTY, supra note 86 , at 35 tbl.2 (identifying the various percentages of subjects who refused to obey).

${ }_{548}$ And so it is that we treat corporations as having a set of stable preferences that they pursue systematically over time. There is a strong and stable set of situational forces, including corporate law, regulatory law, the single maximand of profit, and the markets for products, managers, and capital. These fairly consistent situational influences may allow for a relatively precise dispositionist perspective on corporate behavior. See supra notes 253-54 and accompanying text (discussing how situational forces make corporations behave as if their primary goal is profit maximization). Still, we would caution that a more realistic analysis of corporate conduct is in order, a task that is beyond the scope of this Article. 
where deep capture comes in: the framing of an issue is one of the situational factors that can be disproportionately influenced by those with the motive and power to do so. We have argued that those in power have significant stakes in promoting, among other things, a generally dispositionist framing of an issue. Those stakes have, indeed, led to investments attempting to influence the situation, including the production and distribution of legal-theoretic knowledge that is strongly dispositionist in orientation. Taken together, those elements suggest that the fundamental attribution error is playing an immense and influential role in our policymakers' worldviews and in their policies.

Our thesis can thus be understood as a positive theory intended to explain our presumptions about where the threshold between disposition and situation lies and how high it stands. When do we recognize the role of situation? And what portion of the situation will we tend to acknowledge? Thus far, our primary focus has been on describing, understanding, and critiquing the attributional presumptions of law and economics. Our argument has been that law and economics scholars recognize only a tiny portion-that is, just a few of the most salient features-of the situation. We have focused primarily on that theory, in part, because of its preeminence and, in part, because we believe that its success both reflects and critically reinforces deep capture. But our thesis has implications for legal theory and for laws and policies that seem well outside the purview of law and economics. In fact, the ubiquity of dispositionism in our legal theories and laws likely facilitates the reception of law and economics's more formal, axiomatic rendition.

\section{A. Legal-Theoretic Presumptions}

In this Section, we want to suggest how the fundamental attribution error leads to dispositionist presumptions, not just in law and economics, but also in other mainstream legal theories, and in social policies that reflect such theories. Though we believe this problem can be seen in many, if not all, areas of contemporary legal scholarship, it suffices for our introductory purposes to illustrate the point with reference to a familiar and important common law subject: contract law. ${ }^{549}$ Consider the power of dispositionism

${ }^{549}$ In an excellent article that we discovered only as this one was in its very final stage, Lee Ross (the same Lee Ross whose work we have relied on throughout) and Donna Shestowsky have recently considered the implications of situationism for 
lurking even in traditional, that is to say non-economic, scholarship in contract law.

\section{The Classical Theory of Contract}

In his influential work, Contract as Promise, ${ }^{5,50}$ Professor Charles Fried builds his case for a classical will theory of contract on a foundation of positive presumptions steeped in dispositionism. ${ }^{5.51}$ For theorists like Fried, a contract represents the legal manifestation of "autonomous self-determination." from that perspective, a quintessential expression of individual freedom. So central is the concept of autonomy in the classical will theory of contract that, for Fried, it provides the very basis of moral authority for the principle of contractual obligation. "The moral force behind contract as promise is autonomy: the parties are bound to their contract because they have chosen to be."

Fried appreciates that, to sustain this view of contracts, we must be confident that the choices embodied in contracts do, in fact, represent the expression of the individual wills of the parties involved. How can the traditional contract theorist be certain that disposition is behind contractual decision making and not situation? Enter the doctrine of duress. ${ }^{554}$ In his attempt to explain modern contract doctrines through his will theory, Fried insightfully acknowledges that, far from playing an outcast or ancillary role in conventional contract theory, the doctrine of duress and its

criminal law. See Lee Ross \& Donna Shestowsky, Contemporary Psychology's Challenges to Legal Theory and Practice, 97 Nw. U. L. REv. 1081, 1100-14 (2003). Their focus on criminal law provides a useful complement to our analysis of contract law and confirms our belief that dispositionism infects most, perhaps all, areas of law. Their article also usefully considers some of the possible policy implications of situationism for criminal law. Id.

${ }^{550}$ Charles fried, Contract as Promise: A Theory of Contractual ObliCATION (1981).

${ }^{551}$ See id. at 2 ("The regime of contract law, which respects the dispositions individuals make of their rights, carries to its natural conclusion the liberal premise that individuals have rights. And the will theory of contract, which sees contractual obligations as essentially self-imposed, is a fair implication of liberal individualism." (footnotes omitted)).

\footnotetext{
${ }^{532}$ Id. at 94.

${ }^{553}$ Id. at 57.
}

${ }^{554}$ Fried also addresses related areas of contract law such as mistake and unconscionability. Many of his arguments are overlapping and we believe that our observations here readily apply to these related areas as well. See id. at 58-63, 103-09. 
counterparts are central..$^{5 j}$ According to Fried, "these doctrines perform distinct functions that are not only compatible with the concept of contract as promise but even essential to it." ${ }^{5.566}$ Put in our terms, Fried's treatment of the doctrine of duress plays an essential part in defining the depth of his theory's dispositionism.

It runs deep. As he begins his discussion of duress, Fried never questions the basic dispositionist conception of the contracting agent. Duress is only identified as something that thwarts or exploits a will that remains exogenous to the duress:

Certain contracts are claimed to be unfair although the parties entered into them with their eyes open.

... The victim of duress is all too aware of what is happening and what will happen to him. Duress relates not to rationality or cognition but to freedom or volition.... [Contract as promise] excludes cases in which a person's assent is not voluntary. If I am hypnotized into signing a contract or if my hand is moved by another to make a mark signifying assent, I have not promised.

With such a starting point, only the most salient kinds of situations, and not necessarily the most powerful, will find their way into the doctrine of duress. Fried acknowledges that the forced signature and the hypnotized nod are just "gross instances of involuntary apparent assent" and claims that there are, in fact, "many kinds of situations in which it does not seem right to treat a knowing act of agreement as binding because in one way or another it is felt that there was no fair choice. ${ }^{, 558}$ But this concession is not an "open-ended invitation[] to rearrange the understandings people have reached." $" 599$ Indeed, Fried goes on to map a precise and rather closed-ended set of situations that may, consistent with the will theory of contract, be treated as constituting duress. ${ }^{560}$

Keeping close to the case law (as he must to sustain his project of both explaining and justifying modern contract law), Fried recognizes only the most salient kinds of situational impediments as creating duress. The clearest case for Fried, beyond the two above, is

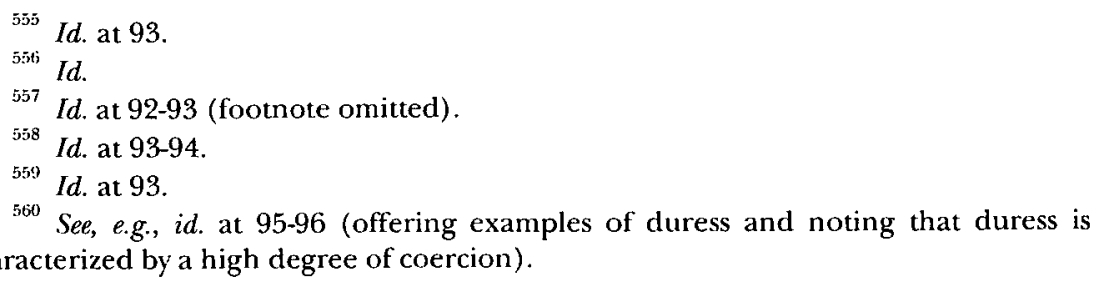


that now familiar trope-the gun to the head: "An armed robber threatens his victim on a dark and lonely street: 'Your money or your life." "ifi

Fried explains that what is troubling about this case is not that there is no choice, for clearly there is: " $[t]$ he shrewd and brave man who hands his wallet over to an armed robber makes a calculated decision." ${ }^{562}$ Rather, what is at issue is the fairness of the choice. ${ }^{563}$ To fashion a principle through which to apply the doctrine of duress in more difficult cases and across the sweep of contract law requires, Fried concludes, a normative determination about what is a fair choice. ${ }^{564}$ For Fried, then, the doctrine of duress may be managed by his theory of rights: "[a] proposal is not coercive if it offers what the proponent has a right to offer or not as he chooses."

This rights analysis generates for Fried a relatively clear view of the parameters of duress. Because the robber has no right to threaten your life to get your money, contracts made in such situations are not enforced. But, at the other end of this spectrum, merchants have a right to offer their wares on extremely onerous terms, so contracts entered with them should be enforced. Our present concern is not so much with showing why we disagree with this particular doctrinal conclusion, but in demonstrating the narrow dispositionist direction that the analysis has taken. Fried began with a case in which the threatening situation was not only extremely conspicuous, but where the element of choice was also clear. In looking beyond that extreme case for a general theory of duress, Fried presumes that the same basic function of dispositional choice remains in place. ${ }^{566}$ This dispositionism blinds the theory to the enormous power of the situation. It ignores the fact that situation shapes the very thoughts and behavior that manifest as the

561 Id. at 95 .

562 Id. at 94 .

50i9 See id. at 5 ("For promissory obligations to be truly self-imposed, the promise must have been freely given. If this means no more than that the promisor acted intentionally, then even an undertaking in response to a gunman's threat is binding.").

${ }^{504}$ See id. at 97 ("These conundrums should be sufficient to show that we cannot escape using some normative criterion to distinguish offers from threats.").

Id.

${ }^{566}$ In a footnote, Fried dismisses one source of opposition to the dispositional presumption. "Sometimes it is said that poor people do not understand contractual provisions or are unable to calculate risks rationally. Such arguments are often patronizing as well as paternalistic. Where they are valid, the doctrine of mistake offers some relief." Id. at $105 \mathrm{n}$.*. 
choices Fried crowns with a dispositionist presumption. For us, an inquiry, which is clearly called for but wholly unanswered by this kind of classical will theory, is whether and in what way the situation influences choice.

Fried concludes his analysis without ever moving beyond the "conundrums" raised by the most salient kinds of situational forces -that is, beyond those "bad acts" ${ }^{\$ 677}$ that can fit within the basic dispositionist framework. In an interesting parallel with economic theorists, the closest Fried gets to taking up the situation on a broader scale is with respect to poverty-when people do not have enough money to properly manifest an otherwise dispositionally determined will. ${ }^{568}$ However, Fried, like the contract law he describes, is very hesitant to allow the doctrine of duress to play much part in ameliorating the challenges posed by that kind of situationist consideration. Keeping the doctrine of duress from undermining "the moral status of calculated choices as embodied in bargains" is "a make-or-break challenge to the liberal economic theory of the market." It is a threat to the regime of "free men freely contracting. ${ }^{\text {,570 }}$

To the extent that poverty remains a situation in need of attention, Fried offers what is also a familiar riposte, that the situation should be handled by the tax-and-transfer system, not contract. Hence, in the end, the dispositionism that Fried begins with, and which he is so deeply committed to, not only drastically limits what kinds of situations are cognizable within the concept of

${ }^{567}$ Interestingly, Fried titles this section of his treatment Bad Samaritans. Id. at 109. See also supra text accompanying notes 163-81 (reviewing a social psychological study replicating the biblical parable of the Good Samaritan and suggesting that whether or not a person will act "as if" they are a Good Samaritan may have less to do with the person's disposition than with the situation in which the person finds herself).

${ }^{568}$ See supra text accompanying notes 116-29 (summarizing economists' analysis of the theoretical problem posed by poverty).

569 FRIED, supra note 550 , at 94 . For Fried, the slippery slope of the poverty situation is perilous. "If . . duress focuses only on the relative wealth or advantages of the parties to a transaction and disparities in these are held to undermine the voluntariness of the choice, then we might just as well redistribute directly, holding the rich but not the poor to their bargains." Id.

${ }^{570}$ Id. Cf. Chen \& Hanson, Illusion of Law I, supra note 84 (describing the way the perception of system threat has strengthened reliance on policy schemes); Hanson \& Yosifon, supra note 30 (describing the more general phenomena as discovered by social psychologists); infra text accompanying notes 639-97 (using Southern slavery as an illustration of how system threats help to promote dispositionism). 
duress, but also what can be done with the doctrine in those situations that it does recognize.

Fried does not go much further than this with the concept of duress, and we need not go further here to make our basic point. Conventional contract theories, of which we believe Contract as Promise is an influential and representative example, are steeped in dispositionism even in those areas that purport to be most concerned with the situation. The lack of any critical examination of the basic dispositionist presumptions in such legal theories results in a fundamental failure to account for the role of the situation in shaping our conduct. It marks an abdication of any realistic inquiry into the basic forces shaping our own behavior beyond what common sense and our intuitions will provide. ${ }^{571}$ Behind this tendency is the fundamental attribution error, which social psychologists have shown is widespread in humanity, that we have argued is at the core of conventional economic theory, and that, as this example suggests, is also robust in more traditional legal theories.

\section{The Dispositionism of Post-Classical Contract Theory}

The classical will theory of contract has been subjected to withering critique by generations now of "modern" or "post-classical" contract theorists. ${ }^{572}$ The critiques, which will not be rehashed here,

${ }^{571}$ Like many traditional theorists, as well as legal economists, Fried repeatedly takes comfort in the fact that his analysis comports with common sense. See, e.g., FRIED, supra note 550, at 6 ("In developing my affirmative thesis I . . propose to perennial conundrums solutions that accord with the idea of contract as promise and with decency and common sense as well."); $i d$. at 105 ("What needs probing is the notion of substantive unfairness. Analysis reveals it to be two parts sentiment and one part common sense."). As we have been arguing, common sense with respect to the relative roles of disposition and the situation is fundamentally flawed.

572 The basic legal realist analytic critique of the classical approach has been the claim that fundamental doctrines in contract law are far too public, and the intent of parties far too difficult to discern, for the will theory to explain contract. The basic political critique has been that so strongly privileging individual "will" in contract law unfairly disadvantages those without bargaining power. Both of these critiques, while not our focus here, are consonant with our views of both classical and modern contract law. The historical and intellectual movement from "classical" to "modern" contract theory has been a subject of sustained analysis by contract theorists. For an overview, see P.S. AtTyah, The Rise and Fall of FreEdom of Contract (1979); HoRwitz, supra note 200, at 33-63; Jack Beatson \& Daniel Friedman, Introduction, From "Classical" to Modern Contract Law, in GOOD FAITH AND FAult in CONTRACt LAW 3 (Jack Beatson \& Daniel Friedmann eds., 1995); see also Jay M. Feinman, Promissory Estoppel and Judicial Method, 97 HARv. L. REv. 678 (1984) (examining the development of promissory estoppel as one of many reforms meant to resolve the contradiction in classic contract theory between freedom and coercion). 
share a common legacy in the American legal realist tradition, which provided both analytical and political reasons for doubting the classical approach. Our purpose here is to show that although the "modern" approach begins by rejecting the will theory of contract, it continues to embrace an unwarranted, and profoundly limiting, dispositionism. While the post-classical tradition has questioned the clarity of central concepts in classical theory, the legal realist approach has nevertheless held tightly to the basic tenets of dispositionism we have been reviewing here. Our very limited goal in this Section is to provide further evidence that dispositionism reaches far beyond law and economics in contemporary legal theory.

We will sketch the dispositionism in modern contract theory through the work of Karl Llewellyn, specifically in his concept of "situation sense." ${ }^{573}$ We take this approach for several reasons, not only because an article that is entitled The Situation, and that makes the claims we are developing here, would be remiss not to engage the legacy of situation sense, but also because Llewellyn's work was seminal and is prototypical of the basic legal realist approach. Moreover, Llewellyn's work has been extremely influential in the postclassical contract theories and positive law that have followed his work. $^{574}$

${ }^{573}$ Of course, we will not offer a comprehensive treatment of Llewellyn's great contribution to legal theory. We join a long list of commentators who have noted that "[a]ny effort to summarize Llewellyn's elaborate theory and the importance of 'situation sense' is bound to fall short." David Shapiro, Continuity and Change in Statutory Interpretation, 67 N.Y.U. L. REV. 921, 941 n.103 (1992). In our view, of all the recent efforts to summarize Llewellyn's work, Professor Rakoff's comes closest to accomplishing the feat. See Todd D. Rakoff, The Implied Terms of Contracts: Of "Default Rules" and "Situation Sense," in GOOD FAITH AND FAULT IN CONTRACT LAW, supra note 572 , at 191, 214 (defining Llewellyn's conception of "situation sense" as a "process of thinking" that considers "the implications of various legal rules, matched up against reasonably intricate models of social situations, and brought together in light of the force of all the claims to be made").

${ }^{574}$ Llewellyn has also had a tremendous influence on the development of contemporary contract theory and law through his contribution to the Uniform Commercial Code. See Lisa Bernstein, The Questionable Empirical Basis of Article 2's Incorporation Strategy: A Preliminary Study, 66 U. CHI. L. REV. 710, 712 (1999) (noting that Llewellyn was a "principle drafter" of Article 2 of the Uniform Commercial Code); Richard Danzig, A Comment on the Jurisprudence of the Uniform Commercial Code, 27 STAN. L. REV. 621, 624-27 (1975) (offering examples of Llewellyn's influence on the Uniform Commercial Code); Feinman, supra note 572, at 698 ("The method of analysis perhaps most characteristic of the modern cases may be characterized in the language of its principle exponent, Karl Llewellyn, as 'situation sense.'"); Allen R. Kamp, Between-theWars Social Thought: Karl Llewellyn, Legal Realism and the Uniform Commercial Code in Context, 59 ALB. L. REv. 325, 370 (1995) (considering whether the Uniform Commercial Code reflects Llewellyn's notion of "reasonableness"). 
Llewellyn opens Part I of the Common Law Tradition, ${ }^{575}$ his most sustained exposition of situation sense, with an announcement that it is now common knowledge ${ }^{576}$ that psychologists have undermined the epistemological ground on which the classical tradition once firmly stood:

When the psychologists began to look into how people go about reaching decisions, the question they were concerned with was: how do people get to a decision at all, to any decision, when faced with a problem-situation out of life? Roughly, they arrived at the conclusion that if it was a true problem-situation, i.e., if it was really a puzzler, then it was seldom that the actual deciding was done by way of formal and accurate deduction in the manner of formal logic. The common process was rather one either of sudden intuition-a leap to some result that eased the tension; or else it was one of successive mental experiments as imagination developed and passed in review various possibilities until one or more turned up which had appeal. In any ordinary case a reasoned justification for the result represented a subsequent job, testing the decision against experience and against acceptability, buttressing it and making it persuasive to self and others.

Today all of this is so familiar and obvious as to bore, but there were reasons why, four or five decades ago, it shocked our legal world..$^{577}$

Llewellyn's actual account of modern contract theory, however, reveals that legal scholars have been too quickly "bore[d]" by the social scientists' challenge to conventional views about the human mind, and so have failed to truly incorporate its teachings. To begin with, interior and exterior situations influence far more than just our ability to reason our way through "puzzlers." Logic and deduction as the primary causal forces behind our behavior are, we now know, the exception to the rule.

More generally, in the development of his notion of situation sense, Llewellyn was unaware of the basic lessons about the situation's unseen power, that psychology, especially social psychology, has now demonstrated. ${ }^{578}$ After opening the Common Law Tradition with a

${ }^{575}$ Karl N. LlewellyN, THE Common Law Tradition (1960). Although the book contains his most compendious discussion of situation sense, he developed the concept in somewhat piecemeal fashion over the course of over three decades of influential scholarship.

${ }^{576}$ The phrase "announcement that it is now common knowledge," which aptly describes the quote that follows, may in a sense sum up the task of the legal analyst in situation-sense theory.

${ }^{577}$ LLEWELLYN, supra note 575, at 11.

${ }^{578}$ See supra text accompanying notes 82-100 (discussing early experimental evidence of the situation's power to influence behavior); see generally Hanson \& Yosifon, supra note 30 (providing more extensive evidence of that power). Of course, 
recognition of the warning signs about our sense of ourselves, Llewellyn readily disregards his own cautions by the middle of his book, claiming that situation sense can clarify what psychology has left obscure:

The argument has been, however, that whereas about other areas of reaching tough decision the psychologists and sociologists and other experts are still groping for more than indications ... yet in our area [of study] the clustered steadying factors combine with our traditions of craft... to provide the wherewithal to reasonably satisfy even the seemingly unreasonable demands made upon [judges] by the men of law and by the citizens who are the law-consumers.

Llewellyn sees the legal analysts' willingness to move ahead of the social scientists' struggles with mere "indications" about human decision making as a great advantage of modern legal theory. This confidence is supported by his basic dispositionist presumption that human thought processes are relatively transparent, and that there is a fairly obvious causal relationship between men and women's preferences and their behaviors or choices. To be sure, not every influence is spottable, but, as Llewellyn puts it,

the unspottables either cancel out or operate rather on the surface than at the root of the deciding, or else hit the crux ... too rarely to do more than slightly decrease the percentage of available correct forecasts. This includes such very occasionally vital factors as the day's news, insomnia, a secretary's or clerk's sickness or blob, the euphoria from a son's engagement to the right girl, and three hundred assorted other "irrelevant" but real stirrers of the man. I discard them not as negligible, but as not altering a basic workable reckonability from other and reachable factors alone.

For Llewellyn, as with Fried, there is little cause for concern about "unspottable" influences on the mind, and consequently little concern for ever-present though "unspottable" situational influences on behavior. ${ }^{581}$ In this way, Llewellyn's situation sense is a rejection of

when Llewellyn wrote, the power of the situation was much less well understood, even by social psychologists.

${ }^{579}$ LLEWELLYN, supra note 575 , at 155.

580 LLEWELLYN, supra note 575, at 131. Llewellyn's comments here parallel the reactions of many legal economists to the challenges posed by social psychology. See Hanson and Kysar, Taking Behavioralism Seriously I, supra note 251; Hanson \& Kysar, Taking Behavioralism Seriously II, supra note 251; Hanson \& Kysar, Taking Behavioralism Seriously III, supra note 257.

${ }^{581}$ Unspottable, that is, within a strong dispositionist mindset. 
classical formalism to be replaced, not by social scientific inquiry, but by "common sense" realism.

Llewellyn's confidence in the reliability of common sense situation-sensing is further boosted by his assurance that beyond those assorted pedestrian distracters of humankind, there is no reason to suspect that more venal distractions might make situation-sensing problematic. His prose aroused to full flare, Llewellyn writes, "if you take the personnel of the appellate bench as an entirety, arranged in the familiar bell-shaped curve ... [and] knock on that bell, there may be a bit of dullness in the ring, but it rings true. ${ }^{, 53}$ So it is that Llewellyn reassures himself and his readers that judges, like the rest of us, are not "unduly easy to bamboozle. , $584^{\circ}$

We believe that Llewellyn's situation sense is badly underdeveloped. Our illusion of dispositionism and blindness to the power of situation renders us all, Llewellyn included, more or less bamboozled. $^{585}$ Llewellyn reveals his own when he writes that "the situation, however eloquent, [can] operate only insofar as its eloquence [can] reach ear and understanding of the particular court or judge. ${ }^{\text {\$86 }}$ Yet it is precisely where attention to situation is blocked

${ }^{582}$ Though a precise definition of "situation sense," is notoriously absent, see supra note 573 and accompanying text, its common sense eclecticism is betrayed in Llewellyn's description of the concept as a "compound[] of Isness and Oughtness and what have you more ...." LLEWELLYN, supra note 575, at 61. See also id. at 121 "The evidence for this [i.e., that otherwise good rules can be twisted out of shape by attempts to do justice in 'hard cases'] draws on more than 'common knowledge' (which can so often be unmasked as common superstition); it draws on that most uncommon knowledge which I call horse sense, the balanced shrewdness of the expert in the art."). As far as what goes into this compound, for Llewellyn, "the main guide is felt sense and decency." Id. at 135. Professor Rakoff comments that "[i]t appears that Llewellyn was in some fashion endorsing a method of practical wisdom." Rakoff, supra note 573 , at 202. The question though is just what method guides the practice of situation sense. Llewellyn's explanation has often been characterized as "unmethodical." See, e.g., id. at 203 (suggesting that Llewellyn offers "many examples [but] no clear description of a method"). Our concern is not so much that it is "unmethodical" but rather that the method it embraces is dispositionist.

${ }^{583}$ LLEWELLYN, supra note 575 , at 130.

${ }^{584} I d$. at 262 . Llewellyn's claims about the abilities of judges often rest on an implicit and sometimes explicit appeal to the reader to see that "judges are like other human beings...." Id at 131 .

${ }^{585}$ We concur with Llewellyn that the problem with post-classical contract law is not that it is naive about the extent to which judges are corrupt or the difficulties they have paying attention. For us, the problem is in Llewellyn's presumption that, if those factors alone can be discounted, there is little else to worry about.

${ }^{586}$ LLEWELLYN, supra note 575 , at 157. 
from the ear and the understanding by dispositionism that situation can have its greatest power.

In addition to shaping Llewellyn's conception of the situationsensing analyst, dispositionism further limits his conception of the situation under inspection. Situation sense involves observing and analyzing the "immanent law" parties. The raw material for this study, the focus of the type-situation inquiry, is an inquiry into patterns of choices and conduct by individuals. The search is for indications ${ }^{588}$ of dispositional intent within different kinds of type-situations. When Llewellyn implores the legal analyst to "see it as it works" he is asking the analyst to follow how the type-situation has been composed by the dispositional actors that make it up. There is no injunction in Llewellyn's method to seek and account for unseen situational influences in type-situations. As David Charny summarizes, "[i]t is apparent that Llewellyn thought that custom was somehow expressive of the attitudes, preferences, and 'mentality' of the transactors themselves . . ..,589

This is because the situation-sensing analyst is urged to look at that which is obviously there, rather than that which may be hidden. And what is obviously there is individual behavior, evidence ready to confirm the dispositionism of the sensor. Thus, Llewellyn counsels that "the best safeguard against counsel's mispainting [of the situation, in an effort to manipulate the judge] lies in visualizing the hands-and-feet operations in the picture, seen as a going scheme, a working setup. Such operating aspects are curiously hard to fake.... ${ }^{590}$ The judge is thus instructed that, in his search for the "immanent law" ${ }^{\text {" } 991}$ of situation, a reliance on what is obvious will

${ }^{587}$ See infra note 591 and accompanying text (briefly discussing the term "immanent law").

${ }^{588}$ See supra text accompanying notes 578-82 (discussing Llewellyn's brush past social sciences' difficulties in discerning indications of human decision making).

${ }^{589}$ David Charny, The Netw Formalism in Contract, 66 U. CHI. L. REv. 842, 846 (1999). Charny is interested in the extent to which the customary practices of areas of industry are legislated or stipulated by hierarchical associations, and the extent to which the trade customs promulgated through such associations have a formal quality reminiscent of classical approaches to contract law-hence, the new formalism in contract. Id. at 842-43.

590 LLEWELLN, supra note 575, at 261.

${ }^{591}$ Llewellyn initially quotes the term "immanent law" from the German legal theorist Levin Goldschmidt:

"Every fact-pattern of common life, so far as the legal order can take it in, carries within itself its appropriate, natural rules, its right law. This is a natural law which is real, not imaginary; it is not a creature of mere reason, but rests 
"safeguard" against mispainting. ${ }^{592}$ This "realism" is a strictly positive realism, not a critical realism, and so it is another symptom of the widely shared perspective in legal theory that begins by overlooking situation. ${ }^{593}$

Were we to extend this discussion further, we would argue that the unreconstructed dispositionism we find in classical and postclassical contract theory can be seen in most other areas of contemporary legal theory as well. The fundamentals of Llewellyn's situation-sense approach remain highly influential in leading non-

on the solid foundation of what reason can recognize in the nature of man and of the life conditions of the time and place; it is thus not eternal nor changeless nor everywhere the same, but is indwelling in the very circumstances of life. The highest task of law-giving consists in uncovering and implementing this immanent law."

Id. at 122 (quoting Levin Goldschmidt, Der Entwurf eines Handelgesetzbuchs für die Preussischen Staaten [Draft Trade Code for the Prussian States], pt. 2, reprinted in 4 KRITISCHE ZEITSCHRIFT FÜR DIE GESAMMTE RECHTSWISSENSCHAFT 289 (Dernburg et al. eds., Heidelberg, Bangel \& Schmitt 1857)).

592 As Jay Feinman states:

The method of situation-sense begins with fact scrutiny, in which the court analyzes and categorizes the facts as might a lay person familiar with the context of the dispute. The fact scrutiny may reveal a consensus regarding applicable values within the affected group or within society as a whole; at a minimum, such scrutiny will limit the range of acceptable choices. The court then determines the appropriate legal remedy for the situation.

Feinman, supra note 572, at 702.

${ }_{593}$ Llewellyn rejects attempts by critics to categorize situation sense and legal realism as a philosophy in general or as a form of positivism in particular. LLEWELLYN, supra note 575, at 508-09. For Llewellyn, situation sense is an approach to decision making that encourages the decision maker to see each situation "fresh" while positivism is a philosophy giving legitimacy to law because it is law. See Karl N. Llewellyn, The Normative, the Legal, and the Law-Jobs: The Problem of Juristic Method, 49 YALE L.J. 1355, 1370-72 (1940); see also HORWITZ, supra note 200, at 208-12 (summarizing the critique of Llewellyn's situation sense on grounds that it is positivism). "Why should realism, which starts out as a reform movement, carry in its loins [an] essentially reactionary principle?" Id. at 211 (quoting L.L. Fuller, American Legal Realism, 82 U. PA. L. REV. 429, 461 (1934)).

Our critique is somewhat different. Beyond the question of whether other concerns will inform the judgment, we claim that there is too much positivism even in that component which is attempting to discern the "type-situation." Our claim is that the type-situation cannot be properly seen unless it is viewed from a critical realist perspective. Post-classical contract theory ultimately rests on the faith that "situation sensing" provides, as Professor Rakoff puts it, "good ground" for legal decision making. Rakoff, supra note 573, at 223; see also id. at 228 ("In short, situation-sense is a very good method for determining what the default rules of contract law should be."). In our view the trouble is that what is obvious to the situation-sensor will only confirm and encourage dispositionist "mispainting." 
economic approaches to criminal law, ${ }^{594}$ civil rights and constitutional law, ${ }^{595}$ statutory interpretation, ${ }^{596}$ and international law. ${ }^{597}$ We will not pursue this exegesis further here, however. Our purpose has solely been to illustrate that conventional legal theorists, like legal economists, begin their legal analysis with dispositional assumptions and, even when claiming to be situationally sensitive, set the threshold unrealistically high.

\section{B. Legal Presumptions}

The attribution error does not stop there. Our laws and policies reflect the same lopsided perceptions. That is, our laws and policies-formal and informal-mirror our human perceptions and, for all the reasons that people generally do, place the threshold for recognizing the situation higher than they should.

To be clear, this is not a claim that our laws totally miss the role of all situational influences. It is a claim that only the most salient, unambiguous situational features-and only those that have fairly straightforward implications for a generally dispositionist legal regime-will be appreciated. As with legal theory, dispositionist presumptions play a governing role in many, if not most, areas of law. To continue this limited exposition, we will again limit our focus to contract law.

The basic dispositionist presumptions seen in Fried's classical will theory of contract are reflected in contemporary contract law. ${ }^{598}$ The Restatement (Second) of Contracts, for example, fashions a theory of

${ }^{594}$ See, e.g., Mark Kelman, Interpretive Construction in the Substantive Criminal Law, 33 STAN. L. REV. 591 (1981) (applying situation-sense approach to the analysis of criminal law).

${ }^{595}$ See, e.g., Richard H. Fallon, Jr., Sexual Harassment, Content Neutrality, and the First Amendment Dog That Didn't Bark, 1994 SuP. CT. REV. 1, 40-41 (1995) (urging the application of "contextualization" to constitutional law problems, although noting that "[c]elebrations of situation sense and practical reason frequently dissolve into philosophical mush").

${ }_{596}$ See, e.g., David L. Shapiro, Continuity and Change in Statutory Interpretation, 67 N.Y.U. L. REV. 921, 941 (1992) (noting that a situation-sense approach to statutory interpretation is "not without defenders and not without force").

$5 \% 7$ See, e.g., LeON E. Trakman, The Law Merchant: The Evolution of COMMERCIAL LAW 93 (1983) ("Judges are compelled to synthesize how merchants think and act if the common law is to progress as international commerce progresses.").

${ }^{598}$ Of course, this is unsurprising given that Fried's project is in part a positive theory of modern contract law. See supra text accompanying notes 551-71 for a discussion of Fried's theory of contract. 
contract that is rooted in the principle of dispositional intent. A contract "requires a bargain in which there is a manifestation of mutual assent . . . ."599 Assent is understood in terms of dispositional intention: " $[\mathrm{t}]$ he conduct of a party is not effective as a manifestation of his assent unless he intends to engage in the conduct . . .,"600 Of course, at the margins of contract law there are a few instances when, because of intense situational forces, the dispositionist presumption may be rebutted. For example, the Restatement (Second) acknowledges the problem of "improper pressure in the bargaining process, in the form of either duress or undue influence."601 Nevertheless, even the doctrine of duress, the doctrine most preoccupied with situation, is wedded to a strong dispositionist foundation. Like legal economists and conventional legal theorists, the law can see the situational power of a gun to the head, but it does not see very much more. ${ }^{602}$

Consider the scope of the doctrine of duress as it has been applied in Massachusetts, which has, like most states, long since adopted the basic view found in the Restatement (Second). ${ }^{603}$ The doctrine actually makes infrequent occurrences in the annals of Massachusetts cases, no doubt because of the extremely narrow range of situations to which it applies. This is not to gainsay its fundamental importance, however, for as Fried recognized, even in its absence, the doctrine serves to sanctify the great range of

${ }^{599}$ RESTATEMENT (SECOND) OF CONTRACTS $\$ 17(1)$ (1981).

${ }^{600} I d . \$ 19(2)$. The Restatement consistently refers back to this section as stating the general rule of assent in contracts.

Id. ch.7, topic 2 , in troductory note.

${ }^{602}$ The same is true in other areas of the law. In tort law, courts recognize the limits of property rights when salient situational conditions of "necessity" are in play. A sudden, unexpected tempest, for instance, will mute the consequences of the otherwise dispositional act of trespass. See, e.g., RESTATEMENT (SECOND) OF TORTS $\S 197(1)$ (1965) ("One is privileged to enter or remain on land in the possession of another if it is or reasonably appears to be necessary to prevent serious harm to the actor...."). In criminal law, killing a person in the "heat of passion" is treated as a less egregious offense than committing the same act in "cold blood." See, e.g., United States v. Bradford, 344 A.2d 208, 215 (D.C. 1975) ("The purpose to kill is in legal contemplation dampened where the killer has been provoked or is acting in the heat of passion ....").

${ }^{603}$ See, e.g., Avallone v. Elizabeth Arden Sales Corp., 183 N.E.2d 496, 499 (Mass. 1962) (explicating the principle of duress as "[c]onduct by one party which causes another to enter into a contract "under the influence of such fear as precludes him from exercising free will and judgment" (quoting RESTATEMENT OF CONTRACTS $\$ 492$ (b) (1932))). 
contracts the enforcement of which go unimpeded. ${ }^{604}$ Where duress is explicitly addressed, Massachusetts courts have adopted a highly dispositionist conception of it. As a recent Massachusetts appellate court summarized in Randall v. Rapoza, "To avoid a contract on the basis of duress, a party must show that conduct by the other party [to the contract] caused him to enter into the contract 'under the influence of such fear as precludes him from exercising free will and judgment." ${ }^{606}$ The court further explained that:

[t]o show economic duress a party must show that he has been the victim of a wrongful or unlawful act or threat, and such act or threat must be one which deprives the victim of his unfettered will. As a direct result of these elements, the party threatened must be compelled to make a disproportionate exchange of values. ${ }^{607}$

The defendant in Randall, who was sued on a promissory note he had signed, told the court that he had entered the contract, under duress "'because of [Randall's] attitude and demeanor' [and] ... "his harassment." ${ }^{608} \mathrm{He}$ also told the court that he was having marital troubles and was not "thinking straight," and that he had been on anti-depressant medication when he entered the contract. ${ }^{609}$ The Massachusetts court, unsurprisingly, found that these allegations fell "far short of painting a picture of duress" because " $[\mathrm{h}]$ is decision was not an 'arbitrary determination, capricious disposition or whimsical thinking, ",610

Randall provides a typical example of the role that duress plays in reported cases in Massachusetts. Our purpose is not to provide an exhaustive account of its application, but rather to highlight that the "picture" of duress made out by the broad strokes of the doctrine demonstrates the deep dispositionist presumptions of contract law generally. It is presumed, for example, that in the typical case, where duress is not present, the choices represented by a contract are the product of "unfettered will." While this might seem like a

${ }^{604}$ FRIED, supra note 550, at 93-95.

${ }^{605}$ Randall v. Rapoza, 2001 Mass. App. Div. 153 (2001).

${ }^{606} I d$. at 156 (quoting Coveney v. President of Coll. of Holy Cross, 445 N.E.2d 136, 140 (Mass. 1983)).

${ }^{607}$ Id.

${ }^{608} I d$. (alteration in original) (quoting Rapoza Aff.).

${ }^{609} I d$. (quoting Rapoza Aff.).

${ }^{610}$ Id. (quoting Bembe v. McKesson Wine \& Spirits Co., 388 N.E.2d 309, 314 (Mass. App. Ct. 1979) (quoting Davis v. Boston Elevated Ry. Co., 126 N.E. 841, 844 (Mass. 1920))).

${ }^{611} I d$. 
high standard, the benefit of the dispositionist presumption actually makes it the routine case. Despite Rapoza's contentions to the contrary, the Randall court concludes that the contract he entered into was in fact a manifestation of his "unfettered will," and refuses to find that the doctrine of duress is applicable. ${ }^{612}$

As the law is described in Massachusetts, only the most conspicuous external sources of influence will be recognized as constituting duress. The court cites as its only example "signing... at the point of a gun." ${ }^{, 613}$ The fundamental attribution error at work here sharply limits the range of relevant situations to only those that can be narrowly attributed to the vivid "bad act" of another individual. The court's explication also reveals a miserly view of what kind of internal situation will be permitted to implicate the doctrine of duress. Only the most palpable kind of internal situation will be seen as evidencing duress-fear. As we have described, there are certainly many other features of our internal situations that can exercise as much influence over our conduct as does the more palpable situation of fear, yet those remain hidden by our dispositionism and are unseen in the law. Restricted by this dispositionist framework, the common law of contract has not developed categories of influence beyond salient external threats and internal fears through which parties can formulate their claims. Unless a choice can be shown to have been arbitrary, it is presumed to be the expression of an unfettered will. With the presumption set so high, parties can strive only to drum up those aspects of their situations that catch the dispositionist eye. Against the situational threshold of a gun to the head, harassing phone calls and antidepressant drugs will easily fail to rebut the strong presumption of unfettered will.

Contract law, like many areas of law, recognizes a point where the situation is seen to be so significant that it renders unreliable the dispositionist assumptions that would otherwise govern. Making someone liable for outcomes over which she wielded comparatively little dispositional control and where her situation is relatively controlling would be unjust, unfair, or inefficient, depending on the theoretical focus. If, as we hypothesize, the threshold in the law is fundamentally misplaced, then the law in many of these areas may be fundamentally unjust, unfair, or inefficient. Put differently, if the

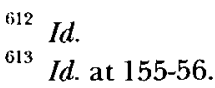


situation was as profoundly recognized in our laws as it is influential in our lives, the role of the situation would be presumptively paramount, rather than presumptively irrelevant. ${ }^{614}$

\section{Social Policy Presumptions: Learning from History Again}

There are other places to look to try to assess the significance of dispositionism. If our hypothesis is correct that the fundamental attribution error contributes to false impressions and self-understandings, and misguided legal theories and laws, then it should find support in the major social policy disputes that animate and define our history. Furthermore, there should be some evidence that the dominant view will typically be one that favors those in power-just as the geocentric view so clearly served the interests of the Catholic Church in the seventeenth century and, as we are arguing, the person-centric view serves the interests of corporations today.

Providing such evidence is also a topic of further work in progress. ${ }^{615}$ For now, we can highlight the major thrust of that work, which is that the power of the dispositionist presumption has had, and is now having, an immense effect on both the framing and the resolution of virtually every major social policy debate-from the obesity epidemic to the War on Terrorism. Although we will postpone defending that claim, it may be illuminating to highlight one particularly revealing and tragic example from our history: slavery. We have chosen that social policy issue to spotlight because we have suggested in this Article that power-even oppressive, totalitarian power-can be exercised through the unseen situation, in part, through the creation and promotion of dispositionist worldviews. Because slavery provides one of the most salient uses of power in United States history, demonstrating the role of dispositionism in enabling that oppression provides especially compelling evidence for our claim.

${ }^{614}$ We should not be understood as arguing that the outcome in Randall was necessarily incorrect. Our point is that the reasoning is based on a flawed vision of what moves us-a flaw with implications that may extend well beyond this case, the doctrine of duress, or even the law of contracts.

${ }^{615}$ See, e.g., Jon Hanson, David Yosifon \& Adam Benforado, Broken Scales: Obesity and Justice in America (unpublished manuscript, on file with authors). 


\section{The Teacher's View of the Learner}

First, to set the stage, it may be helpful to return to Milgram's basic research, in which he manipulated hundreds of subjects to behave in a way that contradicted his and others' initial expectations and thereby revealed the otherwise hidden power of the situation. The teacher was given a situation-induced "preference" to shock the learner, a "preference" that in most cases led teachers to continue to increase the shocks all the way to 450 volts (beyond the point when the learner fell silent after screaming in agony). ${ }^{616}$ The focus of social psychologists analyzing those experiments has long been on certain situational considerations, such as the authority conferred on the experimenter by, say, his white lab coat, in creating that "preference." 617

But an interesting issue emerges-one that has received comparatively little attention-about a different situational factor: that is, the teacher's perception of the learner's dispositions. The learner was one of Milgram's confederates, but he was assigned his position as learner by an apparently (but not actually) random process. The teacher then observed the learner voluntarily agreeing to be strapped into the chair, understanding that he would be shocked. ${ }^{618}$ The fact that subjects in Milgram's study appeared to make a free choice to enter into a "contract" may be central to understanding the large number of teachers who administered the maximum shock level of 450 volts. ${ }^{619}$

Once they had committed to participating, the teachers felt as if they were obligated to continue with and, in most cases, complete the experiment even when they believed they were inflicting pain or actually harming the learners. ${ }^{620}$ The sense of obligation (and the formal appearance of a contract) was likely strengthened by the fact that teachers were paid $\$ 4.50$ for their services prior to beginning the experiment. $^{621}$ It was also likely bolstered by the very structure of the

${ }^{616}$ Milgram, supra note 88 , at 376.

${ }^{617}$ For a discussion of some variations of Milgram's experiment, see Hanson \& Yosifon, supra note 30.

${ }^{618}$ Milgram, supra note 88 , at 373 .

619 Id. at 377.

620 Id

${ }^{621}$ Id. at 372,378 . However, Milgram also notes that the results of the experiment, when conducted with unpaid subjects, were "very similar to those obtained with paid subjects." Id. at 377 n.4. 
experiment, in which the shock level was increased in only very small increments of 15 volts. Because the learner did not protest initially, teachers continued to flip the switch, experiencing little internal conflict. Once the learner did complain, however, it was difficult to stop, even though many teachers experienced cognitive dissonance. ${ }^{629}$

To reduce this dissonance, people seek ways to justify their actions. In Milgram's original experiment, the teacher's initial agreement to administer the first shock to the learner most likely created internal pressure to continue with the experiment. ${ }^{623}$ With each incrementally higher shock level, the teacher had to justify his actions, and once he justified a particular shock level, it became increasingly difficult to determine the level at which he should cease shocking the learner:

How could they say, in effect, "OK, I gave him 200 volts, but not 215 -never 215!"? Each succeeding shock and its justification laid the groundwork for the next shock and would have been dissonant with quitting; 215 volts is not that different from 200 , and 230 is not that different from 215. Those who did break off the series did so against enormous internal pressure to continue.

The fact that the learner willingly provided answers without complaint through shock level twenty in the initial experiment seemed to provide proof that he, too, had accepted the terms of the agreement. $^{625}$ It was only when things started not to go his way (when he started to get many answers wrong) that he refused to honor the terms-a repudiation of the rules of contract. From the teachers' perspective, both they and the learner had voluntarily agreed to participate in an experiment for $\$ 4.50$; the learner had no reason to complain (or void the contract) because his position was assigned through a fair and random process. ${ }^{626}$ In the words of Milgram,

${ }^{622}$ Id. at 377-78. Cognitive dissonance is a feeling of internal discomfort produced when a person holds two or more inconsistent cognitions-in this case, the desire to fulfill the terms of a valid contract and the desire not to harm another person-and performs an action-here, shocking the learner-that is inconsistent with the person's customary positive self-conception. See Elliot ARONSON ET AL., SOCIAL PSYCHOLOGY 174-76 (4th ed. 2002) (defining and explaining "cognitive dissonance"); Hanson \& Yosifon, supra note 30 (discussing the cognitive dissonance and several related phenomena and their relevance for law and legal theory).

\footnotetext{
${ }^{623}$ Milgram, supra note 88 , at 294.

624 Id.

${ }^{625}$ Milgram, supra note 88 , at 378 .

idis at 377.
} 
"[t] hat he later becomes an involuntary subject does not alter the fact that, initially, he consented to participate without qualification., ${ }^{627}$

It is noteworthy, we think, that in Milgram's film, Obedience, the learner went out of his way in front of the teacher to stop and carefully examine the shock generator, with all its levels and warnings. ${ }^{628}$ And we suspect that the teachers tended to see the learner as someone who freely and knowingly chose to participate and who, in essence, wanted, perhaps even deserved, to be shocked-at least up to some level. Indeed, the situation-induced preference to shock the learner might well have solidified that perception. ${ }^{629}$ In this sense, the learner could be understood as having accepted his lot and having assumed the risk that it entailed. Put differently, the learner appeared to "reveal his preference" for getting shocked.

Of course, it is important to note that while theories of contract can be powerful forces of justification, outweighing complaints by the victim, they do not appear strong enough to overcome fully the voice of credible authority. ${ }^{630}$ Milgram attempted to test the power of contract notions by structuring a variation of the experiment in which, before signing the release form, the learner paused and stated, "I'll agree to be in it, but only on condition that you let me out when I say

${ }^{627} I d$.

${ }^{628}$ OBEDIENCE, supra note 149.

${ }^{629}$ Some anecdotal evidence provides loose support for this account. First, as noted above, none of the teachers ever went to find out if the learner was okay. Supra text accompanying note 180 . It is as if the teachers felt that they were not responsible for the learner's condition-in other words, that the learner was responsible for himself. In addition, there is some evidence that the teachers dispositionalized their own actions-blaming themselves for the bad "preference" that was "revealed" by their actions. According to lore among social psychologists, Milgram was able to include only one example of a person flipping the final switch (450 volts) in his famous documentary about the experiments, Obedience, because none of the many others who did so were willing to be shown on film. Presumably, they did not want to be shown as "bad people." Milgram included several after-thefact interviews of subjects, some of which revealed how the subjects attributed their actions to their own dispositions. See, e.g., Milgram, Obedience to AUTHORITY, supra note 86, at 54 ("As my wife said, "[y]ou can call yourself Eichmann.' I hope I can deal more effectively with any future conflicts of values I encounter."). Given that they dispositionalized their own behavior-behavior that was anything but flattering-it seems likely that they also would have partially dispositionalized the learner's behavior. See supra note 110 (describing the heightened tendency to attribute bad outcomes suffered by others-as compared to those we suffer ourselves-to disposition).

${ }^{630}$ See Milgram, OBEDIENCE TO AUTHORITY, supra note 86, at 66 (finding that "the social contract doctrine is a feeble determinant of behavior"). 
so; that's the only condition." to have some effect. Approximately a quarter of the teachers, who defied the experimenter's authority, raised the fact that the learner had explicitly conditioned her consent to participate in the experiment. ${ }^{632}$ A number of other teachers mentioned their concern with the "legalities" of the experiment. ${ }^{693}$ However, sixteen of the forty teachers continued to the end of the experiment, as compared to the twenty in the control, thus showing the enormous power of authority even in the face of contract forces. ${ }^{644}$

But suppose Milgram had tested the issue further. Suppose that the teacher arrived first and that he watched as the learner was dragged to the room in shackles and strapped into the chair involuntarily while begging, "Please, please, I never agreed to be part of this experiment, I was just walking by on my way to the library!" Or, for a less vivid version, suppose the teacher watched as the learner willingly sat in the chair under the false impression that he was going to participate in a sleeping experiment and that the straps were on the chair simply to measure sleep patterns.

We suspect that such variations in the experimental protocol would have had an even more significant effect than the conditional contract on the teacher's willingness to shock the learner. To put it in more general terms, we believe that a person's willingness to harm another depends heavily on whether or not that person perceives her victim to have dispositionally assumed such a risk.

There is, as it turns out, considerable social psychological evidence that is consistent with that understanding. ${ }^{635}$ Perhaps more importantly, however, there is also depressingly weighty support within the annals of history. When, for instance, Nazis murdered millions, many did so, secure in their belief that their victims deserved to be exterminated, for the benefit of the human species and the advancement of evolutionary trends. ${ }^{636}$ The tendency to

631 Id. at 64 .

${ }^{632}$ Id. at 65 .

${ }^{633}$ Id.

${ }^{634} I d$. at 66.

${ }^{635}$ See Hanson \& Yosifon, supra note 30 (summarizing relevant evidence of the "just world" hypothesis and the system-affirming motive in social psychology). For a sample of that work, see authorities cited infra note 686.

${ }^{636}$ See generally JoSePH Tenenbaum, RACE AND Reich 3-28 (Greenwood Press, 1976) (1956) (relating German science of racial superiority to the Nazi extermination campaign). See also Chen \& Hanson, supra note 52. 
dispositionalize in order to oppress has been particularly strong in the United States, where cultural notions of freedom, equality, and selfevident, natural rights have been celebrated at the same time that many of the humans within our borders have been grouped and subjected to bondage, conquest, and exploitation. ${ }^{637}$

Dispositionism has been the legitimating salve.

\section{The Master's View of the Slave}

I have often been utterly astonished, since I came to the north, to find persons who could speak of the singing, among slaves, as evidence of their contentment and happiness. It is impossible to conceive of a greater mistake. Slaves sing most when they are most unhappy. The songs of the slave represent the sorrows of his heart; and he is relieved by them, only as an aching heart is relieved by its tears. At least, such is my experience. I have often sung to drown my sorrow, but seldom to express my happiness. Crying for joy, and singing for joy, were alike uncommon to me while in the jaws of slavery. The singing of a man cast away upon a desolate island might be as appropriately considered as evidence of contentment and happiness, as the singing of a slave; the songs of the one and of the other are prompted by the same emotion.

-Frederick Douglass ${ }^{638}$

Let us return to the topic of slavery. ${ }^{639}$ When plantation owners traded in human beings, they were confronted with a problem not

${ }^{637}$ See generally RONALD T. TAKAKI, IRON CAGES: RACE AND CULTURE IN 19THCENTURY AMERICA (2000) (examining the cultural and economic foundations of racial subjugation in the United States); see also sources cited infra note 639 (examining racism in America).

${ }^{638}$ FrEdERICK DOUGLASS, NARRATIVE OF THE LIFE OF FREDERICK DOUGLASS, AN AMERICAN SLAVE (1845), reprinted in 1 THE NORTON ANTHOLOGY OF AMERICAN LITERATURE 1874, 1887-88 (Nina Baym et al. eds., 3d ed. 1989).

${ }^{639}$ There is a vast, sophisticated, and ever-expanding literature, across many disciplines, that has contributed greatly to our understanding of the shocking reality of slavery in the United States. For useful historical overviews of the ideas we discuss here concerning the basic dispositionist ideology underlying "the peculiar institution," see generally DaVID BRION DAVIS, THE Problem OF SLAVERY IN THE AGe Of REvolution, 1770-1823 (1975) (exploring the competing ideologies of anti-slavery and racist exploitation during the eighteenth and nineteenth centuries); GEORGE $M$. Fredrickson, The Black Image in the White Mind: The Debate on afroAMERICAN CHARACTER AND DESTINY, 1817-1914 (1971) (outlining the rise of formalized racism in the United States from its nineteenth-century beginnings through its apex during World War I); GEORGE M. FREDRICKSON, RACISM: A SHORT HISTORY (2002) (synthesizing over thirty years of historical scholarship on racism); THOMAS $F$. GOSSETT, RACE: THE HISTORY OF AN IDEA IN AMERICA (new ed. 1997) (surveying the development of race theory and race relationships from the colonial period through the twentieth century); STEPHEN JAY GOULD, THE MISMEASURE OF MAN (rev. ed. 1996) 
unlike the one faced by the teachers in Milgram's experiment. In antebellum America, plantation owners and slave traders, among many others, exploited slaves for financial and social gain, while maintaining their own perception of themselves as the sort of people who would never unjustly exploit others. ${ }^{640}$ All who were more or less complicit with the practices and systems of slavery needed to believe that the groups and systems to which they belonged were fair and just, and somehow not in tension with the principles of equality to which so many subscribed. ${ }^{641}$

\section{a. The basic message-dispositionism}

Faced with this situation, the plantation owners did what we all tend to do-and what most of us in their situation would likely have done at that time. They looked at their social world and inferred dispositionist distinctions that made slavery not only palatable, but natural, just, and in effect, Pareto superior. They embraced the self-affirming faith that their captives were intended (by God or nature) to be slaves, and that for their own good they needed to be slaves. ${ }^{64}$ It was the plantation owners that were

(explaining and refuting various "scientific" theories of racial superiority); WINTHROP D. JORDAN, WHITE OVER BLACK: AMERICAN ATTITUDES TOWARD THE NEGRO, 15501812 (1968) (analyzing white men's attitudes towards black Africans from the precolonial period through the early nineteenth century); KENAN MALIK, THE MEANING OF RACE: RACE, HISTORY AND CULTURE IN WESTERN SOCIETY (1996) (linking contemporary, post-Cold War racial ideology to the history of race and racial ideology in the West). Legal scholars have also contributed significantly to our current understanding of racism in general and slavery in particular. See generally CRITICAL RACE THEORY: THE KEY WRTTINGS THAT FORMED THE MOVEMENT (Kimberlé Crenshaw et al. eds., 1995) (collecting seminal writings of critical race theorists engaged in legal scholarship); A. LEON HIGGINBOTHAM, JR., SHADES OF FREEDOM: RACIAL POLITICS AND PRESUMPTIONS OF THE AMERICAN LEGAL PROCESS (1996) (surveying and analyzing the history of racism in the United States and its impact on legal theory and jurisprudence); THOMAS D. MORRIS, SOUTHERN SLAVERY AND THE LAW, 1619-1860 (1996) (theorizing the role of race as a factor influencing the rulings of particular judges in the American South during the two and a half centuries before the Civil War); MARK V. TUSHNET, THE AMERICAN LAW OF SLAVERY 1810-1860: CONSIDERATIONS OF HUMANITY AND INTEREST (1981) (studying Southern case law related to slavery); Ariela J. Gross, Litigating Whiteness: Trials of Racial Determination in the Nineteenth-Century South, 108 YALE L.J. 109 (1998) (examining the role of the law in the construction of race and racism in the nineteenth-century American South).

${ }^{640}$ See supra note 29-31 (providing brief summary of motive to self-affirm); Hanson \& Yosifon, supra note 30 (providing extensive summary of that motive).

${ }^{641}$ See Hanson \& Yosifon, supra note 30 (summarizing evidence of people's tendency to group-affirm and system-affirm).

642 Hig.GinBothaM, supra note 639, at 14. 
designed to be the masters, that could tame, train, and protect the slaves from themselves. ${ }^{643}$ They found ways to believe that slavery was precisely what slaves preferred-for if a person sings, smiles, and otherwise behaves "as if" she is happy, who can deny that she is? $?^{644}$ And if the slaves were not outwardly happy, there was still no good reason to conclude that they were unhappy. As Elizabeth Cady Stanton summarized:

It is impossible to make the Southern planter believe that his slave feels and reasons just as he does-that injustice and subjection are as galling as to him-that the degradation of living by the will of another, the mere dependent on his caprice, at the mercy of his passions, is as keenly felt by him as his master. If you can force on his unwilling vision a vivid picture of the negro's wrongs, and for a moment touch his soul, his logic brings him instant consolation. He says, the slave does not feel this as I would. ${ }^{65}$

Put differently, slaveowners (and, to some extent, most of antebellum society) ${ }^{646}$ inferred dispositional qualities about the slaves when they considered the situation of American slavery. They compared those qualities with their views of their own dispositions and concluded that the African race was dispositionally inferior in almost every way. This subsection will attempt to describe some of the manifestations of that fundamental attribution error-missing the situation-in this human tragedy.

\section{i. Revealed inferiority}

The primary, and perhaps most powerful, tendency of those who defended or were complicit with slavery was to see Africans in America as a subhuman species, or at least as less-highly evolved humans. ${ }^{647}$ The truth of the African slaves' inferiority was so obvious

643 Id.

${ }^{644}$ See infra text accompanying notes $647-82$.

${ }^{645}$ Elizabeth Cady Stanton, Address to the Legislature of New York on Women's Rights (Feb. 14, 1854), reprinted in ELIZABETH CADY STANTON, SUSAN B. ANTHONY: CoRRESPONDENCE, WRITINGS, SPEECHES 44, 50 (Ellen Carol DuBois ed., 1981).

${ }^{646}$ See HigginbothaM, supra note 639, at 12 ("The precept that African Americans were, in some immutable way, inferior became a powerful principle around which all white colonists, even those who did not own slaves, could begin to foster a common identity ....").

${ }^{647}$ A. Leon Higginbotham, Jr. has identified dispositional inferiority as the first of ten basic precepts of American slavery jurisprudence, and summarizes it as follows:

Presume, preserve, protect, and defend the ideal of the superiority of whites and the inferiority of blacks.

By considering the black as a subspecies of man or, most often, a heathen 
as to usually be beyond debate. As Chief Justice Taney put it in the infamous Dred Scott decision:

[Blacks] had for more than a century before been regarded as beings of an inferior order, and altogether unfit to associate with the white race, either in social or political relations; and so far inferior, that they had no rights which the white man was bound to respect; and that the negro might justly and lawfully be reduced to slavery for his benefit. $\mathrm{He}$ was bought and sold, and treated as an ordinary article of merchandise and traffic, whenever a profit could be made by it. This opinion was at that time fixed and universal in the civilized portion of the white race. It was regarded as an axiom in morals as well as in politics, which no one thought of disputing, or supposed to be open to dispute; and men in every grade and position in society daily and habitually acted upon it in their private pursuits, as well as in matters of public concern, without doubting for a moment the correctness of this opinion. ${ }^{64}$

The consequence of this dispositionist assessment of blacks was staggering. There were two principle holdings in Dred Scott. First, it meant that no African could be a citizen of the United States or even of any state "within the meaning of the Constitution.",4: Second, because blacks were not citizens in the eyes of the law, they could be treated as any other kind of property. According to the Court, Congress had no power to treat slaves differently from any other types of property. ${ }^{650}$ Consequently, the Court held, Congress could not exclude slavery from the federal territories, and therefore, that the Missouri Compromise was unconstitutional. ${ }^{651}$ But of course, the

from a less advanced, oppressed civilization, many whites could justify his enslavement. The whites" "logic" went as follows: the African is different in appearance and manner from us; he must not be human or at least not equally as human as we are; therefore, he is inferior to us and can be enslaved by us, his superiors.

A. Leon Higginbotham, Jr., The Ten Precepts of American Slavery Jurisprudence, 17 CARDOZO L. REv. 1695, 1697, 1700 (1996) (citations omitted).

${ }^{648}$ Dred Scott v. Sandford, 60 U.S. (19 How.) 393, 407 (1857). Taney was wrong in his monolithic positive description of white attitudes towards blacks, and we do not mean to suggest that these attitudes were indeed monolithic. But Taney's words certainly represented the dominant view and the powerful role of dispositionism in it. See generally HigGinBOTHAM, supra note 639, at 66 (analyzing Taney's opinion as an argument that "slavery did not render African Americans inferior" because by Taney's logic "African Americans, by their very nature, were inferior").

${ }_{649}$ Dred Scott, 60 U.S. at 406.

${ }^{650}$ Id. at 451 .

${ }^{651}$ See id. at 452 ("[T]he act of Congress which prohibited a citizen from holding and owning [slaves] ... in the territory of the United States north of the line therein mentioned, . . . is therefore void."). 
Court's holding in Dred Scott was considered common sense in much of America at that time. ${ }^{652}$ We all see dispositionally, and this dispositionism had long made people blind to the situation of slavery, and to the situational influence on slaves. ${ }^{6.33}$

Yet this common sense dispositionist presumption about Africans had not always been the common sense. In fact, the dispositionism emerged in America precisely because it was needed, as indicated above, ${ }^{654}$ to reconcile principles with practices. ${ }^{655}$ And few people, we suspect, felt the dissonance and the need to reconcile more intensely than did Thomas Jefferson ${ }^{656}$-civil rights theorist, father of the American Revolution, author of the Declaration of Independence, President of the United States, and Virginian slaveholder. ${ }^{657}$ Indeed,

${ }^{652}$ See HigGinboTHAM, supra note 639, at 66-67 (showing that, although the legal analysis was somewhat controversial, the presumption of black inferiority was commonly held); DON E. FEHRENBACHER, THE DRED SCOTT CASE: ITS SIGNIFICANCE IN AMERICAN LAW AND POLITICS (1978) (noting that most white critics of the decision railed against the Missouri Compromise restriction rather than the issue of Negro citizenship).

${ }^{653}$ See GOSSETT, supra note 639, at 29 ("The importance of Negro slavery in generating race theories in this country can hardly be overestimated.").

${ }_{654}^{65}$ See supra text accompanying notes 639-41.

${ }^{655}$ Cf. Barbara Jeanne Fields, Slavery, Race and Ideology in the United States of America, 181 NEW LEFT REV. 95, passim (1990) (arguing that the concept of race emerged, and continues to this day, in significant part to resolve the contradiction between espoused rights and ideals and actual practices).

${ }^{656}$ We do not mean to suggest, and would be incorrect if we did, that there was any unanimity in public opinion about slaves and slavery. See Gossett, supra note 639, at 53 (noting that, although " $[\mathrm{t}]$ he Negro would have to wait a long time," eventually "impressive voices were raised in behalf of his innate intellectual and temperamental equality with the whites"). There were always dissenters, visionary thinkers, courageous social movements, and individuals of deep perception, who knew for themselves and shouted to others that slaves were suffering from a degrading and dehumanizing situation, not dispositional inferiority. Very often these voices in the dispositional wilderness came from freed or escaped slaves themselves. See, e.g., Douglass, supra note 638, at 1887 (remembering slaves' songs as "tones loud, long and deep; they breathed the prayer and complaint of souls boiling over with the bitterest anguish."); BullwhIP DAYS: The SLAVES Remember 41 (James Mellon ed., 1988) ("'That was all the slave thought about, then: not being a slave. Because slavery time was hell." (quoting former slave Mary Gaffney)). Other oral histories reveal that many slaves themselves internalized the dispositionist account of their predicament. See generally Fed. Writers' Project, Works Progress admin., Slave Narratives: A Fol.k HISTORY OF SLAVERY IN THE UNITED STATES FROM INTERVIEWS WITH FORMER SLAVES (1941) (providing numerous examples from among more than 2,300 first-person accounts of slavery), available at http://lcweb2,loc.gov/ammem/snhtml/. This human tendency is part of what makes dispositionism so powerful.

${ }^{657}$ See Tania Tetlow, The Founders and Slavery: A Crisis of Conscience, 3 LOY. J. PuB. INT. L. 1, 11 (2001) (noting that Jefferson owned 154 slaves in 1794, only ten percent of whom he manumitted upon his death). 
Jefferson presumed to analyze the inherent nature of slaves' inferiority through a neutral and scientific approach. In an extended argument in his Notes on the State of Virginia, Jefferson enumerated in remarkably dispositionist terms the evidence that he found to justify the maintenance of slavery. ${ }^{6.58}$ We quote him here at length, not only because his analysis is so revealing, but also because it is his analysis, the careful work of a man whose desire for a shared freedom for all men is so celebrated in our culture: ${ }^{659}$

The first difference which strikes us is that of colour.... Is it not the foundation of a greater or less share of beauty in the two races? Are not the fine mixtures of red and white, the expressions of every passion by greater or less suffusions of color in the one, preferable to that eternal monotony, which reigns in the countenances, that immoveable veil of black which covers all the emotions of the other race? Add to these, flowing hair, a more elegant symmetry of form, their own judgment in favour of the whites, declared by their preference of them, as uniformly as is the preference of the Oranootan for the black women over those of his own species.... A black, after hard labour through the day, will be induced by the slightest amusements to sit up till midnight, or later, though knowing he must be out with the first dawn of the morning. They are at least as brave, and more adventuresome. But this may perhaps proceed from a want of forethought, which prevents their seeing a danger till it be present. When present, they do not go through it with more coolness or steadiness than the whites. They are more ardent after their female: but love seems with them to be more an eager desire, than a tender delicate mixture of sentiment and sensation. Their griefs are transient. Those numberless afflictions, which render it doubtful whether heaven has given life to us in mercy or in wrath, are less felt, and sooner forgotten with them. In general, their existence appears to participate more of sensation than reflection. To this must be ascribed their disposition to sleep when abstracted from their diversions, and unemployed in labour. An animal whose body is at rest, and who does not reflect, must be disposed to sleep of course. Comparing them by their faculties of memory, reason, and imagination, it appears to me, that in memory they are equal to the whites; in reason much inferior, as I think one could scarcely be found capable of tracing and

${ }^{658}$ ThOMAS JEFFERSON, NOTES ON THE STATE OF VIRGINIA (1787), reprinted in Thomas Jefferson: Writings 123, 264-70 (Merrill D. Peterson ed., 1984).

659 Much has been written on Jefferson's views about slavery. See, e.g., Aaron Schwabach, Jefferson and Slavery, 19 T. JEFFERSON L. REV. 63, 77-87 (1997) (summarizing Jefferson's views on slavery and collecting citations of scholarly work on the issue); Tetlow, supra note 657, at 10-24 (describing the hypocrisy of the founding generation and examining Jefferson's use of racial inferiority to resolve it); see also sources cited supra note 639 (containing extended analyses of Jefferson's thoughts on, and contributions to, American racism). 
comprehending the investigations of Euclid; and that in imagination they are dull, tasteless, and anomalous... But never yet could I find that a black had uttered a thought above the level of plain narration; never see even an elementary trait of painting or sculpture. . . Misery is often the parent of the most affecting touches in poetry.-Among the blacks is misery enough, God knows, but no poetry. Love is the peculiar cestrum of the poet. Their love is ardent, but it kindles the senses only, not the imagination.

... It is not against experience to suppose, that different species of the same genus, or varieties of the same species, may possess different qualifications. ${ }^{660}$ Will not a lover of natural history then, one who views the gradations in all the races of animals with the eye of philosophy, excuse an effort to keep those in the department of man as distinct as

160 Jefferson is attaching himself explicitly to a particular school of thought in the eighteenth century which held that Africans were in fact the same species as man, rather than some lesser species. See, e.g., JORDAN, supra note 639, at 308 (citing a debate at Harvard's 1773 commencement where one student argued that Africans were the same species as white men). But notice how little difference it makes with respect to Jefferson's dispositionism. Whether the Africans were an inferior species or a lesser quality of human, Jefferson sees their condition as resulting from stable, internal dispositional factors, and not from the situation. Later scholars would go further than Jefferson and claim to demonstrate that Africans were, indeed, an inferior race. Samuel Morton, one of the best-known antebellum scientists, amassed the largest skull collection in the world in his scientific endeavor to demonstrate that racial distinctions reflected deep genetic differences. More specifically, he applied this theory of polygeny to "prove" that Africans were inferior. See SAMUEL George MORTON, CRANIA AMERICANA 5-7 (1839) (describing the African race as "the lowest grade of humanity"); see also Am. Philosophical Soc'y, Samuel Ceorge Morton Papers: 1819-1850, at http://www.amphilsoc.org/library/mole $/ \mathrm{m} / \mathrm{mortonsg.htm} \mathrm{(last} \mathrm{visited}$ Oct. 30, 2003). "Morton's work met with a receptive audience in much of the United States. Its massive empirical base was praised by the scientific elite, and his theories on human relations were endorsed avidly by pro-slavery advocates." Id.; see also Gould, supra note 639, at 101-04 (illustrating the connections between Morton's work and American slavery). For a relatively brief history of the emergence of polygeny in America, and the role played by numerous scholars, including Morton and Harvard's Louis Agassiz, see Robert Bernasconi, Introduction to AMERICAN THEORIES OF POLYGENESIS, at v-xiii (Robert Bernasconi ed., 2002). Agassiz, a renowned European scientist who came to America in 1846, had initially concluded that all humans were of one race. Id. But after being in America and reviewing Morton's evidence, he converted to polygeny. Id. Apparently, it was not just Morton's highly credible statistical analysis that influenced Agassiz. In a letter that he wrote to his mother, Agassiz indicated that his own personal encounters with slaves were having an effect. Because they were, by their appearance, an evidently "degraded and degenerate race," Agassiz found it difficult "to repress the feeling that they are not of the same blood as us." Id. For a more extended account of polygeny, see Gould, supra note 639, at 71104 (exploring the development of polygeny throughout the nineteenth century); JOHN S. HALlER, JR., OUTCASTS FROM EVOLUTION: SCIENTIFIC ATTITUDES OF RACIAL INFERIORITY, 1859-1900 passim (1971) (describing the work of numerous American scientists in the late nineteenth century who, inspired largely by Darwin's work on evolution, attempted to use science to prove what they assumed to be true: that nonwhite "races" were more or less inferior to the whites). 
nature has formed them? This unfortunate difference of color, and perhaps of faculty, is a powerful obstacle to the emancipation of these people.

Jefferson's blindness to the situation is obvious to us now. We can, from our vantage, see the situation of slavery like we can see a gun to the head. But, in Jefferson's time, the situation was obscured by the more salient (and affirming) dispositions. While arguing that white people were obviously more beautiful than blacks, Jefferson cites blacks' "own judgment in favour of the whites," see the extreme power disparities that likely lead to this perceived reaction. This is an egregious instance of dispositions wrongly being thought to be "revealed" through behavior. ${ }^{663}$ Jefferson does not see that the situation of forced labor might require the kind of palliative function of song that Douglass spoke of, ${ }^{664}$ but rather concludes that the singing is evidence of a "carefree" disposition. Furthermore, he remarkably infers that blacks dispositionally required less sleep than whites, ignoring the fact that sleep was situationally less available to them. ${ }^{663}$ Jefferson also concludes that blacks had inferior reason and imagination, without appreciating the situation-the fact that blacks were denied schooling, for example, or the opportunity for creative expression ${ }^{666}$ - that created that condition. ${ }^{67}$

At the same time that blacks were perceived as inferior to whites in reason, they were seen as dispositionally superior to whites in doing

${ }^{661}$ JEFFERSON, supra note 658, at 264-67, 270 (footnote added).

${ }^{662} I d$. at 265.

${ }^{663}$ See supra text accompanying note 32 (discussing the role played by "revealed" preference assumptions in conventional economic theory).

${ }_{665}^{6}$ See supra text accompanying note 638.

${ }^{665}$ See, e.g., SOlomon NorThup, Twelve Years a Slave 167, 171 (Dover Publ'ns 1970) (1854) ("An hour before daylight the horn is blown. . . [T] hey oftentimes labor till the middle of the night"); $c f$. WILliam GoOdell, THE AMERICAN SLAvE CODE IN Theory AND Practice 128-29 (Negro Univs. Press 1968) (1853) (citing South Carolina's prohibition on forcing slaves to work more than fifteen hours per day in the summer or fourteen hours a day in the winter).

${ }^{666}$ See Eugene D. GeNOVESE, Roll, JORdan, Roll: THE WORLd THE SlaVes Made 561-63 (1974) (outlining formal bans on slave education).

${ }^{667}$ Of course, Jefferson was not only wrong in his dispositionist explanation of slaves' lack of reason and imagination, he was also wrong to conclude that slaves lacked those qualities. Scholars have unearthed an incredibly rich world of slave culture that was, by situational necessity, largely kept hidden from slaveholders. Seminal studies of the elaborate and extensive cultures built by slaves include, among many others, GENOVESE, supra note 666, and LAWRENCE W. LEVINE, BLACK CULTURE AND BLACK CONSCIOUSNESS: AFRO-AMERICAN FOLK THOUGHT FROM SLAVERY TO FREEDOM (1977). 
the sort of work that the slaveholders needed. As Jefferson noted, they seemed to forget their afflictions, required less sleep, and were more resistant to heat. Therefore, they were well-suited as forced laborers. ${ }^{68}$

It is important to note that Jefferson does not entirely disregard the influence of the situational effects of slavery. In fact, he purports to examine and control for such evidence. He explains that " $[t]$ he improvement of the blacks in body and mind, in the first instance of their mixture with the whites, has been observed by every one, and proves that their inferiority is not the effect merely of their condition of life." slaves to Roman slaves, who he claims were treated significantly worse than American slaves-in other words, their situations were even more stifling. ${ }^{670}$ But, as he then claims,

notwithstanding these and other discouraging circumstances among the Romans, their slaves were often their rarest artists. They excelled too in science, insomuch as to be usually employed as tutors to their master's children. Epictetus, Terence, and Phædrus, were slaves. But they were of the race of whites. It is not their condition then, but nature, which has produced the distinction.

${ }^{668}$ This ability to see "superior" qualities in an "inferior" group helps reveal how the tendency to dispositionalize is often motivated largely by a desire to justify existing power relationships. See infra notes 685-86. By attributing superior physical strength and athleticism to slaves, Jefferson further naturalized the division of labor. Some argue, quite compellingly, that the same sorts of attributions are made today, to the same effect. See, e.g., JOHN HOBERMAN, DARWIN's ATHLETES: HOW SPORT HAS DAMAGED BLACK AMERICA AND PRESERVED THE MYTH OF RACE 31-51 (1996) (arguing that the general success and superstardom of blacks on the athletic field have helped to justify their exclusion and inferior status elsewhere while giving the reassuring appearance of integration).

${ }^{669}$ JEFFERSON, supra note 658, at 267 (emphasis added). Jefferson's suggestion, here, that the inferiority of blacks is genetic, remains only an implicit suggestion. Explicit "proof" for that proposition would await further scientific study by others. See HALLER supra note 660, at 3-39 (describing the schools of thought and methodologies that developed in the nineteenth century to classify races).

${ }_{670}$ JEFFERSON, supra note 658 , at $267-68$.

671 Id. at 268 (emphasis added). Jefferson again, ignored the situation. In Ancient Rome, some slaves were given tasks requiring literacy, such as accounting and education. See Orlando Patterson, Slavery and Social Death: a Comparative STUDY 180 (1982) (noting that in Ancient Rome "skilled and literate slaves came to dominate not only urban industries, but education, the arts, theater, and literature"); THOMAS WIEDEMANN, GREEK AND ROMAN SLAVERY 8 (1981) (noting that Roman slaves were "entrusted with supervisory functions such as responsibility for the city accounts or weights and measures"). By contrast, in many states in the American South, especially after the Nat Turner rebellion, it was a crime to teach a slave to read or write. See Janet DutTsman Cornelius, "When I Can Read My Title Clear": 
Thomas Jefferson, who announced to the world that "all men are created equal," ${ }^{672}$ who founded the University of Virginia and carried the Enlightenment's torch through his lifelong emphasis on the importance of education, who believed he was an objective natural historian and scientist, still could not see the situation in the case of slavery. Dispositionism runs deep, and we can know with fair confidence that, were we living in Virginia at the time that Jefferson wrote, our position likely would have been even less situationally sensitive than his was. ${ }^{679}$

A review of Jefferson's justifications highlights the source and destination of our dispositionist tendencies. When we miss or downplay the situation, and see or exaggerate dispositions, we miss the hurdles, holes, quicksand, and other obstacles that can influence the outcome of any race, and instead attribute the outcomes to the racers themselves. Given the existence of the fundamental attribution error, it is very hard for us not to assume that we are all competing on a level playing field, that the victor deserves the spoils and the losers deserve their fate. And it is not just individuals that are engaged in a dispositional race. Indeed, entire "races" are competing against each other. The fact that one group dominates another often carries its own justification. Superior races, as measured by their ability to dominate, should dominate, as nature appears to reveal. ${ }^{674}$ As Alabama physician Josiah Nott put it in 1854,

LiteraCy, SLAVery AND RELigion IN THE ANTEBEllum SOUTH 32-33 (1991) (describing laws in Georgia, Louisiana, North Carolina, Virginia, Alabama, and South Carolina prohibiting the education of slaves).

${ }^{672}$ THE DECLARATION OF INDEPENDENCE para. 2 (U.S. 1776).

${ }^{673}$ Likely, that is, because acceptance of slavery was the dominant view, as we have noted, and will discuss below. What one thought about slavery may have depended, importantly, not on who one was, but rather where one stood.

${ }^{674}$ For many, however, it is not just revealed by nature, but by God as well. For example, the religious justification for slavery was also extremely popular and powerful. See generally FREDRICKSON, supra note 639, at 15-49 (describing the influence of religion on the advent of racism). The typical religious justification generally began with the claim that God recognized and sanctioned slavery in the Old Testament. Abraham, the benevolent and powerful patriarch, held slaves himself and was therefore considered the ideal for many slaveholders. See EUGENE D.

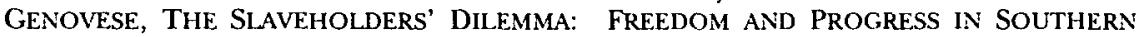
CONSERVATIVE THOUGHT, 1820-1860, at 38 (1992) ("Abraham loomed as the principal Old Testament figure among the slaveholders."). The next step in the religious argument was the assertion that God wanted Africans to become slaves. See William John Grayson, The Hireling and Slave 36-39 (1854) ("Hence has the negro come, by God's command / For wiser teaching, to a foreign land...."). Indeed, even conceding that slavery was a harsh means, proponents would argue that it was for good ends and part of a larger divine plan. See 
shortly before the Dred Scott decision: ${ }^{675} \quad$ "Nations and races, like individuals, have each an especial destiny: some are born to rule, and others to be ruled.... No two distinctly-marked races can dwell together on equal terms.... [H] uman progress has arisen mainly from the war of the races. ..."

id. at 36-37 ("And though the way be rough, the agent stern, / No other mode, can human wits discern, / No better scheme, may wealth or virtue find, / To tame and to instruct the negro mind ...." (footnote omitted)); id. at 38 ("So here, though hid the end from mortal view, / Heaven's gracious purpose brings the negro too; / He comes by God's decree, not chance nor fate, / Not force, nor fraud, nor grasping schemes of State ...."). God worked in mysterious ways, and mere men were not to question the motives of the Almighty. As in Galileo's time, it was very difficult to question the teachings of various churches. See Peter Kolchin, American Slavery: 16191877 , at 185, 186 (1993) (describing the South as the "home of religious and social orthodoxy"). Not surprisingly, the notion that God chose Africans to be slaves found its way into the legal system as well. See HigGinbotham, supra note 639, at 14 (describing how notions of the appropriateness of slavery worked their way into court opinions).

${ }^{675}$ See supra notes 648-51, and accompanying text (quoting Chief Justice Taney's opinion).

${ }^{676}$ J. C. NOTT \& GEORGE R. GLIDDON, TYPES OF MANKIND 53, 79 (1854). For an interesting biographical account of Josiah Nott's life as a humanitarian scientist devoted to understanding and treating yellow fever, on one hand, and as a racial scientist devoted to advancing racial prejudice and white supremacy on the other, see Reginald Horsman, Josiah Nott of Mobile: Southerner, Physician and Racial THEORIST (1987).

It is worth pausing to emphasize our belief that the very concept of "race" is itself based mostly on a fundamental attribution error motivated by this larger motive to justify inequalities. When groups of people appear to be doing better or worse than other groups, those experiencing and observing the difference often have a strong desire to attribute causation for it to a legitimating source. See infra notes 685-86 and accompanying text. Salient group characteristics, if they exist, are often seized upon to carry that weight. Racial differences, from skin color to hair texture, fit the bill nicely. As so often happens, though, the most salient features do not necessarily have much causal significance. And, as many geneticists, biologists, historians, and anthropologists have argued, that appears to be the case with many of the "racial" differences that we observe. See, e.g., JOSEPH L. GRAVES, THE EMPEROR'S NEW Clothes: BIOLOGICAL THEORIES OF RACE AT THE MILLENNIUM (2003) (reviewing the biological theories of "race" and the evidence that "race" has very little to no biological origins beyond those few that are sometimes evident on the surface); AUDREY SMEDLEY, RACE IN NORTH AMERICA: ORIGIN AND EVOLUTION OF A WORLDVIEW 22 (1993) ("[Race] was the cultural invention of arbitrary meanings applied to what appeared to be natural divisions within the human species. The meanings had social value but no intrinsic relationship to the biological diversity itself."). For an interesting and readable on-line article on this topic, see Jonathan Marks, Scientific and Folk Ideas About Heredity, at http://personal.uncc.edu/jmarks/interests/Baltimore.html (last visited Oct. 26, 2003) (describing the naturalizing but false racial categories that most of us have internalized and some of the effects of those categories). Again, there is a strong tendency to miss the larger context and be fooled by the vivid particulars that stand 


\section{ii. Consent-implied and revealed}

Those justifications led to another separate, but related, dispositionist justification of slavery-the myth that, were Africans competent to choose, they would choose slavery for themselves. But because they were not, the responsibility fell on whites to choose for them. George Fitzhugh, a slavery proponent and celebrated Southern polemicist wrote, "[the Negro] is but a grown up child, and must be governed as a child, not as a lunatic or criminal. The master occupies towards him the place of parent or guardian., ${ }^{677}$ Proponents argued that slavery was the best thing for the Africans because it allowed them to become "civilized," to become Christian, and to live a comfortable life, free from the dangers of their former life as African savages. ${ }^{678}$ Thus, there was at least an implied consent on the part of blacks to the slavery system.

out. When Jefferson began his defense of slavery with the phrase "the first difference which strikes us is that of colour," he was evincing what we would call the fundamental racial attribution error.

${ }^{677}$ GeORGE FITZHugh, SOCIOLOGY FOr THE SOUTH, OR THE FAILURE OF FREE SOCIETY 83 (Burt Franklin 1965) (1854).

${ }^{675}$ This concept is vividly portrayed in verse:

And yet the life, so unassailed by care,

So blest with moderate work, with ample fare,

With all the good the pauper Hireling needs,

The happier Slave on each plantation leads;

Safe from harassing doubts and annual fears,

He dreads no famine, in unfruitful years;

If harvests fail from inauspicious skies,

The Master's providence his food supplies;

...

No paupers perish here for want of bread,

Or lingering live, by foreign bounty fed;

No exiled trains of homeless peasants go,

In distant climes, to tell their tales of woe;

Far other fortune, free from care and strife,

For work, or bread, attends the Negro's life,

And Christian Slaves may challenge as their own,

The blessings claimed in fabled states alone-

The cabin home, not comfortless, though rude,

Light daily labour, and abundant food,

The sturdy health, that temperate habits yield,

The cheerful song, that rings in every field,

The long, loud laugh, that freemen seldom share,

Heaven's boon to bosoms unapproached by care,

And boisterous jest and humour unrefined,

That leave, though rough, no painful sting behind;

While, nestling near, to bless their humble lot,

Warm social joys surround the Negro's cot, 
A more extreme version of that paternalistic dispositionist fallacy was the view that slaves actually chose to be slaves-their consent and support for the institution was actually revealed by their happiness and satisfaction. In this view, there was really nothing paternalistic involved. Slaves were perceived to have consented by the fact that they seemed to like it. In this conception, slavery was contrasted with the system of wage labor in the North, and was seen as clearly superior. Fitzhugh again made the argument:

The negro slaves of the South are the happiest, and, in some sense, the freest people in the world. The children and the aged and infirm work not at all, and yet have all the comforts and necessaries of life provided for them. They enjoy liberty, because they are oppressed neither by care nor labor.

In 1861, former United States Senator James Henry Hammond from South Carolina explained the seemingly unchallenged "logic" of the system:

"In all social systems there must be a class to do the menial duties, to perform the drudgery of life. That is, a class requiring but a low order of intellect and but little skill. Its requisites are vigor, docility, [and] fidelity. Such a class you must have, or you would not have that other class which leads progress, civilization, and refinement. It constitutes the very mudsill of society and of political government... Fortunately for the South, she has found a race adapted to that purpose at her hand. A race inferior to her own, but eminently qualified in temper, in vigor, in docility, in capacity to stand the climate, to answer all her purposes. We use them for our purpose, and we call them slaves." ${ }^{680}$

From where Hammond stood, the need for slaves was beyond question. That was the way great societies had always done it. If you accept as a starting point that certain people are inherently and

The evening dance its merriment imparts,

Love, with his rapture, fills their youthful hearts,

And placid age, the task of labour done,

Enjoys the summer shade, the winter's sun,

And, as through life no pauper want he knows,

Laments no poorhouse penance at its close.

GRAYSON, supra note 674 , at $52-54$

${ }^{679}$ GeORGE FITZHugh, CANNibal.s All! OR, Slaves Wirhout Masters 29 (Richmond, A. Morris 1857); see also DON E. FEHRENBACHER, supra note 652, at 428 (noting that Chief Justice Taney described the lives of slaves as "usually cheerful and contented" (quoting SAMUEL TYLER, MEMOIR OF ROGER BROOKE TANEY, L.L.D. 660-64 (2d ed. 1876))).

${ }^{180}$ Carl T. Rowan, Dream Makers, Dream Breakers: The World of Justice THURGOOD MARSHALL 10 (1993) (quoting Senator James Henry Hammond). 
dispositionally inferior, the best way to maximize the utility of society is to put those people at the bottom. ${ }^{631}$ And if it happens that even the slaves prefer-or would if they were competent-to be slaves, then the idea of emancipation is ludicrous.

\section{b. Amplifying dispositionism: The anti-slavery bogeypeople}

In addition to those dispositionist rationales, defenders of the status quo of slavery also pointed to threats of bogeymen lurking in any change to the situation. Change was frightening, and could be made to seem even more so, not only to slaveholders, but to lower classes as well, including non-slaveholding planters and poor white laborers. Each of these groups viewed the maintenance of the social system as essential to keeping their fears from becoming reality. As historian James McPherson puts it, "[slaveholders] managed to

${ }^{681}$ We can now see what might be called a "Pareto inefficiency bogeyman" to justify slavery. It was widely held that the lives of blacks wouldn't improve much after slavery, and that the lives of whites would get considerably worse. Proponents would argue, why rock the boat when it would make some people worse off without making others better? For instance, Alexis de Tocqueville surmised that:

If [a slave] becomes free, he often feels independence as a heavier burden than slavery itself, for his life has taught him to submit to everything, except to the dictates of reason; and when reason becomes his only guide, he cannot hear its voice. A thousand new wants assail him, and he lacks the knowledge and the energy needed to resist them. Desires are masters against whom one must fight, and he has learned nothing but to submit and obey. So he has reached this climax of affliction in which slavery brutalizes him and freedom leads him to destruction.

Alexis de TocQueville, Democracy in America 318 (J.P. Mayer ed., George Lawrence trans., 1969) (1850). George Fitzhugh made a similar point:

Would the abolitionists approve of a system of society that set white children free, and remitted them at the age of fourteen, males and females, to all the rights, both as to person and property, which belong to adults? Would it be criminal or praiseworthy to do so? Criminal, of course. Now, are the average of negroes equal in information, in native intelligence, in prudence or providence to well-informed white children of fourteen? We who have lived with them for forty years, think not. The competition of the world would be too much for the children. They would be cheated out of their property and debased in their morals. Yet they would meet every where with sympathizing friends of their own color, ready to aid, advise and assist them. The negro would be exposed to the same competition and greater temptations, with no greater ability to contend with them, with these additional difficulties. He would be welcome nowhere; meet with thousands of enemies and no friends. If he went North, the white laborers would kick him and cuff him, and drive him out of employment. If he went to Africa, the savages would cook him and eat him. If he went to the West Indies, they would not let him in, or if they did, they would soon make of him a savage and idolater.

FITZHUGH, supra note 677 , at 88 . 
convince most non-slaveholding whites in the South (two-thirds of the white population there) that emancipation would produce economic ruin, social chaos, and racial war."

Even those that perhaps philosophically favored emancipation feared that, if blacks were released, hell might break loose. For instance, in a particularly grave rendition of this concern, Thomas Jefferson predicted that

[d]eep rooted prejudices entertained by the whites; ten thousand recollections, by the blacks, of the injuries they have sustained; new provocations; the real distinctions which nature has made; and many other circumstances, will divide us into parties, and produce convulsions which will probably never end but in the extermination of the one or the other race. ${ }^{633}$

${ }^{682}$ James M. MCPherson, Battle Cry Of Freedom: The Civil War ERA 8 (1988).

This fear expressed is evident within the Dred Scott decision:

For if [slaves] were . . . entitled to the privileges and immunities of citizens, it would exempt them from the operation of the special laws and from the police regulations which they considered to be necessary for their own safety. It would give to persons of the negro race, who were recognised as citizens in any one State of the Union, the right to enter every other State whenever they pleased ... and it would give them the full liberty of speech in public and in private upon all subjects upon which its own citizens might speak; to hold public meetings upon political affairs, and to keep and carry arms wherever they went. And all of this would be done in the face of the subject race of the same color, both free and slaves, and inevitably producing discontent and insubordination among them, and endangering the peace and safety of the State.

Dred Scott v. Sandford, 60 U.S. (19 How.) 393, 416-17 (1857); see also Bryan v. Walton, $14 \mathrm{Ga}$. 185, 202, 206 (1853) ("[The freed slave] resides among us, and yet is a stranger.... Generally, society suffers, and the negro suffers by manumission.... [Freedom] to the colored man ... is worse than slavery itself."); FEHRENBACHER, supra note 652, at 428 (commenting on Taney's view that "sudden emancipation [of African-American slaves] would mean 'absolute ruin."'). Many social historians have studied the part played by the putative advantage of racial superiority in nonslaveholders' support for the social system of slavery, and the racial apartheid that would follow in the Jim Crow period. See DAVID R. ROEDIGER, THE WAGES OF WHITENESS: RACE AND THE MAKING OF THE AMERICAN WORKING ClASS 3-13 (Rev. ed. 1999) (summarizing predecessor scholarship and arguing that notions of racial superiority allowed the white working class to distinguish and bolster itself vis-à-vis blacks, thus encouraging poor whites' complicity in the social system and inhibiting the development of social movements based on shared interests among poor whites and poor blacks).

683 JEFFERSON, supra note 658, at 264. Abraham Lincoln also feared a version of this bogeyman and, therefore, at one point early in the Civil War, suggested that blacks be kept separate from whites after emancipation. See Higcinbotham, supra note 639, at 67 (noting that Lincoln even considered repatriation of African Americans). 
Defenders of slavery pointed to what they saw as the inevitable and total destruction of the fabric of Southern society if slavery was abolished. As historian Eugene Genovese notes, "[ $t]$ he proslavery theorists never tired of proclaiming that the greatness of ancient Egypt, Israel, Greece, and Rome had been based on slavery ... ." ${ }^{684}$ The defenders of slavery assumed that there could not be a great and prosperous society without slavery; they were unable to imagine something that differed from the status quo. The only way to be prosperous, they believed, was the "proven" way, and thinking about alternatives was a dangerous endeavor. Of course, the views that blacks were inferior, that a successful society depended on the social system of slavery, and that only chaos would ensue from changing it, were wrong.

But the fear-mongering served an important purpose for those who engaged in it beyond simply predicting hypothetical future outcomes. As we have hinted throughout this Article and as we will describe in more detail in other work, ${ }^{685}$ there is considerable and growing social psychological research indicating that the presence of a threat to existing systems activates in us a general motive to justify or legitimate the system, as is. ${ }^{686}$ That research further reveals that one of the most effective means of legitimating the system is to dispositionalize those groups that might otherwise be seen as unjustly victimized. By increasing fears that the system was at risk, and that any change to the system would be calamitous, the defenders of slavery were, consciously or not, acting to reinforce the system and the dispositionism of slaves on which the system relied. And they were likely having that effect on all groups, regardless of their relationship with the system of slavery, including those who were in fact being harmed.

${ }^{684}$ GeNOVESE, supra note 674 , at 5 .

${ }^{685}$ See, e.g., Chen \& Hanson, Illusion of Law I, supra note 84; Hanson \& Yosifon, supra note 30 .

${ }^{686}$ A useful sample of that work containing support for the propositions in this paragraph and much more would include the following articles: John T. Jost \& D. Burgess, Attitudinal Ambivalence and the Conflict Between Group and System Justification Motives in Low Status Groups, 26 Personality \& Soc. PsychOl. Bull. 293 (2000); John T. Jost et al., Non-Conscious Forms of System Justification: Implicit and Behavioral Preferences for Higher Status Croups, supra note 215; John T. Jost, Outgroup Favoritism and the Theory of System Justification, supra note 191, at 89; John T. Jost \& Orsolya Hunyady, The Psychology of System Justification and the Palliative Function of Ideology, 13 EUR. REV. SOC. PSYCHOL. 111 (2002); John T. Jost \& Mahzarin R. Banaji, The Role of Stereotyping in System-Justification and the Production of False Consciousness, 33 BRIT. J. SOC. PSYCHOL. 1 (1994). 


\section{c. Dispositionalizing the opposition}

We have thus far explored several ways in which knowledge structures evolved to justify the institution of slavery on behalf of those who sought to legitimize it. More specifically, we have emphasized how slaves-and all identity groups for that matter-were more or less dispositionalized in order to "make sense" of the systems of slavery, and to inoculate them with the "patina of consent." capture of "knowledge" is not accomplished without the deep capture of knowledge production, and that is also part of the unseen situation. As was true during Galileo's struggles with the Catholic Church, as Stigler argued was true four decades ago of administrative regulators, and as we hypothesize is generally true today, conceptions of ourselves, others, and our institutions do not just emerge from bottom-up, individual analyses of the given facts. Nor do they emerge from a fair tournament of ideas, in which the most meritorious ideas, beliefs, and knowledge structures win out. Instead, the winners are created, promoted, subsidized, and protected by the systems, institutions, and individuals who enjoy the greatest power to define the situation. Influencing the interior situation means influencing, among other things, the information people have access to, how it is framed, and its credibility. The success of pro-slavery dispositionism required that dynamic. ${ }^{688}$

In this subsection, we focus briefly on one of its many elements: dealing with competing ideas and criticisms of abolitionists. Here was the problem. Although dispositionalizing slaves helped many Southerners ease the dissonance they felt from not permitting the selfevident natural rights that they were preaching, it did not relieve the dissonance created by the emerging abolition movement. Particularly after the Nat Turner rebellion in 1831, those who justified and endorsed slavery had to explain why so many other people were not persuaded by the force of their seemingly air-tight arguments.

The dissonance was likely significant. According to social psychologists, when such a conflict grows strong, something usually has to

${ }^{687}$ The phrase is Duncan Kennedy's. See Duncan Kennedy, Legal Education as Training for Hierarchy, in THE POLITICS OF LAW: A PROGRESSIVE CRITIQUE 40, 41 (David Kairys ed., 1982) ("Students act affirmatively within the channels cut for them, cutting them deeper, giving the whole a patina of consent and weaving complicity into everyone's life story.").

${ }_{688}$ For a sample of some of the laws prohibiting or discouraging the promotion of any ideas that might encourage questioning or criticism of slavery, see GoODELL, supra note 665 , at $384-86$. 
give. ${ }^{689}$ Of course, a person could reconsider and alter her own views, but that is a rare event, particularly when there is a lot at stake, as there was on the issue of slavery. Research shows that an extremely common means of extinguishing that sort of interpersonal or intergroup dissonance is to attribute the gap between our outlook and someone else's to a lack of objectivity on their part. We assume that there is some dispositional source of their bias-stupidity, or laziness, or corruption, or self-interest. ${ }^{690}$ Again, dispositionism saves the day.

And that is largely what happened in the South. To defend slavery and the entire worldview on which it was based, slavery's proponents dismissed abolitionists and their ilk as ignorant, hypocritical, and jealous of the success achieved in the South. As historian James McPherson summarizes:

[Slavery] also established the foundation for an upper class of gentlemen to cultivate the arts, literature, hospitality, and public service. It created a far superior society to that of the "vulgar, contemptible, counter-jumping" Yankees.... "Instead of an evil," said John C. Calhoun in summing up the southern position, slavery was "a positive good ... the most safe and stable basis for free institutions in the world. ${ }^{\text {"691 }}$

Southern newspapers echoed this sentiment. "The great evil of Northern free society," insisted a South Carolina newspaper, "'is, that it is burdened with a servile class of MECHANICS and LABOURERS, unfit for self-government, yet clothed with the attributes and powers of citizens." ${ }^{692}$ A Georgia newspaper was even more emphatic in its distaste:

Free society! we sicken at the name. What is it but a conglomeration of greasy mechanics, filthy operatives, small-fisted farmers, and moon-

${ }^{689}$ See generally Lee Ross \& Andrew Ward, Naize Realism in Everyday Life: Implications for Social Conflict and Misunderstanding, in VALUES AND KNOWLEDGE 103, passim (Edward S. Reed et al. eds., 1996).

${ }^{690}$ See, e.g., Dale T. Miller \& Rebecca K. Ratner, The Disparity Between the Actual and Assumed Power of Self-Interest, 74 J. PERSONALITY \& SOC. PSYCHOL. 53, 60 (1998) (noting that test-subjects commonly overestimate the impact of self-interest); Dale T. Miller \& Rebecca K. Ratner, The Power of the Myth of Self-Interest, in CURRENT SOCIETAL CONCERNS ABOUT JUSTICE 25, 30 (Leo Montada \& Melvin J. Lerner eds., 1996) (same); Emily Pronin, Daniel Y. Lin \& Lee Ross, The Bias Blind Spot: Perceptions of Bias in Self Versus Others, 28 PERSONALITY \& SOC. PSYCHOL. BULL. 369 (2002) (demonstrating our tendency to see other people as biased while assuming that we are unbiased).

${ }^{691}$ MCPHERSON, supra note 682, at 56 (quoting CONG. GlOBE, 25th Cong, 2d Sess., app. 61-62 (1838) (remarks of Senator Calhoun)).

${ }^{692}$ LAWRENCE R. TENZER, THE ForgotTen CAUSE OF THE CIVIL WAR: A NEW LOOK AT THE SLAVERY ISSUE 126 (1997) (quoting a South Carolina newspaper), 
struck theorists?... The prevailing class one meets with [in the North] is that of mechanics struggling to be genteel, and small farmers who do their own drudgery, and yet are hardly fit for association with a southern gentleman's body servant. ${ }^{693}$

In retrospect, such attacks on the dispositions of abolitionist enemies appear to be a fairly transparent tactic to discredit them. At the time, however, those who offered the critiques and those who shared in them, undoubtedly believed that the attacks were a fairly neutral assessment of the truth.

\section{d. Our dispositionalization of slavery}

In just that way, today, we look back with horror at slavery and the institutions, customs, laws, and mindsets that made it possible. We express outrage that "those people" could have embraced such inappropriate dispositionist assumptions, when it is so clear, in hindsight, that those assumptions were not only wrong, but selfserving mechanisms of oppression.

The same central lessons of the Galileo story are all evident here. We retrospectively witness powerful groups abusing their power by creating and enforcing oppressive laws based on false, but self-serving, dispositionist attributions. As with the Galileo story, we manage to dispositionalize the people involved as "evil"-and obviously different from us. Yet, we are nonetheless confident that history is not repeating itself today, confident that we are not blinded too by some false dispositionism, confident that we are not also unduly missing the situation. In the examples of Galileo and American slavery we can, in hindsight, see situation as palpably as we can see a gun to the head. And such a visible form of influence is, we all agree, unacceptable. Because we can see the situation in retrospect, we can take comfort in the belief that we are not subject to anything similar and that, unlike those who advanced or participated in those oppressive practices or "bad acts," we are dispositionally "good."

But here is the rub. Those are precisely the same dispositionist assumptions that the groups who we see as "bad" made about themselves. They did not see oppressive power shaping their society. We suspect further that we take comfort in our own outrage at these obvious evils of the past, comfort that helps convince us that we must not be missing anything like it in our own situation. ${ }^{694}$ The problem is

${ }^{693}$ MusCOGEE HERALD (Georgia), reprinted in N.Y. TRIB., Sept. 10, 1856.

${ }^{694}$ Today, one of the most well-known parts of Galileo's story is the legend that, 
that we do not understand that the best defense against such patterns comes less from identifying flawed ideas than it does from identifying the flaws in those who construct the ideas. The problem is in the human animal and our faith that we are immune to that which we generally neither see nor understand: the situation.

Indeed, instead of assuming that our current views about slavery and Galileo's imprisonment provide evidence that we will not again make such horrific errors, a more reasonable inference would be that those examples, and the countless others like them, constitute a compelling indication that history will continue to repeat-precisely because we do not appear to know what is moving it. If humans are capable of believing that those we directly harm (be they slaves, or Milgram's "learners") deserve their fate, it should be even easier to rationalize the harms imposed less directly, less saliently, and more situationally.

\section{Conclusion}

We can thus see that the power of dispositionism, and the patterns to which it gives shape, are witnessed again and again not just in social psychology's attributional experiments, nor just in the mundane basic habits of our lives, but in large and central questions of social policy and human society. We will not pursue this exegesis further here, but the basic pattern is becoming clear. When we see disposition and miss situation, we implicitly presume that the situation is neutral, that the playing field is stable, and that everything else is equal. We see outcomes, then, as dispositionally deserved. When the system is challenged or threatened, all those involved in the system have a stake in reinforcing it and, thus, reinforcing its legitimating rationalizations.

As this discussion has indicated, the institution of slavery emerged first and was justified later. And the justifications came piecemeal as the need arose. Jefferson's initial attempt to make sense of the institution was, at least by comparison to later efforts, quite tentative.

as he was leaving his confession, after he had claimed that the Earth did not move, Galileo said under his breath, "and yet it moves." It's just a legend; there is, as far as we have been able to discover, no real evidence that Galileo said it. But, hundreds of years later, we like to believe he did. It comforts us by illustrating how Galileo's capture and ultimate vindication are so very obvious in retrospect. "Those people" should have known better, and our hero, Galileo, did. What should be unsettling is that, in Galileo's time, this part of the story was invisible. No one knew, or probably would have even believed, that Galileo said such a thing. Those living through deep capture are rarely able to see enough of the situation to realize it. 
By the middle of the nineteenth century, with the attacks on slavery growing to a feverish pitch, the institution's justifications were fully formed and robust. And they did the trick. What had once been a "necessary evil" had been rendered a just, natural, and enviable path to civilized greatness. And many in the South were proud of that transition. South Carolina's Senator James H. Hammond spoke of earlier times when Southerners "believed slavery to be an evilweakness-disgrace-nay a sin.... [I]n fear and trembling [they] awaited a doom that [they] deemed inevitable." ${ }^{, 695}$ But that belief was temporary, as was the resultant fear. "“[A] few bold spirits took the question up; they compelled the South to investigate it anew and thoroughly, and what is the result?' [asked Hammond,] 'Why, it would be difficult to find a Southern man who feels the system to be the slightest burthen on his conscience." ${ }^{996}$ Hammond's fellow South Carolinian, John C. Calhoun, recounted the same history from dissonance to resonance as follows: "Many in the South once believed that [slavery] was a moral and political evil; that folly and delusion are gone; we see it now in its true light, and regard it as the most safe and stable basis for free institutions in the world." ${ }^{697}$ And so it is that visible evil fades into the situation and, with it, becomes invisible.

\section{The Situational Bogeypeople}

If not before, it is usually at this point in the presentation of our ideas to friends, family, students, and colleagues that we are stopped with one or another version of "I hear what you are saying and I may even agree, but I think you are going too far. Is it not dangerous to take the situation so seriously?"

We suspect that many of our readers may be experiencing similar reactions, and we understand the concern. To continue our argument, then, we think it is necessary to directly engage several versions of this kind of reaction to our claims. We are doing so not only to try to mollify our readers' worries, but also because these common reactions harmfully narrow the boundaries of most social and political debates in our society today.

${ }^{695}$ William W. Freehling, Prelude to Civil WAR 299 (1966) (quoting Senator James Henry Hammond, Oct. 29, 1858).

${ }^{696} I d$.

697 CONG. Globe, 25th Cong., 2d Sess., App. 61-62 (1838) (remarks of Senator Calhoun). 
One of our main concerns with those arguments is that they are not always what they purport to be. In our experience, they are not offered as a concern that emerges once the power of the situation is fully recognized. Rather, they are implication-based fears that prevent people from truly understanding the nature of our argument -that is, of the situation. Still, those responses are routine, usually as a fallback position-a final trump card. So we will do our best in this Section to respond to commonly held intuitions, which we call situational bogeypeople - siblings of those that we encountered earlier. ${ }^{698}$ These intuitions seem to come in several varieties.

\section{The Communism Bogeyman}

The most popular version of the challenge goes like this:

The playing field is level. And, as long as everyone is starting the race together, there is no reason to be concerned about the fact that there will be some winners and some losers. That's what a fair competition is designed to do: separate winners from losers as it creates incentives to win in the process. Equality of opportunity does not guarantee equality of outcome. If policymakers were to begin looking to outcomes as a measure of opportunity, they would transform our free world into a communist or socialist regime.

A major weakness of this challenge is that it is not actually a response to, as much as it is a denial of, our point. Our claim that situational influences benefit some groups and disadvantage others is a claim that the playing field is, in ways unseen, not level and that we are all operating under the wrong presumption. To assert that the playing field is level may, in fact, confirm our point: people do not see relevant situational influences (which would include many features of the playing field) and overattribute outcomes to dispositions.

That basic challenge sometimes finds some reinforcement, though, by retreating to the following version of the communist bogeyman:

Even if the playing field is not perfectly level, it is level enough for us to attribute success or failure to the participants' dispositions. After all, many people who appear to start with situational disadvantages outrun those who appear to begin with situational advantages-simply because they were dispositionally inclined to overcome those disadvantages.

${ }^{698}$ See supra text accompanying notes $219-25,682-86$ (discussing the concepts of the totalitarian and anti-slavery bogeymen); see also supra notes 312-13 and accompanying text (discussing the Catholic Church's fear of heresy). 
This response is just a more nuanced form of denial. Acknowledging trivial unevenness on the playing field can often be a disarmingly effective means of justifying ignoring that unevenness. Of course, it is possible that the field is only trivially uneven, but the evidence typically adduced for that claim tends to be very thin and seems to be based more on shared intuition than situational sensitivity. We do not want to deny that Horatio Alger, and many like him, have successfully managed to turn adversity into opportunity-or, in other words, have dispositionally chosen to overcome significant situational opposition. Nor do we want to deny that the hope of just such an outcome is inspiring for many poor and hard-working people in our society. ${ }^{699}$ But neither do we believe that such exceptional success stories are much more than that -exceptional. The fact that there is some movement across socioeconomic groups does not imply that situation does not immensely affect outcomes. ${ }^{700}$

First, when members of disadvantaged groups compete against advantaged groups, the situation will influence the outcome even if there are exceptions. An extremely fast and driven runner with a brick tied to his foot may well outpace a slower, unencumbered runner. But a class of brick-laden runners will tend to seem plodding or malingering as they fall behind their brick-free competitors.

Moreover, what may be true individually almost certainly cannot be true generally. For instance, the fact that some hard-working people manage to climb out of poverty does not mean that all could, if only they worked as hard. The point about a competitive race is,

${ }^{699}$ See Barbara EHRENREICH, Nickel AND DIMED: ON (NOT) GETTING BY IN AMERICA 118 (2001) (recounting the response of one of her maid service coworkers to the question of how she feels about working for people with so much when she has so little: "All I can think of is like, wow, I'd like to have this stuff someday. It motivates me and I don't feel the slightest resentment because, you know, it's my goal to get to where they are.").

${ }^{700}$ Perhaps a parallel argument may be useful to help make our point. The tobacco industry for decades successfully clouded the causal connection between smoking and diseases such as lung cancer by emphasizing two key facts: many smokers do not die of lung cancer, and many non-smokers do die of lung cancer. See RICHARD KLUger, ASHES TO ASHES 203, $209-11$ (1996) (discussing the debate over the link between smoking and lung cancer in the 1950s). By focusing on those individuals, cigarette companies succeeded in distracting us from the fuller situation-which was that the trends in lung cancer closely tracked smoking habits, the incidence of lung cancer among smokers vastly exceeded that of non-smokers, and the amount that a person smoked correlated with her probability of contracting lung cancer. $I d$. at 193-97. 
after all, to separate winners from losers. The situation of the competition creates a meaningful limit to the number of winners. If everyone ran as hard as Horatio Alger, the speed of the race would increase to be sure, but the number of winners and losers would not. $^{701}$

In any event, the claim that policymakers should not look to outcomes to help determine if there is a problem with the playing field simply denies a major feature of our argument. Because the playing field is part of the situation, there is little reason to be confident that we can know when it is level and fair.

Recall that nobody believed that the teachers in Milgram's experiment would shock the learners all the way up to 450 volts. ${ }^{702}$ The fact that two-thirds of them did suggests that even the experts, including Milgram, misperceived the power of the situation and overestimated the role of disposition. What social psychology and history teach us is not to trust our perceptions, but to doubt them.

Of course, claiming that we should learn from outcomes is a very different claim than "from each according to his ability, to each according to his needs[.]" ${ }^{703}$ Our argument is not that we should all finish the race together, but that where people finish may reveal more about the race than it reveals about the racers. Outcomes can serve an immensely valuable evidentiary role in any serious attempt to ensure that the playing field is level.

Moreover, the deference to outcomes as a measure of the process is nothing new. Indeed, it was Stigler who introduced that very methodology in assessing whether regulations were serving their purported goal of advancing the public interest. This outcome-based

${ }^{701}$ For example, at Harvard Law School, new students are encouraged to believe that by working hard, they can substantially increase their chances of getting A's in their first-year courses. They are encouraged to attend exam-preparation sessions and to heed feedback on mid-semester assignments. What students and faculty often seem to forget, however, is that those efforts will do little to influence the grade distribution, which is largely determined by a curve. What they may influence, however, is the sense of dispositional control and responsibility that students may feel for their grades. A common complaint among second-and third-year students is that grading is, in fact, not well correlated with how much energy they put into their courses-a belief that may help explain why so many seem to reduce their efforts.

${ }^{702}$ See supra text accompanying notes 87-99 (describing Milgram's experiments).

${ }^{703}$ Karl Marx, Critique of the Gotha Programme, in JUSTICE 162 (Alan Ryan ed., 1993). 
assessment, as we indicated above, is one of the most important foundational insights of conventional economic theory. ${ }^{704}$

Finally, the idea that taking situation into account will somehow reduce the incentives of the situationally disadvantaged to try to win, strikes us as counterintuitive and contrary to the most basic assumptions of those who promote free competition. If, in fact, the playing field is uneven, it seems that all competitors gain, not lose, incentive to run faster by leveling the field. Those who are disadvantaged on the current field will be given a fair chance, and those who are advantaged will be given a meaningful challenge. ${ }^{705}$

\section{The Personal-Responsibility Bogeyman}

\section{A second popular version of the situational bogeyman goes like this:}

If we begin to take situation into account, people will no longer be held personally responsible for their actions. Criminals will be able to blame almost anything they do on the fact that they had a bad situation. "It wasn't me, it was the situation; I'm a victim of circumstances" will be heard in all the courts of the land and criminals will run free.

We have several responses to this bogeyman.

First, as we summarized above, the law already takes situation into account, through doctrines like duress in contract, ${ }^{706}$ necessity in trespass, and "heat of passion" ${ }^{707}$ in criminal law. ${ }^{708}$ The problem, as we see it, is that the situation is far from being an occasional, glaringly obvious gun to the head, as the current law treats it. It is a

${ }^{704}$ Supra text accompanying notes 263-82. Similarly, market-oriented critics of the welfare system motivate their criticisms largely by arguing that the welfare system has failed to achieve its ends.

${ }^{705}$ Another version of the argument to which we are responding is that even if situational influences are significant, it is better to pretend that they are not, because otherwise doing so would remove any self-help incentive from those who are situationally disadvantaged. This version of the personal responsibility argument has several problems. First, it assumes that nothing can be done about leveling the playing field. Clearly, if the playing field could be leveled, there would be no need to pretend or to create the added incentive. Second, it is an argument that seems in direct tension with the pro-freedom assumptions that most of the people who offer it, claim to embrace. In the name of individualism, they are basically calling on us to embrace paternalism: "let's not tell anyone what we admit to be true, for their own benefit."

\footnotetext{
${ }^{706}$ Supra text accompanying notes 554-614.

${ }^{707}$ Supra note 602.

${ }^{708}$ Id.
} 
force of greater or lesser magnitude in nearly every human interaction. When we argue that the law must take situation into account, we are asking the law to continue to function as it always has, but in a way that gives the situation the weight that social science demonstrates it possesses in human affairs.

Second, there is a strong element of stereotype in the account of this bogeyman. The stereotype is that the situational character-our model of the human animal-is a puppet on the strings of the situation, entirely lacking in disposition or volition. But this is a false picture of our model. We fully agree that humans possess dispositions and that dispositions likely play some role in a great portion of our behavior. But, as we argue above, current legal theory and the law overestimate the point at which disposition ends and the situation begins. No one wants criminals to run free, but at the same time, we do not want to lay blame where it is not due. A law that takes a nuanced view of the roles of situation and disposition will be better able to correctly assign dispositional responsibility and blame where they belong.

Nevertheless, it might seem that, if the law were to expand its acknowledgement of situational factors, the result would be to expand the avenues for evading responsibility. Far from it. As we have shown, people systematically-and often quite erroneouslyattribute causation, responsibility, and blame to the most visible actors in a given situation. They compound their mistakes through the fundamental attribution error, by assuming that action is attributable to disposition, rather than situation. Judges, juries, and legislators are as vulnerable to these cognitive biases as anyone else. If we are truly committed to the principle of personal responsibility, then we should be deeply troubled by the prospect that we are applying it without taking these biases into account. For the damages to fit the tort or the punishment to fit the crime, we must first be sensitive to the situation.

It is our contention that, by ignoring situation, we may be ignoring the true role of disposition and letting those actors who are most responsible for the harms we seek to redress off the hook. To better illustrate this point, we offer a thought experiment, a variation on an actual experiment. Imagine an alternate world in which Stanley Milgram is actually interested in studying the effects of negative reinforcement on learning. Having seen the power of the situation, he designs an experiment identical in every respect to the actual one, with one difference: the learner receives real electric 
shocks. Unfortunately, when Milgram runs these experiments, the learner receives third-degree burns and sues for damages. Who should be held responsible?

Under commonly held notions of "personal responsibility," some might blame the learner. He was an adult and ought to have known what he was getting into. After all, everyone knows that electricity is hot! Therefore, he should be made to deal with the consequences of his decision, instead of looking to blame others for them. Some people, also citing "personal responsibility," might blame the teacher who flipped the switches because she had many opportunities to stop. There were teachers who refused to go along with the experiment when they saw the learner's suffering; no one held a gun to this teacher's head. Shouldn't she be responsible for the (quite visible) consequences of her actions?

A typical "personal responsibility" view of this lawsuit would likely stop at that analysis in either allowing the loss or imposing liability. But what of Stanley Milgram? Shouldn't he have known of the risks to the learner? Shouldn't he be held "personally responsible" for setting up a situation in which the teacher was quite likely to flip the switches? Or perhaps Yale University should be held responsible for not better monitoring Milgram. Milgram apparently conducted his original experiments with the university's knowledge and may have been motivated by the university's tenure standards to perform this sort of research. Doesn't Yale profit, even to this day, from the attention garnered by Milgram's work?

If any part of this account conflicts with your intuitions, then consider the famed McDonald's coffee case of a few years ago. ${ }^{709}$ In that case, hot coffee spilled on Stella Liebeck's lap, giving her thirddegree burns. ${ }^{710}$ When she won a verdict against McDonald's, Liebeck became a symbol of the law's role in absolving citizens of personal responsibility and the poster child for tort reform. ${ }^{711}$ "[R]adio talk-show hosts around the country... lambasted the plaintiff, her attorneys and the jurors on air. Declining to be interviewed $[$,$] ... one juror explained that he already had received$

709

See Andrea Gerlin, A Matter of Degree: How a Jury Decided that a Coffee Spill is Worth $\$ 2.9$ Million, WALL ST. J., Sept. 1, 1994, at Al (recounting the events leading up to the lawsuit and the trial).

${ }^{710} \mathrm{Id}$.

711 See, e.g., This is True, Inc., The TRUE Stella Awards, at http://www.stella awards.com (last updated Apr. 2003) (showcasing abuses of the tort system in America and naming an award for such abuse after Stella Liebeck). 
angry calls from citizens around the country." ${ }^{712}$ Under the common sense "personal responsibility" view, Ms. Liebeck was responsible for knowing the coffee was hot and ought to have been more careful in handling it. After all, "she spilled it on herself." "13 However, when the jurors were forced to look at the situation, they were able to see that McDonald's shared responsibility for the burns. ${ }^{714}$

We present this case and our hypothetical to make clear that the term "personal responsibility" does not resolve difficult questions of fault. It merely begs them. Our point is not that people should never be held responsible for their acts, but that one should not assume that their "common sense" can be trusted to assign responsibility. ${ }^{75}$ The law must be concerned with questions of situation.

712 Gerlin, supra note 709, at A1.

713 Aric Press et al., Are Lawyers Buming America?, NewsweEk, Mar. 20, 1995, at 32, 34.

${ }^{714}$ See Gerlin, supra note 709, at A1, A4 (summarizing jurors' views). Contrary to popular perceptions, seventy-nine-year-old Liebeck was not driving, nor was the car in motion, when the accident occurred. Her "absurd" conduct was simply to place the coffee cup between her legs as she tried to remove the plastic lid. CARL T. BOGUS, WHY LAWSUITS ARE GOOD FOR AMERICA 19 (2001). Furthermore, McDonald's served its coffee at between 180 and 190 degrees Fahrenheit, whereas the average household cup of coffee is between 130 and 140 degrees Fahrenheit. Id. A doctor testified that lower temperatures would have slowed the rate of burning. Gerlin, supra note 709, at A4. Although McDonald's had received 700 complaints of coffee burns in the preceding decade, it did not sufficiently warn consumers of the possibility of burns or intend to reduce its coffee temperature. Press et al., supra note 713, at 35; see also John F. Bramfeld, Spilled Coffee and a Shot in the Foot, CHI. DAILY L. Bull., May 18, 1995, at 6 (suggesting that keeping temperatures high despite complaints was a justified, deliberate, profit-maximizing business decision).

Before ever filing a suit, Ms. Liebeck reported her injuries to McDonald's and requested compensation for her medical expenses (she spent eight days in the hospital and underwent a series of skin grafts, leaving her with permanent scars over sixteen percent of her body). BoGUS, supra, at 19-20; Press et al., supra, at 34. Rebuffing Liebeck's request for $\$ 2,000$, McDonald's offered $\$ 800$ to close the matter. Id. At trial, Ms. Liebeck only sought damages based on the difference in injury between spilling 140-degree coffee and spilling 180-degree coffee. BoGUS, supra, at 20. Furthermore, despite media coverage suggesting a "rogue verdict," the jury did not ignore Liebeck's role in the accident or absolve her of responsibility. They found her to be twenty percent comparatively negligent and reduced the compensatory damages for medical costs and disability to $\$ 160,000$ from $\$ 200,000$. Id . Moreover, the punitive damages were not quite as arbitrary as commonly depicted-the $\$ 2.7$ million reflected two days of coffee sales revenues for McDonald's. Gerlin, supra note 709, at A4. The judge later reduced the punitive damages to $\$ 480,000$. BOGUS, supra, at 20 . Finally, to avoid an appeal, Liebeck settled the case for an undisclosed amount. Id.

For similar arguments about other products, see Hanson \& Kysar, Taking Behavioralism Seriously II, supra note 251, at 1467-1553 (providing evidence of how the tobacco industry manipulated-and thus shared responsibility for-consumer smoking habits); Hanson \& Logue, supra note 402, at 1350-52 (challenging the conventional 
How much does the situation influence individuals? Who controls and profits from particular situations? How might the situation be altered to influence individuals in other ways? These are not easy questions, but to avoid them may be to encourage personal irresponsibility.

Put differently, the concern that taking hard-to-see situation into account may "encourage criminals to run freely through our streets" ignores the less visible possibility that disregarding situation may encourage even more.

\section{The Paternalism Bogeyman}

No contingent of bogeypeople would be complete without the paternalism bogeyman. Unlike the prior bogeypeople, the figure of paternalism appears more prominently and openly in legal theoretic discourse. Although its precise definition often remains shrouded in mystery, that has not stopped it from exercising a powerful influence in legal-theoretic debate. ${ }^{716}$ Generations of theorists have agreed that paternalism is no friend of the dispositional human actor presiding at the core of the traditional liberal picture. John Stuart Mill, who early laid down the line against paternalism in a "civilized" society, stated that, "the only purpose for which power can be rightfully exercised over any member of a civilized community, against his will, is to prevent harm to others. His own good, either physical or moral, is not a sufficient warrant." $" 717$

Professor David Shapiro, in his famous article on the subject, claimed that the concept of paternalism can be conceived of in a number of weaker or stronger formulations. ${ }^{718}$ But the basic antipaternalism suspicion has, by now, attached to almost any version of it. In his article, Shapiro set out, in part, to challenge Duncan Kennedy's seminal claim that paternalism was actually quite widespread in private and public social arrangements, including, importantly, many

"personal responsibility" argument against cigarette liability); Hanson, Yosifon \& Benforado, supra note 615 (describing the situational manipulations by the food industry that have contributed to the obesity epidemic).

${ }^{716}$ See, e.g., supra text accompanying notes 388-92 (describing the ALI Reporters' rejection of hard-paternalism in favor of consumer sovereignty).

${ }_{718}^{77}$ JOHN STUART MILL, ON LIBERTY 68 (G. Himmelfarb ed. 1982) (1859). (1988).

David L. Shapiro, Courts, Legislatures, and Paternalism, 74 VA. L. REv. 519, 520 
areas of the law. ${ }^{79}$ Shapiro gave a renewed voice to the traditional view of paternalism as showstopper, arguing that legal justifications for many of the kinds of arrangements Kennedy had pointed to were actually well grounded in anti-paternalism (at least rhetorically). ${ }^{720}$ Professor Shapiro claimed that, in fact, "anti-paternalism (which [we] should perhaps... [be] calling 'pro-autonomy') is a dominant strain in our tradition." economists, when met with claims they perceive as threatening to individual autonomy, are quick to retreat behind, not economics per se, but an anti-paternalistic defense of individual freedom. ${ }^{722}$ Much of the most recent law and economics-oriented scholarship on paternalism has been directed at defining the boundaries and types of paternalistic social policies that can be justified, assuming that strong deference should be given to the basic "libertarian" view of individual autonomy. ${ }^{723}$ The paternalism bogeyman, despite the efforts of Kennedy and others, reigns.

${ }^{719}$ Shapiro was primarily responding to the argument found in Duncan Kennedy, Distributive and Paternalist Motives in Contract and Tort Law, with Special Reference to Compulsory Terms and Unequal Bargaining Power, 41 MD. L. REV. 563, 624-49 (1982). This was also the view taken by H.L.A. Hart. See H.L.A. HART, LAW, LIBERTY AND MORALITY 30-34 (1963) (advocating the separation of law from morality in certain areas of personal conduct).

${ }^{720}$ Shapiro, for example, notes that courts have consistently rested their upholding of "seat belt" or "helmet laws" on public policy grounds such as efficiency, and even, with respect to the upholding of laws against sodomy, on the ground of supporting public morals or public will. Shapiro, supra note 718, at 541-42. Neither type of law has been justified on the ground that it forces people into behavior that is good for them despite their thinking to the contrary. Shapiro himself claims that "one reason" he voted in favor of Massachusetts' seat-belt law was that it would lower insurance rates. Id. at 530 n.37.

${ }^{721}$ Shapiro, supra note 718 , at 572 . While ultimately coming down as a strong antipaternalist, see id. at 572-75, part of Shapiro's purpose was to present an analysis from the perspective of "legal process," an approach to thinking about the law that Shapiro argued had suffered unwarranted neglect by the critical legal scholars who he saw as emergent in 1988 when he wrote his article. Id. at 521.

${ }_{722}$ See supra text accompanying notes 551-70; see also Hanson \& Yosifon, Missing the Situation, (unpublished manuscript, on file with authors) (describing this pattern in legal economists' writings).

${ }^{723}$ See, e.g., Paul Burrows, Analyzing Legal Paternalism, 15 INT'L REv. L. \& ECON. 489,497 (1995) (advocating an expanded emphasis on people's preferences and choice of behavior); Colin Camerer et al., Regulation for Conservatives: Behavioral Economics and the Case for Assymmetric Paternalism (forthcoming) (on file with authors); Cass R. Sunstein \& Richard H. Thaler, Libertarian Paternalism and the Law (forthcoming) (on file with authors) (contributing a new perspective to welfare economics); Eyal Zamier, The Efficiency of Paternalism, 84 VA. L. REv. 229, 230 (1998) (arguing that paternalism is "compatible with theoretical foundations of normative economics" and that "efficiency analysis provides a central justification" for it). 
A central effect of its reign is to scare away potential interventions in the apparent dispositional choices of individuals or arguments that would put the meaning of such choices into doubt. To do so, the paternalism bogeyman patronizes the dispositional actor by highlighting only the most salient kinds of situational exercises of power over individuals, calling these paternalism, and demanding they yield in the name of the freedom that is assumed otherwise to govern. In this way, the paternalism bogeyman, like the others, succeeds against our argument only by denying what social science teaches (and markets reveal) about the power of the unseen situation.

Shapiro, for example, provides a vivid but profoundly dispositionist picture when he "lay[s] out some baselines" for the study of paternalism. ${ }^{724}$ Adopting the axiom of "consent" as central to the analysis, Shapiro discerns the quintessential form of what he and most theorists find to be a permissible kind of paternalism-selfpatermalism. ${ }^{725}$ The guiding figure here is Odysseus, that hero of the disposition human journey, binding himself to the mast of his ship as it passes by the Sirens, and instructing his crew that they should not untie him no matter how vigorously he demands to be unbound. ${ }^{726}$ Odysseus fears his future-self will, if set free, choose to stay forever among the beautiful, seductive voices of the Sirens. ${ }^{727}$ In contrast to this permissible "baseline" of self-paternalism is an even more vivid dispositionist vision of the sinister paternalism bogeyman-the Grand Inquisitor:

[T] he case for a claim of weak paternalism is itself weakened ... when the asserted incapacity exists on a question of basic values or assumptions, especially (but not exclusively) when those values or assumptions are shared by a large group of mature adults. The Grand Inquisitor who is convinced that the souls of the heretics can be saved only if they are coerced into recanting their heresy may see the case as the quintessence of weak paternalism. But I do not. ${ }^{728}$

Shapiro accepts as a premise that power can be exercised to alter people's opinions even on "basic assumptions," but this power is pictured as a salient external power, in the figure of the Grand

${ }^{724}$ Shapiro, supra note 718 , at 523 .

${ }^{725}$ Id. at 522-25.

${ }^{726}$ HOMER, THE ODYSSEY $146-47$ (Walter Shewring trans., Oxford Univ. Press 1980) (n.d.).

${ }^{727}$ Id.

${ }^{728}$ Shapiro, supra note 718 , at 529. 
Inquisitor. ${ }^{729}$ The possibility that power is exercised in unseen ways over "basic assumptions" is not even imagined; and the charge of paternalism becomes a bulwark against examining the power operating in the formation of those assumptions. If paternalism is a troublesome exercise of power when implemented through salient situational influences, then critical realism suggests that we ought to begin our analysis at exactly the place where Shapiro places the bogeyman's barricades. Put differently, if our ambition is to foster a world in which people are encouraged to act according to their values, attitudes, and assumptions, then legal analysts need to look far deeper than just the obvious tip of the situational iceberg.

Further examination reveals that Shapiro's conventional "baselines" are the product not of analysis or theory, but of the fundamental attribution error. Defending his decision to "embrace the anti-paternalist position," ${ }^{, 730}$ Shapiro falls back, as do so many, on intuitions and common sense perceptions: "on so basic a question of human relations I am not sure how feasible it is to do more than chart my own course." ${ }^{731}$ Indeed, most defenders of anti-paternalism, Shapiro admits, have offered weak justification for their urge "to defend freedom against its critics." ${ }^{732}$ In charting such a course, Shapiro argues, "[e]ventually, a leap of faith is inevitable. " addition, the stakes in this leap are profoundly important, for "under prevailing community standards, the paternalist has the burden of persuasion." 734

The problem, of course, is that the prevailing community standards reflect a fundamental flaw in human attributions, a flaw that appears to be greatly encouraged and enhanced by those who can best influence our situation. Thus, in the name of avoiding obvious (that is, paternalistic) influences on people's choices, we may be turning ourselves over to less obvious, but no less powerful, influences. Or, put slightly differently, in the name of protecting dispositionism from

${ }^{729}$ Id. Readers will no doubt be reminded that the same salient inquisitorial power was actually present in the Galileo story. See supra text accompanying notes 297301.

${ }^{730}$ Shapiro, supra note 718 , at 545.

${ }^{731}$ Id. The metaphor of navigational charting may not be coincidence. It implies the kind of choice-contemplating, choice-making dispositional figure that sets the "baselines" of his view of paternalism and who, like Odysseus, straps himself to the mast when anticipated temptations loom.

${ }_{739}^{7 d}$ Id at 546.
Id.
${ }_{734}$ Id. at 545. 
blatant situational threats, we may be unleashing hidden, but deeply captured, situational forces that leave us feeling as though we chose our lot.

Our purpose here is not to propose or defend a strong form of paternalism. Indeed, we think our argument would demand a thorough reconceptualization of such conventional categories (strong-form paternalism, weak-form paternalism, self-paternalism, and so on) before such a discussion could be fruitful. What we are arguing is that the charge of paternalism, as it is typically made, is an inadequate response to the claims we have presented. What we propose is a more realistic exploration, and acceptance, of the powerful situational influences over human behavior that go far beyond the ropes of Odysseus and the fires of the Grand Inquisitor. When we yield in our inquiries to the paternalism bogeyman, we may be yielding to basic assumptions that are themselves contestable and the subject of powerful situational influences. The problem of paternalism is profound, but it cannot be answered with the conventional bogeyman response.

4. Summary: The Bogeypeople as Response to, and Creation of, Threat

Some of the owner men were kind because they hated what they had to do, and some of them were angry because they hated to be cruel, and some of them were cold because they had long ago found that one could not be an owner unless one were cold. And all of them were caught in something larger than themselves. Some of them hated the mathematics that drove them, and some were afraid, and some worshipped the mathematics because it provided a refuge from thought and from feeling....

-John Steinbeck ${ }^{795}$

Although there are others, ${ }^{736}$ the previous Sections provide a fair sample of the bogeypeople. We are less interested in providing a full

${ }^{735}$ JOHN Steinbeck, The GRAPES OF WRATH 42-43 (Viking Critical Library ed. 1972) (1939).

${ }^{736}$ Broadly speaking, virtually any human motive, we suspect, might be tapped into in order to generate a bogeyperson. For instance, the human motive for closure, see Hanson \& Yosifon, supra note 30 , is often activated by those who seem unwilling to take "the situation" seriously unless its precise implications for policy and legal doctrine are made explicit. Similarly, the motive for control, see id., is often tapped into by those who assert that situational causation is far more difficult to influence in predictable ways. (As an aside, we suspect that the combined motives for closure and control may help explain the fundamental attribution error.) 
catalogue of the beasts than we are in understanding what motivates them. People invoking the bogeypeople often begin by claiming to concede that the situation can have an immense, unseen effect on people's conduct. They then follow that concession with a general "so what?" or, more specifically, with the invoking of one or more of the bogeypeople to make their case that it is better to pay no more attention to the situation than people already do. Upon closer inspection, however, this technique of responding is better seen as a disarming means of denying our basic argument about the power of the situation. It is not surprising that our audience would tend to disbelieve our claims. Indeed, it is to be expected-just as it is easy to understand why so many people initially found Galileo's claims to be fanciful. Without the telescope, it was one person's claim against the obvious.

We do not believe that our arguments are immune to critique. We strongly suspect that they are in many ways flawed. But our worry and our experience is that they are not given a chance largely because people reject them because they are hard to see, and, more importantly, because they do not want to see them. The specter of the bogeypeople provides a mechanism for evading the situation. Indeed, we suspect that one major reason for the success of neoclassical economics and disposition-driven theories of law is not simply that they are good for business, but also that they serve to protect us all from the disquieting possibilities that many of our basic systems are both harmful and rigged. With that possibility in mind, it is illuminating to consider Milgram's career.

After revealing, to his own surprise, the power of the unseen situation, Milgram's findings spawned an enormous hullabaloo. In the words of Thomas Blass, "more than any other research in social psychology, the obedience experiments have been embroiled from the beginning in a number of controversies in which they have played a central and enriching role. These include the ethics of research, the social psychology of the psychological experiment, and the deception versus role-playing controversy." criticism found its source in the threat that Milgram's results posed to the notion that these systems are just. To defend against that threat, Milgram's work had to be denied, challenged, and minimized in any way possible.

${ }^{797}$ Thomas Blass, Understanding Behavior in the Milgram Obedience Experiment: The Role of Personality, Situations, and Their Interactions, $60 \mathrm{~J}$. PERSONALITY \& SOC. PSYCHOL. 398, 398 (1991) (citations omitted). 
The upset generated by a Milgram ... in part stems from ethical concerns. But another part of [his experiments'] power lies precisely in their demonstration of how strong situational determinants are in shaping behavior. No resort to a correlation between 'those' people who do 'evil' things is allowed: the subjects were randomly assigned.

Despite his profound influence on psychology and the importance of his work to the fields of philosophy, political science, and education, Milgram was never granted tenure at Harvard. ${ }^{799}$ As Blass suggests, "[s]ome of the opposition toward Milgram came from colleagues who felt uneasy about him, ascribing to him certain negative properties of the obedience experiment." ${ }^{\text {,740 }}$ Focusing on Milgram's protocol may well have been a cover for a deeper uneasiness about his findings, as well as, a means of de-legitimating his work and, more importantly, legitimating our world.

There is another, perhaps more telling, means of demonstrating that those who conjure the bogeypeople are, perhaps unconsciously, denying or minimizing our claim. Consider the likely reaction to our argument if we were describing more visible, salient, and obvious forms of situational constraints. Suppose, for example, that we were writing about antebellum slavery. It does not seem controversial to argue, as we did, that slavery placed an immense and unjust situational constraint on slaves, or that slaves' conduct-including their singing-did not reveal dispositional consent to their fate. We do not believe that the situational bogeypeople would be invoked in response to those claims. Nobody would accuse us of being communists for arguing that the situation of slaves should be taken seriously or that slavery should be abolished. There is no tendency to invoke the communist bogeyman in that context because, in retrospect, the situational constraints that caused the unequal outcomes are clear. If we truly accept the idea that the situation wields a commanding influence, then the idea of attending to that influence seems obvious and unobjectionable.

Similarly, the personal-responsibility bogeyman remains dormant when the situation is slavery. It should be remembered that slaves exercised some freedom under slavery: they developed their own

${ }^{738}$ Robert Helmreich et al., The Study of Small Groups, 24 ANN. REv. PSYCHOL. 337, 343 (1973).

${ }_{799}$ Thomas Blass, The Man Who Shocked the World, PSYCHOL. TODAY, Mar.-Apr. 2002, at 72, available at http://www.psychologytoday.com/htdocs/prod/proarticle/ pto-200203.

${ }_{740}$ Id. In 1967, Milgram was given full professor status as head of the social psychology program at the Graduate Center of the City University of New York. 
cultural patterns and practices; they found or created items of value to trade and sometimes earned money to buy things; they negotiated in various ways with their masters for, among other things, freedom upon their master's death; they plotted and executed escapes; and in some circumstances they bought their own freedom. ${ }^{71}$ So, while slaves undoubtedly operated under severe situational constraints, they were not without recourse to influence their own lives. There was room for disposition, and it undoubtedly played a role in their experiences.

Yet nobody today would claim that slaves should have taken personal responsibility for the conditions in which they lived. Frederick Douglass, among others, bought his own freedom, and yet we do not blame those who did not for their predicament. In such cases, the situation is obvious, and personal responsibility lies less with those enslaved by it, and more with those who created it. Placing personal responsibility on the slave is offensive. When, on the other hand, the situation plays a significant role in the lives and conditions of those who enjoy "freedom" (here defined as "not slaves"), invocations of Horatio Alger and the personal responsibility bogeymen emerge. If we recognized the full sweep of the situational influences over our lives, we might be more hesitant with the charge of "personal responsibility," and the emergence of this bogeyman might be less automatic. ${ }^{742}$

${ }^{741}$ See, e.g., IRA Berlin, Generations of CAPTIVITY: A History of AfricanAMERICAN SLAVES 5 (2003) (depicting the cultural habits and beliefs which transformed the experience of slaves into a culture which joined them together as a class); FRIEDMAN, supra note 36, at 224-27 (discussing the family life and rights of slaves); GENOVESE, supra note 666, passim (illuminating the "world the slaves made"); WALTER JOHNSON, SOUL BY SOUL, LIFE INSIDE THE ANTEBELlUM SLAVE MARKET 63-77 (1999) (commenting on the development of a slave community and the launching of slave revolts).

${ }^{742}$ This, of course, is not to say that we are all slaves, or that the situational constraints on slaves were not more dramatic and severe than those that surround us today. It is, however, to suggest that just as the "personal responsibility" trope loses much of its force when situational constraints are salient, we should be suspicious of its use where situational influences are less visible. 


\section{CONCLUSION: FACING OUR FEARS}

"It may be that we are puppets-puppets controlled by the strings of society. But at least we are puppets with perception, with awareness. And perhaps our awareness is the first step to our liberation."

$$
\text { -Stanley Milgram }{ }^{743}
$$

Man is the only government-making animal in the world.

-Frederick Douglass ${ }^{744}$

We all got to figure. There's some way to stop this. It's not like lightning or earthquakes. We've got a bad thing made by men, and by God that's something we can change.

-John Steinbeck ${ }^{75}$

The inferno of the living is not something that will be; if there is one, it is what is already here, the inferno that we live every day, that we form by being together. There are two ways to escape suffering it. The first is easy for many: accept the inferno and become such a part of it that you can no longer see it. The second is risky and demands constant vigilance and apprehension: seek and learn to recognize who and what, in the midst of the inferno, are not infermo, then make them endure, give them space.'

-Italo Calvino ${ }^{746}$

We understand that there is reason to be frightened and to feel threatened. In fact, that is our point. There is much at stake. But to thwart the real dangers of the situation-the vulnerability to manipulation, the complex legal, social, ethical, and personal problems that it raises-we should look beyond the bogeypeople and face our fears.

The goal of this Article is to encourage us to take seriously the situation. We, and we hope others, will say more in future work about its implications. Regardless, the most important implication

${ }^{743}$ http://www.stanleymilgram.com/quotes.html (attributing quote to Stanley Milgram).

${ }_{744}$ Frederick Douglass, Appeal to Congress for Impartial Suffrage (Jan. 1867), available at $\mathrm{http} / / /$ www.law.ou.edu/hist/suff.html.

${ }^{745}$ STEINBECK, supra note $735,42-43$.

746 ITALO CALVINO, INVISIBLE CITIES 165 (William Weaver trans., Harcourt \& Brace Jovanovich 1974). 
should be evident: there is not going to be a salient, simple policy solution to our predicament. The belief or hope that such solutions exist is a manifestation of the problem-seeing a tiny portion of what is moving us and assuming that nothing else does.

The problem is akin to another problem that is easier to imagine. Who was responsible for slavery in this country? Clearly, it was not the slaves. Their situation was too vividly powerful-like a gun to the head-to conclude otherwise. The most obvious answer is the slavemaster, and for good reason. Slavemasters bought and sold slaves, controlled slaves' environments, and dictated-often using brutal force-much of the slaves' conduct. ${ }^{747}$ There is more, however, to the situation than just the most prominent actors. Slavery was, among other things, a social system-a powerful situation-that was larger than both the slaves and the masters. Slavery was a highly profitable industry, not only for the South, but also for the North, where textile mills, for example, relied on the availability of cheap cotton. A plantation owner who freed his slaves would not only lose the economic value of his chattel but also the ability to produce his crops profitably.

Moreover, freeing slaves was illegal in some states and highly discouraged by social norms and conventions in all slave states. ${ }^{748}$ In that and countless other ways, the laws and the customs that slave owners lived under were highly constraining. But those situational constraints were not, any more than the others, a natural, inevitable, or even random circumstance. The situation was itself the consequence of a profitable economic system that created institutions and individuals with an interest in maintaining it.

As we have described, slave owners held situationally influenced "knowledge" and beliefs that also acted to reinforce the system and justify their place in it as powerful as the economic and social forces that they faced. As we indicated above, a freed slave was, by some accounts, unhappy. If a freed African slave could not function outside of the paternalistic protection of the "peculiar institution," or if they would almost certainly be kidnapped and sold again into slavery and perhaps down the river, or if, at best, "freedom" meant laboring in the North where the working conditions were far worse, how could a plantation owner-even a "social welfare-maximizing" plantation owner-justify freeing his slaves? Furthermore, if

\footnotetext{
${ }^{747}$ HigGinBOTHAM, supra note 639, at 50-51, 201-02.

${ }^{748}$ See GOODELL, supra note 665 , at 338 .
} 
slaveowners faced the threat that without slavery their society would not prosper and evolve, then the emancipation of slaves might come at a cost to freedom. ${ }^{749}$ In short, slaves were not the only people who were subject to powerful situational influences. Slaves, their owners, and their shared society, were all deeply captured. So, who do we blame?

The point is that this may be the wrong question. Suppose we were given the task of developing a means of emancipating African Americans from slavery and the many situational chains that have hindered them since. Suppose that we had to accomplish that end without the horrors and shame of the Civil War, of Reconstruction, of Jim Crow, of segregation, and of disparate opportunities and outcomes that remain with us. What would we do?

Whatever our answer, it won't be simple, and it will require gaining a better understanding of the situation.

${ }^{749}$ See MCPherson, supra note 682 , at 56 (“'Indeed', said Senator Robert M. T. Hunter of Virginia, 'there is not a respectable system of civilization known to history whose foundations were not laid in the institution of domestic slavery.' 'Instead of an evil,' said John C. Calhoun in summing up the southern position, slavery was 'a positive good ... the most safe and stable basis for free institutions in the world."'). 